ADVANCED STEEL CONSTRUCTION

\section{An International Journal}

Volume 2 Number 1

March 2006

CONTENTS

Technical Papers

Monotonic and Cyclic Tests on Shear Diaphragm Dissipators for Steel Frames M.S. Williams and F. Albermani

Seismic Performance of Cylindrical Latticed-Intersected-Three- DimensionalBeam-System Reticulated Mega-Structure With Bouble-Layers Grid Sub-Structures Yongjun He, Xuhong Zhou, Shilin Dong and Jia Li

Efficient Modelling of Composite Building Response to Compartment Fires Zhaohui Huang, Ian Burgess and Roger Plank

Steel-Concrete Composite Beams Prestressed by External Tendons: Effects of Material and Geometric Nonlinearities

Andrea Dall' Asta, Laura Ragni and Alessandro Zona

Wind Tunnel Tests and Wind-Induced Vibration Analysis of Spherical Domes Zhi-hong Zhang and Yukio Tamura

An Investigation on Structural Performance of Profiled Steel Sheet to Develop Self-Supporting Roofing System

S.M. Zahurul Islam, A.A. Abang-Abdullah and M.S. Jafar

The Hong Kong Institute of Steel Construction

Website: http://www.hkisc.org/

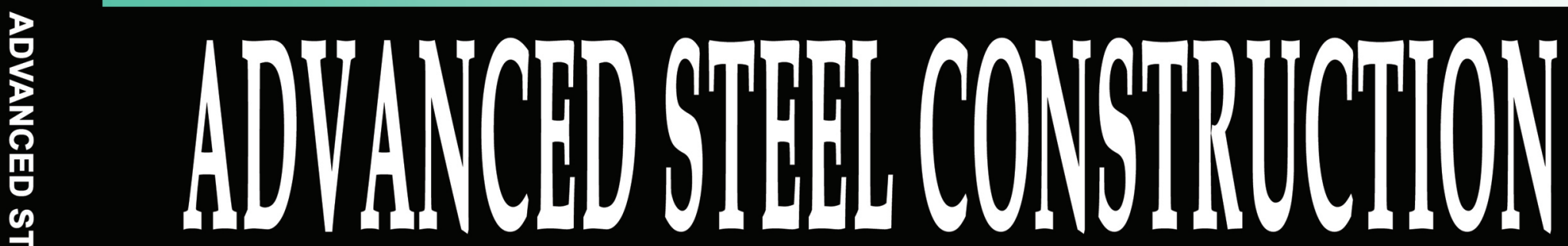

an Intenational ]ounal

ISSN 1816-112X

Volume 2 Number 1

March 2006

(n)

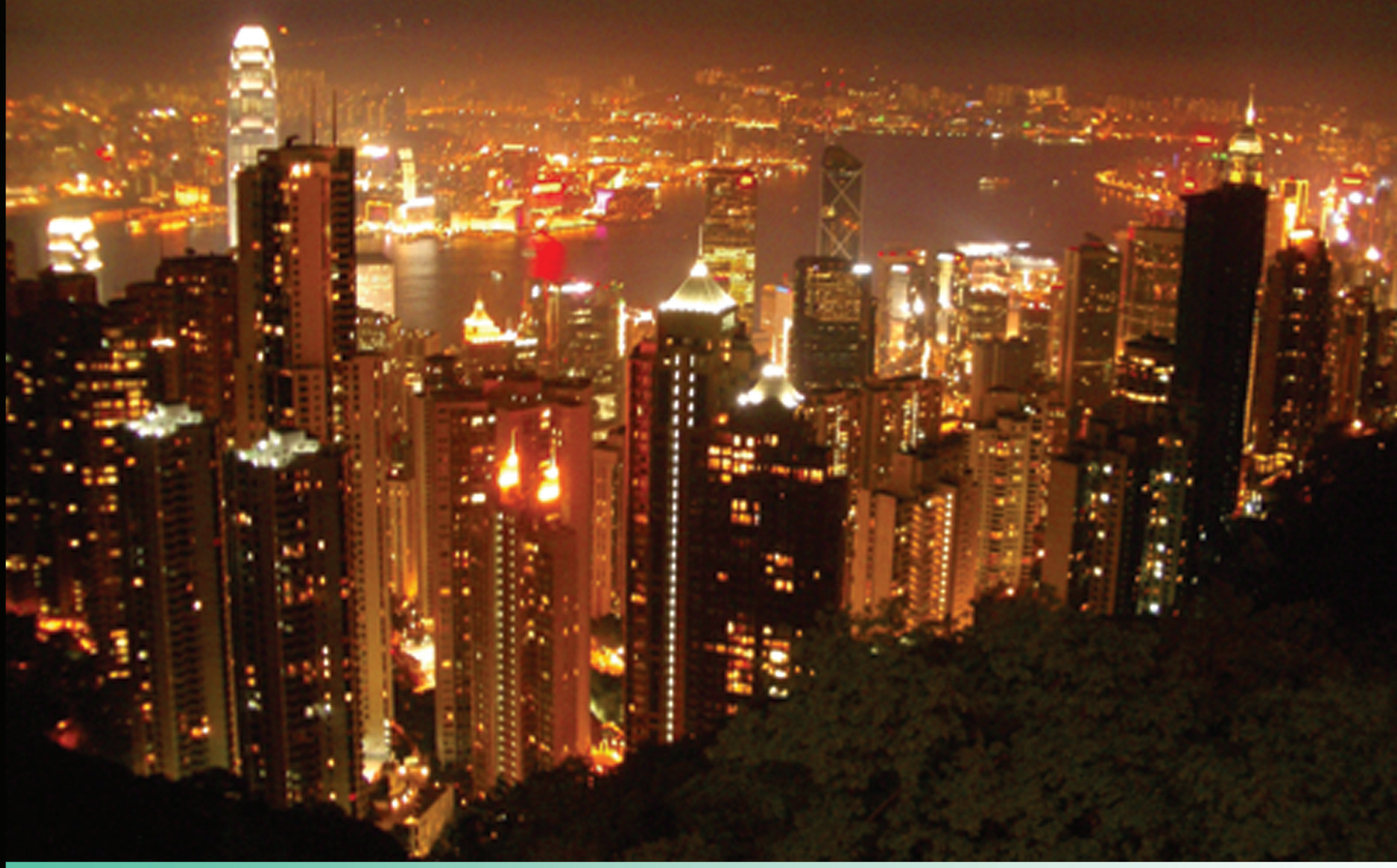

Editors-in-Chief

S.L. Chan, The Hong Kong Polytechnic University, Hong Kong

W.F. Chen, University of Hawaii at Manoa, USA

R. Zandonini, Trento University, Italy 


\title{
MONOTONIC AND CYCLIC TESTS ON SHEAR DIAPHRAGM DISSIPATORS FOR STEEL FRAMES
}

\author{
M.S. Williams ${ }^{1}$ and F. Albermani ${ }^{2}$ \\ ${ }^{1}$ University of Oxford, UK, Email: martin.williams@eng.ox.ac.uk \\ 22University Of Queensland, Australia, Email: f.albermani@uq.edu.au
}

\begin{abstract}
This report describes a series of cyclic tests on a yielding shear panel device. The device consists of a short length of square hollow section (SHS) with a diaphragm plate welded inside it. It is positioned between the braces and the main members of a braced frame, with the diaphragm lying in the plane of the frame, so that it is loaded in pure shear as the frame undergoes lateral deformation. An extensive series of tests on $100 \mathrm{~mm}$ square dissipative devices mounted in a single-storey, planar, K-braced frame was successfully performed, under both monotonic and cyclic loads.

The devices proved easy and cheap to manufacture, fit, remove and replace. All the devices tested yielded at quite low deformations and sustained very large ductilities without failure. The load carried by the device continued to increase after yield, with a ratio of maximum force carried to yield force of around 1.7 in most tests.

While a device with a $2 \mathrm{~mm}$ diaphragm appeared to offer the maximum energy dissipation capacity, thinner devices were prone to buckling and to fracture under repeated, large-amplitude cycling. A thickness of $3 \mathrm{~mm}$ (i.e. thickness to breadth ratio of 0.03 ) is recommended as offering the best combination of dissipative capacity and robustness. A $3 \mathrm{~mm}$ device dissipated approximately $1.3 \mathrm{~kJ}$ of energy when the frame in which it was fitted underwent a single displacement cycle of amplitude $30 \mathrm{~mm}$.

It is concluded that these devices offer a simple, cheap and robust way of dissipating significant amounts of energy in seismically loaded frames. Some improvements to the rig design and suggestions for further work are offered in section 4.6.
\end{abstract}

Keywords: seismic retrofitting, energy dissipative device, shear panel

\section{INTRODUCTION}

This report describes a series of cyclic tests on a yielding shear panel device of the form proposed by U. Dorka (unpublished) at the University of Kassel, Germany. Tests on similar devices, but using different techniques, are currently being performed at the EU Joint Research Centre at Ispra, the National Technical University at Athens, LNEC Lisbon and the University of Oxford, as part of the EU-funded Neforeee research programme (Blackeborough et al., 2001).

The device consists of a short length of square hollow section (SHS) with a diaphragm plate welded inside it. The device is positioned between the braces and the main members of a braced frame, with the diaphragm lying in the plane of the frame, so that it is loaded in pure shear as the frame undergoes lateral deformation. Energy is dissipated through shear yielding of the diaphragm, which is restrained from buckling by the surrounding SHS. Tests are reported on devices mounted in a single-storey planar braced frame, under both monotonic and ramped, reverse-cyclic loads.

\section{TEST RIG DESIGN}

The devices were tested in a single-storey, planar, K-braced frame constructed at approximately half of prototype scale, so as to fit into an existing loading frame. A general arrangement and details of the frame is shown in Figure 2.1. The device design was based around a section of $100 \times$ $100 \times 4$ SHS with a welded diaphragm thickness of up to $6 \mathrm{~mm}$. Taking the tensile yield strength of the diaphragm as $300 \mathrm{MPa}$, the shear modulus as $80 \mathrm{GPa}$ and incorporating an overstrength factor of 1.2 gives the following values of maximum shear yield force, elastic stiffness and yield deformation of the device: 


$$
\begin{aligned}
& F_{y}=1.2 \times \frac{300}{2} \times 100 \times 6=108 \mathrm{kN} \\
& k_{e}=\frac{80 \times 100 \times 6}{100}=480 \mathrm{kN} / \mathrm{mm} \\
& u_{y}=\frac{F_{y}}{k_{e}}=0.225 \mathrm{~mm}
\end{aligned}
$$

Thinner diaphragm plates would be expected to have proportionately smaller yield loads and elastic stiffnesses, but the same yield deformation.

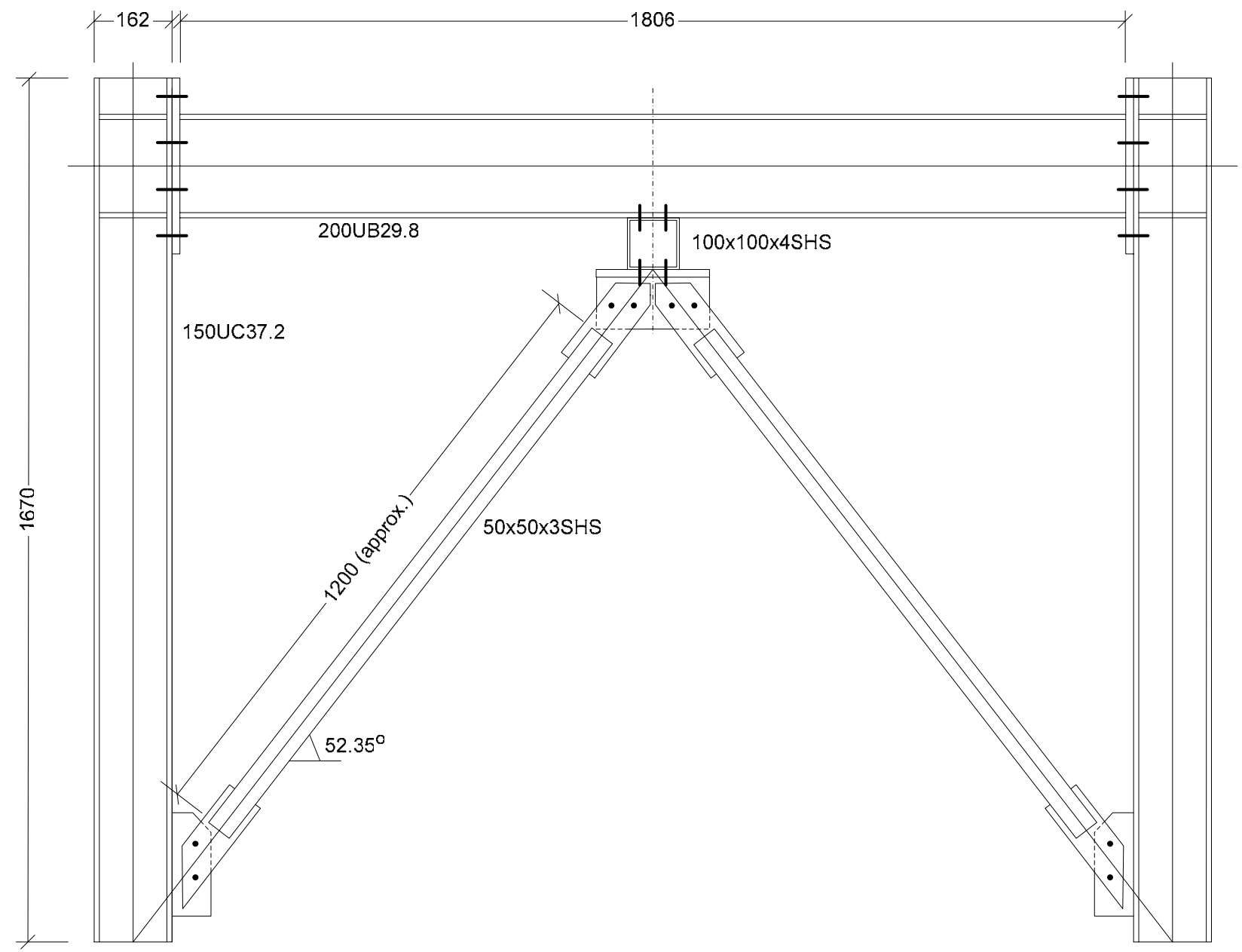

Figure 2.1. Dissipative Device Test Frame - General Arrangement

The remainder of the frame was designed to remain elastic at a lateral load of up to $200 \mathrm{kN}$. Nonlinear static analysis of the frame was performed using Mastan, a simple frame analysis program written in Matlab (Zieman and McGuire, 2000). The device was represented by an elastic-plastic link element with the properties given above. Members and connections were designed in accordance with the Australian steelwork code (AS 4100, 1990), using section properties and material strengths supplied by OneSteel (2003). The results of the analyses indicated that, with a 6 mm diaphragm, device yield would occur at a lateral load of approximately $125 \mathrm{kN}$ and a cap-beam lateral displacement of around $2 \mathrm{~mm}$. Under continued monotonic loading the frame would carry a total load of around $200 \mathrm{kN}$ at a lateral displacement of approximately $9 \mathrm{~mm}$. 


\section{TEST PROCEDURE}

\subsection{Test Setup and Instrumentation}

The test setup is shown in Figures 3.1 and 3.2. Due to limitations in the support frame available, the test structure was rotated through $90^{\circ}$ for testing, with the bases of the columns mounted on one of the verticals of the support frame. Load was applied by a $250 \mathrm{kN}$ capacity hydraulic actuator mounted on the top beam of the support frame and acting along the centreline of the cap beam of the test structure. The instrumentation comprised:

- a $220 \mathrm{kN}$ tension/compression load cell mounted between the actuator and the test frame

- two cable extension transducers to measure the displacements at the centreline of the cap beam and at the top of the braces, immediately below the dissipative device

- strain gauges on the two diagonal braces to enable their axial forces to be determined. An average strain reading from opposite faces of each brace was taken, so as to eliminate the effects of any unintended bending

- dial gauges positioned on the support frame adjacent to the column bases, to monitor any possible base movement

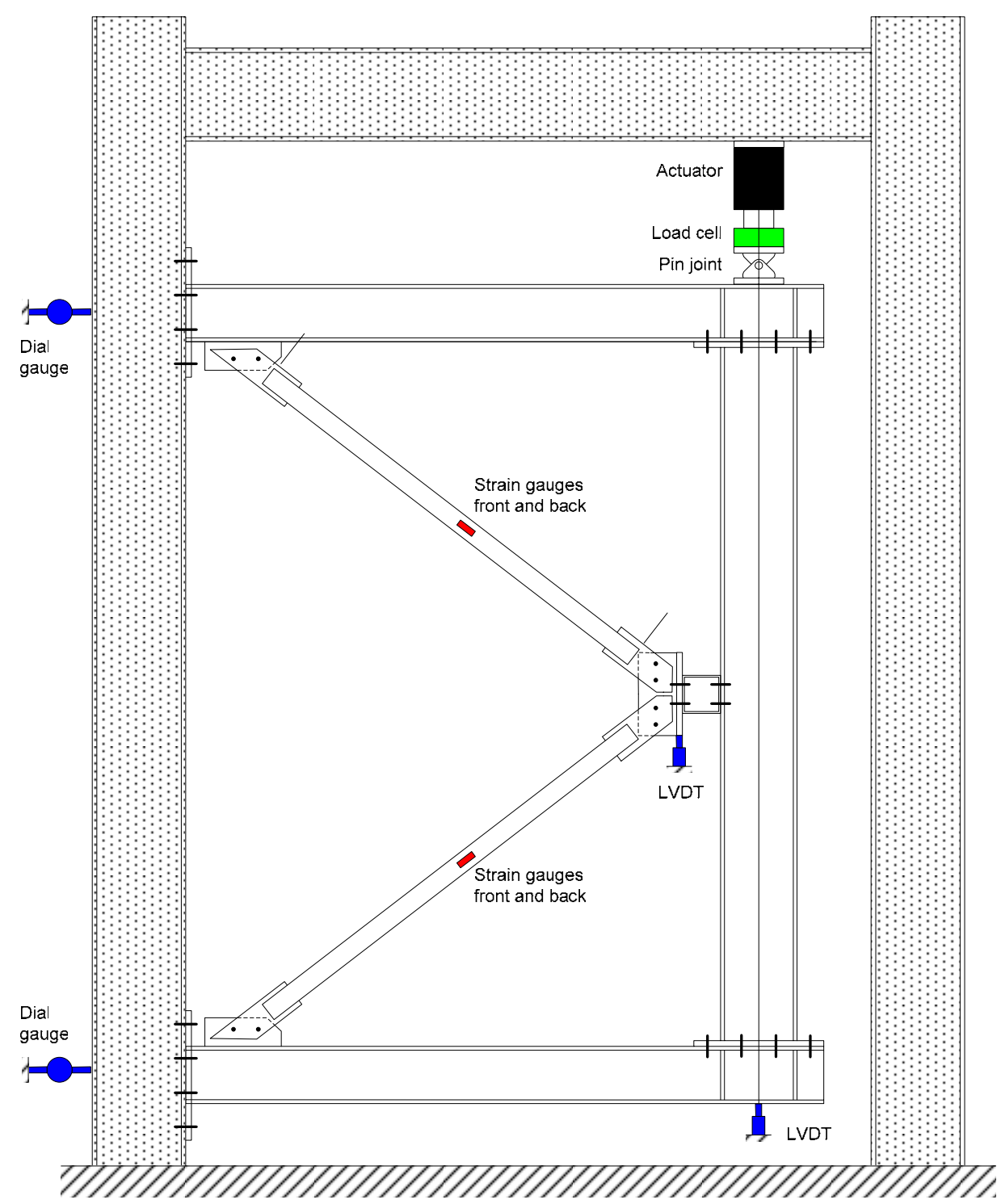

Figure 3.1. $\quad$ Test Setup and Instrumentation 

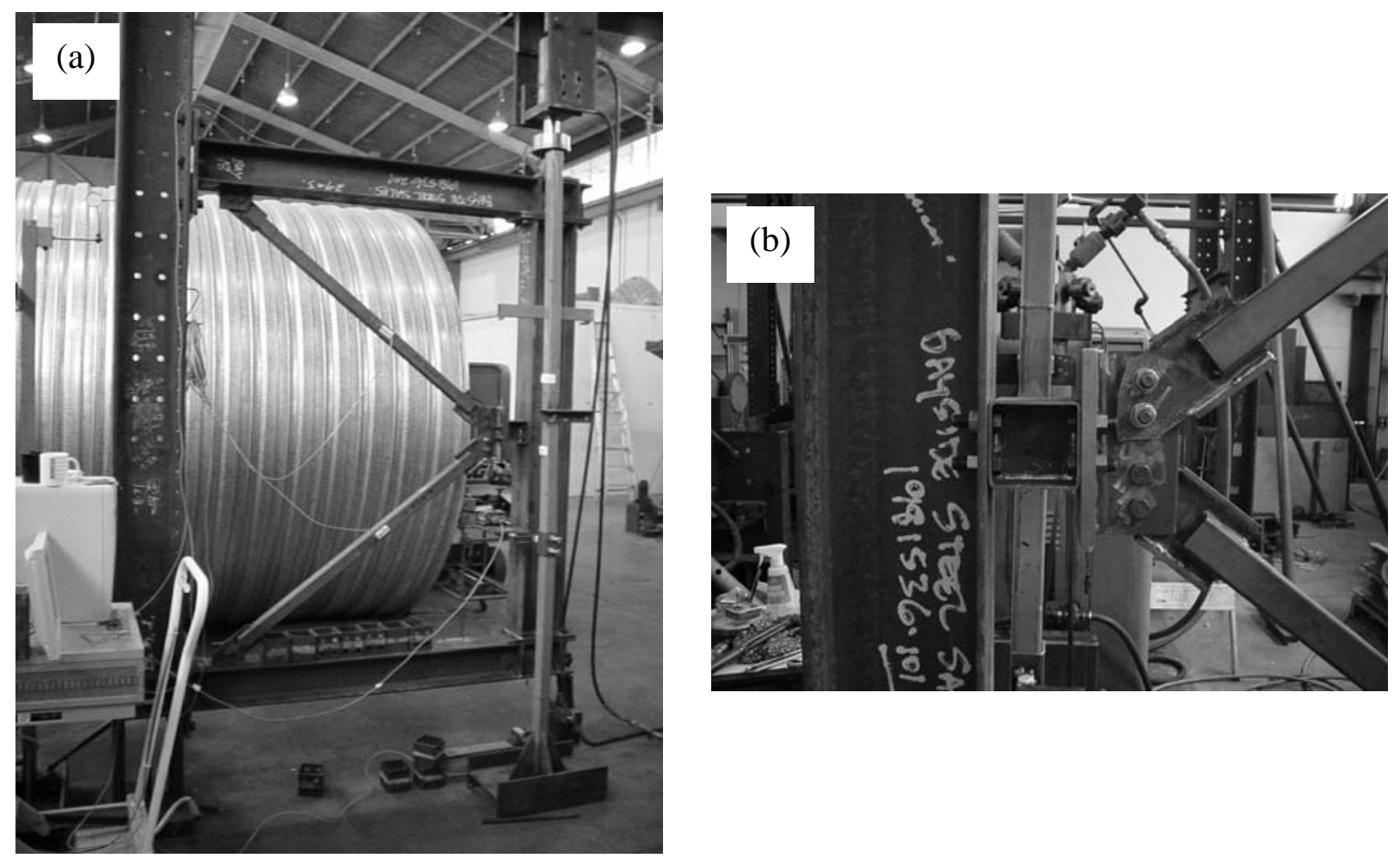

Figure 3.2. Test setup - (a) general layout and (b) device connection detail

The orientation of the test structure raised the possibility that gravity loads might cause some initial sway deformation which would not be measured. To prevent this, the following setup procedure was adopted. Strain gauge zero readings were taken with the braces under zero load. The braces were then bolted in place and the cap beam pulled upwards until the strain gauges returned to their zero readings. The actuator was then locked in position and zero readings of all other instruments were taken.

Tests were performed under several different loading regimes. For each diaphragm plate thickness, the first test comprised a simple, monotonically increasing load up to failure, in order to determine the device's yield point and its ultimate capacity. Ramped reverse-cyclic tests were then performed following the schematic pattern shown in Figure 3.3, with the variation in the number of cycles $n$ at each amplitude intended to assess the vulnerability of the device to low cycle fatigue.

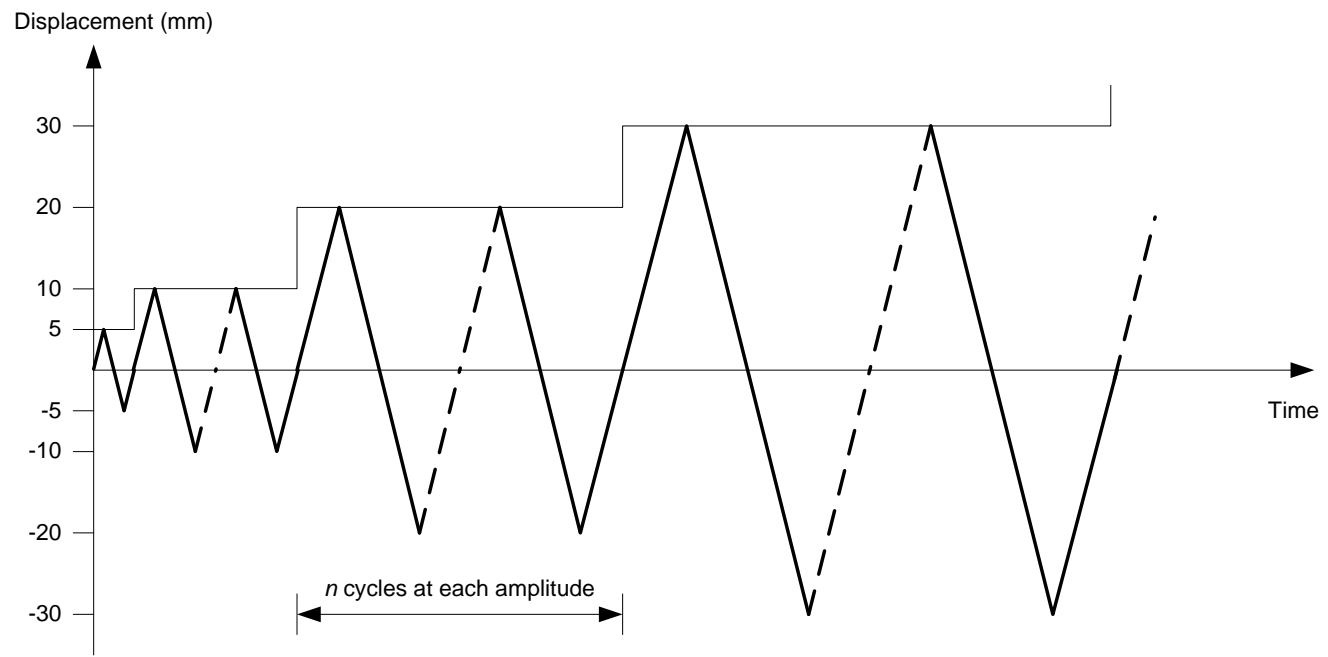

Figure 3.3. Schematic of cyclic loading regime 
Tables 3.1 and 3.2 summarise all the tests performed.

Table 3.1. Summary of test programme (cell entries in last three columns show test numbers)

\begin{tabular}{|c|c|c|c|c|}
\hline $\begin{array}{c}\text { Plate thickness } \\
(\mathrm{mm})\end{array}$ & $\begin{array}{c}\text { Single or double } \\
\text { plate }\end{array}$ & Monotonic test & $\begin{array}{c}\text { Cyclic test (single cycle at } \\
\text { each amplitude) }\end{array}$ & $\begin{array}{c}\text { Cyclic test (three cycles at } \\
\text { each amplitude) }\end{array}$ \\
\hline \hline 1 & Double & 4 & 7 & - \\
\hline 1.5 & Double & 5 & 8 & - \\
\hline 2 & Double & 1,2 & 3,6 & 14 \\
\hline 1 & Single & 9 & 10 & 16 \\
\hline 1.5 & Single & 11 & 12 & 20 \\
\hline 2 & Single & 18 & 19 & 23 \\
\hline 3 & Single & 21 & 22 & - \\
\hline 4 & Single & 13 & 24 & - \\
\hline No plate & - & - & 17 & \\
\hline
\end{tabular}

Table 3.2. Details of tests performed

\begin{tabular}{|c|c|c|c|c|c|c|}
\hline Test no. & $\begin{array}{c}\text { Diaphragm } \\
\text { thickness }(\mathrm{mm})\end{array}$ & $\begin{array}{c}\sigma_{y} \\
(\mathrm{MPa})\end{array}$ & Test type & $n$ & $\begin{array}{c}\text { Max. disp. } \\
(\mathrm{mm})\end{array}$ & $\begin{array}{c}\text { Max. load } \\
(\mathrm{kN})\end{array}$ \\
\hline \hline Free1 & - & - & Cyclic & 1 & 41.7 & 124.4 \\
\hline Free2 & - & - & Cyclic & 1 & 40.3 & 118.9 \\
\hline 1 & $2 \times 2$ & 260 & Monotonic & - & 37.7 & 205.1 \\
\hline 2 & $2 \times 2$ & 260 & Monotonic & - & 32.0 & 176.6 \\
\hline 3 & $2 \times 2$ & 260 & Cyclic & 1 & 40.2 & 184.6 \\
\hline 4 & $2 \times 1$ & 190 & Monotonic & - & 34.0 & 118.5 \\
\hline 5 & $2 \times 1.5$ & 332 & Monotonic & - & 50.0 & 191.0 \\
\hline 6 & $2 \times 2$ & 260 & Cyclic & 1 & 40.9 & 161.0 \\
\hline 7 & $2 \times 1$ & 190 & Cyclic & 1 & 30.4 & 121.9 \\
\hline 8 & $2 \times 1.5$ & 332 & Cyclic & 1 & 40.4 & 149.7 \\
\hline 9 & 1 & 200 & Monotonic & - & 34.3 & 94.8 \\
\hline 10 & 1 & 200 & Cyclic & 1 & 30.1 & 103.9 \\
\hline 11 & 1.5 & 332 & Monotonic & - & 45.5 & 135.6 \\
\hline 12 & 1.5 & 332 & Cyclic & 1 & 43.5 & 134.7 \\
\hline 13 & 4 & 300 & Monotonic & - & 55.2 & 183.2 \\
\hline 14 & $2 \times 2$ & 260 & Cyclic & 3 & 38.9 & 143.8 \\
\hline 15 & 1.5 & 332 & Cyclic & 3 & 32.6 & 111.5 \\
\hline 16 & 1 & 200 & Cyclic & 3 & 30.2 & 99.2 \\
\hline 17 & No plate & - & Cyclic & 1 & 29.9 & 84.8 \\
\hline 18 & 2 & 260 & Monotonic & - & 41.1 & 125.4 \\
\hline 19 & 2 & 260 & Cyclic & 1 & 40.5 & 142.9 \\
\hline 20 & 2 & 260 & Cyclic & 3 & 31.5 & 117.3 \\
\hline 21 & 3 & 285 & Monotonic & - & 51.2 & 159.5 \\
\hline 22 & 3 & 285 & Cyclic & 1 & 40.2 & 151.5 \\
\hline 23 & 3 & 285 & Cyclic & 3 & 30.4 & 119.1 \\
\hline 24 & 4 & 300 & Cyclic & 1 & 40.3 & 158.8 \\
\hline
\end{tabular}

\subsection{Conduct of Tests}

In general the conduct of the tests was straightforward. However, a few minor changes were made as the tests proceeded, to reduce perceived errors.

Initially, the columns were bolted to the support frame using three rows of two bolts, giving a high degree of fixity. In the first test, unexpectedly high loads were achieved and the decision was therefore taken to reduce the support stiffness. This was done by removing all but the middle row of two bolts in each base plate. A further problem was that the base plates then appeared to yield differentially, giving a higher stiffness when pulling up than when pushing down. From test 8 
onwards this effect was alleviated but not eliminated by packing the supports using $5 \mathrm{~mm}$ plates locally around the central line of bolts, as shown in Figure 3.4.

While it was initially intended to test devices with diaphragms up to $6 \mathrm{~mm}$ thick, in the event it was decided to limit the thickness to $4 \mathrm{~mm}$, as it would be possible to impose only very limited ductility on thicker diaphragms with the available test setup. As well as testing single-plate devices, some tests were conducted on devices made up by of two thinner plates positioned next to each other, each welded to the hollow section but not to each other.

Since the brace connections were made with simple black bolts in clearance holes, some slip was inevitable, and indeed desirable in order to ensure that the braces could rotate at their ends and so behave as pin-ended. However, sudden bolt slip did have some detrimental effects on the smoothness of the hysteresis loops for the

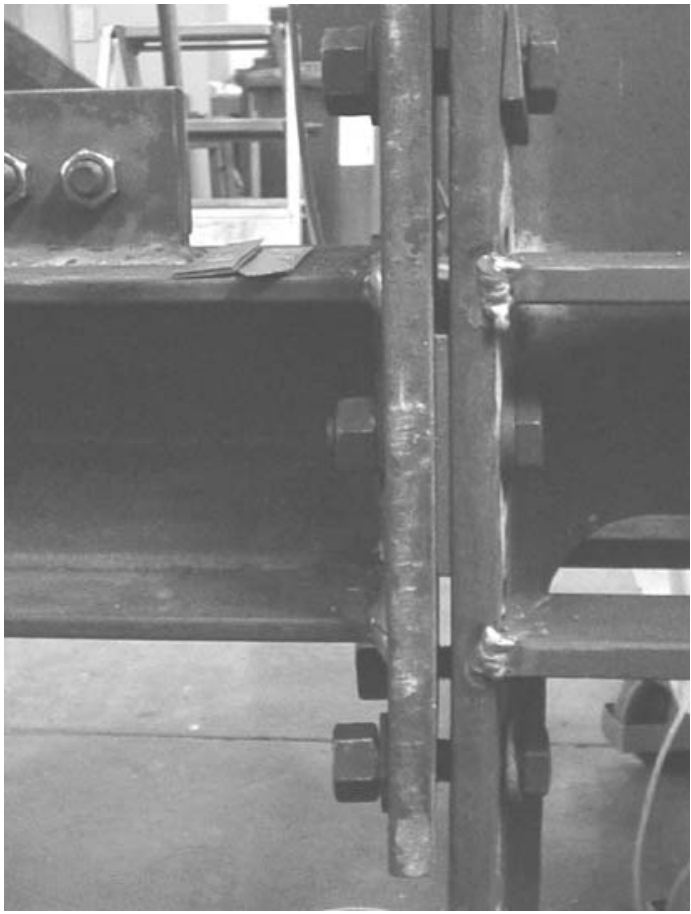

Figure 3.4. Final support arrangement devices, and these appeared to worsen in some of the later tests as some bolt holes elongated. From test 21 onwards, attempts were made to reduce the slip by clamping sheets of sandpaper between the brace connection plates. This had limited success.

\section{RESULTS}

\subsection{Presentation of Results}

In this section results from each test are briefly presented and discussed. In each case, test observations are recorded and force-deformation characteristics for the whole frame and for the device alone are presented. Subsequent sections then present a variety of comparisons and postprocessing. First, "free" tests on the portal frame without any device or bracing are presented. The main tests are then presented in the order: monotonic, cyclic (single cycle at each amplitude) and cyclic (repeated cycles). Within each subset, results are presented in order of increasing plate thickness.

\subsubsection{Free tests}

Test Free1 - no device, two-bolt connection at each support. This test was performed to investigate the cause of the apparently unsymmetrical behaviour of the frame, as observed in the early device tests. It was clear during the tests that the base plates of the columns were becoming curved and making uneven contact with the support. This resulted in the hysteresis curves shown in Figure 4.1.

Test Free2 - no device, packing plates added at supports (see Figure 3.4). The addition of packing plates around the single line of bolts prevented contacted between the main plates and the support frame, and so resulted in a far more symmetrical performance, though still with limited hysteresis at large amplitudes, as can be seen in Figure 4.2. 


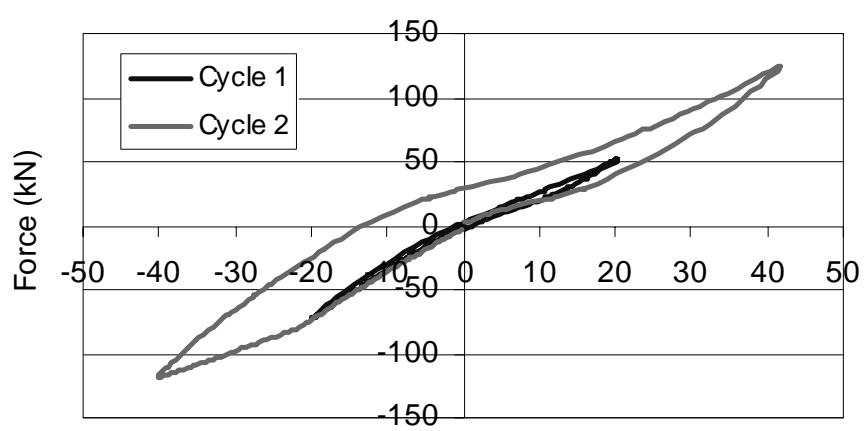

Cap beam deflection $(\mathrm{mm})$

Figure 4.1. Test Free1 - no device

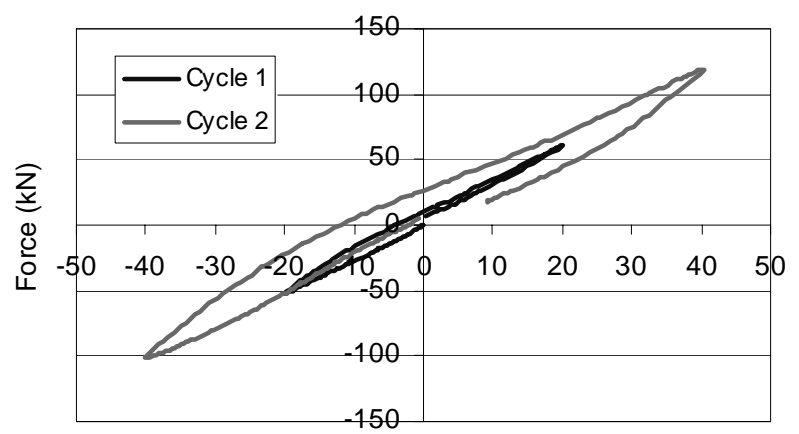

Cap beam deflection $(\mathrm{mm})$

Figure 4.2. Test Free2 - no device

\subsubsection{Monotonic tests}

$1 \mathbf{~ m m}$ single plate (Test 9). First buckle appeared at a cap beam displacement of approximately $7 \mathrm{~mm}$, corresponding to a device deformation of $2.8 \mathrm{~mm}$. The onset of buckling is not obviously visible in the force-deformation plots of Figure 4.3. Buckles became more pronounced with increasing amplitude but no failure occurred.
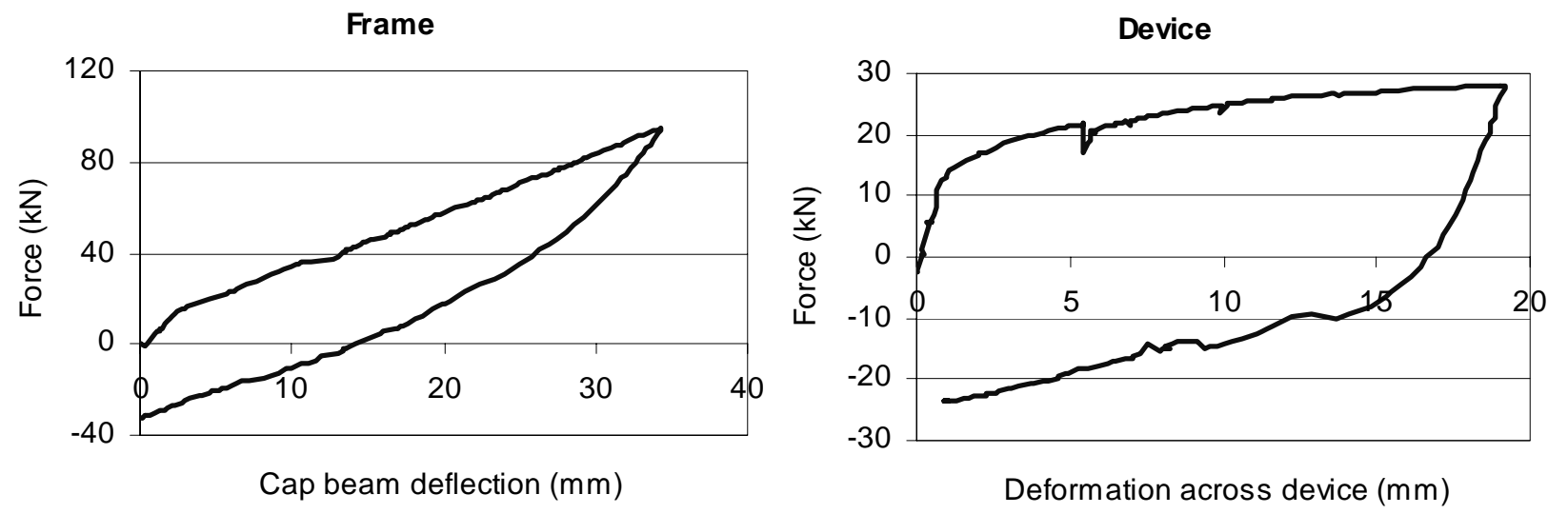

Figure 4.3. Monotonic test, $1 \mathrm{~mm}$ single plate

$1.5 \mathrm{~mm}$ single plate (Test 11). First buckle appeared at a cap beam displacement of $15 \mathrm{~mm}$, at which point the device deformation was around $5 \mathrm{~mm}$.
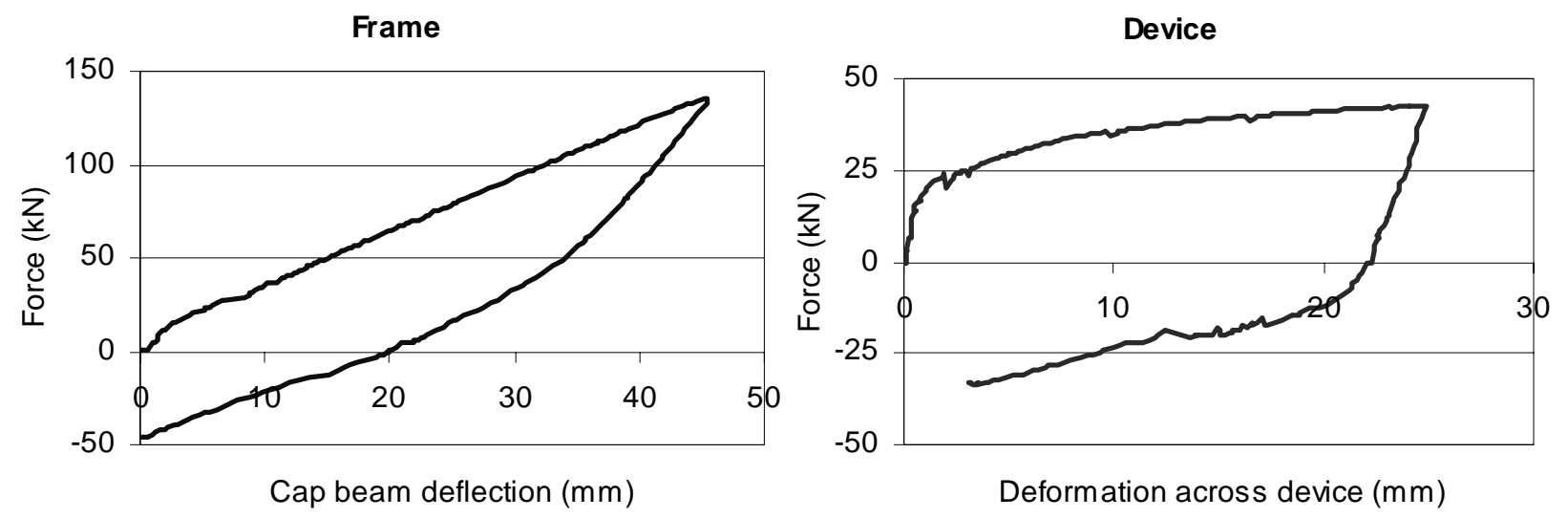

Figure 4.4. Monotonic test, $1.5 \mathrm{~mm}$ single plate 
$2 \mathbf{~ m m}$ single plate (Test 18). First buckle appeared at a cap beam displacement of $18-20 \mathrm{~mm}$, at which point the device deformation was 9-10 mm.
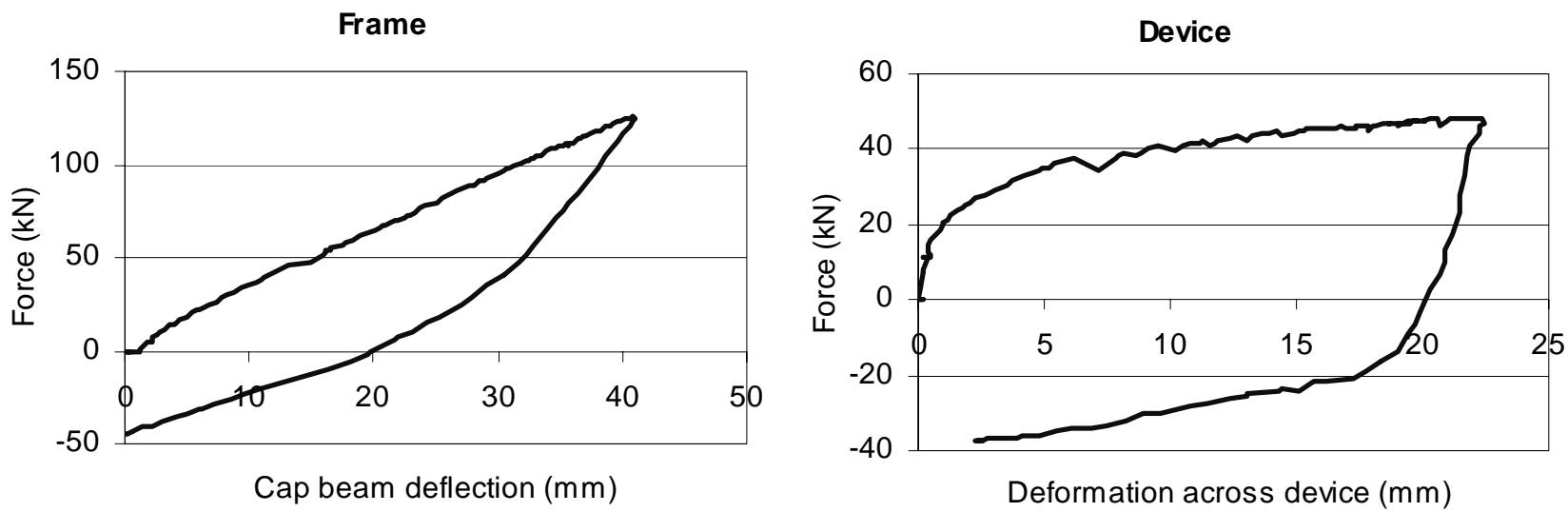

Figure 4.5. Monotonic test, $1.5 \mathrm{~mm}$ single plate

2 x $1 \mathrm{~mm}$ plates (Test 4). First buckle appeared at a cap beam displacement of around $20 \mathrm{~mm}$, at which point the device deformation was $8 \mathrm{~mm}$.
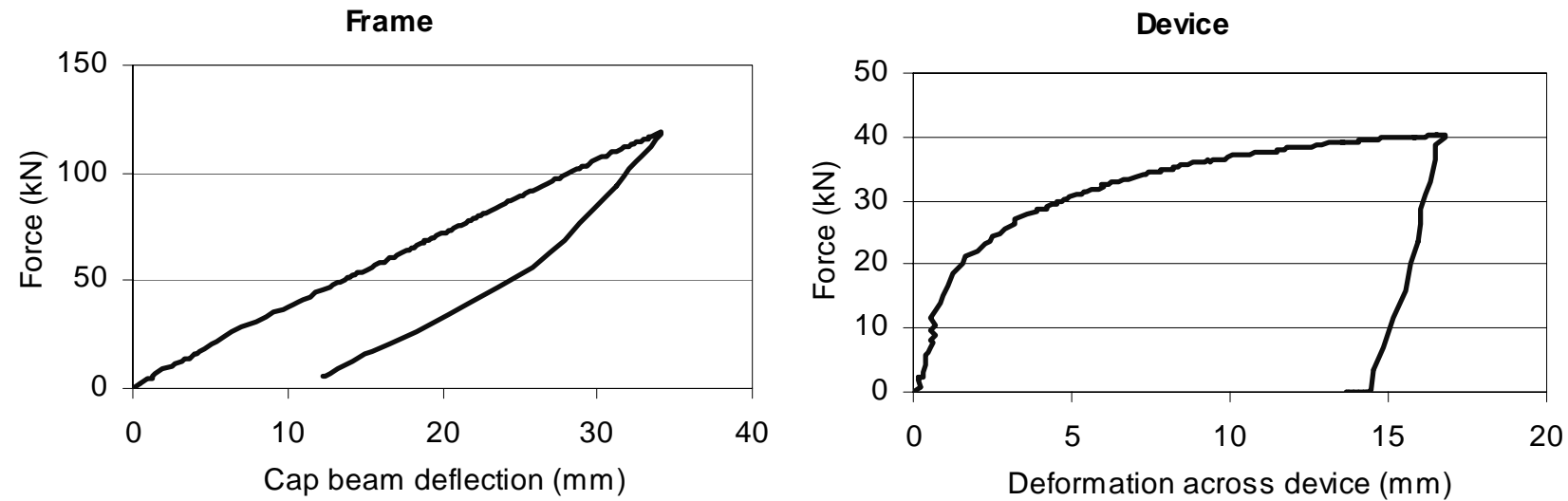

Figure 4.6. Monotonic test, 2 x 1 mm plates

$3 \mathbf{~ m m}$ single plate (Test 21). No apparent buckling at cap beam displacements of up to $50 \mathrm{~mm}$.
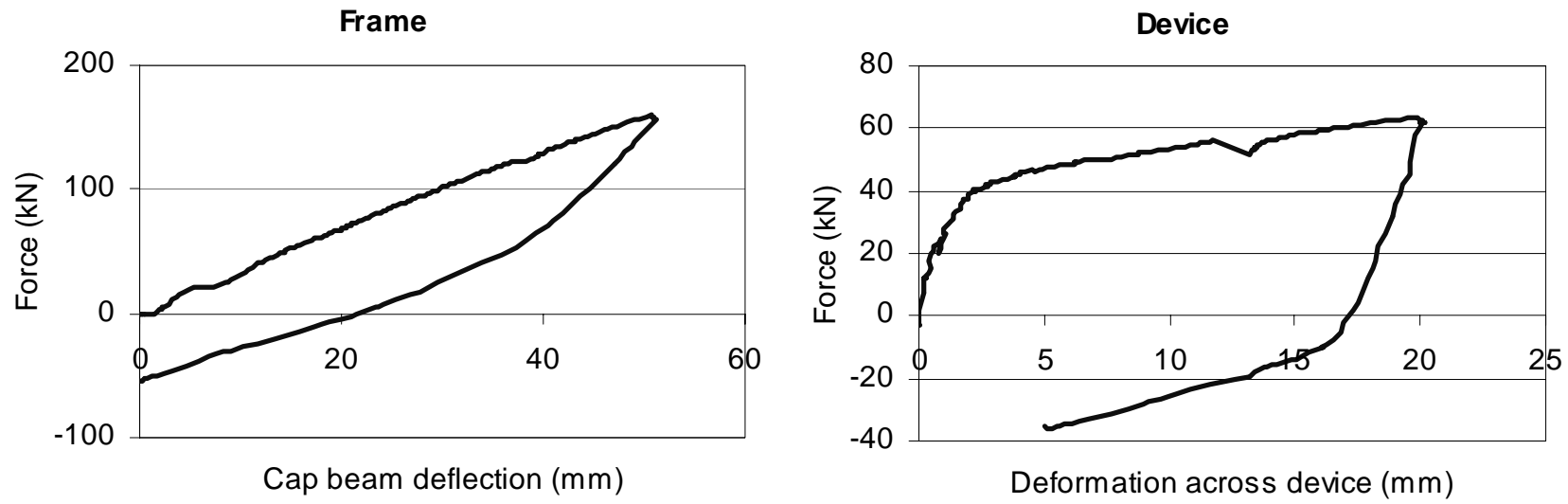

Figure 4.7. Monotonic test, $3 \mathrm{~mm}$ single plate 
$2 \times 1.5 \mathrm{~mm}$ plates (Test 5). First buckle appeared at a cap beam displacement of around $25 \mathrm{~mm}$, at which point the device deformation was $11 \mathrm{~mm}$. Buckling is not evident in the load-deformation plots of Figure 4.8, which are quite similar to those for a single $3 \mathrm{~mm}$ plate, Figure 4.7.
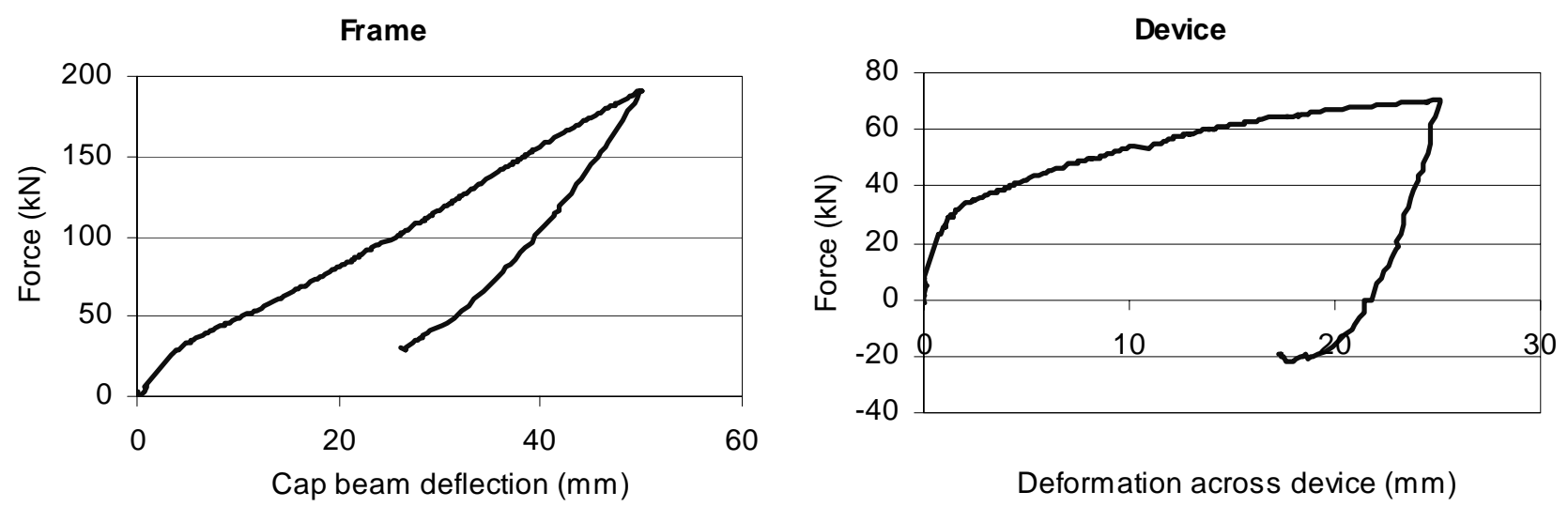

Figure 4.8. Monotonic test, 2 x $1.5 \mathrm{~mm}$ plates

$4 \mathbf{~ m m}$ single plate (Test 13). No apparent buckling at cap beam displacements of up to $55 \mathrm{~mm}$. A $60 \mathrm{kN}$ reverse load was required to bring the frame back to zero displacement.
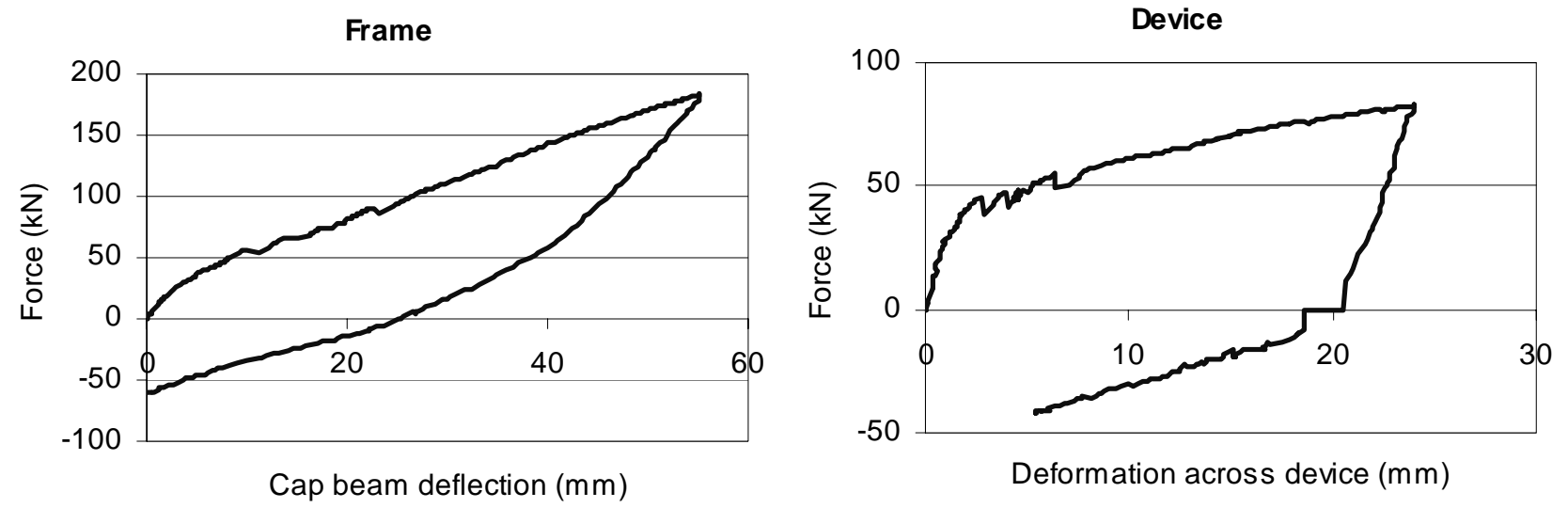

Figure 4.9. Monotonic test, $4 \mathrm{~mm}$ single plate

$2 \times 2 \mathrm{~mm}$ plates (Test 2). First buckle appeared at a cap beam displacement of around $25 \mathrm{~mm}$, at which point the device deformation was $10 \mathrm{~mm}$. Buckling is not evident in the load-deformation plots of Figure 4.10, which are quite similar to those for a single $4 \mathrm{~mm}$ plate, Figure 4.9. Figure 4.11 shows the device at the point of maximum deformation.
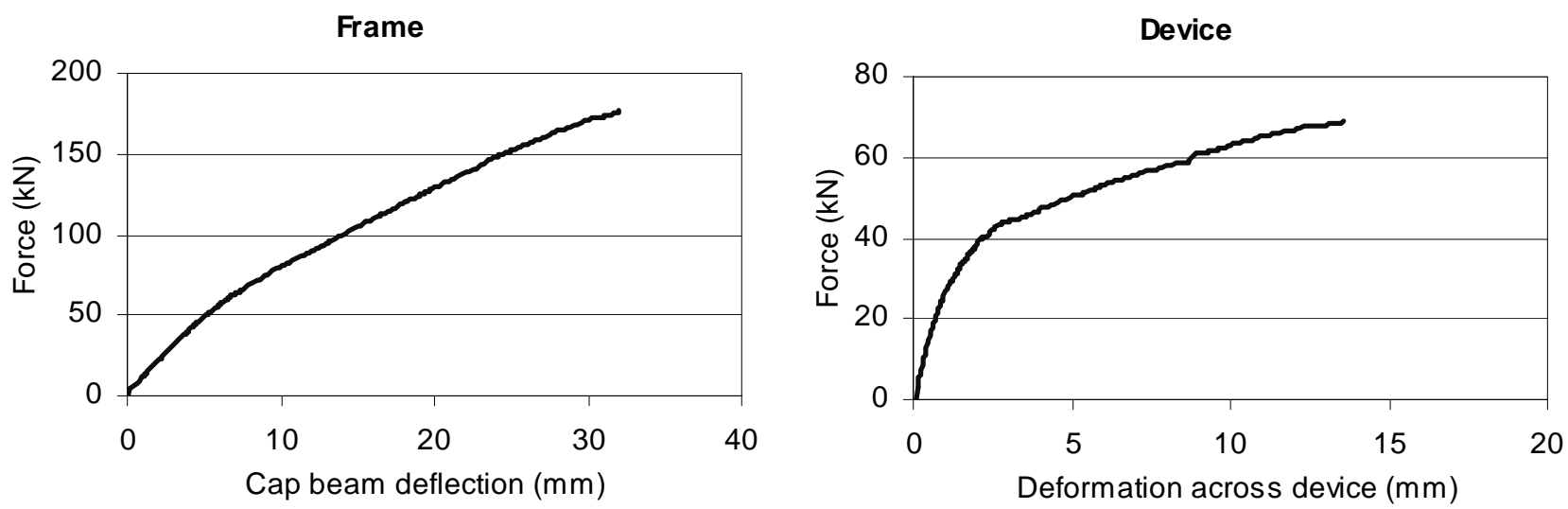

Figure 4.10. Monotonic test, 2 x 2 mm plates 
Test 1 was also a monotonic test on two $2 \mathrm{~mm}$ plates but is not reported here as it was the only test conducted with fixed column bases, and so is not easy to compare to the others.

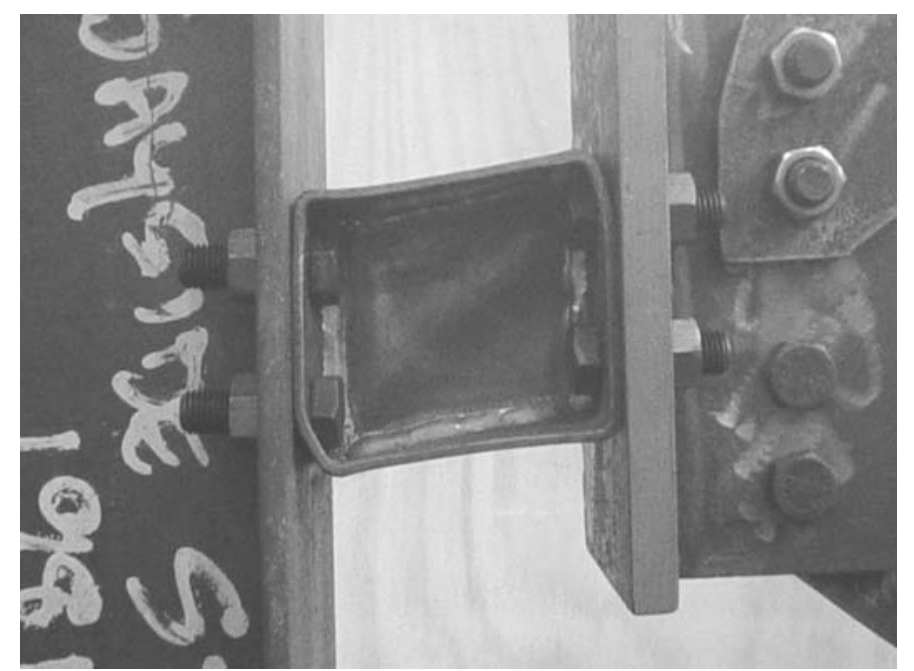

Figure 4.11. 2 x 2 mm plate device at point of maximum deformation

\subsubsection{Simple cyclic tests}

In these tests a single reverse cycle was imposed at each displacement amplitude.

Open box section - no plate (Test 17). This test was conducted as a control. The device yielded at a very low load and carried no load on the unloading cycle until it had been pushed back past its zero deformation point.

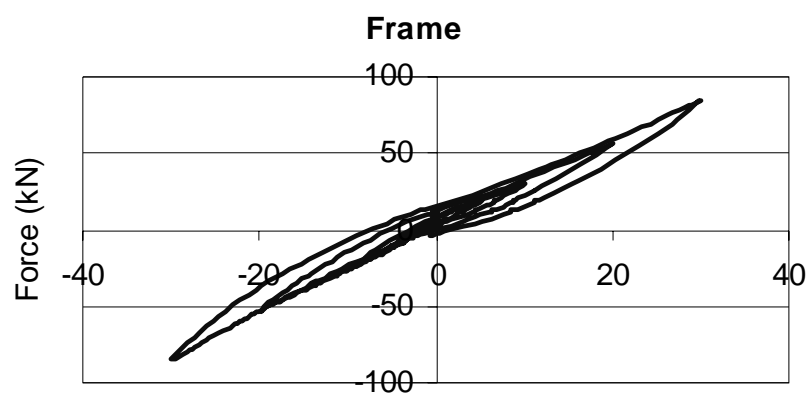

Cap beam deflection $(\mathrm{mm})$

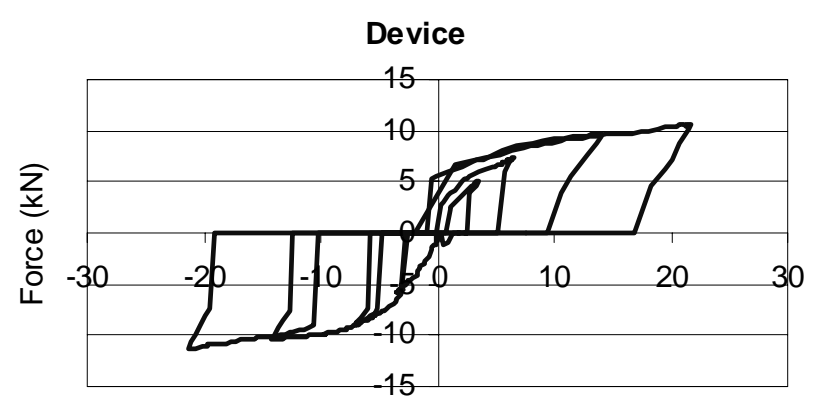

Deformation across device $(\mathrm{mm})$

Figure 4.12. Cyclic test - no plate

$1 \mathrm{~mm}$ single plate (Test 10). A very slight buckle developed during the $5 \mathrm{~mm}$ cycle, and amplified in subsequent cycles. The test was discontinued midway through the $30 \mathrm{~mm}$ cycle as the buckle amplitude was becoming very large, although the device continued to carry load. The deformations imposed on the device were highly unsymmetrical, with much larger demands on the initial upwards pull (negative quadrant) than in the subsequent downwards push (positive quadrant). It is thought that the large flat region of the device hysteresis curve at zero load when unloading from the negative quadrant is due to flattening out of a buckle. Other minor kinks are due to bolt slip. 


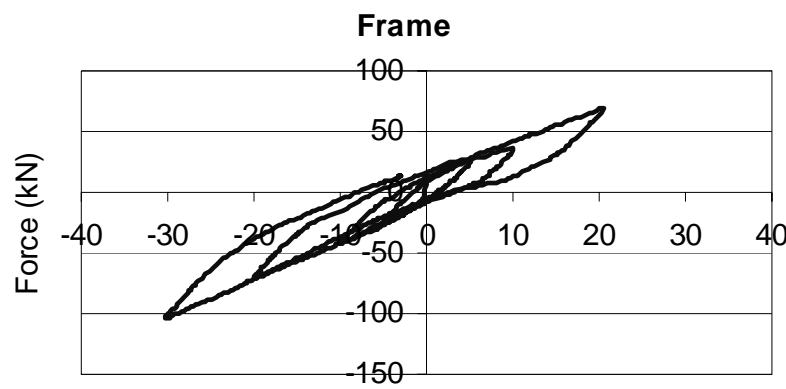

Cap beam deflection $(\mathrm{mm})$

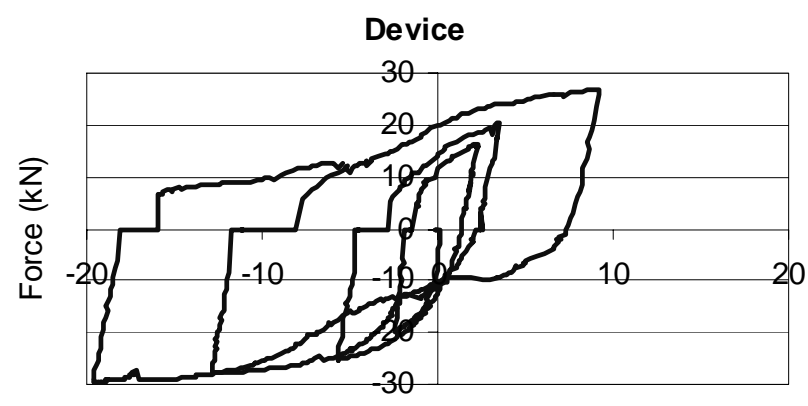

Deformation across device $(\mathrm{mm})$

Figure 4.13. Cyclic test $-1 \mathrm{~mm}$ single plate

$1.5 \mathrm{~mm}$ single plate (Test 12). A very slight buckle developed during the $10 \mathrm{~mm}$ cycle, and amplified in subsequent cycles. The test was discontinued midway through the $40 \mathrm{~mm}$ cycle as the buckle amplitude was becoming very large, although the device continued to carry load. The deformations imposed on the device were again rather unsymmetrical. The device hysteresis curve is in general rather smoother than in Test 10.
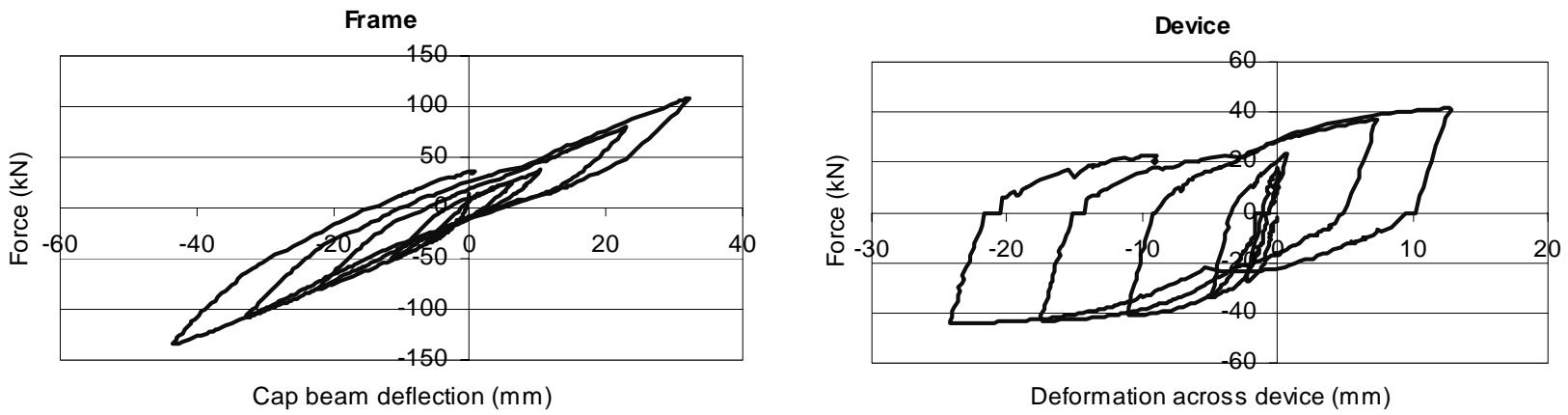

Figure 4.14. Cyclic test $-1.5 \mathrm{~mm}$ single plate

$2 \mathrm{~mm}$ single plate (Test 19). Buckling became evident early in the $20 \mathrm{~mm}$ cycle, but the device went on to withstand a full cycle at $\pm 40 \mathrm{~mm}$. The device hysteresis loop shows a noticeable pinching at a small negative displacement, thought to be related to the transition from a buckle in one direction to the other.
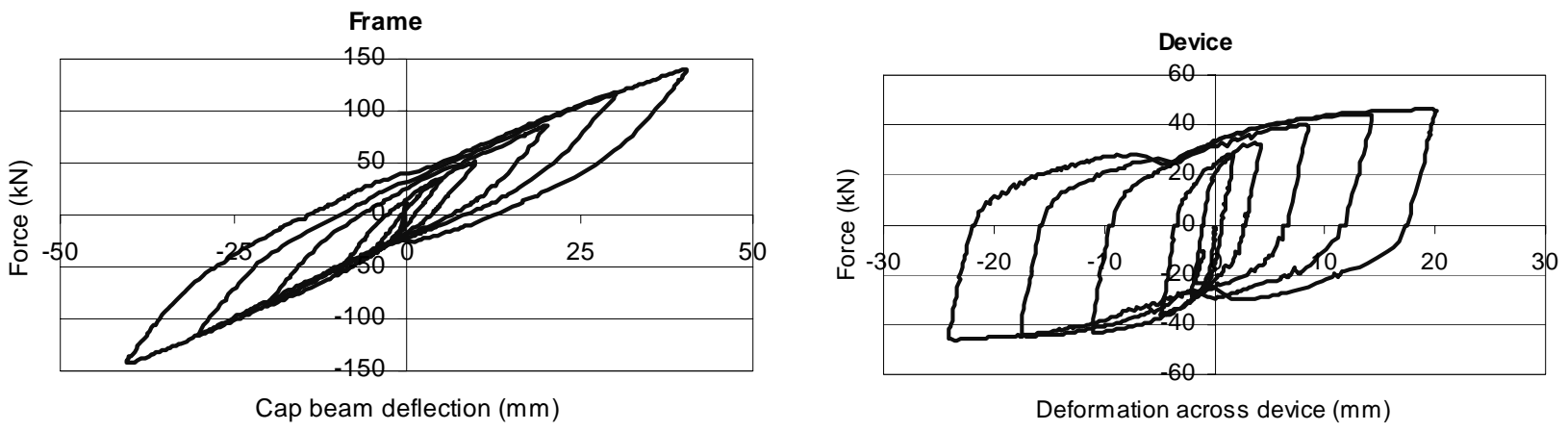

Figure 4.15. Cyclic test $-2 \mathrm{~mm}$ single plate

$2 \times 1 \mathrm{~mm}$ plates (Test 7). Buckling was visible from the $10 \mathrm{~mm}$ cycle onwards (significantly earlier than the single $2 \mathrm{~mm}$ plate), and the test was continued up to $\pm 30 \mathrm{~mm}$. Nevertheless, the device hysteresis loop is broadly similar to the single $2 \mathrm{~mm}$ plate case (compare Figures 4.15 and 4.16). Figure 4.17 shows the device at two different deformation amplitudes. 


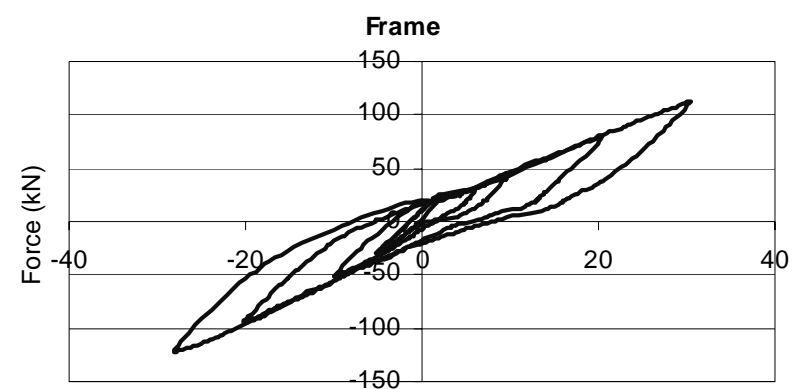

Cap beam deflection $(\mathrm{mm})$

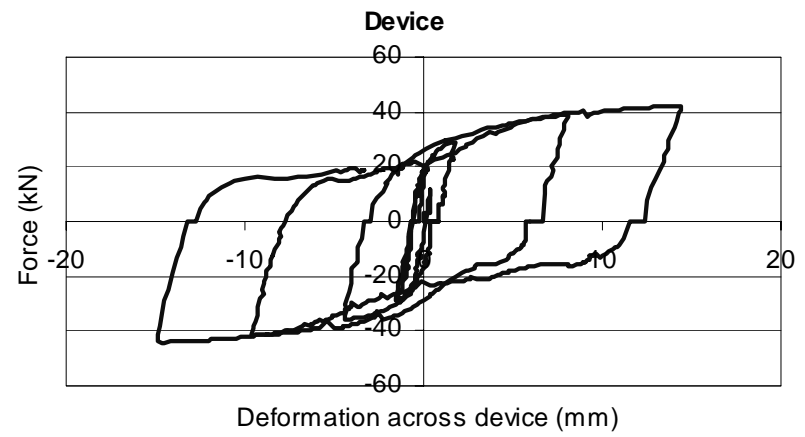

Figure 4.16. Cyclic test $-2 \times 1 \mathrm{~mm}$ plates
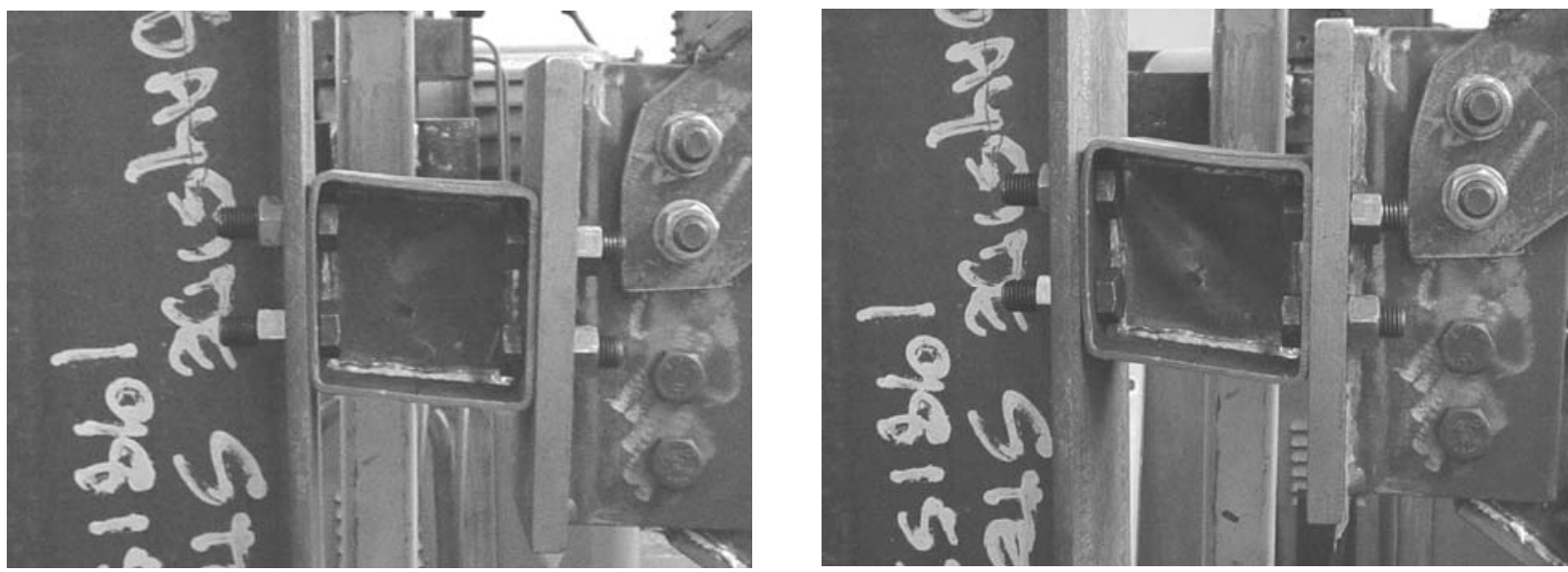

Figure 4.17. 2 x $1 \mathrm{~mm}$ plate device at upwards cap beam displacements of $20 \mathrm{~mm}$ (left) and $30 \mathrm{~mm}$ (right)

$3 \mathbf{~ m m}$ single plate (Test 22). A very shallow buckle developed on the second half of the $\pm 40 \mathrm{~mm}$ cycle, but otherwise the device performed very well, exhibiting large, open hysteresis loops. The device response is again highly unsymmetrical, confirming that the asymmetry is not related to device buckling.

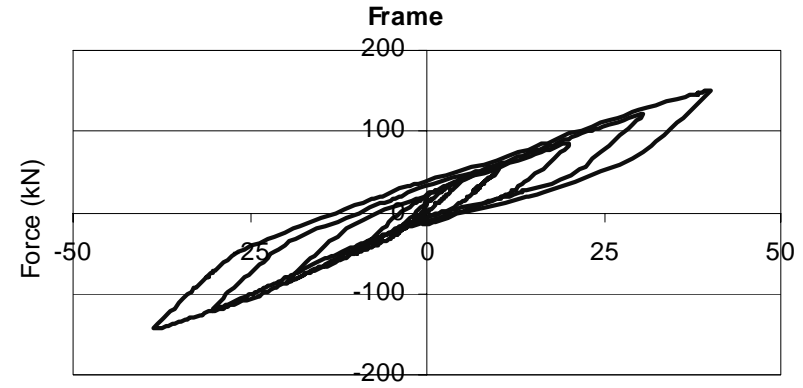

Cap beam deflection $(\mathrm{mm})$

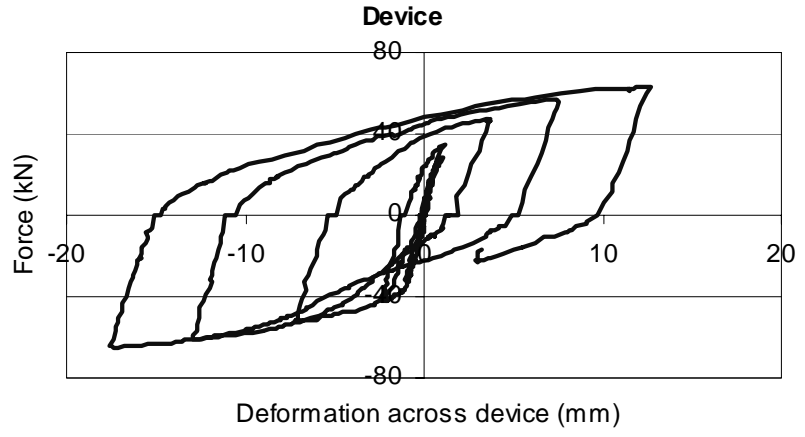

Deformation across device $(\mathrm{mm})$

Figure 4.18. Cyclic test $-3 \mathrm{~mm}$ single plate

$2 \times 1.5 \mathrm{~mm}$ plates (Test 8). Buckling was visible from early in the $30 \mathrm{~mm}$ cycle onwards (significantly earlier than the single $3 \mathrm{~mm}$ plate), and the test was continued up to the first half of the $40 \mathrm{~mm}$ cycle. Peak loads and deformations were similar to those of the single $3 \mathrm{~mm}$ plate, but the hysteresis loops are rather narrower, implying less energy dissipation. 

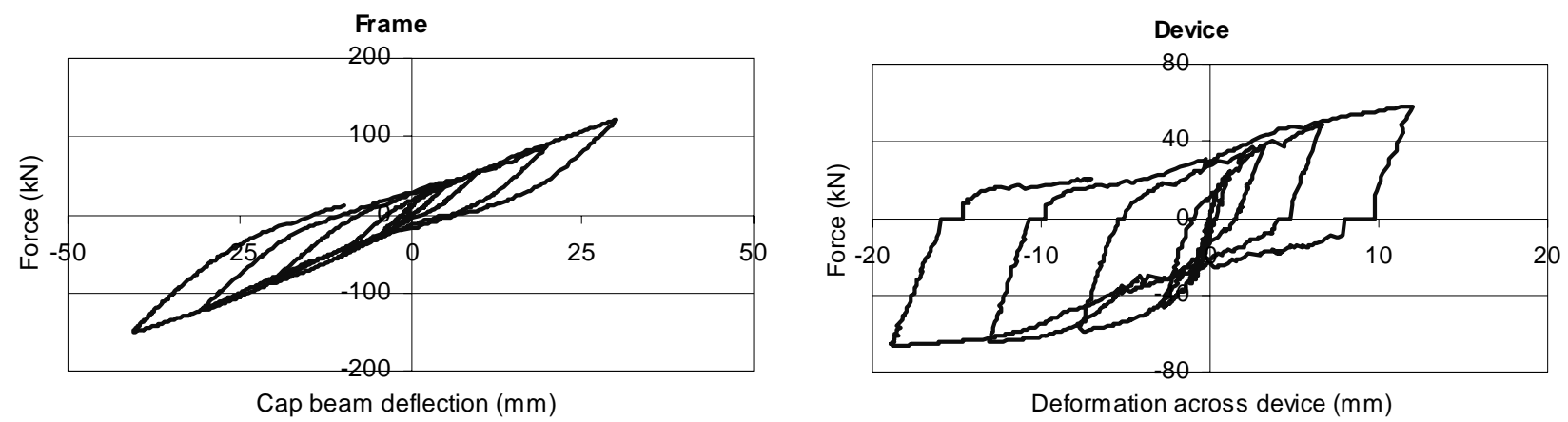

Figure 4.19. Cyclic test $-2 \times 1.5 \mathrm{~mm}$ plates

$4 \mathrm{~mm}$ single plate (Test 24). The test proceeded up to the first half of the $40 \mathrm{~mm}$ cycle, with no buckling evident at any stage. The device response was again highly unsymmetrical. This was the last test performed and there was some evidence that parts of the frame were deteriorating after being subjected to a large number of high-load cycles.
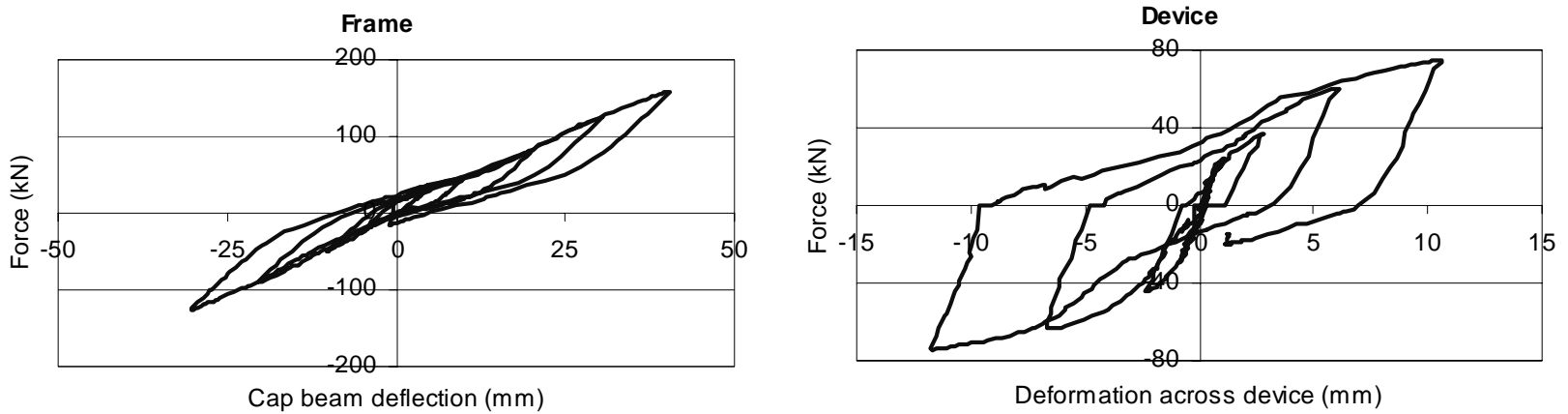

Figure 4.20. Cyclic test $-4 \mathrm{~mm}$ single plate

$2 \times 2 \mathbf{~ m m}$ plates (Test 6). Buckling was visible from late in the $20 \mathrm{~mm}$ cycle onwards (compared with no buckling for the single $4 \mathrm{~mm}$ plate), and the test was continued up to the first half of the 40 mm cycle. Peak loads and deformations were similar to those of the single $4 \mathrm{~mm}$ plate.

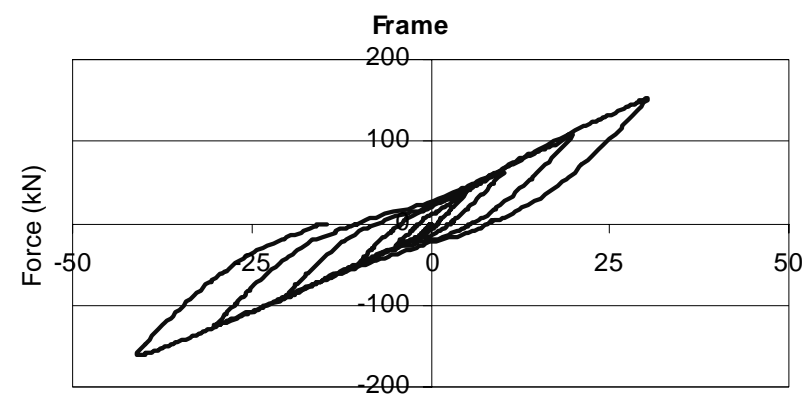

Cap beam deflection $(\mathrm{mm})$

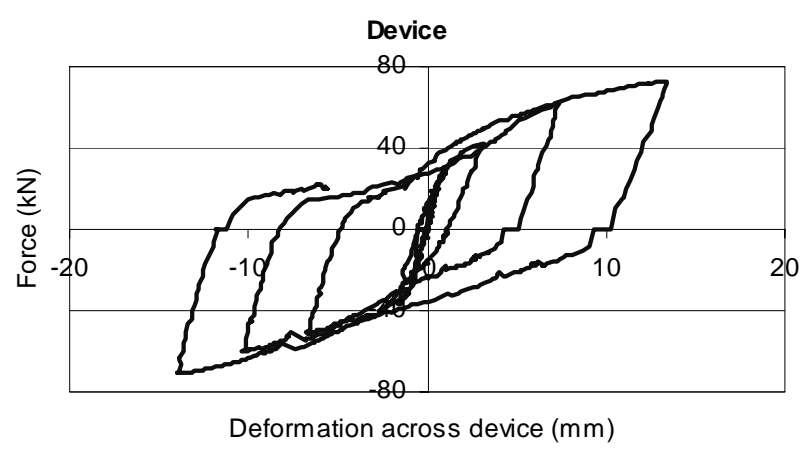

Deformation across device $(\mathrm{mm})$

Figure 4.21. Cyclic test - 2 x 2 mm plates

\subsubsection{Repeated cyclic tests}

In these tests three reverse cycles were imposed at each displacement amplitude, from the $10 \mathrm{~mm}$ cycle onwards. The overall frame hysteresis plots showed very little deterioration between cycles and so added little to the single-cycle plots already presented. Therefore only the device hysteresis plots are presented here. The key indicates the cap beam displacement amplitude for each cycle. 
$1 \mathrm{~mm}$ single plate (Test 16). Some buckling occurred during the $5 \mathrm{~mm}$ cycles, and grew as the imposed displacements increased. Figure 4.22 shows the buckling state at three instants during the $\pm 20 \mathrm{~mm}$ cycles. With the cap beam displaced $20 \mathrm{~mm}$ upwards a very severe top-left-to-bottomright diagonal buckle is visible. Because the plate has been greatly stretched, the reverse buckle has formed by the time the device returns to its centre position. This buckle then amplifies as the device distorts the other way. The device failed by tearing along the welds at the top right and bottom left of the diaphragm while unloading at the end of the first $\pm 30 \mathrm{~mm}$ cycle. The hysteresis loops in Figure 4.23 show very limited degradation between cycles, and large zero-load plateaus when unloading from the negative displacement cycles, thought to be due to flattening/reversal of buckles.
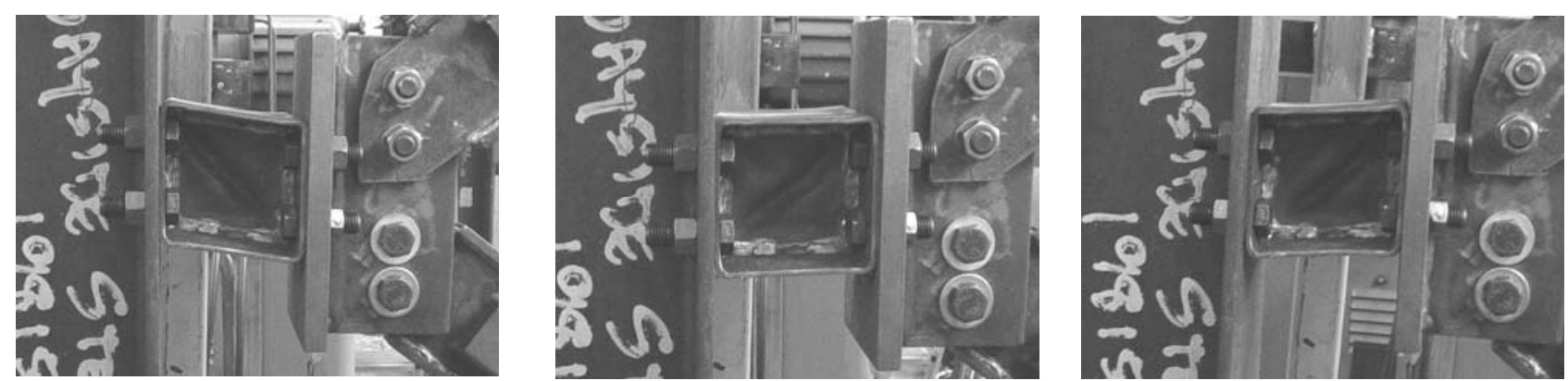

Figure 4.22. $1 \mathrm{~mm}$ single plate device during $20 \mathrm{~mm}$ cycles - from left to right: end of upward stroke; device brought back to zero deformation; end of downward stroke

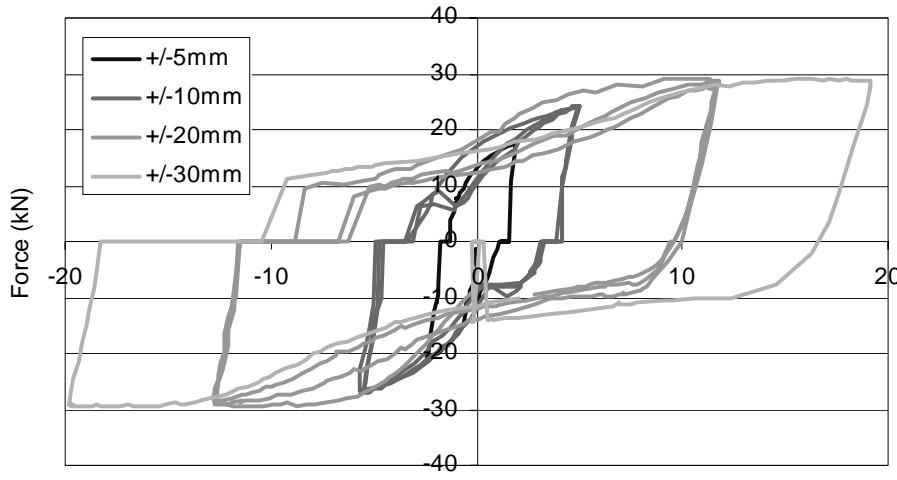

Deformation across device $(\mathrm{mm})$

Figure 4.23. Device hysteresis in repeated cyclic test $-1 \mathrm{~mm}$ single plate

$1.5 \mathrm{~mm}$ single plate (Test 15). Buckling was first noticed at an amplitude of $13 \mathrm{~mm}$ during the first $20 \mathrm{~mm}$ cycle. The device subsequently failed by tearing along a diagonal buckle line during the second $30 \mathrm{~mm}$ cycle. This test suffered a lot of bolt slip, resulting in rather noisy data.

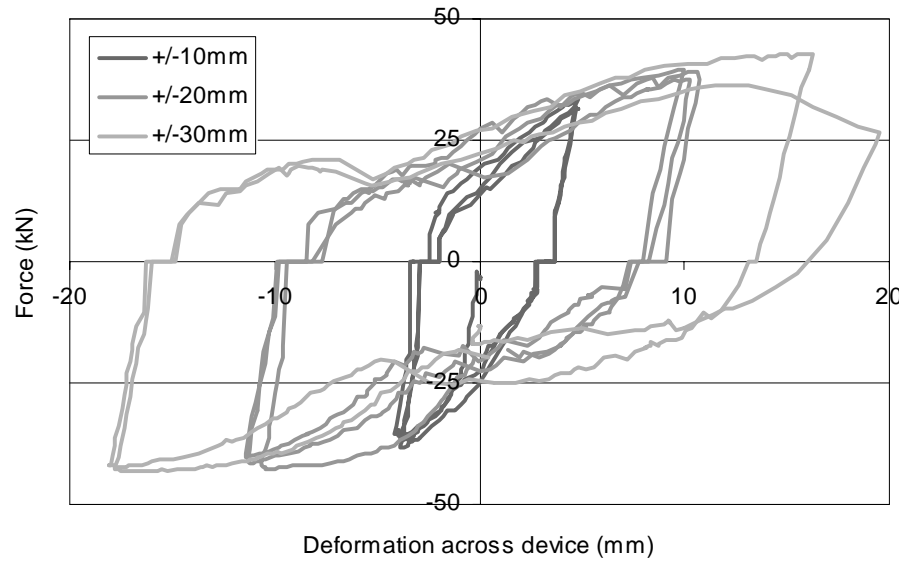

Figure 4.24. Device hysteresis in repeated cyclic test $-1.5 \mathrm{~mm}$ single plate 
2 mm single plate (Test 20). Buckling was first noticed near the maximum of the first $20 \mathrm{~mm}$ cycle. No failure occurred. For most of the test a good degree of consistency was achieved between repeated cycles at a given amplitude.

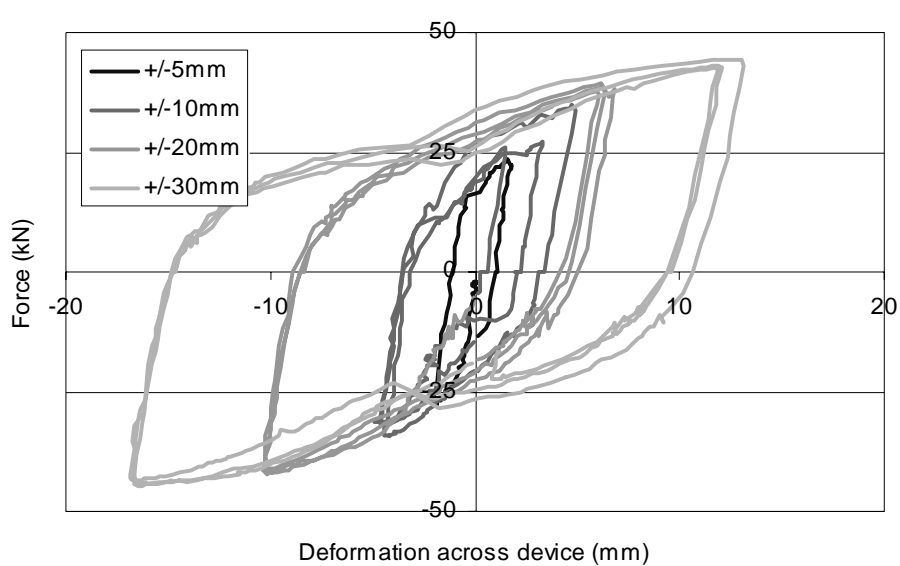

Figure 4.25. Device hysteresis in repeated cyclic test $-2 \mathrm{~mm}$ single plate

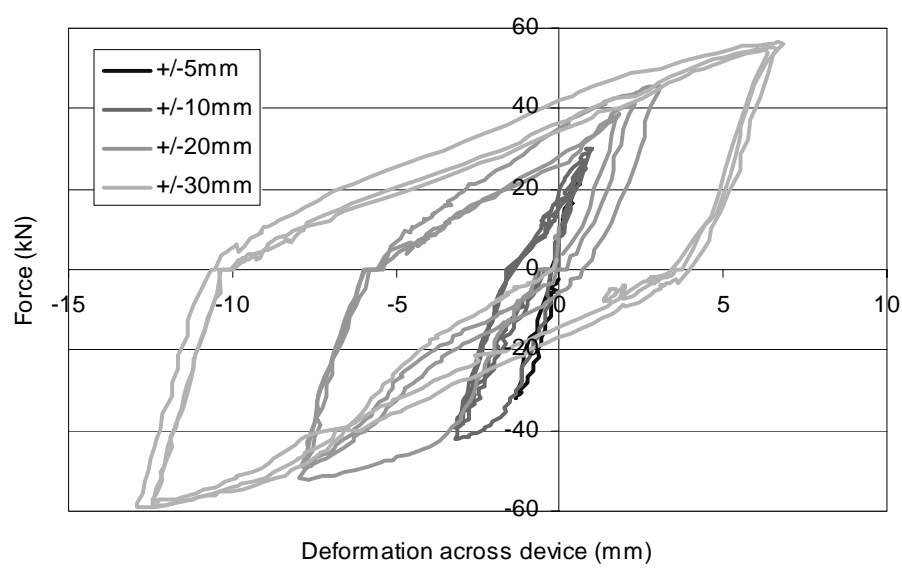

Figure 4.26. Device hysteresis in repeated cyclic test $-3 \mathrm{~mm}$ single plate

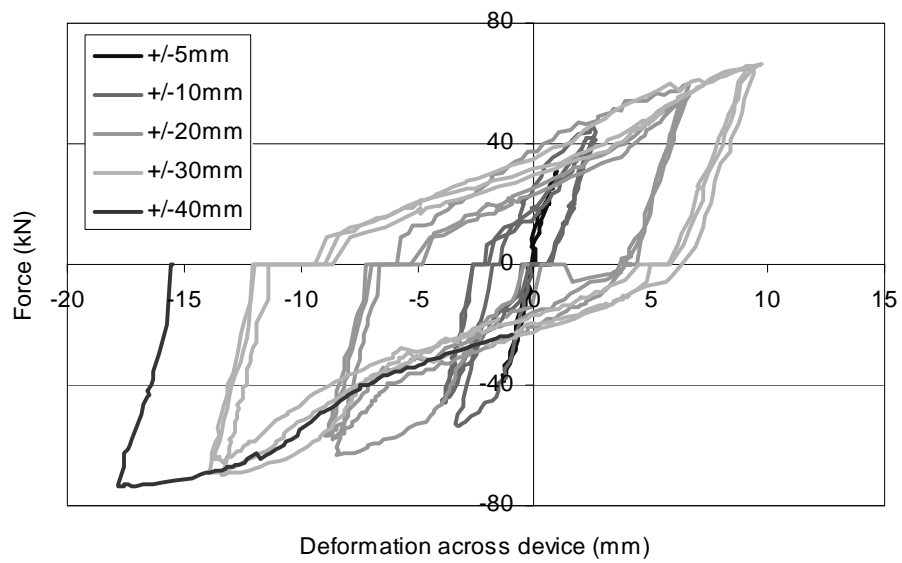

Figure 4.27. Device hysteresis in repeated cyclic test $-2 \times 2 \mathrm{~mm}$ plates

\subsection{Analysis of Monotonic Test Results}

The monotonic test performance was broadly as expected, with both yield load and buckling load increasing with plate thickness. However, there were some differences between observed yield loads and those predicted by assuming simple shear yielding of the diaphragm plate. Table 4.1 shows experimentally deduced yield loads for the devices (deduced by fitting a best-fit bilinear curve to the date) and theoretical values. 
Table 4.1. Experimental and theoretical yield loads for monotonic tests

\begin{tabular}{|c|c|c|}
\hline Diaphragm thickness $(\mathrm{mm})$ & \multicolumn{2}{|c|}{ Yield load $(\mathrm{kN})$} \\
\cline { 2 - 3 } & Experiment & Theory \\
\hline 1 & 18.5 & 10 \\
\hline 1.5 & 28 & 24.9 \\
\hline 2 & 28 & 26 \\
\hline $2 \times 1$ & 32 & 19 \\
\hline 3 & 32 & 42.8 \\
\hline $2 \times 1.5$ & 41.5 & 49.8 \\
\hline 4 & 43 & 60 \\
\hline $2 \times 2$ & 40 & 52 \\
\hline
\end{tabular}

Clearly the theory underestimates the yield load for the thinner plates, but overestimates it for the thicker ones. A possible explanation for the case of the thinner plates is that they are significantly strengthened by the confinement provided by the short length of box section, an effect ignored in the simple theoretical calculation. The reason for the overestimate in the case of the thicker plates is less clear, but this result possibly implies that the stress state in the plates is more complex than pure shear.

Another interesting point of comparison is the relative performances of single and double plate devices having the same effective thickness. Figure 4.28 shows comparisons up to the point of maximum load for effective thicknesses of 2, 3 and $4 \mathrm{~mm}$. Clearly the differences in performance between equivalent devices are not great in a monotonic test, in spite of the fact that buckling was general observed at significantly lower deformations for single plate than for double plate devices.

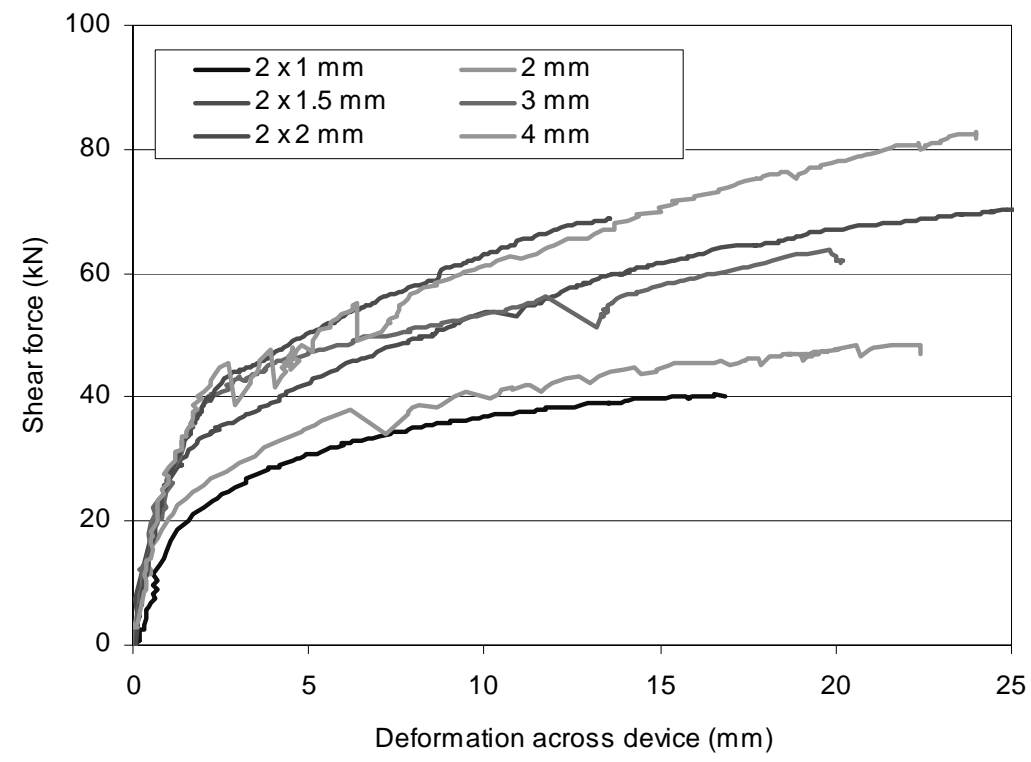

Figure 4.28. Comparisons of force-deformation characteristics of single and double plate devices

\subsection{Cyclic Test Performance}

The devices generally performed well in cyclic tests involving only a single cycle at each amplitude. Despite relatively early and repeated buckling of the thinner diaphragms, all devices remained stable up to frame displacement amplitudes of at least $30 \mathrm{~mm}$, with no fracture or failure occurring in any case. In general, single-plate devices seem to have suffered less buckling and given slightly larger, more stable hysteresis loops than the equivalent double-plate devices, though the differences are not great. 
To give some further insight into the relative performances of the devices and their influence on the frame behaviour, some further post-processing has been undertaken. First, the monotonic results were used to estimate yield forces and deformations, both for the frame as a whole, and for the force and deformation in the device itself. It should be noted that the yield deformations are quite difficult to estimate to a high degree of accuracy and, with the exception of the very thinnest device, did not show much variation between devices - the figures used are therefore approximate averages over a number of different devices. Using these results together with peak forces and deformations measured in the cyclic tests, it is then possible to estimate the load increase beyond yield and the ductility achieved. In each case, figures have been computed both for the frame as a whole and for the device in isolation. The results are shown in Table 4.2. Note that the maximum values achieved here are not ultimate values since no device actually failed - they are simply the maximum values reached before the decision was taken to stop the test.

Table 4.2. Force ratios and ductilities in simple cyclic tests

\begin{tabular}{|l||l|l|l|l|l|l|l|l||l|l|l|l|}
\hline $\begin{array}{l}\text { Plate } \\
\text { Th. } \\
(\mathrm{mm})\end{array}$ & \multicolumn{3}{|l|}{$F_{y}(\mathrm{kN})$} & \multicolumn{3}{l|}{$u_{y}(\mathrm{~mm})$} & \multicolumn{2}{l|}{$F_{\max }(\mathrm{kN})$} & \multicolumn{2}{l|}{$u_{\max }(\mathrm{mm})$} & $F_{\max } / F_{y}$ & \multicolumn{2}{l|}{$\mu$} \\
\hline \hline 1 & Fr. & Dev. & Fr. & Dev. & Fr. & Dev. & Fr. & Dev. & Fr. & Dev. & Fr. & Dev. \\
\hline 1.5 & 26 & 18.5 & 3.5 & 1.2 & 103.9 & 26.9 & 30.1 & 19.7 & 4.0 & 1.5 & 8.6 & 16.4 \\
\hline 2 & 45 & 28 & 5.0 & 1.2 & 134.7 & 44.4 & 43.5 & 24.2 & 3.0 & 1.6 & 8.7 & 20.2 \\
\hline $2 \times 1$ & 59 & 28 & 5.0 & 1.2 & 142.9 & 46.2 & 40.5 & 24.1 & 4.0 & 1.7 & 8.1 & 20.1 \\
\hline 3 & 41 & 32 & 5.0 & 1.2 & 121.8 & 44.1 & 30.4 & 14.9 & 2.1 & 1.4 & 6.1 & 12.4 \\
\hline $2 \times 1.5$ & 61 & 41.5 & 5.0 & 1.2 & 149.7 & 66.1 & 40.4 & 18.9 & 2.5 & 1.6 & 8.1 & 15.8 \\
\hline 4 & 54 & 43 & 5.0 & 1.2 & 158.8 & 74.9 & 40.3 & 11.8 & 2.9 & 1.7 & 8.1 & 9.8 \\
\hline $2 \times 2$ & 71 & 40 & 5.0 & 1.2 & 168.0 & 72.8 & 40.9 & 14.0 & 2.4 & 1.8 & 8.2 & 11.7 \\
\hline
\end{tabular}

Firstly, it can be seen the devices strain harden significantly and so carry substantial additional load after first yield - up to double the yield load in one case. Any analysis that treats the device as elastic-perfectly plastic is likely to underestimate the loads on the structure by a large amount. Of course, with the main frame elements remaining elastic, the overall frame carries significantly more load after yield of the device - up to four times the load at the onset of yielding.

Turning to the ductilities, it can be seen that the thinner diaphragms sustain ductilities of the order of 20, while for thicker ones the maximum ductility in these tests was 10-15. In all cases the overall ductility of the frame (i.e. the ratio of peak cap beam displacement to the value at first yield) was around 8. Note that these figures are approximate, because of the difficulty in accurately estimating the yield deformations, as discussed above.

Another way of normalising the device deformations would be to calculate a shear strain. Since the plate dimension is $100 \mathrm{~mm}$, the calculation is very simple - the plate deformation in mm is equal to the shear strain in \%. So the diaphragms in these tests withstood maximum shear strains in the range 11.8 to $24.2 \%$ without fracturing.

\subsection{Device Deformation and Hysteretic Energy Absorption}

Since the key objective of a dissipative device is to absorb seismic energy, the measured energy dissipation is a key test parameter. This is quite easily calculated as the area within the hysteresis loops. The energy absorbed depends on both the size of the diaphragm and the amount of plastic deformation it sustains. 
Figure 4.29 shows the diaphragm deformation as a function of its thickness for different cap beam displacement amplitudes. As would be expected, the thicker devices tend to undergo less deformation than the thinner ones for a given frame displacement. Figure 4.30 then shows the energy absorption plotted in the same way. This appears to show that the $2 \mathrm{~mm}$ diaphragm offers the best energy absorption capacity - thinner diaphragms buckle too easily and simply do not have as much material to deform, thicker ones are more resistant to yielding and so undergo less plastic deformation.

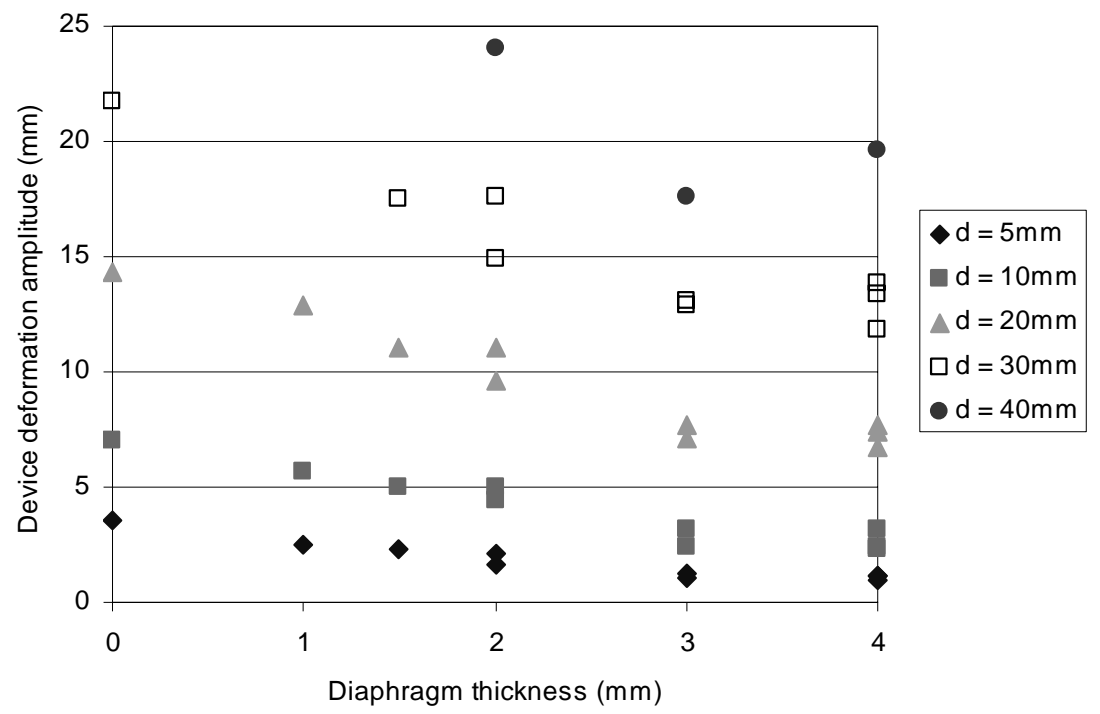

Figure 4.29. Device deformations at different cap beam displacement amplitudes

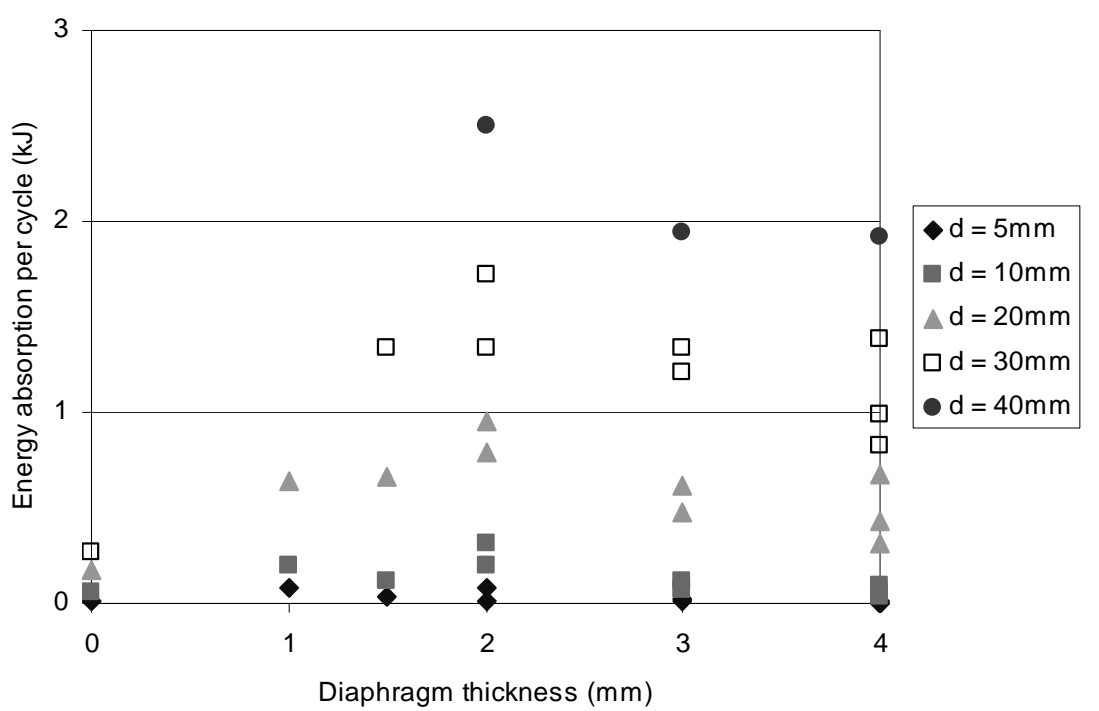

Figure 4.30. Energy absorption at different cap beam displacement amplitudes

An alternative presentation of the same data is shown in Figures 4.31 and 4.32, in which the energy absorption is plotted as a function of cap beam displacement and device deformation respectively. Figure 4.32 shows that, for a given device deformation, the thicker plates generally dissipate more energy. However, since thicker plates undergo less deformation for a given cap beam displacement, they may not be optimal. Figure 4.31 again suggests that the $2 \mathrm{~mm}$ diaphragms give the best energy dissipation for this frame, with the $3 \mathrm{~mm}$ diaphragms not far behind. 


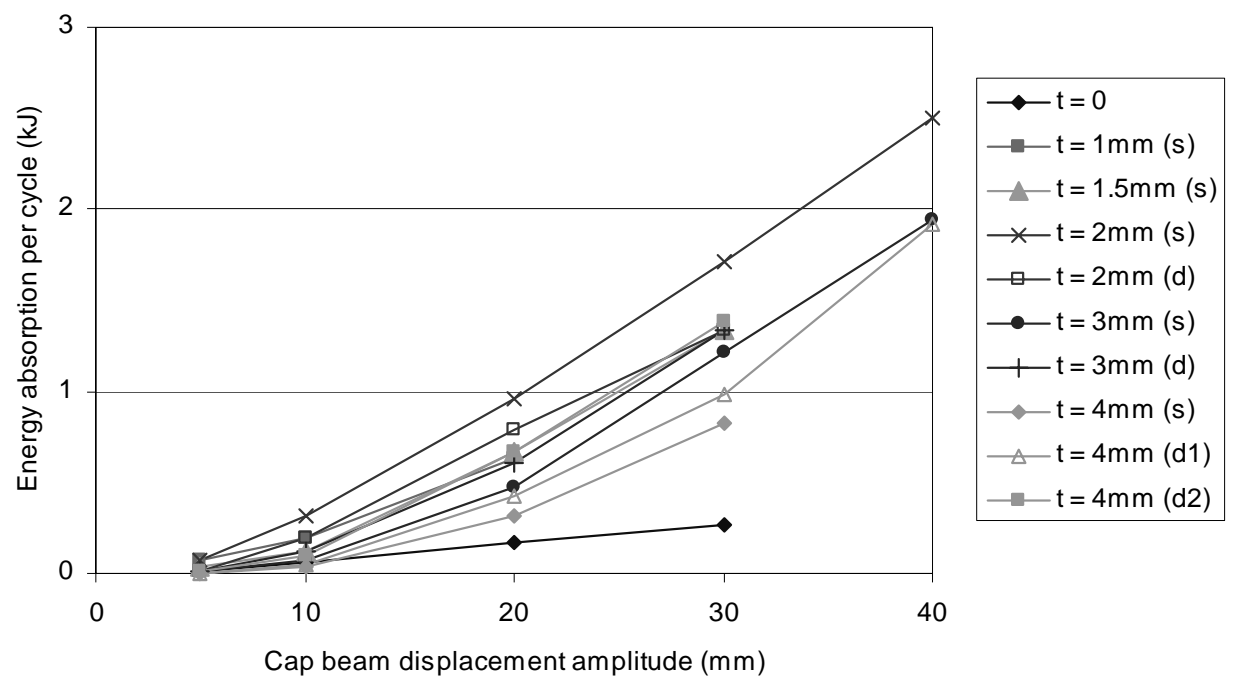

Figure 4.31. Energy absorption as a function of cap beam displacement amplitude $(\mathrm{t}=$ total plate thickness, $\mathrm{s}=$ single plate, $\mathrm{d}=$ double plate $)$

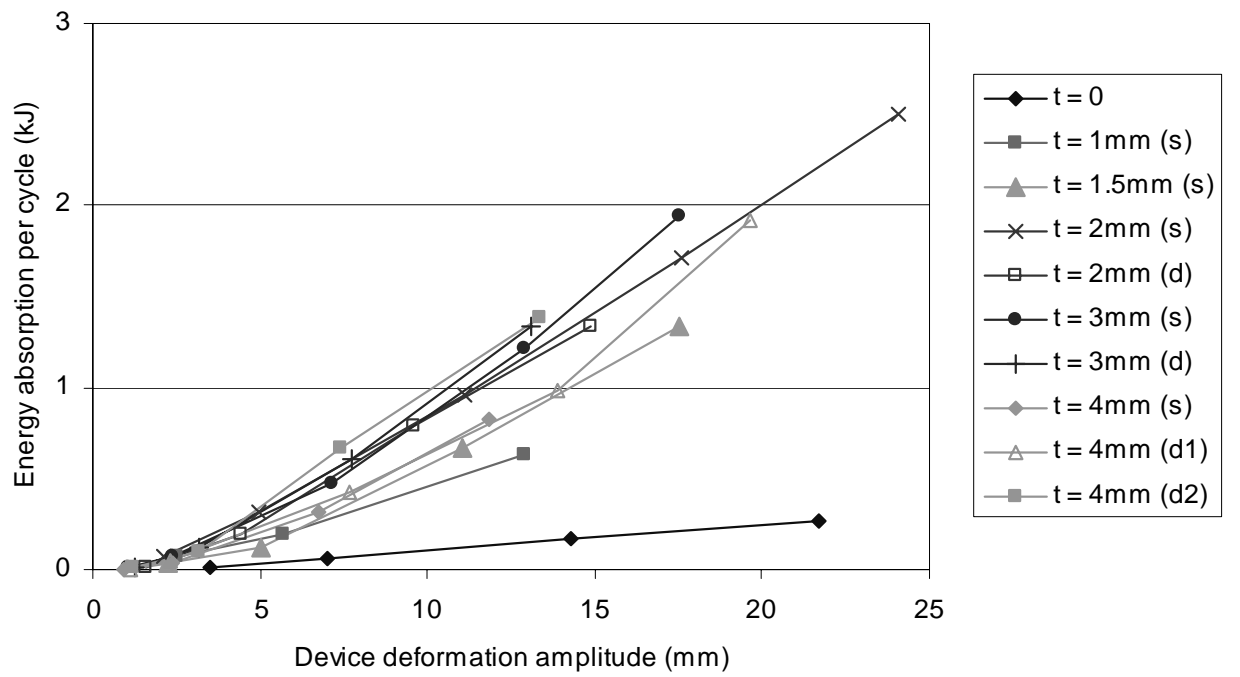

Figure 4.32. Energy absorption as a function of device deformation amplitude ( $\mathrm{t}$ = total plate thickness, $\mathrm{s}=$ single plate, $\mathrm{d}=$ double plate $)$

The magnitude of the energy absorption is also worthy of comment. For the devices tested (100 mm square and up to $4 \mathrm{~mm}$ thick) the energy absorbed is of the order of 1-2 kJ per large-amplitude cycle. It is reasonable to assume that this figure would scale roughly proportionally for larger devices. To put this figure in perspective, a 100 tonne mass moving sinusoidally at $1 \mathrm{~Hz}$ with displacement amplitude $30 \mathrm{~mm}$ has a peak kinetic energy of $1.8 \mathrm{~kJ}$. Clearly the devices possess sufficient energy dissipation capacity to make a significant impact on the performance of a building.

\subsection{Comparison of Single-Cycle and Multi-Cycle Tests}

In general, the device performance with three cycles at each amplitude was very similar to that with a single cycle at each amplitude - compare Figures 4.13 and 4.23, 4.14 and 4.24, 4.15 and 4.25, 4.18 and 4.26, 4.21 and 4.27. The devices mostly show very stable hysteresis loops, with only a small reduction in load between cycles at a given amplitude. 
The important exceptions are the two thinnest plates tested. Both the $1 \mathrm{~mm}$ and the $1.5 \mathrm{~mm}$ diaphragms fractured during cycling at $\pm 30 \mathrm{~mm}$, presumably due to low cycle fatigue at the large plastic strains experienced. These are therefore clearly unsuitable. The $2 \mathrm{~mm}$ diaphragm did not fracture but did undergo large-scale plastic buckling, which gives rise to the risk of failure. The 3 mm diaphragm, however, showed no ill effects even under the most severe test regime. Since its energy absorption performance is close to that of the $2 \mathrm{~mm}$ device, the $3 \mathrm{~mm}$ device is considered to offer the best combination of energy dissipation and device stability. This represents a ratio of plate thickness to breadth of 0.03 , a figure which may be transferable to other devices.

\subsection{Comments on Performance of Tests and Possible Improvements}

The tests were easy to perform. The bolted connections to the device suffered some slip but this did not appear to have a dramatic effect on the overall hysteresis response. The connections survived the test well and the devices were easy to remove and replace between tests, which is important for their practical use. However, there were some minor problems which could be reduced by a modest re-design of the rig before conducting further tests.

First, there was a noticeable asymmetry in many of the cyclic test results. The reasons for this have not been fully established, but are thought to be mainly due to the frame support conditions. In future it would be better if the rig could be rotated through $90^{\circ}$ and mounted on a rigid base, with the actuator horizontal. The provision of proper, machined pin supports would also reduce the nonlinearity.

In some tests, quite a large amount of longitudinal slip occurred at the brace connections near the device, and the bolt-holes in the brace connection plates became elongated in later tests. Some bolt slip is desirable to enable the connection to rotate and so not transfer moments into the braces. However, thicker connection plates and two lines of bolts would help to prevent the excessive slip that was observed in some tests. No slip is desirable in the connection of the device itself - it might therefore be advisable to use friction grip bolts for this connection.

Load in these tests was provided by a simple manually controlled actuator, which meant that the applied load/displacement and loading rate could not be controlled exactly. Although reasonably accurate control was achieved, the tests could be improved and automated if a servo-controlled actuator could be use, with electronic control based on either load or displacement.

The tests performed here represent a start to a fuller investigation of these devices. Only a single overall device size (100 mm square) has been studied, together with a variety of diaphragm thicknesses. To investigate the size dependency, at least two further device sizes should be studied.

Lastly, the device performance has not proved completely predictable and greater insight could be achieved through detailed, non-linear finite element modelling of a device under both monotonic and cyclic loads.

\section{CONCLUSIONS}

1. A quite extensive series of tests on $100 \mathrm{~mm}$ square dissipative devices has been successfully performed. The simple setup proved reasonably robust and repeatable, though some improvements have been suggested in section 4.6. 
2. The devices were easy and cheap to manufacture, fit, remove and replace. They therefore have the potential to offer practical, low-cost protection to buildings.

3. All the devices tested yielded at quite low deformations and sustained very large ductilities (greater than 10) without failure. This suggests that they would begin to dissipate energy early in an earthquake, and would continue to do so as the earthquake motion increased.

4. The load carried by the device continued to increase after yield, with a ratio of maximum force carried to yield force of around 1.7 in most tests.

5. While a device with a $2 \mathrm{~mm}$ diaphragm appeared to offer the maximum energy dissipation capacity, thinner devices are prone to buckling and to fracture under repeated, largeamplitude cycling. A thickness of $3 \mathrm{~mm}$ (i.e. thickness to breadth ratio of 0.03 ) is recommended as offering the best combination of dissipative capacity and robustness.

6. A $3 \mathrm{~mm}$ device dissipated approximately $1.3 \mathrm{~kJ}$ of energy when the frame in which it was fitted underwent a single displacement cycle of amplitude $30 \mathrm{~mm}$.

\section{REFERENCES}

[1] AS 4100 - 1990. Steel structures. Australian Standards Association, Homebush NSW, Australia.

[2] Blackeborough, A., Williams, M.S., Darby, A.P. and Williams, D.M., "The development of real-time substructure testing”, Philosophical Transactions of the Royal Society of London, Series A, 2001, 359(1786), 1869-92.

[3] OneSteel, Structural steel products tables, 2003. www.onesteel.com

[4] Zieman, R.D. and McGuire, W., “Mastan 2 Version 1.0”, Wiley, New York, 2000. 


\title{
SEISMIC PERFORMANCE OF CYLINDRICAL LATTICED-INTERSECTED-THREE-DIMENSIONAL- BEAM-SYSTEM RETICULATED MEGA-STRUCTURE WITH DOUBLE-LAYERS GRID SUB-STRUCTURES
}

\author{
Yongjun $\mathrm{He}^{1, *}$, Xuhong Zhou ${ }^{2}$, Shilin Dong ${ }^{3}$ and $\mathrm{Jia}^{1} \mathrm{i}^{1}$ \\ ${ }^{1}$ College of Civil Engineering of Hunan University, Changsha 410082, China; \\ *(Corresponding author: Email: hyj0087@163.com) \\ ${ }^{2}$ Chang'an University, Xi'an 710064, China; \\ ${ }^{3}$ Zhejiang University, Hangzhou 310027, China
}

\begin{abstract}
This paper is focused on the research of seismic response of cylindrical latticed-intersectedthree-dimensional-beam-system (LITDBS) reticulated mega-structure with double-layers plane-plate grid sub-structures using response spectrum technique. The distribution law of dynamic internal forces of members in this new structure is researched firstly. Reasonable number of vibration modes recommended for use is discussed. Seismic behaviors of the structure under different directional seismic loads are analyzed; therefore the reasonable required components of seismic loads for seismic design are obtained. A series of geometrical parameters analysis are carried out at last. All the works will provide guides in theory for the use of this structure.
\end{abstract}

Keywords: latticed-intersected-three-dimension-beam-system (LITDBS), mega-structure, plane-plate grid sub-structure, seismic response, vibration mode-decomposition-response-spectra method, parameters analysis

\section{INTRODUCTION}

Cylindrical latticed-intersected-three-dimensional-beam-system (LITDBS) reticulated megastructure with double-layers plane-plate grid sub-structures is an important style of reticulated mega-structure [1-3], which is a new structure meeting the need of super span for space structure. As showed in Figure 1, the whole structure is made up of two levels structures: the first level is the big grid structure called main structure which is made up of the arched 3d latticed beams (x-direction) and the longitudinal $3 \mathrm{~d}$ latticed beams (y-direction); the second level is the sub-structures which are double-layers plane-plate grids installed in big grids of the main structure generally. The main structure bears all of the loads and transfers them to the supporting structure. One sub-structure only bears the loads within the corresponding big grid and then transfers them to the main structure. Therefore a new structure of big grids filled with small grids is formed (for legible, many sub-structures are not showed in figure). The structure has been completely researched on its constitution, form parameters, supporting style, static property and stability in reference [2], it is fond that the main structure can be decided by six parameters as following: span of the main structure; rise; height of latticed 3d beam; number of big girds in the direction of arch; number of big girds in longitudinal direction; the number

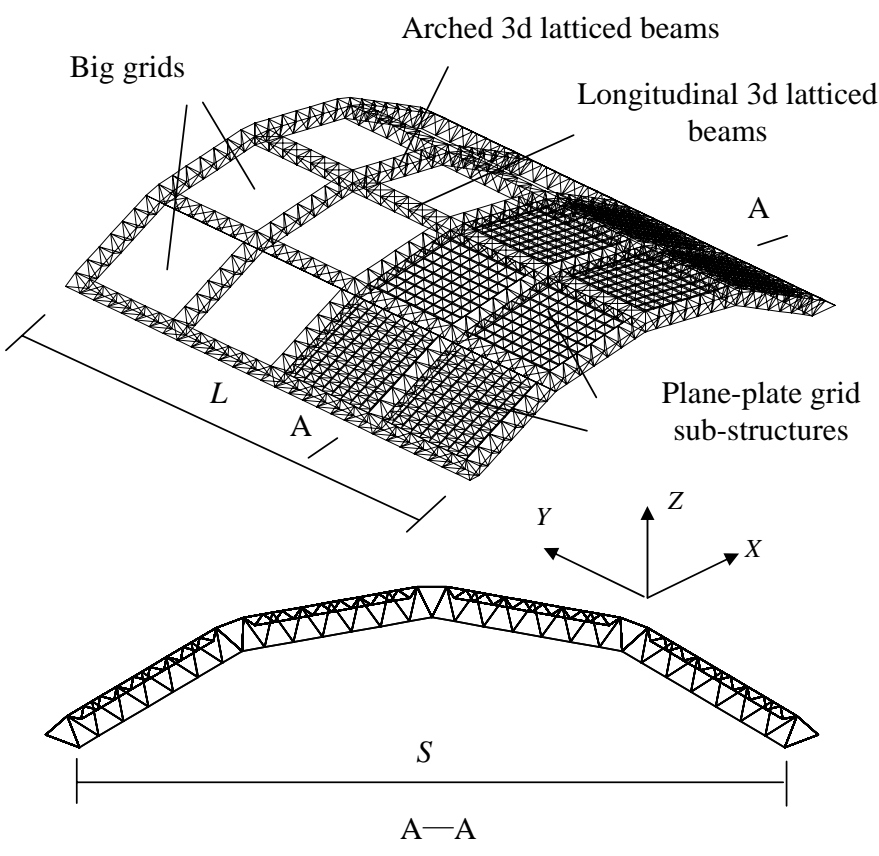

Figure 1. Cylindrical LITDBS reticulated mega-structure with double layer plane-plate grid substructures 
of mall grids in a latticed 3d beam segment within a big gird, and a program to form this structure automatically was developed based on these six parameters, but the seismic response property is not known. This paper is focused on the research of elastic seismic response property of cylindrical LITDBS reticulated mega-structure with double-layers plane-plate grid sub-structures.

Time history analysis is a direct dynamic analysis method, which can reflect the whole process state of the structure under keen earthquakes exactly and roundly. But the calculating course is excessive and complex. The response spectrum method is mostly used at present. Though the time history analysis exists in design codes in some countries, mainly it is a supplement for response spectrum method. So the response spectrum method is used in this paper and corresponding programs are worked out based on subspace iterative method for character of eigen-vibration and response spectrum method for seismic internal forces [4].

The distribution law of dynamic internal forces of members in this new structure is researched firstly; the reasonable combination of vibration modes and reasonable required components of seismic loads for seismic design are discussed; a series of geometrical parameters analysis are carried out at last. All the works will provide guides in theory for the use of this structure.

\section{ANALYSIS OF THE BASIC SEISMIC PROPERTY OF THE STRUCTURE}

\subsection{Basic seismic property of the main structure}

Assuming that the span of the main structure is $100 \mathrm{~m}$, ratio of height of arch to span is $1 / 5$, numbers of big grids is $5 \times 5$, the height of $3 \mathrm{~d}$ latticed beams is $3.5 \mathrm{~m}$, the number of grids in each $3 d$ latticed beam segment is 6 , the section of members in main structure is $\Phi 180 \times 10$, the thickness of the plane-plate grid sub-structure is $1.2 \mathrm{~m}$ and the section of members in it is $\Phi 76 \times 4$. The sub-structures are braced on main structure and the main structure is bound along the two longitudinal sides. The value of the vertical area load upon upper surface of the whole structure is 1 $\mathrm{kN} / \mathrm{m}^{2}$. The seismic response properties are calculated using vibration mode-decompositionresponse-spectra method; the loads are translated to the equivalent of point loads on nodes. The basic dynamic parameters are as follows: the seismic

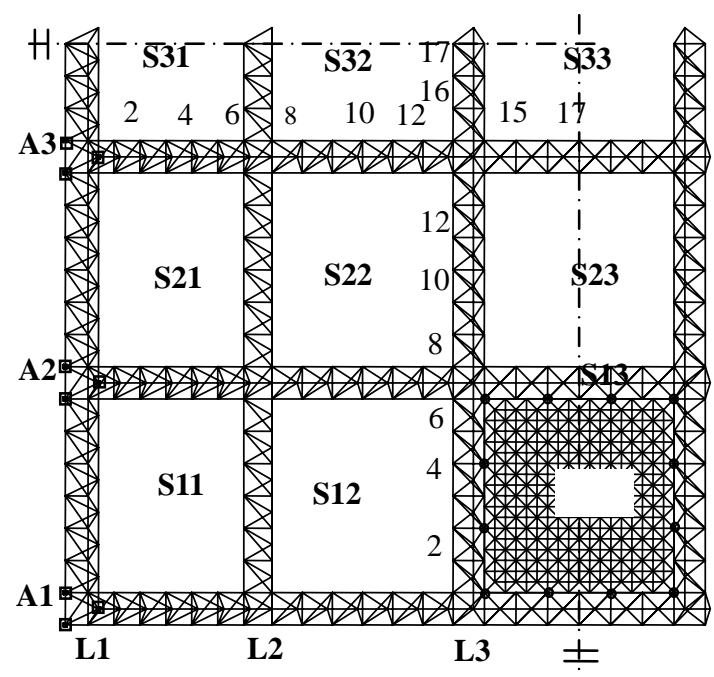

Figure 2. The schematic plan of the structure with codes of some sub-structures and members fortification intensity is 8 degree; near earthquake, class II site, which are referred to national criterion of China [5]. As many steel structural systems, 0.02 is adopted as the damping ratio of this structure. The three-dimensional earthquake action is considered.

The dynamic internal forces of corresponding members in the same position of parallel arched 3d latticed beams are listed in Tables 1 and 2 on both conditions of the main structure bearing the loads by itself and corporately with sub-structures. The codes " $n 1$ " and " $n 2$ " in tables represent positions of members in arches and codes of arched 3d latticed beams respectively (please see Figure 2); “UM”, “ LM", "UBM”, “UCM” and "WM” represent upper chord members, lower 
chord members, upper diagonal bracing members, upper crossbar members and web members in arched 3d latticed beams respectively. Contrasting Tables 1 and 2 we can see that the dynamic internal forces in members of arched 3d latticed beams especially in upper chord members and upper crossbar members at bottom and center are big relatively on condition of the main structure bearing the loads by itself. Mainly because the longitudinal stiffness is smaller than that in other directions on condition of the main structure bearing the loads by itself, the first vibration mode represents longitudinal vibration mostly [6]. And because the upper chord members are restricted with two parallel sustainers, dynamic internal forces in upper chord members at bottom and center of the arch especially near the sustainers are big remarkably when the structure vibrate in longitudinal direction. But the peak value of dynamic internal forces in lower chord members near the sustainers is not obvious because the single sustainer of lower chord member restrict longitudinal vibration little. On condition of the main structure bearing load corporately with sub-structures the dynamic internal forces of upper chord members and upper crossbar members at bottom and center decline evidently, but the dynamic internal forces of lower chord members at top of the arched 3d latticed beams increase evidently. The dynamic internal forces in upper and lower chord members of arched 3d latticed beams become homogeneous for the participation of sub-structures in bearing load.

Table 1. Comparison of dynamic internal forces in corresponding members of arched 3d latticed beams in different positions $(\mathrm{kN})$ (Main structure bearing load corporately with sub-structures)

\begin{tabular}{|c|c|c|c|c|c|c|}
\hline$n 1$ & $n 2$ & UM & LM & UBM & UCM & WM \\
\hline \multirow{3}{*}{$\begin{array}{c}1 \\
\text { (Bottom) }\end{array}$} & A1 & $23.2(0.065)$ & $43.3(0.065)$ & $27.5(1.517)$ & $19.4(1.764)$ & $9.3(0.141)$ \\
\cline { 2 - 7 } & A2 & $43.8(0.094)$ & $54.7(0.054)$ & $30.2(0.460)$ & $21.3(0.441)$ & $17.9(0.146)$ \\
\cline { 2 - 7 } & A3 & $49.9(0.103)$ & $70.2(0.068)$ & $31.1(0.390)$ & $22.0(0.377)$ & $21.9(0.186)$ \\
\hline \multirow{4}{*}{$\begin{array}{c}9 \\
\text { (Center) }\end{array}$} & A1 & $15.0(0.038)$ & $35.8(0.114)$ & $9.7(0.172)$ & $6.7(0.181)$ & $8.5(0.087)$ \\
\cline { 2 - 7 } & A2 & $29.7(0.052)$ & $48.0(0.118)$ & $18.2(0.409)$ & $14.3(0.081)$ & $11.6(0.079)$ \\
\cline { 2 - 7 } & A3 & $38.2(0.068)$ & $59.0(0.139)$ & $18.3(0.362)$ & $16.2(0.085)$ & $14.6(0.092)$ \\
\hline \multirow{3}{*}{$\begin{array}{c}17 \\
\text { (Top) }\end{array}$} & A1 & $20.1(0.047)$ & $35.0(3.035)$ & $2.3(0.049)$ & $1.6(0.044)$ & $4.0(0.092)$ \\
\cline { 2 - 7 } & A2 & $31.8(0.052)$ & $43.4(0.685)$ & $3.3(0.057)$ & $2.3(0.054)$ & $5.1(0.081)$ \\
\cline { 2 - 7 } & A3 & $41.5(0.067)$ & $58.6(1.783)$ & $4.0(0.067)$ & $3.0(0.067)$ & $6.0(0.095)$ \\
\hline
\end{tabular}

* Data in brackets represent ratio of dynamic to static internal members

Table 2. Comparison of dynamic internal forces in corresponding members of arched 3d latticed beams in different positions $(\mathrm{kN})$

(Main structure bearing load by itself)

\begin{tabular}{|c|c|c|c|c|c|c|}
\hline $\mathrm{n} 1$ & $\mathrm{n} 2$ & $\mathrm{UM}$ & $\mathrm{LM}$ & $\mathrm{UBM}$ & UCM & WM \\
\hline \multirow{3}{*}{$\begin{array}{c}1 \\
\text { (Bottom) }\end{array}$} & $\mathrm{A} 1$ & $121.3(0.379)$ & $24.3(0.035)$ & $39.5(1.503)$ & $27.9(1.368)$ & $10.9(0.206)$ \\
\cline { 2 - 7 } & $\mathrm{A} 2$ & $131.7(0.246)$ & $54.9(0.048)$ & $46.5(0.678)$ & $32.9(0.653)$ & $16.3(0.356)$ \\
\cline { 2 - 7 } & $\mathrm{A} 3$ & $138.8(0.248)$ & $76.4(0.065)$ & $47.1(0.655)$ & $33.3(0.632)$ & $21.0(0.641)$ \\
\hline \multirow{3}{*}{\begin{tabular}{c} 
Center $)$ \\
\cline { 2 - 7 }
\end{tabular}} & $\mathrm{A} 1$ & $29.1(0.074)$ & $29.7(0.084)$ & $29.6(1.077)$ & $20.3(0.510)$ & $6.9(0.097)$ \\
\cline { 2 - 7 } & $\mathrm{A} 2$ & $43.7(0.068)$ & $50.6(0.089)$ & $39.2(0.525)$ & $27.0(0.369)$ & $9.8(0.136)$ \\
\hline \multirow{2}{*}{$\begin{array}{c}17 \\
\text { (Top) }\end{array}$} & $\mathrm{A} 1$ & $52.2(0.080)$ & $69.7(0.116)$ & $37.8(0.471)$ & $26.2(0.339)$ & $12.2(0.169)$ \\
\cline { 2 - 7 } & $\mathrm{A} 2$ & $56.7(0.072)$ & $38.4(0.185)$ & $4.3(0.049)$ & $3.2(0.049)$ & $5.5(0.071)$ \\
\cline { 2 - 7 } & $\mathrm{A} 3$ & $67.5(0.082)$ & $54.3(0.280)$ & $5.7(0.061)$ & $4.2(0.062)$ & $7.3(0.092)$ \\
\hline
\end{tabular}

* Data in brackets represent ratio of dynamic to static internal members

We can see from the tables that the dynamic internal forces of the same kind of members in corresponding positions of arched 3d latticed beams increase gradually with the change of arches' locations from the end (A1) to the center (A3) of the whole structure, and the distribution laws of the dynamic internal forces of members in every parallel arches are the same, so this segment lays emphasis on the research of the central arched 3d latticed beam (A3). The distribution laws of the dynamic internal forces of members in every parallel longitudinal $3 \mathrm{~d}$ latticed beam are also analogous; so it is reasonable to lay emphasis on the research of the central longitudinal $3 \mathrm{~d}$ latticed beam (L2). 
To analyze in detail, the dynamic internal forces of members in A3 and L2 are listed in Table 3 and Table 4 respectively. The code " $D F_{\mathrm{m}}$ " and " $\xi$ " in tables represent the dynamic internal forces and ratios of dynamic to static internal force in members; " $n$ " represents the positions of members in the 3d latticed beams; "UM”, “ LM”, "UBM”, "UCM” and "WM” represent upper chord members, lower chord members, upper diagonal bracing members, upper crossbar members and web members in 3d latticed beam respectively.

Table 3. Distribution of dynamic internal forces and ratios of dynamic to static internal force in members of central arched 3d latticed beam

(Main structure bearing load corporately with sub-structures)

\begin{tabular}{|c|c|c|c|c|c|c|c|c|c|c|}
\hline \multirow{2}{*}{$n$} & \multicolumn{2}{|c|}{ UM } & \multicolumn{2}{|c|}{ LM } & \multicolumn{2}{c|}{ UBM } & \multicolumn{2}{c|}{ UCM } & \multicolumn{2}{|c|}{ WM } \\
\cline { 2 - 11 } & $\begin{array}{c}D F_{\mathrm{m}} \\
(\mathrm{kN})\end{array}$ & $\xi$ & $\begin{array}{c}D F_{\mathrm{m}} \\
(\mathrm{kN})\end{array}$ & $\xi$ & $\begin{array}{c}D F_{\mathrm{m}} \\
(\mathrm{kN})\end{array}$ & $\xi$ & $\begin{array}{c}D F_{\mathrm{m}} \\
(\mathrm{kN})\end{array}$ & $\xi$ & $\begin{array}{c}D F_{\mathrm{m}} \\
(\mathrm{kN})\end{array}$ & $\xi$ \\
\hline $0^{*}$ & 67.2 & 0.107 & 96.5 & 0.078 & 26.0 & 0.126 & 17.1 & 0.106 & 35.2 & 0.620 \\
\hline 1 & 49.9 & 0.103 & 70.2 & 0.068 & 31.1 & 0.390 & 22.0 & 0.377 & 21.9 & 0.186 \\
\hline 2 & 34.4 & 0.059 & 49.1 & 0.060 & 31.0 & 0.388 & 18.8 & 0.089 & 21.8 & 0.199 \\
\hline 3 & 30.3 & 0.060 & 45.9 & 0.058 & 21.0 & 0.413 & 14.7 & 0.389 & 18.9 & 0.525 \\
\hline 4 & 29.4 & 0.057 & 55.0 & 0.072 & 20.6 & 0.405 & 16.3 & 0.086 & 18.5 & 0.448 \\
\hline 5 & 30.3 & 0.058 & 72.2 & 0.080 & 22.1 & 0.501 & 15.4 & 0.466 & 16.1 & 0.237 \\
\hline 6 & 36.6 & 0.081 & 90.7 & 0.087 & 21.5 & 0.485 & 6.8 & 0.275 & 15.7 & 0.208 \\
\hline $7 *$ & 41.7 & 0.084 & 90.5 & 0.095 & 13.4 & 0.156 & 8.8 & 0.288 & 14.4 & 0.139 \\
\hline 8 & 40.4 & 0.081 & 74.1 & 0.109 & 19.2 & 0.380 & 13.3 & 0.351 & 14.6 & 0.092 \\
\hline 9 & 38.2 & 0.068 & 59.0 & 0.139 & 18.3 & 0.362 & 16.2 & 0.085 & 14.3 & 0.096 \\
\hline 10 & 33.8 & 0.063 & 46.2 & 0.138 & 14.3 & 0.282 & 9.8 & 0.257 & 12.1 & 1.704 \\
\hline 11 & 35.6 & 0.062 & 35.9 & 0.138 & 13.2 & 0.261 & 15.0 & 0.084 & 11.9 & 0.989 \\
\hline 12 & 35.7 & 0.059 & 34.6 & 0.100 & 14.3 & 0.266 & 9.7 & 0.242 & 12.9 & 0.899 \\
\hline 13 & 36.5 & 0.065 & 43.0 & 0.097 & 13.1 & 0.244 & 9.5 & 0.366 & 12.8 & 0.598 \\
\hline $14 *$ & 41.9 & 0.064 & 52.0 & 0.133 & 10.0 & 0.080 & 9.9 & 2.382 & 10.7 & 0.410 \\
\hline 15 & 37.6 & 0.066 & 53.9 & 0.258 & 5.9 & 0.097 & 3.9 & 0.087 & 10.1 & 0.106 \\
\hline 16 & 43.5 & 0.066 & 58.7 & 1.454 & 5.1 & 0.083 & 10.9 & 0.061 & 9.5 & 0.113 \\
\hline 17 & 41.5 & 0.067 & 58.6 & 1.783 & 4.0 & 0.067 & 3.0 & 0.067 & 6.0 & 0.095 \\
\hline
\end{tabular}

From Table 3 we can see that the upper and lower chord members of the arched $3 \mathrm{~d}$ latticed beam are the main bearing components under $3 d$ earthquake action. The biggest dynamic internal force exists in lower chord member at the bottom of the arch. The biggest dynamic internal force of upper chord member also exists at the bottom of the arch. In the 3d latticed beam segments at the bottom and center of the arch, the dynamic internal forces of the central members appear smallest locally. The dynamic internal forces of members in cross-area of the 3d latticed beams appear largest locally, and the gradient of dynamic internal forces is largest at the bottom of the arch and it is smallest at the top of the arch. Most ratios of dynamic to static internal force keep within 0.1. The dynamic internal forces of lower chord members are larger than that of upper chord members obviously, but the distribution law is the same as that in upper chord members. The ratios of dynamic to static internal forces of lower chord members in center and top of the arch are higher than that of upper chord members in the corresponding positions obviously, and the difference becomes larger and larger when the position becomes closer and closer to the top of the arch. Since static internal forces of lower chord members of the arch change from big to small evidently with the positions change from bottom to top [2], but the dynamic internal forces change little, so the ratios of dynamic to static internal forces changes remarkably. The ratios of dynamic to static internal forces of lower chord members in top of the arch reach to 1.78, which proves that the static internal forces are small but dynamic internal forces are large relatively; we must pay attention to their section design. The internal forces of upper diagonal bracing members are not large but the ratios of dynamic to static internal forces are large relatively, which proves that the upper diagonal bracing members play an important role in bearing dynamic loads. The dynamic internal forces of upper crossbar members are small and the distribution law is not clear, but the static internal forces of a few members are very small which induces their ratios of dynamic to static internal forces are large comparatively. 
The dynamic internal forces and ratios of dynamic to static internal forces in members of longitudinal 3d latticed beam (L2) are listed in Table 4, comparing Table 4 with Table 3 we can see that the seismic internal forces in members of longitudinal 3d latticed beams are less than that of arched 3d latticed beams. The largest dynamic internal forces of longitudinal 3d latticed beams exists almost in upper diagonal bracing members except in cross-area which proves that upper diagonal bracing members play an important role in bearing earthquake load. The largest dynamic internal force of longitudinal 3d latticed beams exists in upper crossbar members in cross-area, because these members are just the upper chord members of the arched $3 \mathrm{~d}$ latticed beams in this area. The dynamic internal forces of upper chord members of longitudinal 3d latticed beam

Table 4. Distribution of dynamic internal forces and ratios of dynamic to static internal force in members of central longitudinal 3d latticed beam (Main structure bearing load corporately with sub-structures)

\begin{tabular}{|c|c|c|c|c|c|c|c|c|c|c|}
\hline \multirow{2}{*}{$n$} & \multicolumn{2}{|c|}{ UM } & \multicolumn{2}{|c|}{ LM } & \multicolumn{2}{c|}{ UBM } & \multicolumn{2}{c|}{ UCM } & \multicolumn{2}{|c|}{ WM } \\
\cline { 2 - 12 } & $\begin{array}{c}D F_{\mathrm{m}} \\
(\mathrm{kN})\end{array}$ & $\xi$ & $\begin{array}{c}D F_{\mathrm{m}} \\
(\mathrm{kN})\end{array}$ & $\xi$ & $\begin{array}{c}D F_{\mathrm{m}} \\
(\mathrm{kN})\end{array}$ & $\xi$ & $\begin{array}{c}D F_{\mathrm{m}} \\
(\mathrm{kN})\end{array}$ & $\xi$ & $\begin{array}{c}D F_{\mathrm{m}} \\
(\mathrm{kN})\end{array}$ & $\xi$ \\
\hline $0^{*}$ & 7.9 & 2.238 & 2.7 & 0.046 & 12.0 & 0.680 & 23.7 & 0.059 & 8.1 & 0.191 \\
\hline 1 & 17.3 & 0.239 & 6.04 & 0.051 & 19.4 & 4.249 & 13.7 & 1.866 & 6.7 & 0.447 \\
\hline 2 & 6.4 & 0.067 & 10.1 & 0.061 & 19.4 & 1.874 & 14.1 & 0.216 & 6.5 & 0.289 \\
\hline 3 & 12.4 & 0.128 & 10.0 & 0.067 & 16.4 & 0.914 & 11.6 & 0.690 & 6.3 & 0.253 \\
\hline 4 & 9.06 & 0.106 & 9.5 & 0.079 & 16.4 & 0.691 & 12.7 & 0.177 & 6.3 & 0.499 \\
\hline 5 & 8.9 & 0.119 & 5.8 & 0.168 & 18.7 & 0.338 & 13.2 & 0.306 & 7.0 & 0.147 \\
\hline 6 & 12.5 & 0.619 & 6.9 & 0.107 & 18.7 & 0.306 & 29.1 & 0.059 & 7.2 & 0.126 \\
\hline $7 *$ & 6.3 & 1.069 & 7.4 & 0.087 & 11.2 & 0.127 & 35.1 & 0.068 & 12.1 & 0.262 \\
\hline 8 & 16.2 & 0.415 & 3.2 & 0.178 & 20.7 & 3.550 & 14.6 & 1.774 & 8.5 & 0.594 \\
\hline 9 & 8.8 & 0.131 & 8.4 & 0.234 & 20.7 & 1.781 & 13.0 & 0.132 & 8.2 & 2.043 \\
\hline 10 & 12.5 & 0.228 & 8.4 & 0.234 & 17.0 & 1.476 & 12.0 & 0.980 & 7.0 & 0.460 \\
\hline 11 & 11.5 & 0.213 & 7.6 & 0.331 & 17.0 & 0.982 & 12.7 & 0.149 & 7.0 & 1.085 \\
\hline 12 & 9.1 & 0.228 & 2.5 & 0.057 & 20.2 & 0.407 & 14.3 & 0.365 & 8.0 & 0.204 \\
\hline 13 & 14.7 & 0.851 & 9.8 & 0.080 & 20.2 & 0.365 & 39.6 & 0.080 & 8.7 & 0.180 \\
\hline $14 *$ & 7.8 & 0.282 & 10.8 & 0.083 & 13.4 & 0.156 & 43.8 & 0.087 & 14.4 & 2.490 \\
\hline 15 & 15.9 & 0.707 & 6.3 & 0.115 & 20.6 & 3.49 & 14.6 & 3.844 & 9.4 & 0.361 \\
\hline 16 & 10.5 & 0.204 & 11.9 & 1.394 & 20.6 & 3.880 & 13.2 & 0.133 & 8.0 & 0.531 \\
\hline 17 & 13.8 & 0.305 & 12.4 & 0.818 & 17.1 & 2.456 & 12.1 & 1.340 & 7.0 & 0.523 \\
\hline
\end{tabular}

fluctuate but have no regularity and appear smallest locally in cross-area. The ratios of dynamic to static internal force are large comparatively though the dynamic internal forces are small and the largest ratio can reach above 2 . The dynamic internal forces of lower chord members are less than that of upper chord members in the same position; and appear local maximum in the center of every longitudinal 3d latticed beam. The ratios of dynamic to static internal forces are small except few members in the middle of the longitudinal 3d latticed beam. The upper diagonal bracing members are the main bearing components of longitudinal 3d latticed beams under the earthquake action, in which dynamic internal forces in the middle of cross-area are small but appear local maximum in the position near to cross-area. The ratios of dynamic to static internal forces are large, most of which are above 1.0, some one reach to 4.0. The dynamic internal forces of the upper crossbar members are large comparatively and fluctuate along the axial direction of the longitudinal 3d latticed beam, appearing wave crest in the cross-area with the arched 3d latticed beams and appearing wave trough in the middle of every $3 d$ latticed beam segment. The ratios of dynamic to static internal forces of upper crossbar members are high comparatively but not uniform. The dynamic internal forces in web members are small comparatively and all keep within $10 \mathrm{kN}$ except members in the cross-area. The ratios of dynamic to static internal force are still high comparatively. In a word, compared with the arched 3d latticed beam, the dynamic internal forces in longitudinal 3d latticed beams are all small comparatively but the ratios of dynamic to static internal forces are high comparatively for their static internal forces are very small. So we must pay attention to the dynamic checking calculation of these members after design according to static loads. 
Comparing Table 3 and Table 4 we can see that as the main bearing components the ratios of dynamic to static internal forces in upper and lower chord members of arched 3d latticed beams are almost kept within 0.1 which proves that the seismic property of this structure are good. Though the ratios of dynamic to static internal force in some upper diagonal brace members, upper cross-bar members, web members of arched 3d latticed beams and some members of longitudinal 3d latticed beams are high, their dynamic and static internal forces are all very small, which make it possible to design these members according to constructional demands.

\subsection{Distribution law of dynamic internal forces in sub-structures}

As sub-structures of the reticulated mega structure, the plane-plate girds have two functions: one is to bear the loads within their corresponding big grids, The other is to brace the main structure and bear the loads cooperatively with main structure. The calculation results show that the distribution laws of dynamic internal forces of different sub-structures at the same height are very alike and the numerical values are close to each other, but that of different sub-structures at different heights from bottom to top of the whole structure are unlike. So in this segment the different sub-structures at different heights from bottom to top such as S31, S32, and S33 (please see Figure 2) are researched. The upper chord members of sub-structures in arch direction are combined as folded linear arches by the upper crossbar members of longitudinal 3d latticed beams. Results of static analysis show that these parallel folded linear arches are the main bearing components of sub-structures while cooperating with main structure and their internal forces are greatly larger than other members of sub-structures. But the distribution laws of dynamic internal forces are different from that of static internal forces. The web members especially at bottom and center of sub-structures also become the main bearing components under the earthquake action. Dynamic internal forces of web members are larger than upper and lower chord members in central and bottom of sub-structures. The dynamic internal forces of web members become small gradually from low to upside in a sub-structure. The dynamic internal forces of web members in the corresponding position of different sub-structures become small gradually as the sub-structure's positions change from low to upside, At the top of the whole structure, the dynamic internal forces become very small and the chord members become the main bearing components. The ratios of dynamic to static internal force in members of sub-structures especially at bottom and center of the whole structure are large comparatively and many reach above 1.0, some one to 10 . Concrete numerical values are not listed here.

\section{ANALYSIS OF SEISMIC BEHAVIORS OF THE STRUCTURE UNDER DIFFERENT DIRECTIONAL EARTHQUAKE ACTION}

The seismic response behaviors of different structures under different directional earthquake waves are different. So the directions of earthquake wave that should be considered for designing different structure are different either. As to the cylindrical LITDBS reticulated mega-structure braced with plane-plate grids sub-structures, for the difference in stiffness, geometrical character between the main structure and sub-structures must cause the different sensitivities of the whole structure to different directional earthquake waves. This segment analyzes the distribution law of dynamic internal forces of the structure under different directional earthquake waves and determines the directions of earthquake waves that should be laid emphasis on accordingly.

Take the structure that geometrical parameters, restrictions, loads and the sections of components are the same as the structure showed in segment 1 to analyze. Different combinations of three 
directional earthquake waves such as horizontal transverse (X), longitudinal (Y) and vertical $(\mathrm{Z})$ are considered, and the results are listed in Tables 5, 6, and 7. In tables the codes " $D F_{\mathrm{m}}$ " and " $D F_{\mathrm{s}}$ " represent the dynamic internal forces of members in main structure and sub-structures respectively. Taking the dynamic internal forces under three-dimensional earthquake waves as the accurate value, the percentages of different values of dynamic internal forces under one-dimensional or two-dimensional earthquake waves to the accurate value represent the error. The values of error reflect the degree of approximation of substituting one-dimensional or two-dimensional result for the accurate value.

Table 5. Comparison of dynamic internal forces in main structure under earthquake action with different components

(Main structure bearing load corporately with sub-structures)

\begin{tabular}{|c|c|c|c|c|c|c|c|}
\hline \multirow{3}{*}{$\begin{array}{l}\text { Earth- } \\
\text { quake } \\
\text { wave }\end{array}$} & \multirow{3}{*}{$\begin{array}{c}\text { Compared } \\
\text { target }\end{array}$} & \multicolumn{6}{|c|}{ Positions of members } \\
\hline & & \multicolumn{2}{|c|}{4} & \multicolumn{2}{|c|}{10} & \multicolumn{2}{|c|}{16} \\
\hline & & $\mathrm{UM}^{*}$ & $\mathrm{LM}^{*}$ & UM & LM & UM & $\mathrm{LM}$ \\
\hline $3 \mathrm{~d}$ & $D F_{\mathrm{m}}(\mathrm{kN})$ & 29.36 & 54.95 & 33.77 & 46.22 & 43.54 & 58.68 \\
\hline \multirow{2}{*}{$X-1 d$} & $D F m(\mathrm{kN})$ & 6.18 & 14.65 & 8.76 & 34.70 & 2.41 & 6.84 \\
\hline & Error & $78.9 \%$ & $73.5 \%$ & $74.1 \%$ & $24.9 \%$ & $94.5 \%$ & $88.3 \%$ \\
\hline \multirow{2}{*}{ Y-1d } & $D F_{\mathrm{m}}(\mathrm{kN})$ & 10.16 & 1.59 & 2.74 & 1.51 & 6.86 & 1.14 \\
\hline & Error & $65.4 \%$ & $97.1 \%$ & $91.9 \%$ & $96.7 \%$ & $84.2 \%$ & $98.1 \%$ \\
\hline \multirow{2}{*}{ Z-1d } & $D F_{\mathrm{m}}(\mathrm{kN})$ & 26.63 & 52.93 & 32.42 & 30.50 & 42.91 & 58.27 \\
\hline & Error & $9.3 \%$ & $3.7 \%$ & $3.4 \%$ & $34.0 \%$ & $1.5 \%$ & $0.7 \%$ \\
\hline \multirow{2}{*}{$X Z-2 d$} & $D F_{\mathrm{m}}(\mathrm{kN})$ & 27.41 & 54.92 & 33.58 & 46.20 & 42.99 & 58.66 \\
\hline & Error & $6.6 \%$ & $0.05 \%$ & $0.6 \%$ & $0.04 \%$ & $1.3 \%$ & $0.03 \%$ \\
\hline \multirow{2}{*}{ YZ-2d } & $D F_{\mathrm{m}}(\mathrm{kN})$ & 28.63 & 52.96 & 32.61 & 30.54 & 43.47 & 58.28 \\
\hline & Error & $2.5 \%$ & $3.6 \%$ & $3.4 \%$ & $33.9 \%$ & $0.2 \%$ & $0.7 \%$ \\
\hline \multirow{2}{*}{ XY-2d } & $D F_{\mathrm{m}}(\mathrm{kN})$ & 12.30 & 14.74 & 9.42 & 34.73 & 7.35 & 6.93 \\
\hline & Error & $58.1 \%$ & $73.2 \%$ & $72.1 \%$ & $24.9 \%$ & $83.1 \%$ & $88.2 \%$ \\
\hline
\end{tabular}

*UM and LM represent upper and lower chord members respectively

From the results of Table 5 we can see that, on condition of the main structure bearing the load corporately with sub-structures, compared with the three-dimensional results, the $\mathrm{X}$-one-dimensional or Y-one-dimensional results are all very small and most of the error percentages are above $70 \%$. But under vertical earthquakes most of Z-one-dimensional results are close to the accurate values; the error percentages are within $10 \%$. Only the percentages of lower chord members at the half-height position of the arch reach to 34\%. Comparing the dynamic internal forces under one-dimensional earthquake wave of $\mathrm{X}, \mathrm{Y}$ and $\mathrm{Z}$ direction we can see that the response of the main structure to vertical earthquake wave exceeds greatly that to horizontal earthquake wave, so vertical component of the earthquake should be considered, but it is not enough for the largest error percentages of lower chord members at the half-height position of the arch reach to $34 \%$. When we consider YZ-two-dimensional earthquake wave, the largest error percentages reach to 33.9\%, which cannot meet the needs. But when we consider XZ-two-dimensional earthquake wave, most of the result error percentages keep within 1\% except that the largest error percentages of few upper chord members at the bottom of the arch reach to $6.6 \%$, which can meet the needs.

The results of sub-structures on condition of the main structure bearing the load corporately with sub-structures are listed in Table 6, from which we can see that the dynamic internal forces of members in different positions are irregular under different directional one-dimensional earthquake waves. Most of error percentages of X-one-dimensional results reach to $90 \%$. While only considering Y-directional one-dimensional earthquake wave, the error percentages of web members in central or lower position of sub-structures are $0 \%$, which proves that the dynamic internal forces of web members in central or lower position of sub-structures are caused by the longitudinal one-dimensional earthquake action, but the error percentages of upper and lower chord members can reach to $90 \%$. While only considering vertical one-dimensional earthquake wave, the error 
percentages of upper and lower chord members in central or lower position of sub-structures decline greatly and keep within $10 \%$, but the error percentages of web members reach to $95 \%$. So it is not enough only to consider one-dimensional earthquake action. If considering XZ-two-dimensional earthquake action, the error percentages of chord members decline greatly and keep within $0.5 \%$, but the error percentages of web members in central or lower position of sub-structures are still 90\%. While considering XY-two-dimensional earthquake action, result error percentages of many chord members reach to $90 \%$, which cannot meet the needs obviously. While considering YZ-two-dimensional earthquake action the largest error percentages of chord members in central or lower position of sub-structures reach to $12.1 \%$, but that of other members are small comparatively. We can see that the dynamic internal forces of members at the top of sub-structures are determined by the vertical earthquake action, which is similar to the seismic response property of general plane-plate grids structure. The responses of sub-structures at different height under earthquake waves from different directions are different for their different slopes. So it is not enough to get the real response results of the whole structure by only considering one-dimensional or two-dimensional earthquake action, and it is necessary to consider three-dimensional earthquake action for safety. While considering XZ-two-dimensional earthquake action, the largest error percentage of members in main structure is $6.6 \%$ and many of the error percentages are very small, the error percentages of chord members in sub-structures are all kept within 1\%, but that of web members in sub-structures are very large. Generally, the dynamic and static internal forces of web members in sub-structures are all small comparatively, and their cross-sections are redundant though they are designed according to construction demands, so we can only lay emphasis on seismic design of members in main structure and chord members in sub-structures, and we can only consider the XZ-two-dimensional earthquake wave.

Table 6. Comparison of dynamic internal forces in sub-structures under earthquake action with different components

(Main structure bearing load corporately with sub-structures)

\begin{tabular}{|c|c|c|c|c|c|c|c|c|c|c|}
\hline \multirow{3}{*}{$\begin{array}{l}\text { Earth- } \\
\text { quake } \\
\text { wave }\end{array}$} & \multirow{3}{*}{$\begin{array}{c}\text { Compared } \\
\text { target }\end{array}$} & \multicolumn{9}{|c|}{ Codes of sub-structures } \\
\hline & & \multicolumn{3}{|c|}{ S31 (Bottom) } & \multicolumn{3}{|c|}{ S32 (Center) } & \multicolumn{3}{|c|}{ S33 (Top) } \\
\hline & & $\mathrm{UM}^{*}$ & WM & LM & UM* $^{*}$ & WM & LM & $\mathrm{UM}^{*}$ & WM & LM \\
\hline $3 \mathrm{~d}$ & $D F_{\mathrm{s}}(\mathrm{kN})$ & 3.98 & 10.88 & 4.63 & 6.52 & 7.31 & 6.20 & 7.85 & 0.17 & 6.01 \\
\hline \multirow{2}{*}{$X-1 d$} & $D F_{s}(\mathrm{kN})$ & 1.29 & 0.15 & 2.21 & 1.33 & 0.03 & 0.35 & 0.01 & 0.01 & 0.00 \\
\hline & Error & $67.6 \%$ & $98.6 \%$ & $47.9 \%$ & $79.6 \%$ & $99.6 \%$ & $94.4 \%$ & $99.9 \%$ & $94.1 \%$ & $100 \%$ \\
\hline \multirow{2}{*}{ Y-1d } & $D F_{s}(\mathrm{kN})$ & 0.24 & 10.88 & 0.17 & 0.15 & 7.31 & 0.13 & 0.06 & 0.04 & 0.01 \\
\hline & Error & $94.0 \%$ & $0.0 \%$ & $96.3 \%$ & $97.7 \%$ & $0.0 \%$ & $97.9 \%$ & $99.2 \%$ & $76.5 \%$ & $0.2 \%$ \\
\hline \multirow{2}{*}{ Z-1d } & $D F_{s}(\mathrm{kN})$ & 3.76 & 0.18 & 4.07 & 6.38 & 0.25 & 6.19 & 7.85 & 0.17 & 6.01 \\
\hline & Error & $5.5 \%$ & $98.3 \%$ & $12.1 \%$ & $2.1 \%$ & $96.6 \%$ & $0.2 \%$ & $0.0 \%$ & $0.0 \%$ & $0.0 \%$ \\
\hline \multirow{2}{*}{$X Z-2 d$} & $D F_{s}(\mathrm{kN})$ & 3.97 & 0.24 & 4.63 & 6.51 & 0.25 & 6.20 & 7.85 & 0.17 & 6.01 \\
\hline & Error & $0.3 \%$ & $97.8 \%$ & $0.0 \%$ & $0.2 \%$ & $96.6 \%$ & $0.0 \%$ & $0.0 \%$ & $0.0 \%$ & $0.0 \%$ \\
\hline \multirow{2}{*}{ YZ-2d } & $D F_{s}(\mathrm{kN})$ & 3.77 & 10.88 & 4.07 & 6.38 & 7.31 & 6.19 & 7.85 & 0.17 & 6.01 \\
\hline & Error & $5.3 \%$ & $0.0 \%$ & $12.1 \%$ & $2.1 \%$ & $0.0 \%$ & $0.2 \%$ & $0.0 \%$ & $0.0 \%$ & $0.0 \%$ \\
\hline \multirow{2}{*}{$\mathrm{XY}-2 \mathrm{~d}$} & $D F_{s}(\mathrm{kN})$ & 1.31 & 10.88 & 2.22 & 1.34 & 7.31 & 0.38 & 0.06 & 0.04 & 0.01 \\
\hline & Error & $67.1 \%$ & $0.0 \%$ & $52.1 \%$ & $79.4 \%$ & $0.0 \%$ & $93.9 \%$ & $99.2 \%$ & $76.4 \%$ & $0.2 \%$ \\
\hline
\end{tabular}

The results of main structure on condition of the main structure bearing the load by itself are listed in Table 7, from which we can see that the largest error percentage of dynamic internal forces of members under X-one-dimensional or Y-one-dimensional earthquake action all are above $90 \%$ and the vertical seismic internal forces are still the main component of response value. But the largest error percentage of vertical one-dimensional results reach to $35.5 \%$. If considering two-dimensional earthquake action, the largest error percentage of XZ-two-dimensional results reach to $22.4 \%$ and the largest error percentage of YZ-two-dimensional results reach to 35.3\%, which all cannot meet the needs. So it is necessary to consider three-dimensional earthquake action for seismic design on condition of the main structure bearing loads by itself. 
Table 7. Comparison of dynamic internal forces in main structure under earthquake action with different components

(Main structure bearing load by itself)

\begin{tabular}{|c|c|c|c|c|c|c|c|}
\hline \multirow{3}{*}{$\begin{array}{l}\text { Earth- } \\
\text { quake } \\
\text { wave }\end{array}$} & \multirow{3}{*}{$\begin{array}{c}\text { Compared } \\
\text { target }\end{array}$} & \multicolumn{6}{|c|}{ Positions of members } \\
\hline & & \multicolumn{2}{|c|}{4 (bottom) } & \multicolumn{2}{|c|}{10 (center) } & \multicolumn{2}{|c|}{ 16（top） } \\
\hline & & *UM & LM & UM & LM & UM & LM \\
\hline $3 d$ & $D F_{\mathrm{m}}(\mathrm{kN})$ & 43.50 & 64.15 & 46.81 & 56.28 & 64.16 & 54.48 \\
\hline \multirow{2}{*}{$X-1 d$} & $D F m(\mathrm{kN})$ & 14.35 & 19.11 & 13.16 & 42.90 & 4.92 & 8.03 \\
\hline & Error & $67.0 \%$ & $70.2 \%$ & $71.9 \%$ & $23.8 \%$ & $92.3 \%$ & $85.3 \%$ \\
\hline \multirow{2}{*}{ Y-1d } & $D F_{\mathrm{m}}(\mathrm{kN})$ & 21.91 & 2.83 & 21.10 & 3.00 & 40.37 & 0.50 \\
\hline & Error & $49.6 \%$ & $95.6 \%$ & $54.9 \%$ & $94.7 \%$ & $37.1 \%$ & $99.1 \%$ \\
\hline \multirow{2}{*}{ Z-1d } & $D F_{\mathrm{m}}(\mathrm{kN})$ & 30.31 & 61.17 & 39.56 & 36.31 & 49.47 & 53.89 \\
\hline & Error & $30.3 \%$ & $4.6 \%$ & $15.5 \%$ & $35.5 \%$ & $22.9 \%$ & $1.1 \%$ \\
\hline \multirow{2}{*}{$\mathrm{XZ}-2 \mathrm{~d}$} & $D F_{\mathrm{m}}(\mathrm{kN})$ & 37.23 & 64.09 & 41.70 & 56.20 & 49.77 & 54.48 \\
\hline & Error & $14.4 \%$ & $0.1 \%$ & $10.9 \%$ & $0.1 \%$ & $22.4 \%$ & $0.0 \%$ \\
\hline \multirow{2}{*}{ YZ-2d } & $D F_{\mathrm{m}}(\mathrm{kN})$ & 41.06 & 61.23 & 44.91 & 36.44 & 63.93 & 53.89 \\
\hline & Error & $5.6 \%$ & $4.6 \%$ & $4.1 \%$ & $35.3 \%$ & $0.4 \%$ & $1.1 \%$ \\
\hline \multirow{2}{*}{$\mathrm{XY}-2 \mathrm{~d}$} & $D F_{\mathrm{m}}(\mathrm{kN})$ & 26.26 & 19.32 & 24.97 & 43.00 & 40.76 & 8.04 \\
\hline & Error & $39.6 \%$ & $69.9 \%$ & $46.7 \%$ & $23.6 \%$ & $36.5 \%$ & $85.2 \%$ \\
\hline
\end{tabular}

*UM and LM represent upper and lower chord members respectively

\section{RESEARCH ON THE REASONABLE COMBINATION OF VIBRATION MODES}

Based on the theory of vibration mode-decomposition-response-spectra method, generally in civil engineering, we can only consider the combination of the first several modes for seismic checking calculation of the structure. But the necessary number of vibration modes is different for different structures. The cylindrical LITDBS reticulated mega-structure with plane-plate grids sub-structures is a new structure. The difference in stiffness between the main structure and sub-structures leads to its complex vibration modes. The reasonable number of vibration modes for seismic design is not known, so this problem is researched in this segment. Taking the structure in Figure 2 for example, calculate the first thirty order modes and taking the dynamic internal forces from the combination of the first thirty modes as the accurate value. Then take different numbers of vibration modes in turn to calculate the dynamic internal forces and compare the results with the accurate value, from which we can know how many vibration modes should be taken to calculate the dynamic internal forces. Here the combinations numbers of vibration modes are 3, 6, 9, 12, 15, 16, 18, 25, 30 in turn. The geometrical parameters, restrictions, loads and the sections of components of the structure are the same as that showed in segment 1 .

The calculating results of upper chord members, lower chord members, upper brace members in center of the arched 3d latticed beam (A3) with different combined numbers of vibration modes are listed in Tables 8, 9 and 10 (Please see Figure 2 for the members positions). The calculating results of upper chord members, web members in sub-structures are listed in Table 11. The code " $n$ " in tables represents the number of combined vibration modes; "a" represents the dynamic internal forces; "b" represents the error of the calculating results compared with the accurate value, its calculating method are showed as formula (1).

$$
b(i)=\frac{a(30)-a(i)}{a(30)} \times 100 \%
$$

where $i$ represents the number of combined vibration modes. 
Table 8. Comparison of calculating dynamic internal forces in upper chord members of arched 3d latticed beam with different combined vibration modes

(Main structure bearing load corporately with sub-structures)

\begin{tabular}{|c|c|c|c|c|c|c|c|c|c|c|c|c|}
\hline \multirow{3}{*}{$n$} & \multicolumn{10}{c|}{ Positions of members } \\
\cline { 2 - 15 } & \multicolumn{2}{|c|}{1} & \multicolumn{1}{|c|}{4} & \multicolumn{2}{|c|}{7} & \multicolumn{2}{|c|}{10} & \multicolumn{2}{|c|}{13} & \multicolumn{2}{|c|}{16} \\
\cline { 2 - 14 } & $\begin{array}{c}\mathrm{a} \\
\mathrm{kN})\end{array}$ & $\begin{array}{c}\mathrm{b} \\
(\%)\end{array}$ & $\begin{array}{c}\mathrm{a} \\
(\mathrm{kN})\end{array}$ & $\begin{array}{c}\mathrm{b} \\
(\%)\end{array}$ & $\begin{array}{c}\mathrm{a} \\
(\mathrm{kN})\end{array}$ & $\begin{array}{c}\mathrm{b} \\
(\%)\end{array}$ & $\begin{array}{c}\mathrm{a} \\
(\mathrm{kN})\end{array}$ & $\begin{array}{c}\mathrm{b} \\
(\%)\end{array}$ & $\begin{array}{c}\mathrm{a} \\
(\mathrm{kN})\end{array}$ & $\begin{array}{c}\mathrm{b} \\
(\%)\end{array}$ & $\begin{array}{c}\mathrm{a} \\
(\mathrm{kN})\end{array}$ & $\begin{array}{c}\mathrm{b} \\
(\%)\end{array}$ \\
\hline 3 & 36.66 & 27.2 & 12.66 & 56.9 & 6.76 & 83.8 & 17.14 & 49.4 & 30.93 & 15.4 & 41.78 & 4.28 \\
\hline 6 & 47.05 & 6.52 & 16.63 & 43.4 & 15.15 & 63.7 & 17.59 & 48.1 & 33.93 & 7.19 & 42.34 & 3.00 \\
\hline 9 & 47.45 & 5.7 & 29.07 & 1.02 & 40.49 & 3.04 & 33.07 & 2.39 & 36.34 & 0.60 & 43.45 & 0.46 \\
\hline 12 & 47.52 & 5.58 & 29.32 & 0.17 & 40.89 & 2.08 & 33.35 & 1.56 & 36.38 & 0.49 & 43.45 & 0.46 \\
\hline 15 & 47.54 & 5.54 & 29.32 & 0.17 & 40.89 & 2.08 & 33.36 & 1.53 & 36.40 & 0.44 & 43.53 & 0.27 \\
\hline 16 & 49.95 & 0.76 & 29.36 & 0.03 & 41.72 & 0.10 & 33.77 & 0.32 & 36.51 & 0.14 & 43.54 & 0.25 \\
\hline 18 & 49.95 & 0.76 & 29.37 & 0.0 & 41.73 & 0.07 & 33.77 & 0.32 & 36.51 & 0.14 & 43.54 & 0.25 \\
\hline 25 & 49.95 & 0.76 & 29.37 & 0.0 & 41.73 & 0.07 & 33.78 & 0.30 & 36.51 & 0.14 & 43.54 & 0.25 \\
\hline 30 & 50.33 & - & 29.37 & - & 41.76 & - & 33.88 & - & 36.56 & - & 43.65 & - \\
\hline
\end{tabular}

Table 9. Comparison of calculating dynamic internal forces in lower chord members of arched 3d latticed beam with different combined vibration modes

(Main structure bearing load corporately with sub-structures)

\begin{tabular}{|c|c|c|c|c|c|c|c|c|c|c|c|c|}
\hline \multirow{3}{*}{$n$} & \multicolumn{12}{|c|}{ Positions of members } \\
\hline & \multicolumn{2}{|c|}{1} & \multicolumn{2}{|c|}{4} & \multicolumn{2}{|c|}{7} & \multicolumn{2}{|c|}{10} & \multicolumn{2}{|c|}{13} & \multicolumn{2}{|c|}{16} \\
\hline & $\begin{array}{c}\mathrm{a} \\
(\mathrm{kN})\end{array}$ & \begin{tabular}{|c|}
$\mathrm{b}$ \\
$(\%)$
\end{tabular} & $\begin{array}{c}\mathrm{a} \\
(\mathrm{kN})\end{array}$ & $\begin{array}{l}\mathrm{b} \\
\text { (\%) }\end{array}$ & $\begin{array}{c}\mathrm{a} \\
(\mathrm{kN})\end{array}$ & $\begin{array}{c}\mathrm{b} \\
(\%)\end{array}$ & $\begin{array}{c}\mathrm{a} \\
(\mathrm{kN})\end{array}$ & $\begin{array}{l}\mathrm{b} \\
\text { (\%) }\end{array}$ & $\begin{array}{c}\mathrm{a} \\
(\mathrm{kN})\end{array}$ & $\begin{array}{l}\text { b } \\
(\%)\end{array}$ & $\begin{array}{c}\mathrm{a} \\
(\mathrm{kN})\end{array}$ & $\begin{array}{c}\mathrm{b} \\
(\%)\end{array}$ \\
\hline 3 & 31.55 & 55.4 & 52.61 & 4.62 & 86.11 & 5.44 & 42.45 & 8.61 & 26.62 & 39.1 & 33.99 & 42.5 \\
\hline 6 & 31.66 & 55.2 & 52.64 & \begin{tabular}{|l|l}
4.57 \\
\end{tabular} & 86.14 & 5.40 & 42.49 & 8.53 & 26.70 & 38.9 & 34.01 & 42.5 \\
\hline 9 & 67.35 & 4.79 & 53.82 & 2.43 & 88.24 & 3.10 & 44.22 & 4.8 & 42.03 & 3.81 & 58.14 & 1.72 \\
\hline 12 & 67.96 & 3.93 & 53.83 & 2.41 & 88.26 & 3.07 & 44.28 & 4.7 & 42.33 & 3.16 & 58.63 & 0.90 \\
\hline 15 & 67.97 & 3.92 & 53.85 & 2.37 & 88.32 & 3.01 & 44.31 & 4.6 & 42.35 & 3.11 & 58.65 & 0.86 \\
\hline 16 & 70.16 & 0.82 & 54.95 & \begin{tabular}{|l|l|}
0.38 \\
\end{tabular} & 90.53 & 0.58 & 46.22 & 0.50 & 42.96 & 1.72 & 58.68 & 0.81 \\
\hline 18 & 70.16 & 0.82 & 54.96 & 0.36 & 90.53 & 0.58 & 46.23 & 0.47 & 42.98 & 1.67 & 58.68 & 0.81 \\
\hline 25 & 70.16 & 0.82 & 54.96 & 0.36 & 90.53 & 0.58 & 46.23 & 0.47 & 42.98 & 1.67 & 58.68 & 0.81 \\
\hline 30 & 70.74 & - & 55.16 & - & 91.06 & - & 46.45 & - & 43.71 & - & 59.16 & \\
\hline
\end{tabular}

Table 10. Comparison of calculating dynamic internal forces in upper diagonal brace members of arched 3d latticed beam with different combined vibration modes

(Main structure bearing load corporately with sub-structures)

\begin{tabular}{|c|c|c|c|c|c|c|c|c|c|c|c|c|}
\hline \multirow{3}{*}{$n$} & \multicolumn{10}{|c|}{ Positions of members } \\
\cline { 2 - 15 } & \multicolumn{2}{|c|}{1} & \multicolumn{2}{|c|}{4} & \multicolumn{2}{|c|}{7} & \multicolumn{2}{|c|}{10} & \multicolumn{2}{|c|}{13} & \multicolumn{2}{c|}{16} \\
\cline { 2 - 14 } & $\begin{array}{c}\mathrm{a} \\
(\mathrm{kN})\end{array}$ & $\begin{array}{c}\mathrm{b} \\
(\%)\end{array}$ & $\begin{array}{c}\mathrm{a} \\
(\mathrm{kN})\end{array}$ & $\begin{array}{c}\mathrm{b} \\
(\%)\end{array}$ & $\begin{array}{c}\mathrm{a} \\
(\mathrm{kN})\end{array}$ & $\begin{array}{c}\mathrm{b} \\
(\%)\end{array}$ & $\begin{array}{c}\mathrm{a} \\
(\mathrm{kN})\end{array}$ & $\begin{array}{c}\mathrm{b} \\
(\%)\end{array}$ & $\begin{array}{c}\mathrm{a} \\
(\mathrm{kN})\end{array}$ & $\begin{array}{c}\mathrm{b} \\
(\%)\end{array}$ & $\begin{array}{c}\mathrm{a} \\
(\mathrm{kN})\end{array}$ & $\begin{array}{c}\mathrm{b} \\
(\%)\end{array}$ \\
\hline 3 & 5.32 & 82.9 & 2.47 & 88.0 & 1.66 & 87.6 & 1.53 & 89.3 & 2.33 & 82.3 & 3.23 & 37.4 \\
\hline 6 & 30.86 & 0.93 & 20.45 & 0.82 & 11.25 & 16.2 & 13.95 & 2.4 & 12.51 & 4.79 & 4.36 & 15.5 \\
\hline 9 & 30.98 & 0.55 & 20.52 & 0.48 & 13.13 & 2.23 & 14.20 & 0.63 & 12.87 & 2.05 & 4.45 & 13.8 \\
\hline 12 & 31.03 & 0.39 & 20.60 & 0.10 & 13.23 & 1.49 & 14.27 & 0.14 & 13.05 & 0.68 & 4.46 & 13.6 \\
\hline 15 & 31.04 & 0.35 & 20.60 & 0.10 & 13.24 & 1.41 & 14.27 & 0.14 & 13.10 & 0.30 & 5.06 & 1.94 \\
\hline 16 & 31.13 & 0.06 & 20.62 & 0.0 & 13.41 & 0.15 & 14.28 & 0.07 & 13.10 & 0.30 & 5.07 & 1.74 \\
\hline 18 & 31.14 & 0.03 & 20.62 & 0.0 & 13.43 & 0.0 & 14.28 & 0.07 & 13.10 & 0.30 & 5.07 & 1.74 \\
\hline 25 & 31.14 & 0.03 & 20.62 & 0.0 & 13.43 & 0.0 & 14.28 & 0.07 & 13.13 & 0.08 & 5.12 & 0.77 \\
\hline 30 & 31.15 & - & 20.62 & - & 13.43 & - & 14.29 & - & 13.14 & - & 5.16 & - \\
\hline
\end{tabular}

From the result in tables we can see that the dynamic internal forces in members increase as the increasing of the number of combined vibration modes, which do not increase equably. The main increases of dynamic internal forces are focused within the first nine order modes. From Tables 8, 9 and 10, we can see that the largest error percentage of upper chord members in arched 3d latticed beam reach to $60 \%$ and that of lower chord members reach to $50 \%$ while considering six combined vibration modes. But considering nine combined vibration modes the error percentage of upper and lower chord members decline greatly. The error percentages of all upper chord members at the bottom of arch except one reaching to $5.7 \%$ are kept within 5\%, which can meet the needs. The error percentages of most upper brace members are kept within $3 \%$. The error percentages of a few 
upper brace members in top of arch reach to $13.8 \%$, but the dynamic internal forces of members in this position are small comparatively so it is not the key position of seismic design. From Table 11 we can see that the error percentages of members in sub-structures keep within $10 \%$ while considering nine combined vibration modes, and the error percentages of members with larger dynamic internal forces are small comparatively. The error percentages of members with smaller dynamic internal forces are large comparatively. So while using the vibration mode-decompositionresponse-spectra method to calculate the seismic behaviors the result error percentages of main bearing components keep within 5\% if considering nine combined vibration modes, which can meet the needs basically. The error of calculating result of dynamic internal forces decline step by step with the increase of combined vibration modes. If considering sixteen vibration modes, as main bearing components, the error percentages of dynamic internal forces in upper chord members of the arched 3d latticed beam keep within 1\%, and that in most of lower chord members keep within 1\% except few members at center and top of the arch, and that in most of upper brace members keep within $0.5 \%$ except few members at top of the arch. The error percentages of dynamic internal forces in members of sub-structures all keep within 3\% and those in web members are $0 \%$.

Table 11. Comparison of calculating dynamic internal forces in members of sub-structures with different combined vibration modes (Main structure bearing load corporately with sub-structures)

\begin{tabular}{|c|c|c|c|c|c|c|c|c|c|c|c|c|}
\hline \multirow{4}{*}{$n$} & \multicolumn{10}{|c|}{ Positions of sub-structures } \\
\cline { 2 - 14 } & \multicolumn{3}{|c|}{ S31 (bottom) } & \multicolumn{3}{c|}{ S32 (center) } & \multicolumn{3}{c|}{ S33 (top) } \\
\cline { 2 - 14 } & $*$ UM & \multicolumn{2}{c|}{ WM } & \multicolumn{2}{c|}{ UM } & \multicolumn{2}{c|}{ WM } & \multicolumn{2}{c|}{ UM } & \multicolumn{2}{c|}{ WM } \\
\cline { 2 - 14 } & $\begin{array}{c}\mathrm{a} \\
(\mathrm{kN})\end{array}$ & $\begin{array}{c}\mathrm{b} \\
(\%)\end{array}$ & $\begin{array}{c}\mathrm{a} \\
(\mathrm{kN})\end{array}$ & $\begin{array}{c}\mathrm{b} \\
(\%)\end{array}$ & $\begin{array}{c}\mathrm{a} \\
(\mathrm{kN})\end{array}$ & $\begin{array}{c}\mathrm{b} \\
(\%)\end{array}$ & $\begin{array}{c}\mathrm{a} \\
(\mathrm{kN})\end{array}$ & $\begin{array}{c}\mathrm{b} \\
(\%)\end{array}$ & $\begin{array}{c}\mathrm{a} \\
(\mathrm{kN})\end{array}$ & $\begin{array}{c}\mathrm{b} \\
(\%)\end{array}$ & $\begin{array}{c}\mathrm{a} \\
(\mathrm{kN})\end{array}$ & $\begin{array}{c}\mathrm{b} \\
(\%)\end{array}$ \\
\hline 3 & 0.49 & 87.9 & 0.11 & 99.0 & 3.00 & 55.0 & 0.23 & 88.1 & 7.20 & 10.4 & 0.14 & 17.6 \\
\hline 6 & 0.55 & 86.4 & 10.84 & 0.4 & 3.01 & 54.9 & 7.29 & 0.3 & 7.26 & 9.7 & 0.15 & 11.8 \\
\hline 9 & 3.66 & 9.4 & 10.84 & 0.4 & 6.30 & 5.5 & 7.29 & 0.3 & 7.67 & 4.6 & 0.17 & 0.0 \\
\hline 12 & 3.79 & 6.2 & 10.88 & 0.0 & 6.45 & 3.3 & 7.31 & 0.0 & 7.68 & 4.5 & 0.17 & 0.0 \\
\hline 15 & 3.79 & 6.2 & 10.88 & 0.0 & 6.49 & 2.7 & 7.31 & 0.0 & 7.85 & 2.4 & 0.17 & 0.0 \\
\hline 16 & 3.98 & 1.5 & 10.88 & 0.0 & 6.52 & 2.2 & 7.31 & 0.0 & 7.85 & 2.4 & 0.17 & 0.0 \\
\hline 18 & 4.02 & 0.5 & 10.88 & 0.0 & 6.52 & 2.2 & 7.31 & 0.0 & 7.85 & 2.4 & 0.17 & 0.0 \\
\hline 25 & 4.04 & 0.0 & 10.88 & 0.0 & 6.53 & 2.1 & 7.31 & 0.0 & 7.86 & 2.2 & 0.17 & 0.0 \\
\hline 30 & 4.04 & - & 10.88 & - & 6.67 & - & 7.31 & - & 8.04 & - & 0.17 & - \\
\hline
\end{tabular}

*UM and WM represent upper chord members and web members respectively

Changing the geometrical parameters such as ratios of rise to span or length to span of the main structure, height of latticed 3d beam, height of substructures etc within a reasonable range can reach similar conclusion (the concrete data omitted). So considering both main structure and the sub-structures, for seismic calculating of the cylindrical LITDBS reticulated mega-structure with plane-plate grids sub-structures using vibration mode-decomposition-response-spectra method, the error percentages of dynamic internal forces of the main bearing components keep within $5 \%$ if considering nine vibration modes, which can meet the needs basically. If condition permits we can consider the first sixteen vibration modes, the error percentages of dynamic internal forces of the main bearing components keep within $1 \%$.

\section{ANALYSIS ON PARAMETERS OF STRUCTURE}

The cylindrical LITDBS reticulated mega-structure with plane-plate grids sub-structures has several shape parameters such as ratio of rise to span of the main structure, ratio of length to span, height of 3d latticed beam and the thickness of sub-structures etc. The influence of these parameters on dynamic internal forces in members of the structure is researched in this segment. Take the maximum of absolute values as target to analyze. Suppose that the vertical uniform loads act on the 
top surface of the whole structure and transfer them to equivalent of lumped masses on nodes. The main structure is bound along the two longitudinal sides (See the black block in Figure 2). The meanings of codes in the following segments are as follows:

$S$ : span of the main structure, $f$ : ratio of rise to span of the main structure, $m$ : number of big grids in arched direction, $a$ : size of big grids, $h$ : height of $3 d$ latticed beam, $h s$ : thickness of sub-structures, Load: vertical uniform loads, Sm: sectional dimension of members in main structure, Ss: sectional dimension of members in sub-structures.

\subsection{Influence of ratio of rise to span $-\mathbf{f}$}

Suppose that: $S=100 \mathrm{~m}, \quad m=5, h=3.5 \mathrm{~m}$, $S m=\Phi 180 \times 10, h s=1.2 \mathrm{~m}, \quad S s=\Phi 76 \times 4$, Load $=1 \mathrm{kN} / \mathrm{m}^{2}$, numbers of upper chord grids of sub-structures are $9 \times 9$. Different values of ratio of rise to span such as $1 / 8$, $1 / 6,1 / 5,1 / 4$ and 0.3 are considered in turn to analyze. The relationship curves of the maximum of absolute values of member's dynamic internal forces with the change of ratio of rise to span are showed in figure 3 , in which " $\mathrm{X}$ ", "Y", " $\mathrm{Z}$ " and "XYZ"
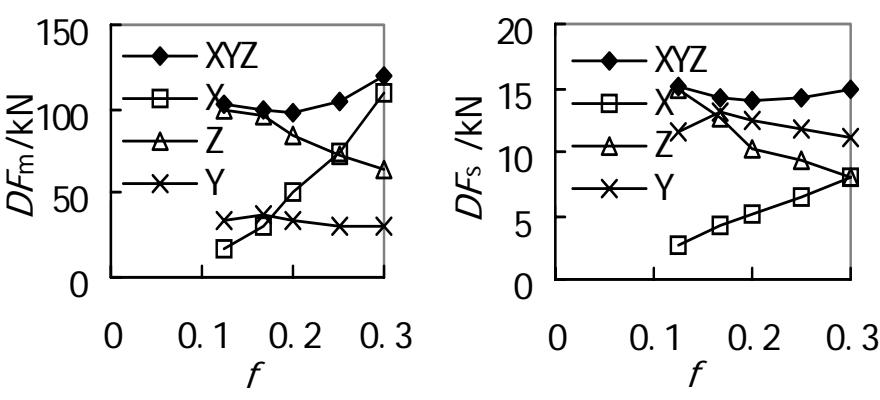

Figure 3. Relationship between maximum of absolute value of dynamic internal forces and ratio of rise to span - $f$

represent the horizontal transverse, horizontal longitudinal, vertical one-dimensional and three-dimensional earthquake action respectively, $D F_{\mathrm{m}}$ and $D F_{\mathrm{s}}$ represent the maximum of absolute values of members' dynamic internal forces in main structure and sub-structures respectively. The codes used in the following text have the same meaning. From the figure we can see that with the increase of ratio of rise to span, the $D F_{\mathrm{m}}$ and $D F_{\mathrm{s}}$ under vertical earthquake action decline gradually, but the $D F_{\mathrm{m}}$ and $D F_{\mathrm{s}}$ under x-one-dimensional earthquake action increase gradually. The $D F_{\mathrm{m}}$ and $D F_{\mathrm{s}}$ under y-one-dimensional earthquake action also decline gradually except within the range of very small ratio of rise to span. The change extents of the $D F_{\mathrm{m}}$ are small comparatively and that of the $D F_{\mathrm{s}}$ are large comparatively. With the increase of ratio of rise to span, the $D F_{\mathrm{m}}$ and $D F_{\mathrm{s}}$ under three-dimensional earthquake action decrease slightly at first then increase gradually, and reach their minimum value when $f=1 / 5$. So the cylindrical LITDBS reticulated mega-structure with plane-plate grids sub-structures has the best seismic property when its ratio of rise to span takes value of $1 / 5$.

\subsection{Influence of height of the $3 d$ latticed beam $-h$}

In the same way, suppose that $S=100 \mathrm{~m}$, $f=1 / 5, h s=1.2 \mathrm{~m}$, then different values of height of 3d latticed beams such as 2.0, 2.5, 3.0, 3.5 and $4.0 \mathrm{~m}$ are considered in turn to analyze. The relationship curves of the maximum of absolute values of member's dynamic internal forces with the change of $h$ are showed in figure 4 . From the figure we can see that, under $\mathrm{x}$-one-dimensional earthquake action, the $D F_{\mathrm{m}}$ decreases gradually and the
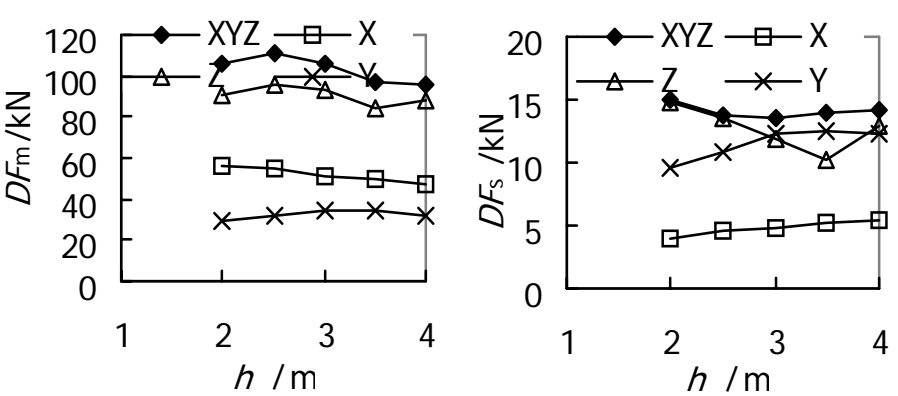

Figure 4. Relationship between maximum of absolute value of dynamic internal forces and height of 3d latticed beam - $h$ 
$D F_{\mathrm{s}}$ increases gradually with the increase of $h$. Under vertical one-dimensional earthquake action, the maximum of absolute value of members' dynamic internal forces fluctuate with the change of $h$, and the $D F_{\mathrm{m}}$ and $D F_{\mathrm{s}}$ are all at their minimum value when $h$ takes value close to $3.5 \mathrm{~m}$. Under horizontal longitudinal $(\mathrm{Y})$ one-dimensional earthquake action, the $D F_{\mathrm{m}}$ does not change a lot, but the $D F_{\mathrm{s}}$ increases gradually at first with the increase of $h$ and does not change any more when $h$ arrives to above $3 \mathrm{~m}$. Under three-dimensional earthquake action, the $D F_{\mathrm{m}}$ decreases gradually with increase of $h$ except $h$ is very small (less than $2.5 \mathrm{~m}$ ) and does not change any more when $h$ arrive to above $3.5 \mathrm{~m}$. The $D F_{\mathrm{s}}$ decrease gradually at first then increase a little with increase of $h$, but all the changes are not very large.

\subsection{Influence of thickness of sub-structure - hs}

Suppose that $S=100 \mathrm{~m}, f=1 / 5, h=3.5 \mathrm{~m}$, then diffenrent values of thickness of sub-structure such as 1.0, 1.2, 1.4 and $1.6 \mathrm{~m}$ are considered in turn to analyze. The results are showed in Figure 5, from which we can see that, the $D F_{\mathrm{m}}$ under $\mathrm{x}$-one-dimensional, $\mathrm{y}$-onedimensional, z-one-dimensional and three-dimensional earthquake actions increases gradually with increase of thickness of sub-structure. The $D F_{\mathrm{s}}$
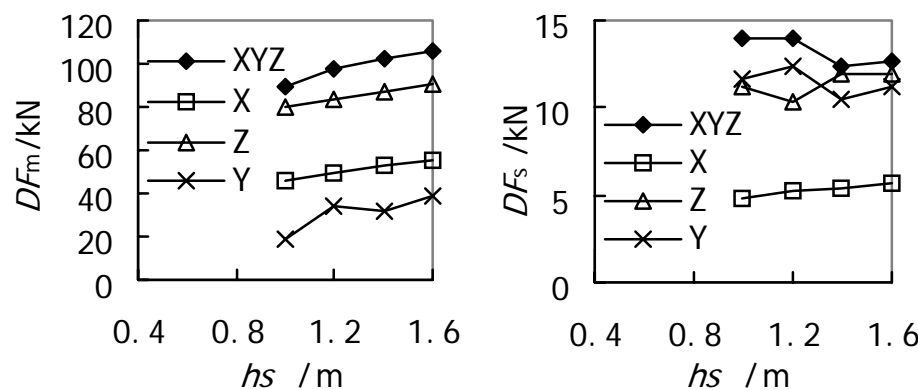

Figure 5. Relationship between maximum of absolute value of dynamic internal forces and thickness of sub-structures - hs under x-one-dimensional earthquake action increases gradually, and that under z-one-dimensional, $\mathrm{y}$-one-dimensional or three-dimensional earthquake actions fluctuate with the increase of thickness of sub-structure, but as a whole, the $D F_{\mathrm{s}}$ under y-one-dimensional and three-dimensional earthquake actions has the trend of decrease and that under z-one-dimensional earthquake actions has the trend of increase.

\subsection{Influence of ratio of length to span of main structure - LS}

Suppose that $L=80 \mathrm{~m}, f=1 / 5, h=3 \mathrm{~m}$, $m=4, \quad S \mathrm{~m}=\Phi 180 \times 10, \quad h s=1.2 \mathrm{~m}$, Ss $=\Phi 76 \times 4$, Load $=1 \mathrm{kN} / \mathrm{m}^{2}$; then the following values of number of longitudinal big rids are considered to analyze: 2, 4, 5 and 7 , the corresponding length of main structure are 46.063, 92.126, 115.157 and $161.220 \mathrm{~m}$ respectively, and the corresponding ratio of length to span of main structure are $0.576,1.152$, 1.439 and 2.015. The calculating results are show in Figure 6.
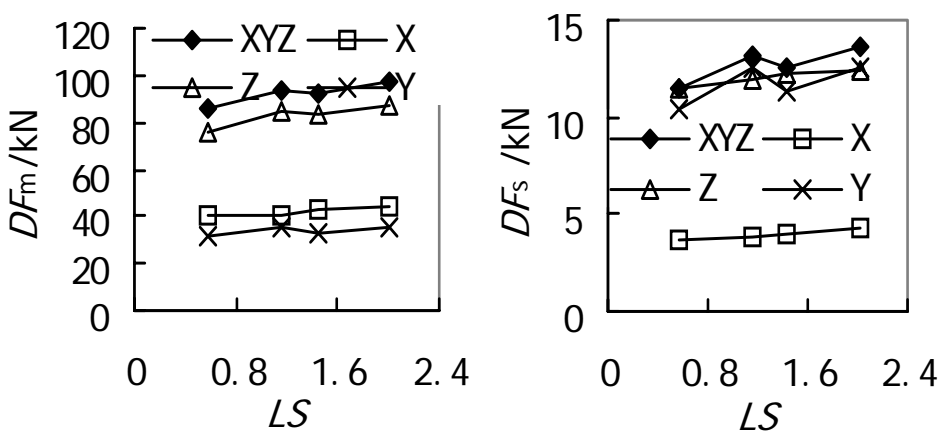

Figure 6. Relationship between maximum of absolute value of dynamic internal forces and ratio of length to span of main structures - $L S$

From the figure we can see that, with the increase of ratio of length to span of the main structure, the $D F_{\mathrm{m}}$ under y-one-dimensional earthquake action almost has no change, and that under $\mathrm{x}$-one-dimensional, z-one-dimensional or three-dimensional earthquake action has the trend of increase but the changes are very small. The $D F_{\mathrm{s}}$ under x-one-dimensional or z-one-dimensional earthquake action has the trend of gradual increase, and that under y-one-dimensional or 
three-dimensional earthquake action has the trend of fluctuating increase, but all the changes are very small. In a word, the influence of ratio of length to span of the main structure on the maximum of absolute value of dynamic internal forces is small comparatively.

\section{CONCLUSION}

This paper is focused on the research of seismic response of cylindrical (LITDBS) reticulated mega-structure with double-layers grid sub-structures using response spectrum technique. The distribution laws of dynamic internal forces of elements in its main structure and sub-structures are researched firstly. Reasonable vibration modes combination of vibration mode-decompositionresponse-spectra method is discussed. Seismic behaviors of the structure under different directional seismic loads are analyzed; therefore the reasonable required components of seismic loads for aseismic design are obtained. A series of parameter analysis are carried out at last. The main conclusions are as follows.

1) As the main bearing components, the ratios of dynamic internal forces to static internal forces in upper and lower chord members of the arched 3d latticed beams are almost kept within 0.1, which proves that the seismic property of this structure is good. Though the ratios of dynamic internal forces to static internal forces in some upper diagonal bracing members, upper cross-bars, web members of the arched $3 d$ latticed beams and many members of the longitudinal 3d latticed beams are high, their dynamic internal forces and static internal forces are all very small, which make it possible to design these members according to constructional demands.

2) While calculating the seismic internal forces using mode-decomposition-response spectra method, if the first nine vibration modes are considered, the errors of dynamic internal forces in main bearing members are kept within 5 percent, which can almost meet the needs. If possible we can consider the first sixteen vibration modes and the errors of dynamic internal forces in main bearing members are kept within 1 percent.

3) Generally three-dimensional earthquake action should be considered for the seismic checking calculation of this structure. But on condition of the main structure bearing the load cooperatively with substructures, for the dynamic and static internal forces in web members of substructures are all small and they can be designed according to constructional demands, we can lay emphasis on the seismic checking calculation of the main structure and the chord members of substructures and can only consider two-dimensional earthquake action combination of transverse horizontal and vertical components.

All the works will provide guides in theory for the use of this new structure, but the elastic-plastic performances and the broken rules under keen earthquakes are needful to be more researched.

\section{ACKNOWLEDGEMENTS}

This work was financially supported by the National Natural Science Foundation of China under Grant No. 50508013, which is gratefully acknowledged. 


\section{REFERENCES}

[1] He Yongjun, "Research on structural form, static and stability of latticed mega-structure [D]”, Zhejiang University, 2001.

[2] He Yongjun, Zhou Xuhong and Dong Shilin, "Research on mega-structure braced with sub-structures of double layer grids”, China Civil Engineering Journal, 2002, 35(6), pp.24-43.

[3] He Yongjun, "Research on dynamic property, seismic response and simplified analysis method of reticulated mega-structure [R]”, Hunan University, 2003.

[4] Shen Jumin, Zhou Xiyuan, Gao Xiaowang and Liu Jingbo, “Aseismic Engineering”, China Architecture \& Building Press, 2000.

[5] Ministry of Construction P.R. China, "Code for Seismic Design of Buildings", China Architecture \& Building Press, 2001.

[6] He Yongjun, Zhou Xuhong and Dong Shilin, "Research on dynamic characteristic of cylindrical latticed intersected three-dimensional beam system reticulated mega-structure with Double Layer Sub-structure”, Building Science, 2003, 19(5), pp.10-15.

[7] Anagnostopoulos, S.A., "Response Spectrum Techniques for Three-Component Earthquake Design”, Earthquake Engineering and Structural Dynamics, 1981, 9(4). 


\title{
EFFICIENT MODELLING OF COMPOSITE BUILDING RESPONSE TO COMPARTMENT FIRES
}

\author{
Zhaohui Huang ${ }^{1, *}$, Ian Burgess ${ }^{2}$ and Roger Plank ${ }^{3}$ \\ ${ }^{1}$ Lecturer, Department of Civil \& Structural Engineering, University of Sheffield, S1 3JD, UK. \\ *(Corresponding author: Email: z.huang@sheffield.ac.uk, Tel: +44 (0) 114 2225710, Fax: +44 (0) 114 2225700) \\ ${ }^{2}$ Professor, Department of Civil \& Structural Engineering, University of Sheffield, S1 3JD, UK. \\ ${ }^{3}$ Professor, School of Architectural Studies, University of Sheffield, S10 2TN, UK.
}

\begin{abstract}
In this paper a numerical analysis procedure which employs a sub-structuring technique together with selective node re-numbering, is described as a way of efficiently modelling the response of buildings to fires which are restricted to internal compartments. In this procedure user-defined cool regions of the building model are substructured and condensed into a linear "super-element", which has nodes connected to the non-linear sub-structures located within and in the immediate vicinity of the fire zone. The procedure has been incorporated into the non-linear program Vulcan which has been developed to model the structural response of loaded structures to fire attack, and two full-scale fire tests have been modelled to examine the computational efficiency of the method. The method makes it much easier than previously to investigate the influence of the surrounding cool structure on the behaviour of elements within the fire compartment, and its efficacy has been investigated for these two tests.
\end{abstract}

Keywords: Super-element; Sub-structuring; Re-numbering; Structural fire behaviour; Finite element analysis.

\section{INTRODUCTION}

The performance of structural elements exposed to fire is usually described in terms of their fire resistance, which is the period of time during exposure to fire at which "failure", according to a criterion usually based on deflection, occurs. Currently, this fire resistance is expressed only in relation to isolated element behaviour as determined by standard fire tests using a time-temperature curve given in ISO834 [1] and reproduced in most countries' codes of practice for fire testing. Predicting the behaviour of elements within a building in a real fire from ISO834 fire tests on isolated elements involves a clear and considerable simplification much greater than that which is made routinely in ambient-temperature design analysis. An important way in which the behaviour of elements in buildings differs from that of similar elements in these furnace tests derives from the very different boundary conditions which are imposed in the two situations. In a real building structural elements form part of a continuous assembly, and building fires often remain localised, with the fire-affected structure within a fire compartment being subject to significant restraint from the cooler areas surrounding it. The real behaviour of these structural elements, which is affected by the interaction of thermal expansion, material degradation and this boundary restraint, can therefore be totally different from that indicated by standard furnace tests. In 1995-96, six largescale fire tests were carried out on a composite steel-concrete building at the BRE Fire Research Laboratory at Cardington, in which the observed structural response supported this viewpoint.

Because such full-scale fire tests are extremely expensive, the development of analytical methods that can predict the behaviour of building structures when subjected to fire conditions is becoming increasingly important. In recent years a computer program Vulcan [2-8], has been developed at the University of Sheffield for three-dimensional analysis of the structural behaviour of composite and steel-framed buildings in fire. The program is based on a 3-D non-linear finite element procedure in which composite steel-framed buildings are modelled as an assembly of beam-column, spring, shear connector and slab elements. The beam-column line elements are three-noded, and their cross-section is divided into a number of segments to allow consideration of non-linear variation of temperature, stress and strain through the cross-section. A two-noded spring element of zero length is used to model the characteristics of steel member connections. In order to model partial interaction of the steel beam and the concrete slab in composite construction a shear 
connector elements has been developed to link slab and beam elements. The slabs are modelled using a nine-noded layered flat-shell element based on Mindlin-Reissner theory, in which each layer can have different temperature and material properties.

Modelling the structural behaviour of buildings in fire is inherently rather complex, because nonlinear structural analysis needs to be performed over the time-period of a given fire, during which element temperatures vary across the sections of members and slabs and also with location in the structure relative to the fire source. The materials of construction (steel and concrete of various grades) are subject to two dominant effects which depend on temperature; thermal straining and degradation of constitutive relationships. Material properties are non-linear, and it is necessary also to analyse the structural response up to much higher deflections than would be necessary at ambient temperature. Analyses can therefore be very expensive in computing time, especially when modelling large-scale problems. For example, for modelling a full-scale fire test [9] in a single corner bay of a composite building frame more than 10 hours' processing time was necessary on a 2.6GHz Pentium 4 personal computer. The modelling in that case used 226 elements (152 beamcolumn and 74 slab elements with 10 layers) with 369 nodes. For larger models with over 500 nodes run-times of the order of 20-30 hours are fairly usual. This has made the need to improve the computational efficiency of Vulcan a major issue of the program's development.

Fortunately, the design of buildings is influenced by fire safety legislation so that fires are often contained by internal fireproof compartmentation and remain localised. The influence on the behaviour of cool structure adjacent to the fire compartment is very important, because of the effects of continuity of structure into a much stiffer region, and also because of the restraint which is provided to thermal expansion of heated elements. It is therefore necessary to include a region of the surrounding cool structure in the modelling in order to represent more realistically the conditions affecting the fire compartment.

In fire conditions it is usual to assume that the loading applied generally to the structure is at a level well below that which would cause ambient-temperature yield to occur, and it is therefore reasonable to assume that, even during the fire, the adjacent cool structure remains linearly elastic, apart from some areas which are very close to the fire compartment. This is confirmed by observations from both test results and numerical studies. The objective of the present development was to take advantage of this observation in increasing the program's computational efficiency. The procedures for sub-structuring and static condensation in linear structural analysis are now well known [10-13], but little work has been done in extending the sub-structuring technique to non-linear analysis of the behaviour of buildings in fire. This paper describes the use of an appropriate procedure for using the sub-structuring technique, together with a re-numbering algorithm for more efficient modelling of this type. User-defined cool regions of the structures are sub-structured and condensed as a linear super-element, which has nodes connected to the nonlinear meshed sub-structure representing the fire compartment and a cool border zone. The procedure has been incorporated into Vulcan and some examples will be shown of the increased computational efficiency which is achieved.

\section{BUILDING A SUPER-ELEMENT}

In this paper a user-defined region of the finite element mesh, which includes only unheated elements, is assumed as a linear-elastic sub-structure (see Figure 1). For this region the relationship between the stiffness matrix $\mathbf{K}_{\mathbf{s b}}$, the corresponding displacement vector $\mathbf{U}_{\mathbf{s b}}$ and the load vector $\mathbf{R}_{\mathbf{s b}}$ is expressed as

$$
\mathbf{K}_{\mathrm{sb}} \mathbf{U}_{\mathrm{sb}}=\mathbf{R}_{\mathrm{sb}}
$$


In order to establish a super-element the static condensation procedure is used. Eq. (1) is partitioned, as in [14], into the form

$$
\left[\begin{array}{ll}
\mathbf{K}_{\mathrm{aa}} & \mathbf{K}_{\mathrm{ac}} \\
\mathbf{K}_{\mathrm{ca}} & \mathbf{K}_{\mathrm{cc}}
\end{array}\right]\left[\begin{array}{l}
\mathbf{U}_{\mathbf{a}} \\
\mathbf{U}_{\mathbf{c}}
\end{array}\right]=\left[\begin{array}{l}
\mathbf{R}_{\mathbf{a}} \\
\mathbf{R}_{\mathbf{c}}
\end{array}\right]
$$

in which $\mathbf{U}_{\mathbf{a}}$ and $\mathbf{U}_{\mathbf{c}}$ are respectively the vectors of the degrees of freedom to be retained (the boundary nodes between the super-element and the non-linear mesh) and those which are to be condensed out (the other nodes of the super-element).

The matrix equation for the nodes to be condensed out can be expressed from Eq. (2) as:

$$
\mathbf{U}_{\mathrm{c}}=\mathbf{K}_{\mathrm{cc}}^{-1}\left(\mathbf{R}_{\mathrm{c}}-\mathbf{K}_{\mathrm{ca}} \mathbf{U}_{\mathrm{a}}\right)
$$

The relationship in Eq. (3) is used to substitute for $\mathbf{U}_{\mathbf{c}}$ into the boundary node equations in Eq. (2) to obtain the condensed equations

$$
\left(\mathbf{K}_{\mathrm{aa}}-\mathbf{K}_{\mathrm{ac}} \mathbf{K}_{\mathrm{cc}}^{-1} \mathbf{K}_{\mathrm{ca}}\right) \mathbf{U}_{\mathrm{a}}=\mathbf{R}_{\mathrm{a}}-\mathbf{K}_{\mathrm{ac}} \mathbf{K}_{\mathrm{cc}}^{-1} \mathbf{R}_{\mathrm{c}}
$$

If we use

$$
\mathbf{K}_{\text {super }}=\mathbf{K}_{\mathrm{aa}}-\mathbf{K}_{\mathrm{ac}} \mathbf{K}_{\mathrm{cc}}^{-1} \mathbf{K}_{\mathrm{ca}}
$$

and

$$
\mathbf{R}_{\text {super }}=\mathbf{R}_{\mathrm{a}}-\mathbf{K}_{\mathrm{ac}} \mathbf{K}_{\mathrm{cc}}^{-1} \mathbf{R}_{\mathrm{c}}
$$

Eq. (4) becomes

$$
\mathbf{K}_{\text {super }} \mathbf{U}_{\mathbf{a}}=\mathbf{R}_{\text {super }}
$$

in which $\mathbf{K}_{\text {super }}$ and $\mathbf{R}_{\text {super }}$ are respectively the stiffness matrix and load vector of the super-element. From Eq. (7) it can be seen that the degrees of freedom related to the super-element are the displacements $\mathbf{U}_{\mathbf{a}}$ which are to be retained. Since Eq. (1) represents the relationship between the stiffness matrix $\mathbf{K}_{\mathbf{s b}}$, the corresponding displacement vector $\mathbf{U}_{\mathbf{s b}}$ and the load vector $\mathbf{R}_{\mathbf{s b}}$ for a linear-elastic sub-structure, $\mathbf{K}_{\mathbf{s b}}$ is unchanged during non-linear analysis. Hence, the stiffness matrix of the super-element $\mathbf{K}_{\text {super }}$ is constant.

A frontal solution method [15] is used during the condensation procedure for the super-element, to enable the program to model large-scale structures without difficulty.

\section{MODELLING OF STRUCTURES IN FIRE}

When the stiffness matrix for the super-element has been constructed it is used as a boundary element connected to the sub-structure which is modelled using normal meshing of non-linear elements. During the subsequent non-linear analysis the stiffness matrix of the super-element $\mathbf{K}_{\text {super }}$ remains constant. This non-linear solution procedure determines the deformations $\mathbf{U}_{\mathbf{n l}}$ of the nodes under equivalent external loads $\mathbf{R}_{\mathbf{n l}}$, which are assumed to be applied the nodes and are usually constant in the fire condition, whilst the temperature increases. In this procedure a number of parameters are temperature-dependent. The basic equilibrium equation at any load or temperature step is

$$
\mathbf{R}_{\mathbf{n l}}-\mathbf{Q}_{\mathbf{n l}}=\mathbf{0}
$$

where $\mathbf{Q}_{\mathbf{n l}}$ is the vector of internal nodal forces.

The stiffness matrix $\mathbf{K}_{\mathbf{n l}}$, the internal force vector $\mathbf{Q}_{\mathbf{n l}}$ and the equivalent external loads $\mathbf{R}_{\mathbf{n l}}$ for the structure being analysed are expressed as 


$$
\begin{aligned}
& \mathbf{K}_{\mathrm{nl}}=\sum_{\mathrm{j}=1}^{\mathrm{n}} \mathbf{K}_{\mathbf{j}}+\mathbf{K}_{\text {super }} \\
& \mathbf{Q}_{\mathrm{nl}}=\sum_{\mathrm{j}=1}^{\mathbf{n}} \mathbf{Q}_{\mathbf{j}}+\mathbf{Q}_{\text {super }} \\
& \mathbf{R}_{\mathrm{nl}}=\sum_{\mathbf{j}=1}^{\mathrm{n}} \mathbf{R}_{\mathbf{j}}+\mathbf{R}_{\text {super }}
\end{aligned}
$$

in which $\mathbf{K}_{\mathbf{j}}, \mathbf{Q}_{\mathbf{j}}, \mathbf{R}_{\mathbf{j}}$ and $\mathrm{n}$ are respectively the element stiffness matrix, internal force vector and external load vector, and $\mathrm{n}$ is the total number of elements of the non-linear sub-structure. $\mathbf{Q}_{\text {super }}$ is the internal force vector of the super-element. Because the super-element is linearly elastic, $\mathbf{Q}_{\text {super }}$ can be calculated using

$$
\mathbf{Q}_{\text {super }}=\mathbf{K}_{\text {super }} \mathbf{U}_{\text {super }}
$$

where $\mathbf{U}_{\text {super }}$ is the nodal displacement vector of the super-element and $\mathbf{U}_{\text {super }}=\mathbf{U}_{\mathbf{a}}$.

The stiffness matrix of the super-element $\mathbf{K}_{\text {super }}$ is symmetric and banded. After its skyline has been determined only the elements below the upper skyline, including the diagonal elements, are stored in a one-dimensional array and are used to form $\mathbf{K}_{\mathbf{n l}}$ and $\mathbf{Q}_{\text {super }}$.

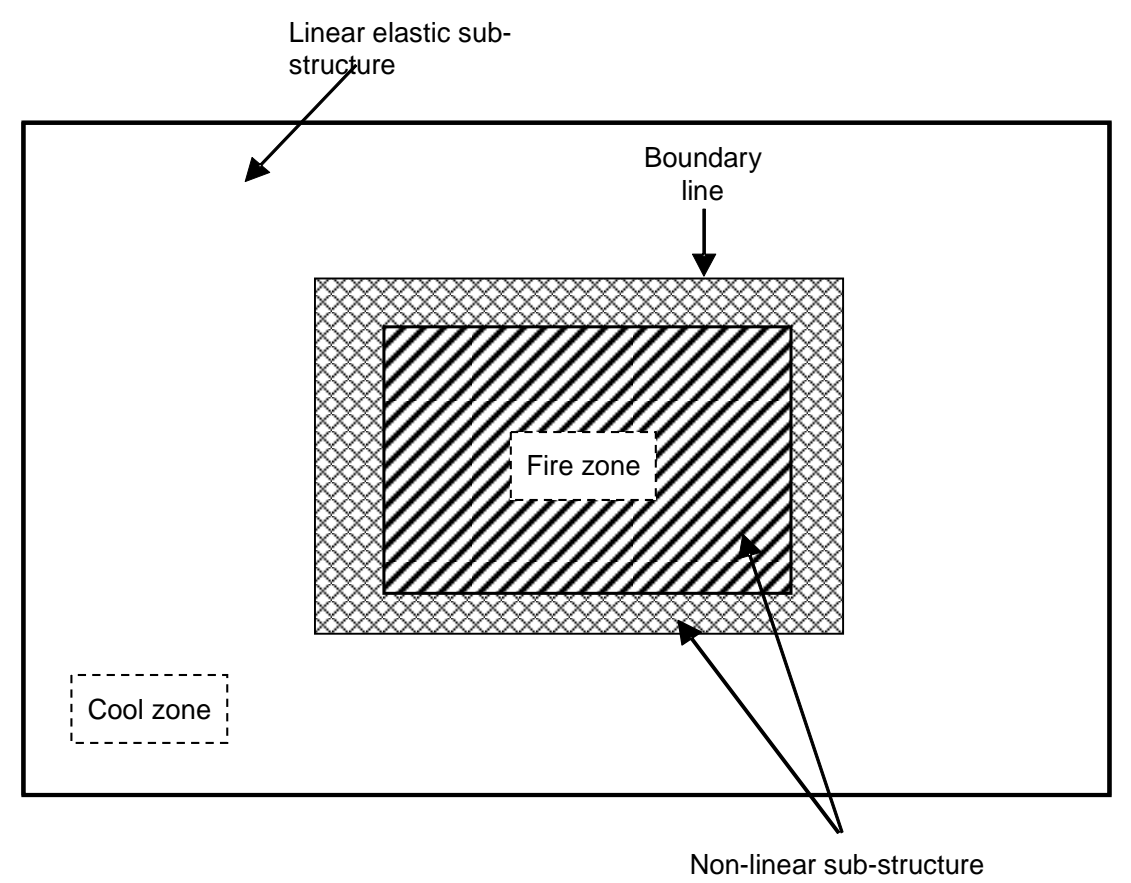

Figure 1. Sub-structuring scheme for structural analysis in fire.

For composite steel-framed buildings in fire, Eq. (8) is highly non-linear, and the Newton-Raphson iteration procedure is employed. The total time period or temperature range for which the response of the structure is to be traced is divided into a number of steps. It is assumed that changes in the loads or temperatures occur only at the beginning or end of a step. During any step the external loads, and the temperatures in the layers of slab elements and the segments of beam-column elements, are assumed to remain constant. During this incremental solution process the stiffness matrix of the super-element $\mathbf{K}_{\text {super }}$ remains constant. The total number of nodes and elements for which non-linear analysis has to be carried out is reduced to those within the selected region, whilst retaining the effect of either the whole or a large part of the structure which is not directly involved in the fire. 


\section{RE-NUMBERING PROCEDURE}

An undesirable effect of the condensation process is that it creates an element with a very large number of nodes, whose stiffness matrix is very highly populated and therefore has a bandwidth very close to the maximum possible for its final degrees of freedom. The node numbering of the remaining sub-structure for non-linear analysis may become very badly conditioned when it is reassembled with the super-element. This can cause a very much broader bandwidth of the structural stiffness matrix than would occur if the problem were solved without sub-structuring. In general solution time is related to the square of the bandwidth, while it is only linearly related to the dimension of the stiffness matrix. Thus the considerable decrease in the number of nodes considered due to condensation may be offset by the increase in bandwidth [10], and may in consequence produce no improvement in processing times. It is therefore necessary to re-number the remaining sub-structure, including the nodes connecting the super-element to the non-linear region, in order to reduce the bandwidth to a more optimal level.

A re-numbering algorithm proposed by Burgess and Lai [16] has been adopted in this paper. There are seven stages in this re-numbering procedure:

1. The nodes and elements of the remaining sub-structure for non-linear analysis are listed using a continuous number sequence, removing the gaps created by the creation of the super-element. A mapping array is created to relate this numbering to the original scheme which has been used by the creator of the data file.

2. A nodal inter-connectivity matrix is built up based on this new node numbering.

3. Based on the inter-connectivity matrix a starting node for re-numbering is chosen using the method proposed by Gibbs, Poole and Stockmeyer [17].

4. Starting from this starting node and working according to the stiffness connectivities, the original node structure is converted to a level structure of nodes.

5. A second pass is made across the level structure, and an attempt is made to 'smooth' the level heights to a more uniform average height before re-numbering takes place [16].

6. The modified node level structure is then re-numbered using the well-known method based on the work of Cuthill and McKee [18] and Cheng [19].

7. After re-numbering the mapping array is updated. The structural information relating to the original numbering system is re-sequenced in the new numbering system and is then ready for starting non-linear analysis. The details of the stages from (3) to (5) can be found in Burgess and Lai [16].

\section{NUMERICAL EXAMPLES}

The procedures described above for creating a super-element and re-numbering the residual substructure have now been incorporated within Vulcan, and have been tested in three-dimensional modelling of the structural behaviour of composite steel-framed buildings in fire. The numerical procedure is summarised in Figure 2. The program is now capable of being run in three ways: (1) using the original procedure without any sub-structuring or re-numbering; (2) using the original procedure after re-numbering; (3) using the new procedure with a super-element and subsequent renumbering. In order to demonstrate the key effects of the new procedures, two of the six full-scale compartment fire tests which were carried out in 1995-96 in an 8-storey composite frame structure at the BRE laboratory at Cardington are modelled here. The Cardington building was constructed during 1994, to resemble a modern city-centre medium-rise office development typical of current UK practice. The influence of the modelling of the cool structure adjacent to fire compartments on the behaviour of the structure within it is investigated. The studies were run on a Pentium 4, 2.6GHz personal computer with 1.0Gb of RAM. 


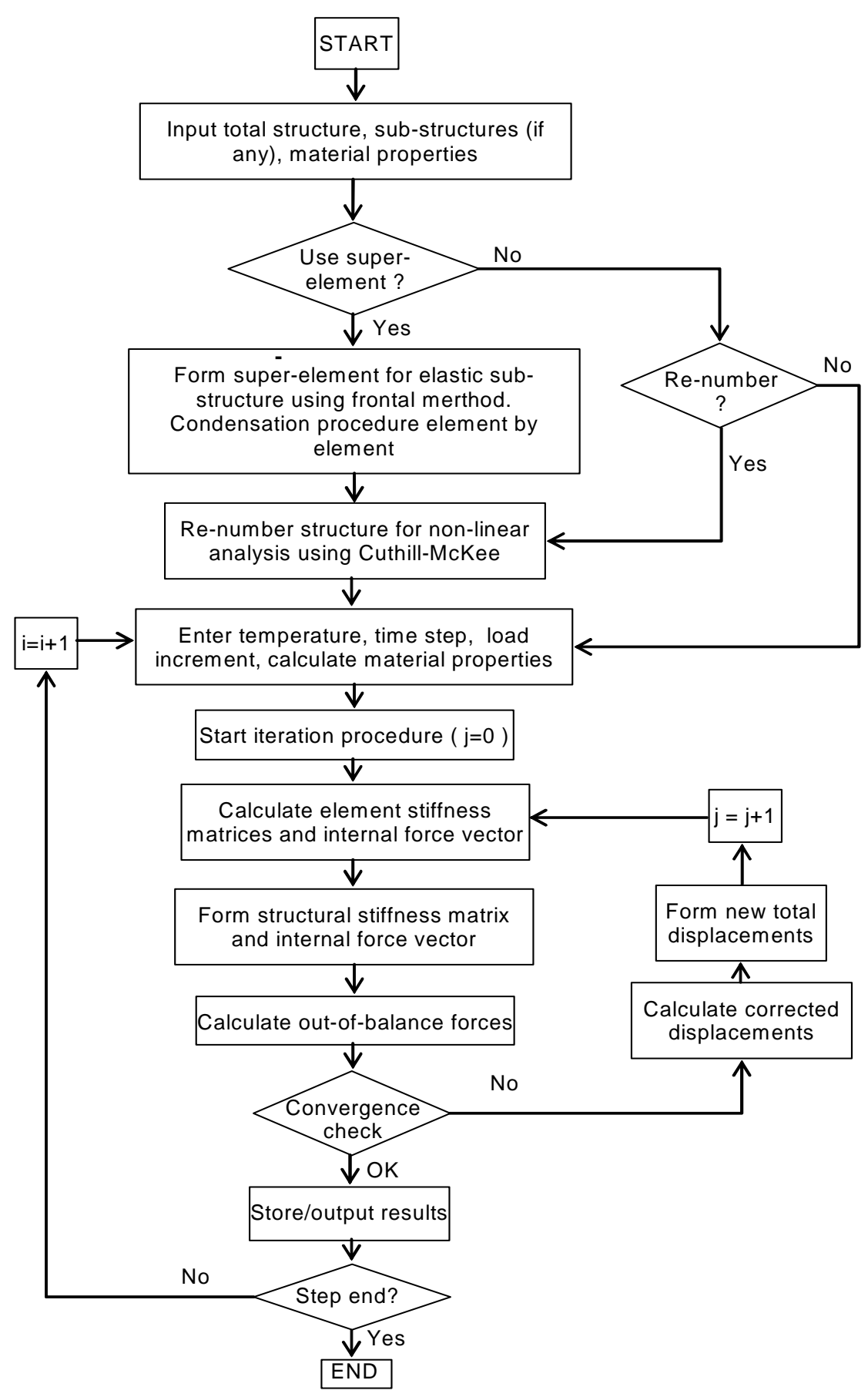

Figure 2. A flowchart of the program Vulcan including the sub-structuring scheme.

\section{MODELLING OF THE “RESTRAINED BEAM TEST”}

The "Restrained Beam Test" was the first, and the smallest, of the fire tests carried out on the test building. It was conducted [20, 21] by British Steel plc in January 1995, and involved heating a single secondary beam and an area of the surrounding slab on the seventh floor. The steel member tested consisted of a 305x165UB40 section spanning between columns D2 and E2, and was heated using a specially constructed gas-fired furnace over the central $8 \mathrm{~m}$ of its $9 \mathrm{~m}$ length. The location of the test is shown in Figure 3. The sub-frame which has been modelled, including a region of the surrounding cool structure, is also shown in Figure 3, with a more detailed representation, including the finite element mesh layout adopted, in Figure 4. 


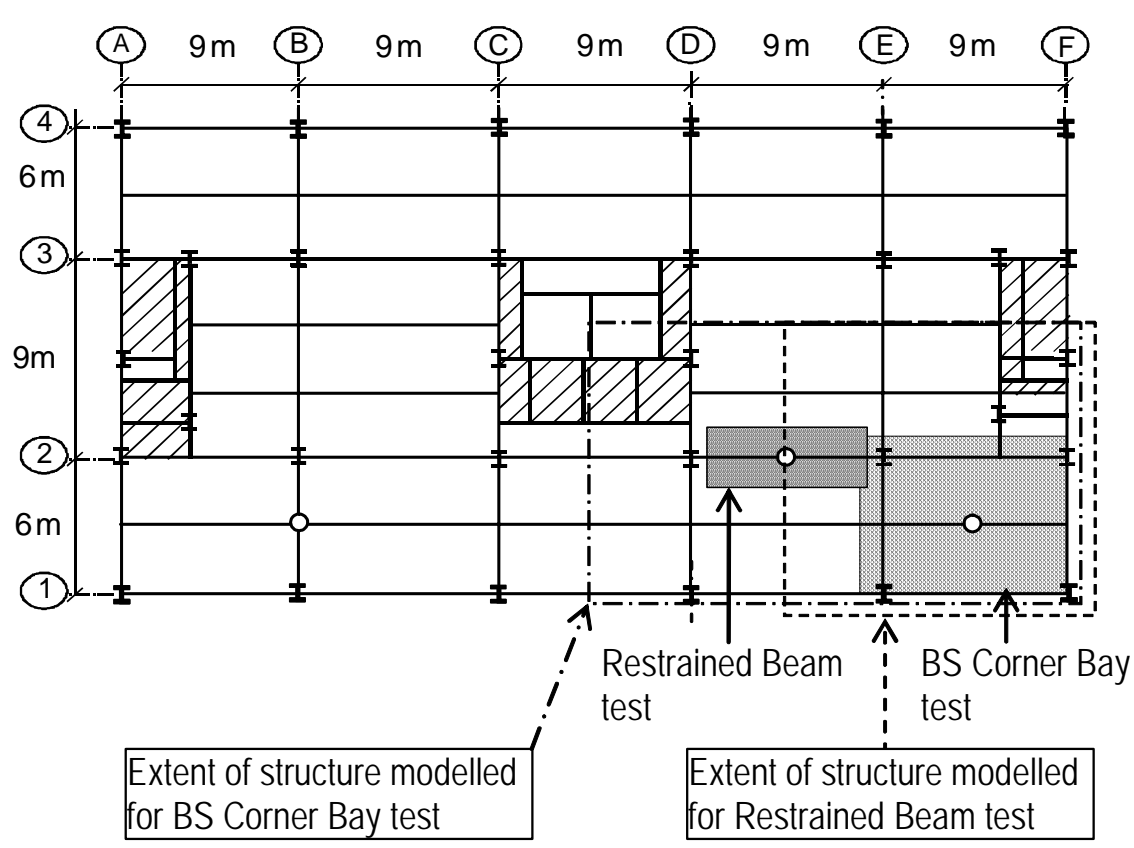

Figure 3. Locations of Restrained Beam Test and British Steel Corner Bay Test in the Cardington composite test frame.

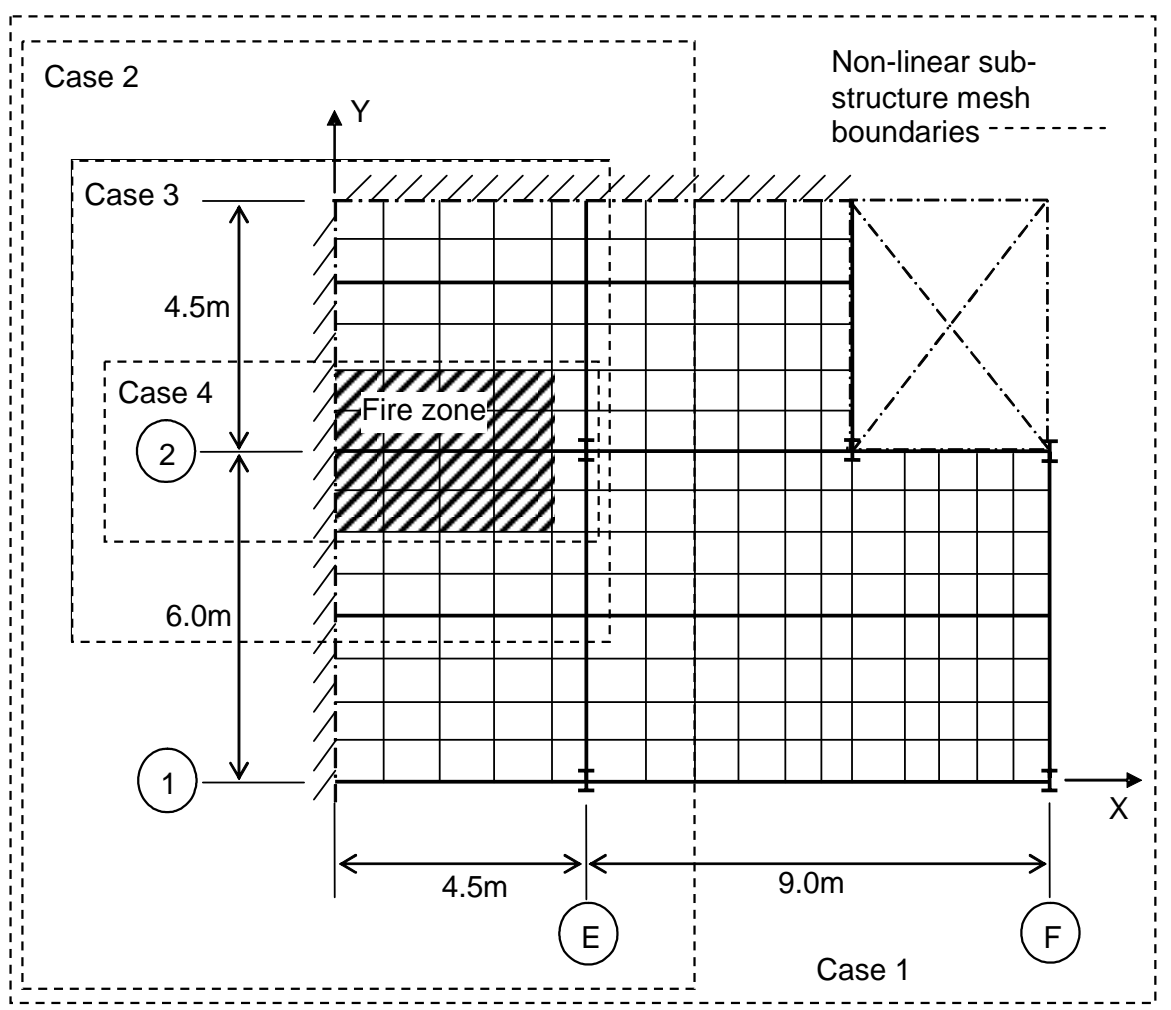

Figure 4. Finite element layout adopted in the analysis of the Restrained Beam Test, together with the boundaries of the non-linear sub-structures for the four cases studied.

The ambient-temperature material properties used in the modelling were as follows:

- The yield strength of steel was assumed as 308MPa for Grade 43 steel (S275) and 390MPa for Grade 50 (S355), based on coupon test results provided by the supplier.

- The yield strength of reinforcing steel was assumed to be $460 \mathrm{MPa}$.

- The elastic modulus of steel was $210 \mathrm{kN} / \mathrm{mm}^{2}$.

- The average concrete compressive strength was 35MPa. 
A uniform floor load of $5.48 \mathrm{kN} / \mathrm{m}^{2}$ was applied using sandbags. The temperature distributions in the steel beam and the slab were taken as the average of the recorded temperature distributions across the cross-section of the beam and the thickness of the slab at any stage in the test. The test was terminated due to a failure of some instrumentation when the steel beam temperature was above $800^{\circ} \mathrm{C}$, and no structural failure was seen although large deflections were achieved.

In this example four cases, all of which are illustrated in Figure 4, have been analysed. In Case 1 (normal modelling) the whole sub-frame was modelled as a non-linear sub-structure, but different extents of non-linear sub-structure were used for Cases 2 to 4 . Their basic statistics, including runtimes, are given in Table 1. In the selection of super-element configurations here only the intuitively sensible arrangements shown in Figure 4 have been considered. The ten-fold time saving between Cases 1 and 2 is achieved by using the whole developed procedure. The influence of re-numbering within this process (considered separately from the creation of a super-element) can be gauged from a re-run of Case 1 after re-numbering. The run-time in this case was 201 minutes, compared with 280 for the original numbering, a significant but unspectacular saving. The presence of columns above and below the floor structure is capable of causing very large, sparsely populated bandwidths without re-numbering, and the height of skyline within the total structural stiffness matrix is increased dramatically.

Table 1. Cardington Restrained Beam test: performance using different super-elements.

\begin{tabular}{|l|c|c|c|c|c|c|}
\hline \multirow{2}{*}{ Case } & \multicolumn{2}{|c|}{ Elements } & \multicolumn{2}{c|}{ Nodes } & \multicolumn{2}{c|}{ Run-time } \\
& $\begin{array}{c}\text { Non-linear } \\
\text { sub-frame }\end{array}$ & $\begin{array}{c}\text { Super- } \\
\text { element }\end{array}$ & $\begin{array}{c}\text { Non-linear } \\
\text { sub-frame }\end{array}$ & $\begin{array}{c}\text { Super- } \\
\text { element }\end{array}$ & & (\%) \\
\hline 1 (normal) & 208 & 0 & 343 & 0 & 280 & 100.0 \\
\hline 2 & 116 & 92 & 214 & 129 & 25.3 & 9.0 \\
\hline 3 & 65 & 143 & 135 & 208 & 18.8 & 6.7 \\
\hline 4 & 20 & 188 & 77 & 266 & 4.3 & 1.5 \\
\hline 1 (re-numbered) & 208 & 0 & 343 & 0 & 201 & 71.8 \\
\hline
\end{tabular}

It is necessary to check that accuracy is being maintained in the prediction of overall response, and also that the localised behaviour in the zone of interest is not changed radically by connection to the super-element. In order to examine the effect on overall accuracy of the modelling the mid-span deflections of the heated beam are plotted in Figure 5 for all cases against the temperature of the bottom flange of the beam, together with the measured test results. It can be seen that Case 2 produces results almost identical to those from normal modelling (Case 1), which itself compares well with the test results. Case 3 involves some minor sacrifice of accuracy in the final range of test temperatures; this might be anticipated to increase if the temperatures were increased further. Case 4, in which only the tested beam and the concrete slab within the furnace width are contained within the non-linear sub-frame, shows the effect of eliminating failure in the immediately adjacent zones from the analysis. Below a beam lower flange temperature of $200^{\circ} \mathrm{C}$ the deflections are almost identical to those given by the other modelling, whereas above $400^{\circ} \mathrm{C}$, when

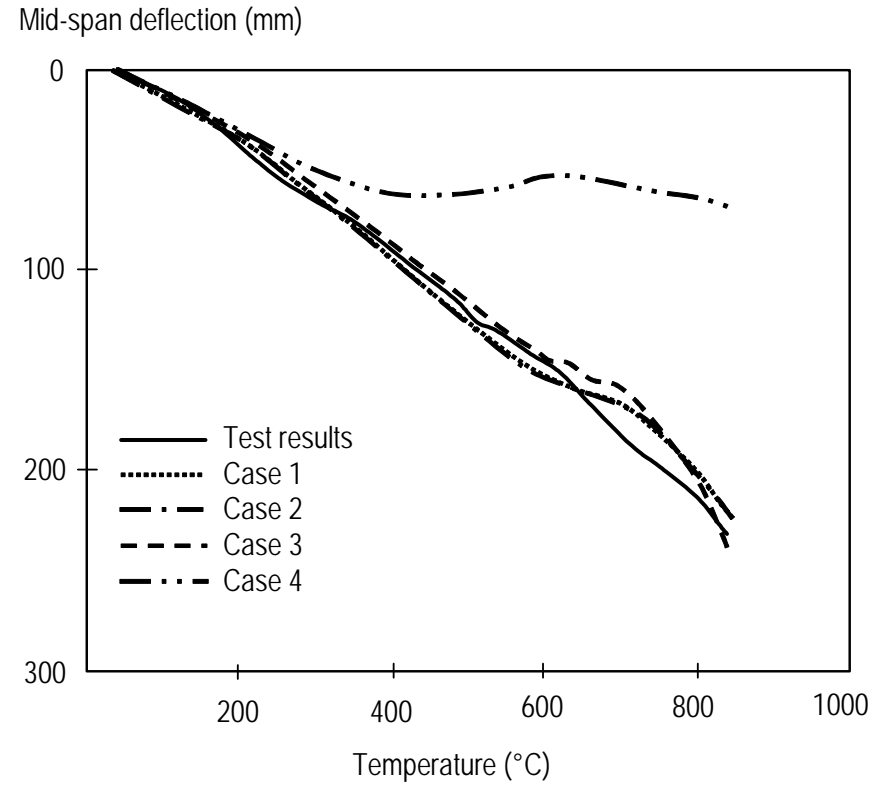

Figure 5. Comparison of predictions with measured mid-span deflections for the different non-linear sub-structures analysed in the Restrained Beam Test. 
the steel loses strength rapidly, the deflections cease as the heated zone effectively re-distributes its load to the surrounding elastic material.

In order to examine local failure behaviour the slab cracking patterns shown in the normal modelling (Case 1) and the most moderate of the other cases (Case 2) are shown at ambient temperature and at the final stage, when the beam lower flange is at $835^{\circ} \mathrm{C}$. Nine Gauss integration points are used for each slab element, and at these positions the development of cracking or crushing in the concrete can be detected in the non-linear sub-structure. Figures 6(a)-(d) and Figures 7(a)-(d) show schematically the cracking and crushing patterns at the top and bottom of the floor slab at ambient temperature and a beam lower flange temperature of $835^{\circ} \mathrm{C}$ for Cases 1 and 2 respectively. It can be seen that there is some cracking of the concrete slabs at ambient temperature, which of course includes both the test area and the surrounding cool structure. At the final temperature there is considerably more cracking, and some small zones of concrete crushing. It is interesting to observe that the failure patterns of the concrete slabs within the non-linear substructures for both cases are very similar.

Figures 8(a)-(d) show the vector plot of distribution of principal membrane tractions (forces per unit width of slab) at the Gauss points of the slab elements, both at ambient temperature and at a beam lower flange temperature of $835^{\circ} \mathrm{C}$ for Cases 1 and 2 respectively. In the figures the lengths of the vectors are proportional to their magnitudes; thin vector lines denote tension and thick lines denote compression. It can be seen that at ambient temperature the slabs above the secondary and primary beams act very much in line with the normal engineer's assumption for the flanges of composite beams, being in compression parallel to the beam. This reduces somewhat in the areas mid-way between parallel beams due to the well-known phenomenon of shear lag. In contrast, it can be seen that at high temperature (beam lower flange $835^{\circ} \mathrm{C}$ ) very high compressive tractions are formed in the slab surrounding the edges of the fire compartment, and within the fire compartment the compressive tractions gradually reduce from the edges into the central areas. It is evident that the distributions of membrane tractions of the concrete slabs within the non-linear substructures are very similar for both cases. This suggests that the behaviour of structure in the fire compartment is mainly influenced by its immediate surroundings, which can be included within the non-linear sub-structure, and that the use of a linear super-element outside this zone is justifiable.
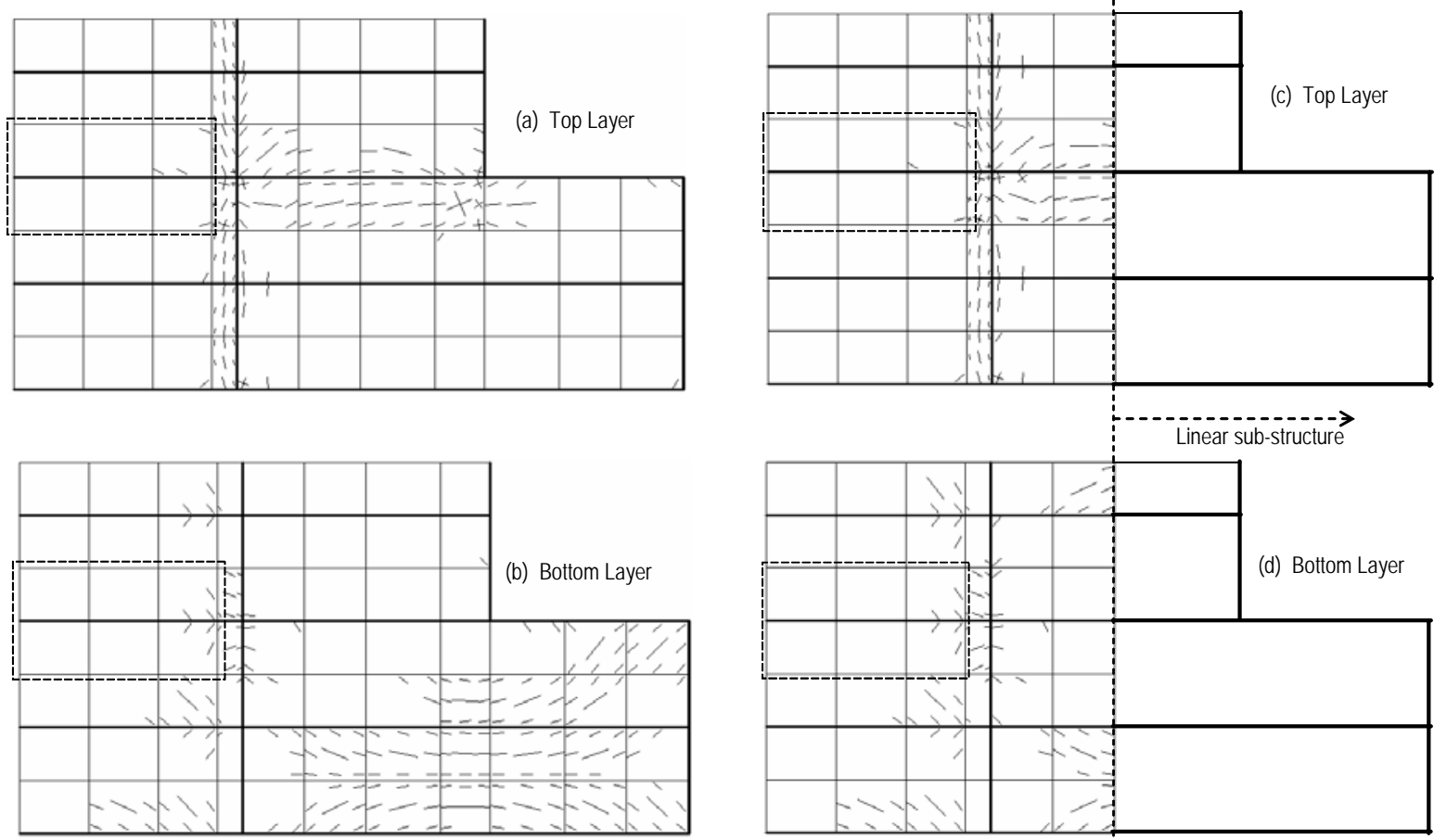

Figure 6. Predicted cracking patterns of top and bottom layers of floor slab at $20^{\circ} \mathrm{C}$ in the Restrained Beam Test for Case 1 (a, b) and Case 2 (c, d). 

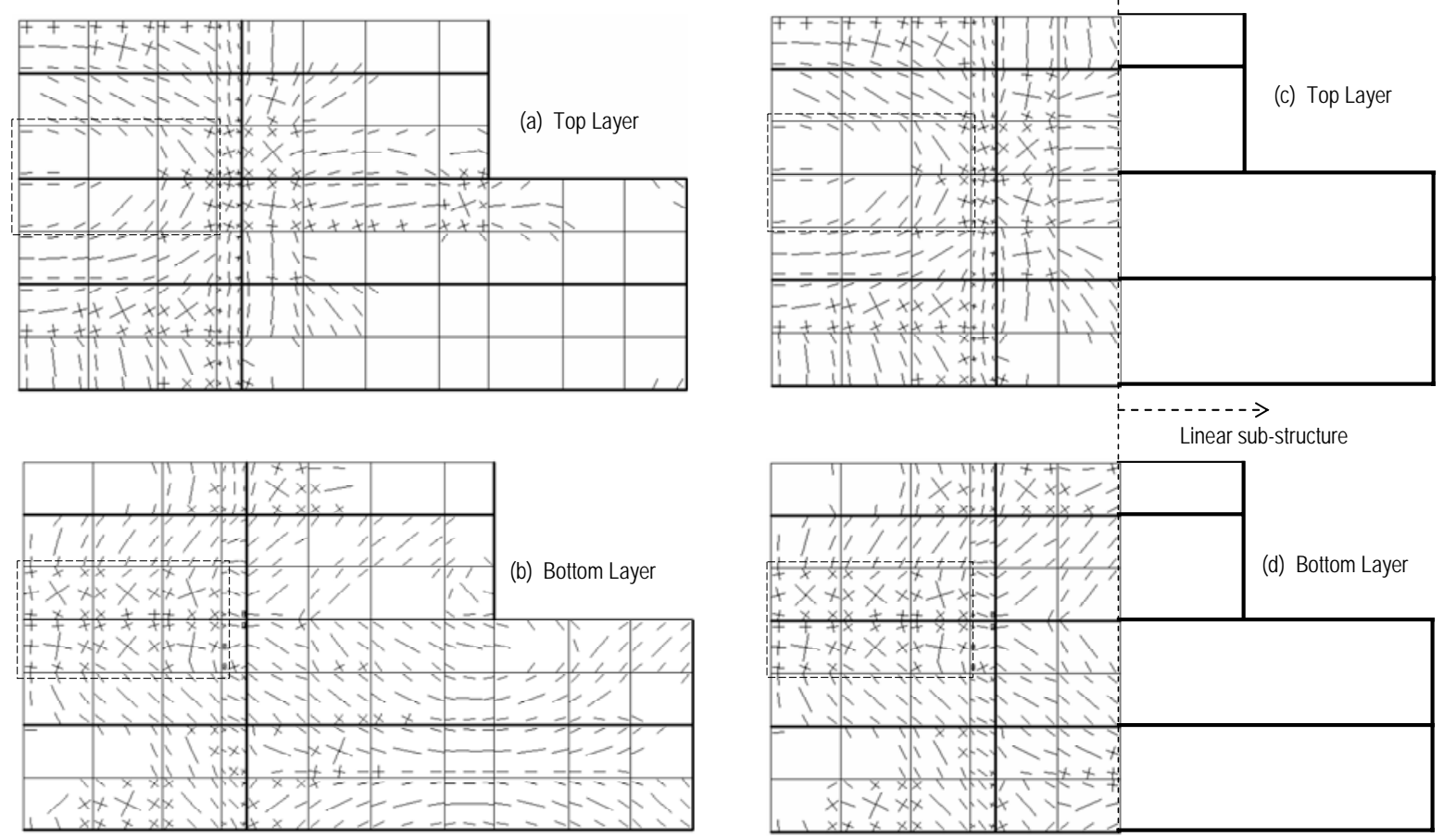

Figure 7. Predicted cracking patterns of top and bottom layers of floor slab at beam temperature $835^{\circ} \mathrm{C}$ in the Restrained Beam Test for Case 1 (a, b) and Case 2 (c, d).
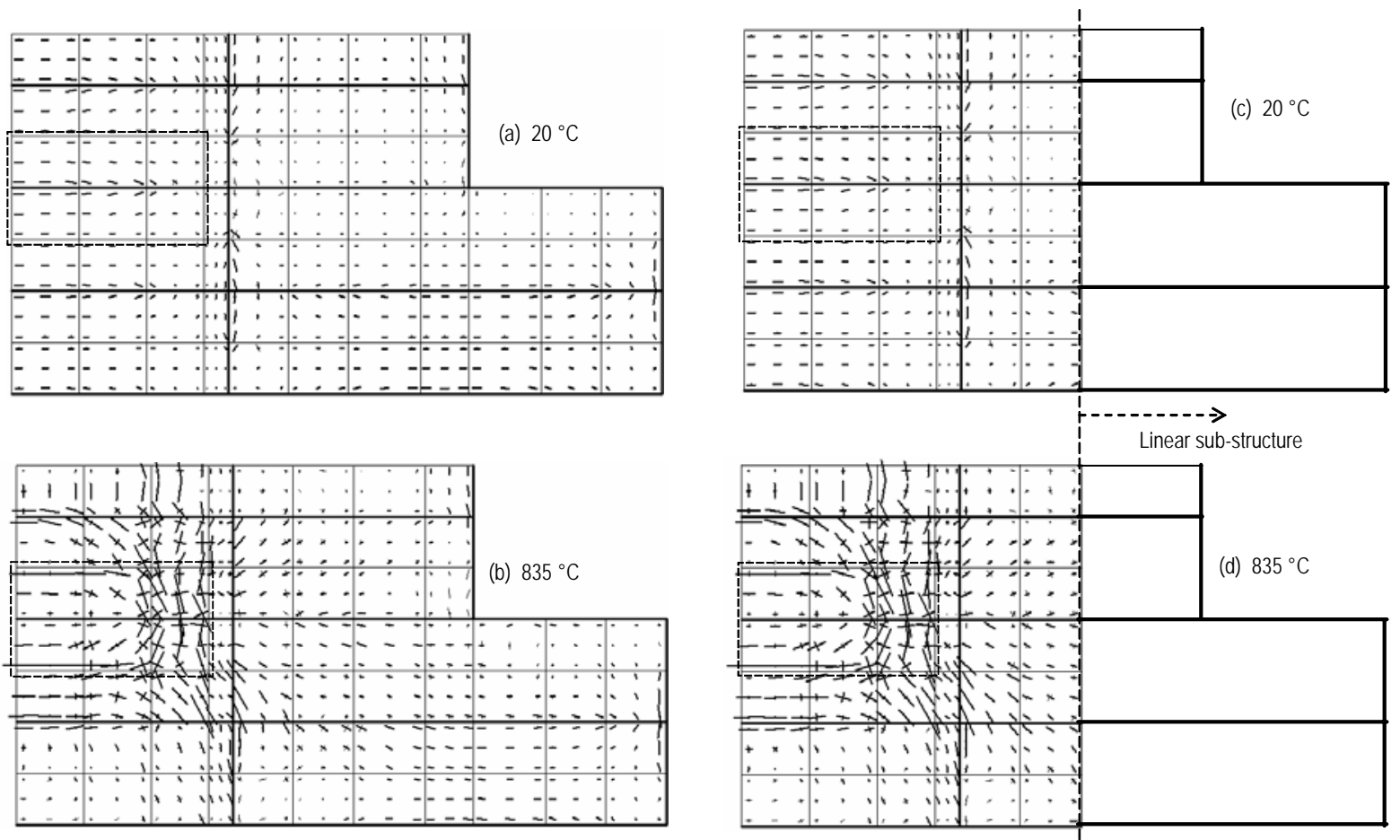

Figure 8. Predicted distribution of principal membrane tractions at $20^{\circ} \mathrm{C}$ and $835^{\circ} \mathrm{C}$ in the Restrained Beam Test for Case 1 (a, b) and Case 2 (c, d). (thick line=compression; thin line=tension).

Use of the super-element had the effect not only of reducing the total elements and nodes needed for the analysis but also of making the non-linear procedure more stable and of reducing the average number of iterations needed for each step. 


\section{MODELLING OF THE “BRITISH STEEL CORNER TEST”}

In July 1995 a fire test (Test 3 of the British Steel series) was carried out [22, 23] in a compartment of dimensions $9.98 \mathrm{~m} \times 7.57 \mathrm{~m}$ in a corner bay of the structure. The walls of the fire compartment, shown schematically in Figure 3, were constructed using lightweight concrete blockwork, the top of which was detached from the structure above so as to allow free deflection. The columns and building-edge beams were wrapped with ceramic fibre, but all other structural elements were left unprotected. The test used timber cribs giving an overall fire load of $45 \mathrm{~kg} / \mathrm{m}^{2}$ to produce a natural fire. During the fire test the maximum recorded atmosphere temperature in the compartment was $1028^{\circ} \mathrm{C}$, which occurred after 80 minutes. Steel temperatures and structural deflections were recorded at key locations and at required intervals throughout the test, providing information for comparison with analytical results. A description of the test, and comprehensive records of measured temperatures and deflections, are given in Refs. 22 and 23.

The test location, the extent of the structure incorporated within the numerical modelling, and the finite element mesh layout are shown in Figures 3 and 9. The ambient-temperature material properties are identical to those given for the Restrained Beam Test. The uniform floor load of $5.48 \mathrm{kN} / \mathrm{m}^{2}$ was again applied using sandbags. In order to rationalise the test temperature profiles of beams and columns (see Figure 9 for the beam positions) the following assumptions were made:

- $\quad$ Unprotected beams B1/2, B2, and BE have the same temperature distributions, in which the maximum temperatures of the bottom flange, web and top flange are $900^{\circ} \mathrm{C}, 860^{\circ} \mathrm{C}$, and $800^{\circ} \mathrm{C}$ respectively.

- Protected beams B1 and BF have the same temperature distributions, in which the maximum temperatures of the bottom flange, web and top flange were $250^{\circ} \mathrm{C}, 180^{\circ} \mathrm{C}$, and $110^{\circ} \mathrm{C}$ respectively.

- The cross-sections of all protected columns have uniform temperature distributions with a maximum temperature of $160^{\circ} \mathrm{C}$.

- $\quad$ The average test temperature distribution through the thickness of the concrete slab was used at each stage, with the maximum temperatures of the bottom and top layers at $360^{\circ} \mathrm{C}$ and $70^{\circ} \mathrm{C}$ respectively. In the following text the temperature quoted in all figures refers to the temperature of the bottom flange of the hottest beams.

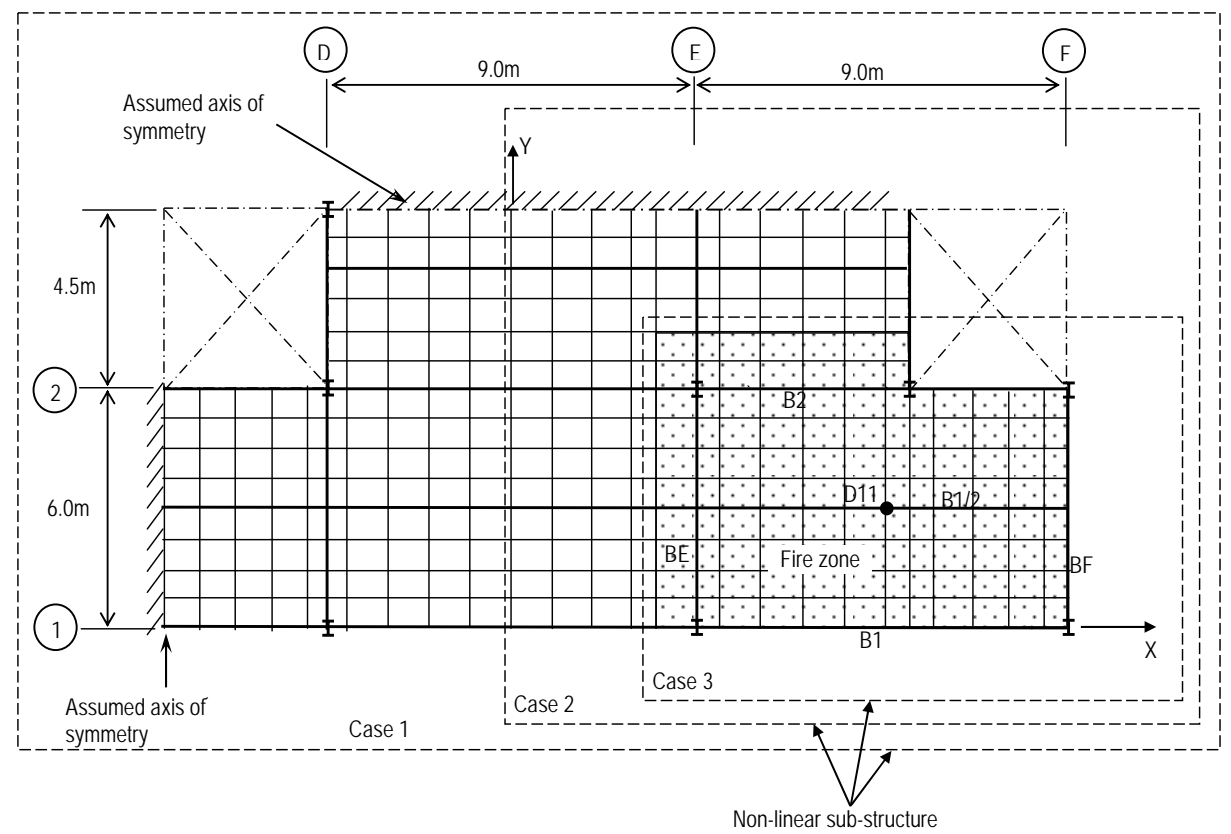

Figure 9. Finite element layout adopted in the analysis for British Steel Corner Test, together with the locations of non-linear sub-structures for the three cases studied. 
In this example three cases, which are illustrated in Figure 9, have been analysed. In Case 1 (normal modelling) the whole sub-frame was modelled as a non-linear sub-structure, while different sizes of non-linear sub-structure were employed for Cases 2 and 3. Their basic statistics, including run-times, are given in Table 2.

Table 2. Cardington British Steel Corner Test: performance using different super-elements.

\begin{tabular}{|l|c|c|c|c|c|c|}
\hline \multirow{2}{*}{ Case } & \multicolumn{2}{|c|}{ Elements } & \multicolumn{2}{c|}{ Nodes } & \multicolumn{2}{c|}{ Run-time } \\
& $\begin{array}{c}\text { Non-linear } \\
\text { sub-frame }\end{array}$ & $\begin{array}{c}\text { Super- } \\
\text { element }\end{array}$ & $\begin{array}{c}\text { Non-linear } \\
\text { sub-frame }\end{array}$ & $\begin{array}{c}\text { Super- } \\
\text { element }\end{array}$ & & (\%) \\
\hline 1 (normal) & 334 & 0 & 532 & 0 & 1800 & 100.0 \\
\hline 2 & 226 & 108 & 387 & 145 & 236 & 13.1 \\
\hline 3 & 134 & 200 & 250 & 282 & 212 & 11.7 \\
\hline 1 (re-numbered) & 334 & 0 & 532 & 0 & 851 & 47.0 \\
\hline
\end{tabular}

The deflections at position D11, which is the mid-span of heated beam B1/2 are plotted in Figure 10 against the temperature of the bottom flange of this beam for all three cases, together with the measured test result. It can be seen that the three modelling cases produced almost identical results, the only small difference appearing for temperatures above $800^{\circ} \mathrm{C}$. There was a significant saving of run-time for Case 2, at $13.1 \%$ of the time for Case 1 (normal modelling). For Case 3 a further saving was achieved, at only $11.7 \%$ of the time for Case 1 , but with a sacrifice of some accuracy in the analysis. The normal modelling, Case 1, was re-run after simply re-numbering the mesh, and the run-time in this case was 851 minutes, or $47 \%$ of that for Case 1 .

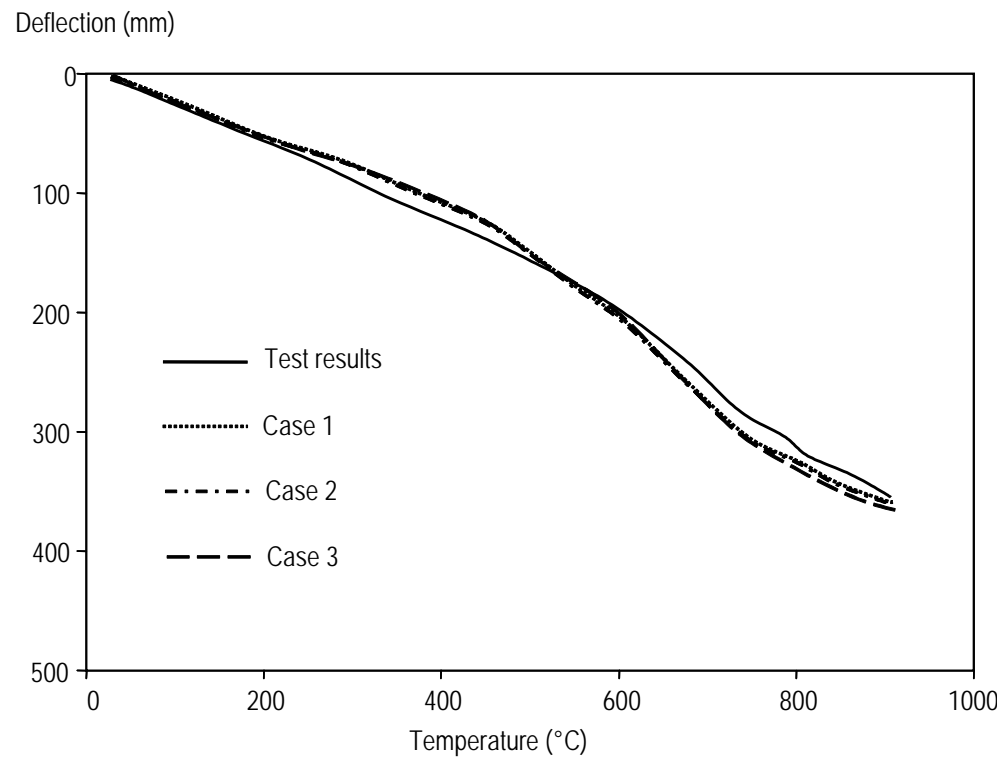

Figure 10. Comparison of predictions with measured deflections at position D11 for different non-linear sub-structures analysed for the British Steel Corner Test.

Once again the cracking and crushing patterns of the top and bottom layers of the floor slab, at ambient temperature and at a beam lower flange temperature of $900^{\circ} \mathrm{C}$, are shown in Figures $11(\mathrm{a})$ (d) and Figures 12(a)-(d) for Cases 1 and 2 respectively. As for the Restrained Beam Test the failure patterns of the concrete slabs within the non-linear sub-structures for both cases were very similar. Figures 13(a)-(d) show the distributions of principal membrane tractions at ambient temperature and at a beam lower flange temperature of $900^{\circ} \mathrm{C}$ for Cases 1 and 2 respectively. The distribution of the two principal membrane tractions in the slab at a heated beam lower flange temperature of $900^{\circ} \mathrm{C}$ shows that the load-carrying mechanism has very visibly changed at this high-temperature stage of the structural action. It can be seen from Figure 10 that, when the temperatures of the steel beam were less than $700^{\circ} \mathrm{C}$ and the vertical deflections were less than 
$300 \mathrm{~mm}$, there was little influence of geometric non-linearity on the load-carrying mechanism. On further increase of temperature, when the steel beams had lost most of their strength, the loads above fire compartment were largely carried by the floor slab rather than by composite bending. In this corner test little in-plane restraint was capable of being provided by surrounding cool structure, and so the floor slabs within the corner bay need to be almost self-equilibrating in the horizontal plane. This means that the tensile membrane tractions within the central zone of the floor slab are balanced by the compression forces formed around the perimeter of the fire compartment. These are made possible by the presence of vertical support due to the protected beams, which forces the slab to deform in double curvature and thus to generate the membrane traction fields shown in Figures 13(b) and (d). The load-carrying capacity of the slabs was increased significantly due to this tensile membrane action, in which the anti-cracking reinforcement mesh is a key component. Once more the distributions of membrane tractions of the concrete slabs within the non-linear substructures for both cases are very similar.

(a) Top Layer

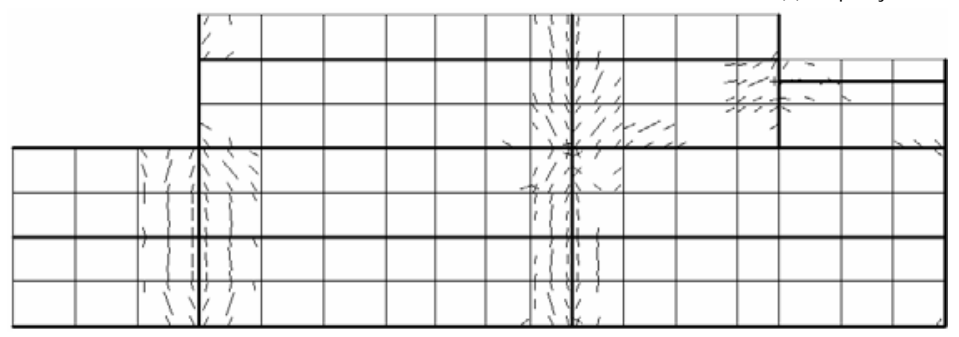

(b) Bottom Layer

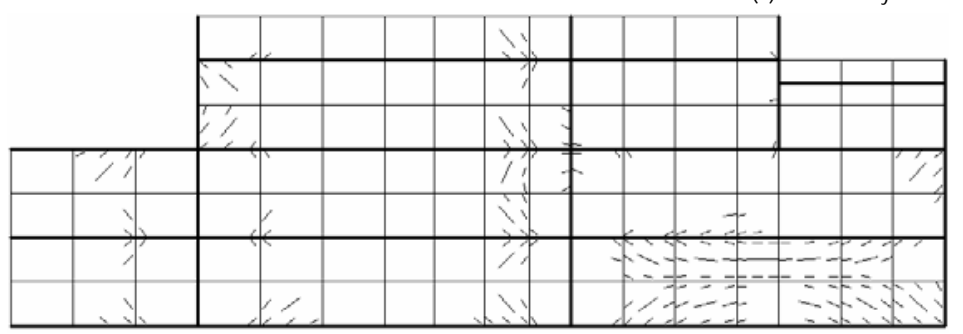

(c) Top Layer

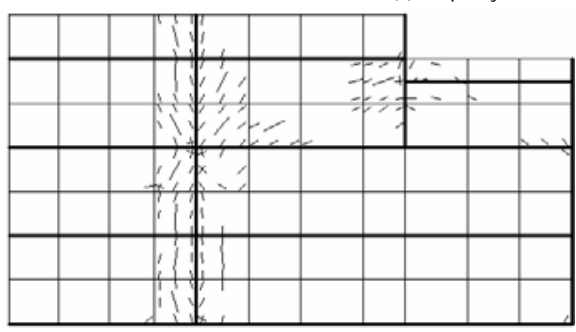

(d) Bottom Layer

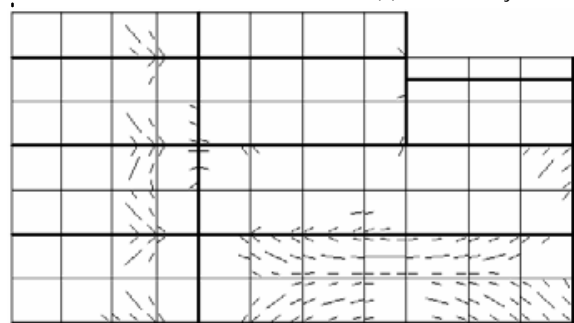

Figure 11. Predicted cracking patterns of top and bottom layers of floor slab at $20^{\circ} \mathrm{C}$ in the British Steel Corner Test for Case 1 (a, b) and Case 2 (c, d).

(a) Top Layer

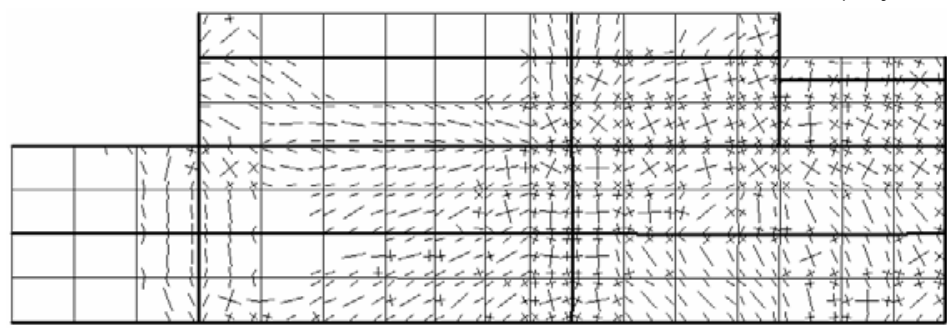

(b) Bottom Layer

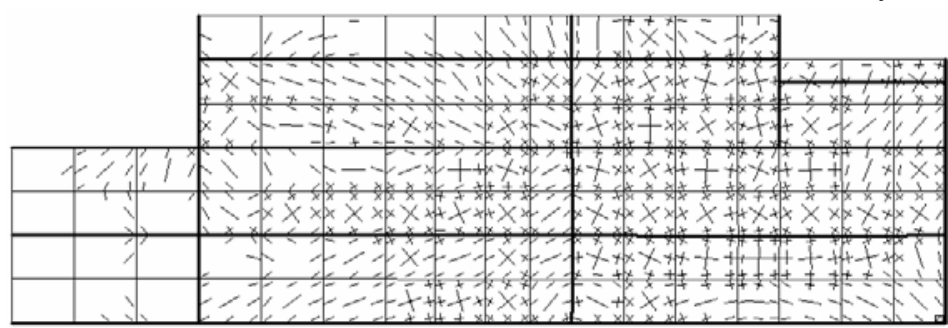

(c) Top Layer

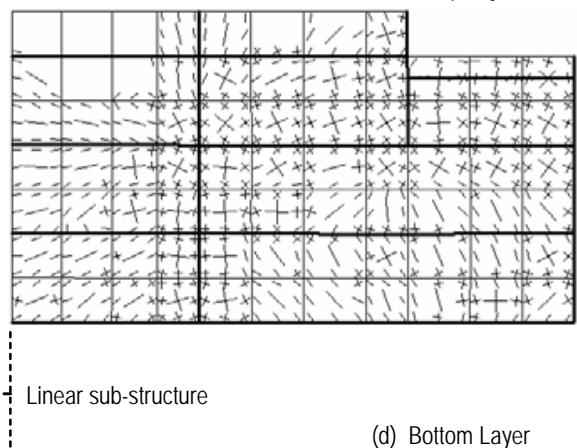

(d) Bottom Layer

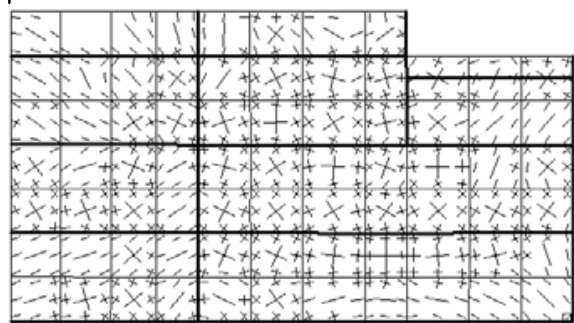

Figure 12. Predicted cracking patterns of top and bottom layers of floor slab at beam lower flange temperature $900^{\circ} \mathrm{C}$ in the British Steel Corner Test for Case 1 (a, b) and Case 2 (c, d). 
(a) $20^{\circ} \mathrm{C}$

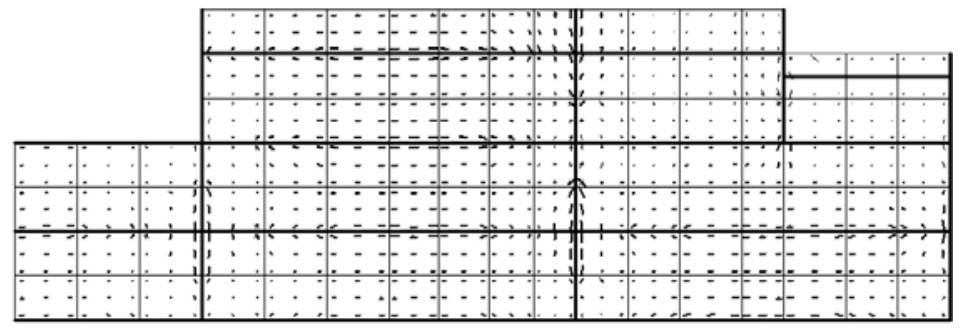

(b) $900^{\circ} \mathrm{C}$

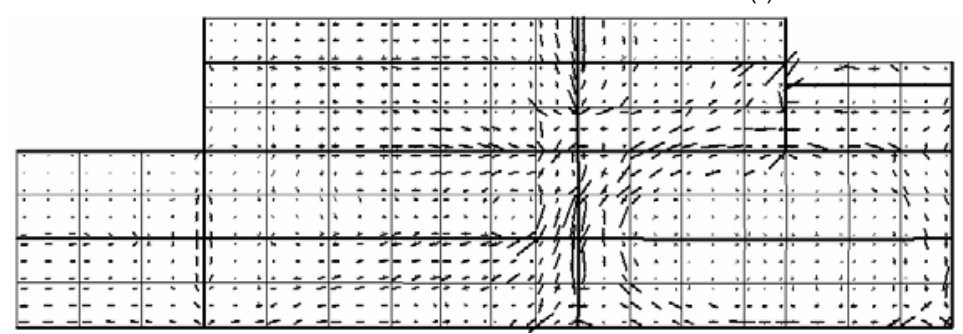

(c) $20^{\circ} \mathrm{C}$

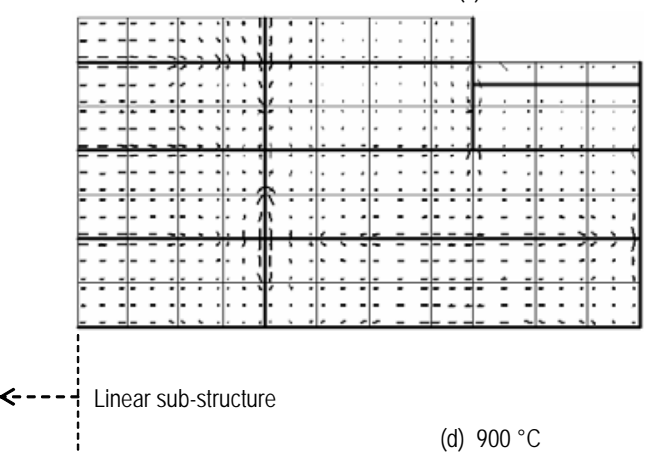

(d) $900^{\circ} \mathrm{C}$

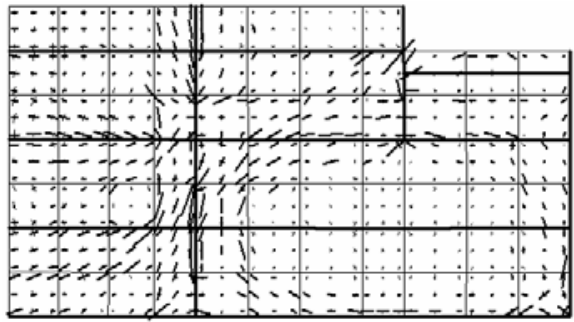

Figure 13. Predicted distribution of principal membrane tractions at $20^{\circ} \mathrm{C}$ and $900^{\circ} \mathrm{C}$ in the British Steel Corner Test for Case 1 (a, b) and Case 2 (c, d). (thick line=compression; thin line=tension).

Comparing Case 3 of the Corner Bay test with Case 4 of the Restrained Beam test, both represent extreme situations in which all elements outside the fire compartment are included within the elastic super-element. In the Corner Bay the fire zone was much more extensive than in the Restrained Beam Test so there was less opportunity for loads in the fire zone to be redistributed to the surrounding cool structure. Additionally, there was little in-plane restraint to thermal expansion of components within the fire compartment, whereas for the Restrained Beam Test a completely surrounding cool slab provided considerable restraint of this kind. It can be seen that the main influence of the surrounding cool structure was to provide structural continuity, especially in the concrete slab floors, to the two interior edges of the fire compartment. It is therefore logical that the Corner Bay Test results should be less affected by the modelling of the cool adjacent structure than were those from the Restrained Beam Test, so that Case 3 is modelled with almost the same accuracy as Case 1. This contrasts markedly with the Restrained Beam Test, in which thermal expansion is resisted and there is an obvious mechanism available for redistribution of loading.

\section{CONCLUSIONS}

This paper illustrates the use of the sub-structuring technique and a re-numbering algorithm to increase the efficiency of modelling the structural behaviour of buildings in fire conditions. In this process a user-defined cool region of the structure is sub-structured and condensed as a linear super-element with connecting nodes which interact with the non-linear sub-structure representing the fire zone, plus a border zone of unheated elements. The procedure has been incorporated into Vulcan and two full-scale fire tests have been modelled, both to show the computational efficiency of the method and to investigate the principles which control selection of super-elements. This depends on the way in which restraint from the surrounding structure resists thermal expansion of the fire compartment and provides support which diverts load paths away from the heated members. From the modelling of two full-scale fire tests it has been seen that, if the surrounding cool structure is capable of providing high restraint to thermal expansion of the fire compartment (as in the Restrained Beam Test), this has a very important influence on the behaviour of the heated structure. Of course, the structural continuity provided by the adjacent structure is also important. For fire compartments subjected to very little in-plane restraint (as in the British Steel Corner Test) 
structural continuity is the only major factor influencing the structural behaviour in the fire compartment. It is reasonable to conclude that, in order to achieve accurate analytical results for small fire compartments with high restraint from surrounding cool structure the non-linear mesh zone should extend well (at least three to four elements) beyond the fire compartment. However, for large fire compartments with little restraint the non-linear sub-structure can extend no further than the edges of the fire compartment.

It is evident that using this sub-structuring technique to represent the cool structure adjacent to a fire compartment is one of the building blocks in increasing the efficiency of modelling of structures in fire. The re-numbering procedure based on the model proposed by Burgess and Lai [16] is computationally efficient, and it is important when modelling three-dimensional building structures to attempt to create as optimal a numbering system as is feasible. The procedure proposed in this paper is a combination of sub-structuring and re-numbering, and should therefore maximise computational efficiency as much as possible for any given hardware and solution scheme. In the examples analysed savings of computing run-time of the order of 5 to 10 times were achieved. Within the Vulcan software the introduction of the frontal solution method into the super-element procedure also makes it capable of modelling very large problems without any difficulty.

\section{REFERENCES}

[1] “ISO 834: Fire resistance tests - elements of building construction", International Organisation for Standardisation, 1985.

[2] Najjar, S.R. and Burgess, I.W., "A non-linear analysis for three-dimensional steel frames in fire conditions”, Engineering Structures, 1996, 18(1), pp.77-89.

[3] Bailey, C.G., "Simulation of the structural behaviour of steel-framed buildings in fire”, $\mathrm{PhD}$ Thesis. University of Sheffield, 1995.

[4] Huang, Z., Burgess, I.W. and Plank, R.J., "Non-linear analysis of reinforced concrete slabs subjected to fire”, ACI Structural Journal, 1999, 96(1), pp.127-135.

[5] Huang, Z., Burgess, I.W. and Plank, R.J., "Influence of shear connectors on the behaviour of composite steel-framed buildings in fire", Journal of Constructional Steel Research, 1999, 51(3), pp.219-237.

[6] Huang, Z., Burgess, I.W. and Plank, R.J., "Modelling membrane action of concrete slabs in composite buildings in fire. Part I: Theoretical development", Journal of Structural Engineering, ASCE, 2003, 129(8), pp.1093-1102.

[7] Huang, Z., Burgess, I.W. and Plank, R.J., "Modelling membrane action of concrete slabs in composite buildings in fire. Part II: Validations”, Journal of Structural Engineering, ASCE, 2003, 129(8), pp.1103-1112.

[8] Huang, Z., Burgess, I.W. and Plank, R.J., “3D Modelling of beam-columns with general cross-sections in fire”, Structures in Fire, Proceedings of the Third International Workshop, Ottawa, Canada, 2004, pp.323-334.

[9] Huang, Z., Burgess, I.W. and Plank, R.J., "Modelling of six full-scale fire tests on a composite building”, The Structural Engineer, 2002, 80(19), pp.30-37.

[10] Dodds, R.H. and Lopez, L.A., "Sub-structuring in linear and non-linear analysis", International Journal for Numerical Methods in Engineering, 1980, 15, pp.583-597.

[11] Sheu, C.H. et al., "Application of the sub-structuring technique to non-linear dynamic structural analysis”, Computers \& Structures, 1990, 35(5), pp.593-601.

[12] Behin, Z. and Murray, D.W., "A sub-structure-frontal technique for cantilever erection analysis of cable-stayed bridges”, Computers \& Structures, 1992, 42(2), pp.145-157. 
[13] Liu, X.L. and Lam, Y.C., "Condensation algorithms for the regular mesh sub-structuring”, International Journal for Numerical Methods in Engineering, 1995, 38, pp.469-488.

[14] Bathe, K.J., “Finite element procedures”, Prentice-Hall Inc., New Jersey, 1996.

[15] Hinton, E. and Owen, D.R.J., "Finite element programming”, Academic Press, London, 1977.

[16] Burgess, I.W. and Lai, P.K.F., “A new node re-numbering algorithm for bandwidth reduction”, International Journal for Numerical Methods in Engineering, 1986, 23, pp.16931704.

[17] Gibbs, N.E., Poole, W.G. and Stockmeyer, P.K., "An algorithm for reducing the bandwidth and profile of a sparse matrix”, SIAM Journal of Numerical Analysis, 1976, 13, pp.236250.

[18] Cuthill, E.H. and McKee, J.M., "Reducing the bandwidth of sparse symmetric matrices", Proceeding of 24th National Conference ACM., Barndon Systems Press, New Jersey, 1969, pp.157-172.

[19] Cheng, K.Y., "Note on minimizing the bandwidth of sparse symmetric matrices", Computing, 1973, 11, pp.27-30.

[20] Bentley, P.K., Shaw, D. and Tomlinson, I., "ECSC project: behaviour of a multi-storey steel framed building subjected to natural fires. Test 1: restrained beam, data files: temperature measurements”, Report S423/1/Part T1, Swinden Technology Centre, British Steel plc, Rotherham, UK, 1995.

[21] Bentley, P.K., Shaw, D. and Tomlinson, L., "ECSC project: behaviour of a multi-storey steel framed building subjected to natural fires. Test 1: restrained beam, data files: deflection measurements”, Report S423/1/Part D1, Swinden Technology Centre, British Steel plc, Rotherham, UK, 1995.

[22] Bann, M.S., Bentley, P.K., Shaw, D. and Tomlinson, L., "ECSC project: behaviour of a multi-storey steel framed building subjected to natural fires. Test 3: corner compartment, data files: temperature measurements”, Report S423/3/Part T1-T3, Swinden Technology Centre, British Steel plc, Rotherham, UK, 1996.

[23] Bentley, P.K., Shaw, D. and Tomlinson, L., "ECSC project: behaviour of a multi-storey steel framed building subjected to natural fires. Test 3: corner compartment, data files: deflection/displacement measurements”, Report S423/3/Part D1, Swinden Technology Centre, British Steel plc, Rotherham, UK, 1996. 


\title{
STEEL-CONCRETE COMPOSITE BEAMS PRESTRESSED BY EXTERNAL TENDONS: EFFECTS OF MATERIAL AND GEOMETRIC NONLINEARITIES
}

\author{
Andrea Dall'Asta ${ }^{1, *}$, Laura Ragni ${ }^{2}$ and Alessandro Zona ${ }^{1}$ \\ ${ }^{1}$ Dipartimento di Progettazione e Costruzione dell'Ambiente, Università di Camerino \\ Viale delle Rimembranza, 63100, Ascoli Piceno, Italy. \\ *(Corresponding author: E-mail: andrea.dallasta@unicam.it) \\ ${ }^{2}$ Dipartimento di Architettura, Costruzioni e Strutture, Università Politecnica delle Marche \\ Via Brecce Bianche 60131, Ancona, Italy.
}

\begin{abstract}
The analysis of externally post-tensioned beams is characterized by some specific issues related to the coupling between the local strain of the cable and the global deformation of the structure. Collapse modalities are influenced by the nonlinear behavior of materials and in many cases by non-negligible geometric nonlinear effects. The authors present a model for externally prestressed steel-concrete composite beams that includes geometric and material nonlinearities. The proposed model is based on the theory of small strains and moderate rotations obtained from the exact nonlinear theory. Comparisons with experimental tests are shown to validate the results obtained with the proposed formulation. Some numerical applications involving simply supported and two-span continuous composite beams post-tensioned with external cables are discussed to illustrate the nonlinear geometric effects and their influence on the ultimate capacity.
\end{abstract}

Keywords: External prestressing, steel-concrete composite beams, nonlinear analysis, material nonlinearity, geometric nonlinearity, finite elements.

\section{INTRODUCTION}

Externally prestressed steel-concrete composite members have been used since the late 1950s in buildings and bridge construction (e.g., Szilard [1], Hoadley [1]). External post-tensioning gives many advantages in new composite constructions, e.g., elastic behavior extended to higher loads, increased ultimate capacity, smaller deflections under service loads, reductions in beam depth and structural weight, control of deck cracking in continuous beams. These benefits may offset the extra costs of cables and deviators, and offer solutions of high aesthetic value. In addition external post-tensioning is extensively applied in existing bridges to reinforce damaged structures or to increase the ultimate capacity when larger than designed loads are applied (e.g., Berridge and Donovan [3], Mancarti [4]). Moreover, in new and old structures, it is possible to replace cables or to adjust their force whenever required.

The analysis of externally post-tensioned beams is characterized by a number of specific features. External tendons interact with the beam at anchorages and deviators only. Tendon-deviator relative slips are not prevented since negligible friction occurs in many common cases (e.g., Conti et al. [5]). Thus the local strain of the cable depends on the global deformation of the beam-tendon structural system. As a result a global analysis is required, where the balance conditions of the whole system replace the differential equations of the cross-section equilibrium.

At serviceability the displacements and strains of the beam-tendon system are small and the increment in tendon force can be neglected. In this case an approximate structural analysis can easily be performed by considering the effect of the cable on the beam as constant external equivalent loads and by carrying out a local linear analysis. At the ultimate state the prestressed system undergoes large deflections; as a consequence the cable traction increases and the beamtendon relative position between two consecutive deviators changes considerably. Therefore geometric nonlinear effects as well as material nonlinearities cannot be neglected in a global analysis at collapse. 
In the scientific literature there are a number of models including the nonlinear behavior of materials in the analysis of concrete or composite beams prestressed by external tendons. From simplified methods, such as Virlogeux [6], Saadatmanesh et al. [7], Ayyub et al. [8][9], to more general approaches considering different cable patterns and static schemes, such as Dall'Asta and Dezi [10]. The effects at collapse of geometric nonlinearities was included in few recent papers dealing with concrete beams only. From simplified iterative approaches where cable eccentricity is updated at each load step, such as Alkhairi and Naaman [11] and Harajli et al. [12], to more general models based on the finite element method where the cable position changes with respect to the beam when the system deflects (Ramos and Aparicio [13], Ariyawardena and Ghali [14]). These papers start from the geometric linear theory and then include the effect of the variation of the cable eccentricity that occurs when the beam deflects.

The aim of this work is to introduce a beam model for describing all the geometric nonlinear effects by means of a more rigorous method: the formulation for the beam-tendon system is deduced from the finite deformation theory (large displacements and finite strains). For this purpose a material and geometric nonlinear model within the finite deformation theory is first described, with reference to steel-concrete composite beams. The balance equations obtained are formally simple but their solution is quite complex. For simplifying the numerical solution, a reduced formulation based on the theory of small strains and moderate rotations (Naghdi and Vongsarnpigoon [15], Marzano and De Tommasi [16]) is afterward derived; hypotheses of small strain (up to 1/200) and moderate rotations (up to 1/20) are limitations compatible with the displacements observed at collapse in experimental tests. The weak form of the balance condition is obtained by considering the total Lagrangian formulation and the numerical solution is sought with a displacement-based finite element formulation (Dall'Asta and Zona [17]). The numerical model implemented is verified by comparison with experimental tests. Some numerical applications to simply supported and two-span continuous composite beams post-tensioned with external cables are reported to discuss the influence on the ultimate capacity of nonlinear geometric effects together with material nonlinearities affecting a reduction of stiffness and the redistribution of internal stress.

\section{ANALYTICAL MODEL}

\subsection{Nonlinear Kinematics}

The present formulation describes the behavior of a rectilinear beam prestressed by external tendons with generic path. Tendons are anchored at the beam ends and their profile is defined by a certain number of saddle points at which they can slip with negligible friction. The problem is assumed to be symmetric with respect to the vertical plane containing the beam axis. The analysis is carried out by assuming a Kirchhoff model for the beam deformation (i.e., the cross section remains plane and orthogonal to the beam axis after deformation) and no limits on amplitude of displacements and strain are assumed. Let $\left\{\mathrm{O}: \mathbf{A}_{\mathrm{i}}, \mathrm{i}=1,2,3\right\}$ be a fixed orthonormal basis, where $\mathbf{A}_{3}$ is parallel to the beam axis and $\mathbf{A}_{1} \mathbf{A}_{3}$ is the plane of symmetry of the system. The position of a generic point $\left(X_{1}, X_{2}, S\right)$ of the beam in the reference configuration is given by

$$
\mathbf{R}\left(X_{\beta} ; S\right)=S \mathbf{A}_{3}+X_{\beta} \mathbf{A}_{\beta}=\mathbf{R}_{0}+X_{\beta} \mathbf{A}_{\beta} \quad(\beta=1,2)
$$

where $\left(X_{1}, X_{2}\right) \in \mathrm{A}$ and $S \in[0, L]$, being $\mathrm{A} \subset \mathrm{R}^{2}$ the domain of the cross section of the beam and $L$ the beam length. A pair of external cables are considered and modeled as a unique tendon on the symmetry plane of the system. Its profile is described by the following piecewise linear function

$$
\mathbf{H}(S)=\mathbf{H}_{d-1}+\frac{\mathbf{H}_{d}-\mathbf{H}_{d-1}}{\left|\mathbf{H}_{d}-\mathbf{H}_{d-1}\right|}\left(S-S_{d-1}\right) \quad S \in\left[S_{\mathrm{d}-1}, S_{\mathrm{d}}\right]
$$

with $\mathbf{H}_{d}=\mathbf{R}_{d}$ where $\mathbf{R}_{d}=S_{d} \mathbf{A}_{3}+X_{2 d} \mathbf{A}_{2}(d=1, \ldots, D)$ are the position of $D$ beam points where 
the deviators and end anchorages are located (Figure 1). The total length of the tendon is

$$
L_{t}=\sum_{d}\left|\mathbf{R}_{d}-\mathbf{R}_{d-1}\right|=\sum_{d} \sqrt{\left[\Delta_{d}(S)\right]^{2}+\left[\Delta_{d}\left(X_{2}\right)\right]^{2}}
$$

The beam and the tendon are two different geometric entities that constrain each other, so that the system deformation is described by two coupled functions.

The deformed configuration of the beam, where the cross sections do not deform transversally, can be described by the following function (Simo [18], Simo and Vu-Quoc [19])

$$
\mathbf{r}\left(X_{\beta} ; S\right)=\mathbf{r}_{0}(S)+X_{\beta} \mathbf{Q}(S) \mathbf{A}_{\beta}
$$

where $\mathbf{r}_{0}(S)$ describes the deformed position of the beam axis and $\mathbf{Q}$ is the rotation matrix

$$
\mathbf{Q}(S)=\mathbf{I}+\sin \alpha(S) \boldsymbol{\Omega}+[1-\cos \alpha(S)] \mathbf{\Omega}^{2}
$$

that describes the section rotations (I is the identity operator and $\boldsymbol{\Omega}=\mathbf{A}_{2} \otimes \mathbf{A}_{3}-\mathbf{A}_{3} \otimes \mathbf{A}_{2}$ ). Consequently the displacements are

$$
\mathbf{u}\left(X_{\beta} ; S\right)=\left[v(S)-X_{2}(1-\cos \alpha)\right] \mathbf{A}_{2}+\left[w(S)-X_{2}(1-\sin \alpha)\right] \mathbf{A}_{3}
$$

where $v(S)$ and $w(S)$ are two scalar functions expressing the displacements of the beam axis in directions $\mathbf{A}_{2}$ and $\mathbf{A}_{3}$ respectively. From the assumption of orthogonality between cross sections and beam axis, the rotation is a function of the displacements

$$
\sin \alpha=\frac{v^{\prime}}{1+e} \quad \cos \alpha=\frac{1+w^{\prime}}{1+e}
$$

where the prime denotes the derivative with respect to $S$ and $e=\sqrt{v^{\prime 2}+\left(1+w^{\prime}\right)^{2}}-1$. Let $\mathbf{F}$ be the deformation gradient (Malvern [20])

$$
\mathbf{F}=\mathbf{Q} \mathbf{U}=\mathbf{Q}\left[\left(e+\alpha^{\prime} X_{2}\right) \mathbf{A}_{3} \otimes \mathbf{A}_{3}+\mathbf{I}\right]=\mathbf{Q}\left[\varepsilon \mathbf{A}_{3} \otimes \mathbf{A}_{3}+\mathbf{I}\right]
$$

where $\mathbf{U}$ is the deformation tensor and $\varepsilon$ the beam axial deformation. It is worth noting that the axial deformation $\varepsilon$ is the only non zero strain component.

The cable profile in the deformed configuration can be described by means of a piecewise linear function

$$
\mathbf{h}(S)=\mathbf{h}_{d-1}+\frac{\mathbf{h}_{d}-\mathbf{h}_{d-1}}{\left|\mathbf{h}_{d}-\mathbf{h}_{d-1}\right|}\left(S-S_{d-1}\right) \quad S \in\left[S_{\mathrm{d}-1}, S_{\mathrm{d}}\right]
$$

that is connected to the beam at the saddle points $\mathbf{h}_{d}=\mathbf{r}_{d}$ (i.e. anchorages and deviators). Because of the cable slip there is no correspondence between the material points at the position $\mathbf{H}(S)$ in the reference configuration and the material points at the position $\mathbf{h}(S)$ in the deformed configuration (Dall'Asta [21]). For this reason it is not trivial to deduce the deformed cable position. Nevertheless by assuming that the friction at the deviators is negligible the cable deformation is uniform and can be deduced from the total profile length only without quantifying the tendon slip at each deviator

$$
\varepsilon_{t}=\frac{1}{L_{t}} \sum_{d}\left(\left|\mathbf{r}_{d}-\mathbf{r}_{d-1}\right|-\left|\mathbf{R}_{d}-\mathbf{R}_{d-1}\right|\right)
$$

where

$$
l_{t}=\sum_{d}\left|\mathbf{r}_{d}-\mathbf{r}_{d-1}\right|=\sum_{d} \sqrt{\left[\Delta_{d}(S)+\Delta_{d}(w)-\Delta_{d}\left(X_{2} \sin \alpha\right)\right]^{2}+\left[\Delta_{d}(v)+\Delta_{d}\left(X_{2} \cos \alpha\right)\right]^{2}}
$$

with $l_{t}$ the cable length in the deformed configuration and $\Delta_{d}(\bullet)=(\bullet)_{d}-(\bullet)_{d-1}$. 


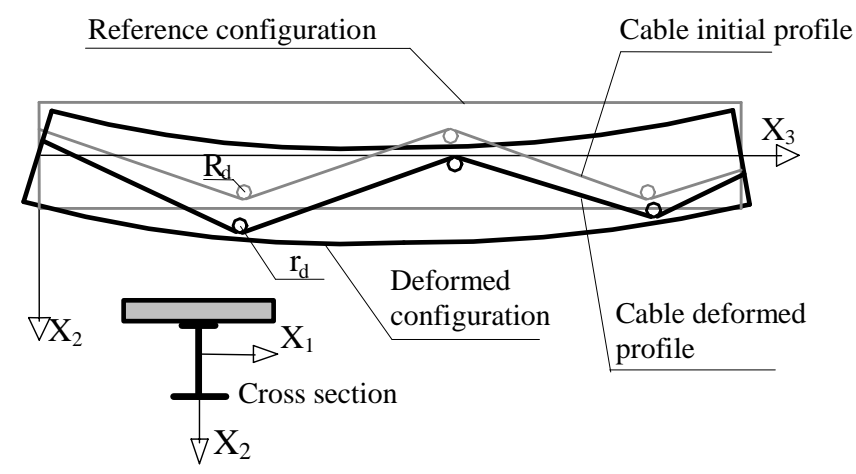

Figure 1. Beam with external prestressing

\subsection{Moderate Rotations Formulation}

The beam-tendon model previously illustrated is able to describe large deformations of the system without limitations on the displacement field. It is however rather complicated to obtain a numerical solution of the problem. In addition it can be observed that the collapse of beams usually used in bridge structures occurs when the maximum strains of materials are very small and attain values from about $0.2 \%$ to $1.0 \%$, while the maximum rotations of the cross sections are about $1 / 20$ that can be considered as a moderately small quantity. This makes it convenient to develop a simplified theory, able to describe real situations, by introducing some hypotheses on the displacement field. The aim of this paragraph is to develop an approximated nonlinear theory by considering the hypothesis that the symmetric and anti-symmetric parts of the displacement gradient have a different magnitude

$$
\mathbf{E}=\frac{1}{2}\left(\nabla \mathbf{u}+\nabla \mathbf{u}^{\mathrm{T}}\right)=\mathrm{O}(\eta) \quad \text { and } \quad \mathbf{W}=\frac{1}{2}\left(\nabla \mathbf{u}-\nabla \mathbf{u}^{\mathrm{T}}\right)=\mathrm{O}\left(\eta^{1 / 2}\right)
$$

where $\eta$ is a measure of smallness (Naghdi and Vongsarnpigoon [15]). Consequently the deformation tensor $\mathbf{U}$ and the rotations tensor $\mathbf{Q}$ can be approximated as

$$
\begin{aligned}
& \mathbf{U}=\mathbf{I}+\mathbf{E}-\frac{1}{2} \mathbf{W}^{2}+\mathrm{o}(\eta) \\
& \mathbf{Q}=\mathbf{I}+\mathbf{W}+\frac{1}{2} \mathbf{W}^{2}+\mathrm{o}(\eta)
\end{aligned}
$$

In other words $\mathbf{U}-\mathbf{I}=\mathrm{O}(\eta)$ and $\mathbf{Q}-\mathbf{I}=\mathrm{O}\left(\eta^{1 / 2}\right)$. This means that a local deformation is given by a small strain and a moderate rotation (Marzano and De Tommasi [16]).

With reference to the described beam model, assumption (12b) leads to the following formulas

$$
\sin \alpha=v^{\prime}+\mathrm{o}(\eta) \quad \cos \alpha=1-\frac{1}{2} v^{\prime 2}+\mathrm{o}(\eta)
$$

and the displacement field becomes

$$
\mathbf{u}=\left(v-\frac{1}{2} X_{2} v^{\prime 2}\right) \mathbf{A}_{2}+\left(w-X_{2} v^{\prime}\right) \mathbf{A}_{3}+o(\eta)
$$

while the strain of a generic fiber measured in its deformed configuration is given by

$$
\varepsilon=w^{\prime}+\frac{1}{2} v^{\prime 2}-X_{2} v^{\prime \prime}+\mathrm{o}(\eta)
$$

The difference with respect to the linear theory consists of the quadratic term that represents the axial strain of a generic fiber due to its rotation that can be added to the strain due to its axial deformability. Hence the vertical displacements of the beam influence its axial strain and this may be interpreted as a reduction of the beam axial stiffness caused by its deflection.

It is important to remark that limitations not only on the beam displacements but also on the beam 
geometry are necessary to obtain expression Eq. (16). In particular the following hypotheses are required

1. $w^{\prime}=\mathrm{O}(\eta)$;

2. $L v^{\prime \prime}=\mathrm{O}\left(\eta^{1 / 2}\right)$;

3. $X_{2} / L=\mathrm{O}\left(\eta^{1 / 2}\right)$.

From the second hypothesis derives $v^{\prime}=\mathrm{O}\left(\eta^{1 / 2}\right)$ and $v^{\prime 2}=\mathrm{O}(\eta)$ being $v^{\prime}=\int_{0}^{L} v^{\prime \prime} d z \leq L \sup \left(v^{\prime \prime}\right)$.

The last hypothesis on beam slenderness is necessary in Eq. (17) if the deformations are to remain small despite the fact that rotations are moderate. It is important to note that this hypothesis is acceptable in the cases in question. In fact, with reference to the beams used in bridge construction, depth-to-span ratios are about equal to $1 / 20$ which can be considered as moderately small quantities.

While the beam problem is already known, the extension of the small strains and moderate rotations theory to the cable terms needs further consideration. The simplified expression of the cable deformation measured in its deformed configuration is given by

$$
\varepsilon_{t}=\frac{1}{L_{t}}\left\{\sum_{d}\left[\Delta_{d}(S)+\Delta_{d}(w)+\frac{1}{2} \frac{\left[\Delta_{d}\left(X_{2}\right)+\Delta_{d}(v)\right]^{2}}{\Delta_{d}(S)}-\Delta_{d}\left(X_{2} v^{\prime}\right)\right]-L_{t}\right\}+\mathrm{o}(\eta)
$$

where $L_{t}$ is the tendon length in the reference configuration and can be written as

$$
L_{t}=\Delta_{d}(S)+\frac{\left[\Delta_{d}\left(X_{2}\right)\right]^{2}}{2}+\mathrm{o}(\eta)
$$

A geometric hypothesis, similar to the third hypothesis is also necessary for the cable. In particular the strain $\varepsilon_{t}$ remains small if the inclination of the cable profile is moderate, in the following sense

$$
\text { 4. } \frac{\Delta_{d}\left(X_{2}\right)}{\Delta_{d}(S)}=\mathrm{O}\left(\eta^{1 / 2}\right)
$$

This hypothesis is realistic if the cable pattern is included in the beam depth, as in most cases. Also for the cable the difference between this theory and the linear theory (Dall'Asta and Dezi [10]) consists of a quadratic term. In this case the quadratic contribution does not involve the vertical displacements only, but depends on the initial cable inclination by means of the mixed term $\Delta_{d}\left(X_{2}\right) \Delta_{d}(v)$. Consequently this deformation becomes more important when the cable initial inclination increases.

Because of the particular compatibility condition in which the cable strain depends on the displacements of all the saddle points, it is not convenient to write the balance condition in terms of equilibrium of the beam cross sections (local equilibrium). A global balance condition of the whole system can be deduced by starting from the general expression of the virtual work theorem

$$
\int_{V} \sigma \hat{\varepsilon} d V+L_{t} A_{t} \sigma_{t} \hat{\varepsilon}_{t}=\int_{[0, L]} \mathbf{t}_{0} \cdot \hat{\mathbf{u}}_{0} d S+\left.\mathbf{T}_{0 \theta} \cdot \hat{\mathbf{u}}_{0 \theta}\right|_{\theta=0, L} \quad \forall \hat{\varepsilon}, \hat{\varepsilon}_{t}, \hat{\mathbf{u}}_{0} \subset U
$$

where $\mathbf{t}_{0}$ and $\mathbf{T}_{0}$ are the forces related to the beam axis line and beam ends respectively and $U$ is the space of displacements and strains compatible with internal and external constraints. It should be observed that beam-tendon interaction terms do not appear in this equation because of the no friction assumption. In the following expression the two functions $v(\mathrm{~S})$ and $w(\mathrm{~S})$ which furnish the displacement field $\mathbf{u}$ are assumed as the problem unknowns and generic nonlinear constitutive laws are introduced for the tendon and the beam 


$$
\begin{aligned}
& \sigma=\sigma(\varepsilon) \\
& \sigma_{t}=\sigma_{t}\left(\varepsilon_{t}-\varepsilon_{t 0}\right)
\end{aligned}
$$

where $\sigma$ is the normal stress of a generic beam fibre and $\sigma_{t}$ is the tendon stress. The configuration in which the beam is in its natural state (zero stress) is chosen as the reference configuration. In this configuration the stress $\sigma_{t}$ in the cable is not null and can be controlled by the initial cable strain $\varepsilon_{t 0}$. The virtual strains, according to the moderate rotation theory, have the following expressions

$$
\begin{aligned}
& \hat{\varepsilon}=\hat{e}+X_{2} \hat{\alpha}^{\prime}=v^{\prime} \hat{v}^{\prime}+\hat{w}^{\prime}-X_{2} \hat{v}^{\prime \prime} \\
& \hat{\varepsilon}_{t}=\frac{1}{L_{t}} \sum_{d}\left[\mathbf{g}_{d} \cdot \Delta_{d}(\hat{\mathbf{u}})\right]=\frac{1}{L_{t}} \sum_{d}\left[\left(\Delta_{d}(\hat{w})+\frac{\Delta_{d}\left(X_{2}\right)+\Delta_{d}(v)}{\Delta_{d}(S)} \Delta_{d}(\hat{v})-\Delta_{d}\left(X_{2} \hat{v}^{\prime}\right)\right)\right]
\end{aligned}
$$

where $\mathbf{g}_{d}$ is the unit vector in the direction of the tract considered after its deformation (Dall'Asta [21]). Consequently the following expression is obtained

$$
\begin{aligned}
& \int_{[0, L]}\left(N \hat{w}^{\prime}+N v^{\prime} \hat{v}^{\prime}+M \hat{v}^{\prime \prime}\right) d S+ \\
& +t_{t} \sum_{d}\left(\Delta_{d}(\hat{w})+\frac{\left(\Delta_{d}\left(X_{2}\right)+\Delta_{d}(v)\right)}{\Delta_{d}(S)} \Delta_{d}(\hat{v})-\Delta_{d}\left(X_{2} \hat{v}^{\prime}\right)\right)=\quad \forall \hat{v}, \hat{w} \in U \\
& =\int_{[0, L]}\left(t_{02} \hat{v}+t_{03} \hat{w}\right) d S+\left.\left(T_{02 \theta} \hat{v}_{\theta}+T_{03 \theta} \hat{w}_{\theta}\right)\right|_{\theta=0, L}
\end{aligned}
$$

where $t_{02}$ and $t_{03}$ represent the transversal and longitudinal forces acting on the beam, while $T_{02}$ and $T_{03}$ are the total forces acting on the beam ends along the longitudinal and transverse directions respectively, while $N, M, t_{t}$ are the total force and total moment at beam cross sections and the total tendon force respectively, given by the following expressions

$$
\begin{aligned}
& N=\int_{\Omega} \sigma d \mathbf{X} \\
& M=-\int_{\Omega} \sigma X_{2} d \mathbf{X} \\
& t_{t}=A_{t} \sigma_{t}
\end{aligned}
$$

where $\Omega$ is the cross section domain. Eq. (25) is a global balance condition where the equilibrium of the whole system is enforced in the deformed configuration. This formulation (i.e., Lagrangian formulation) is very convenient since each quantity (e.g., length, surface, volume etc.) is referred to the known reference configuration.

\section{NUMERICAL SOLUTION}

\subsection{Nonlinear finite element model}

The solution of the geometric and material nonlinear problem defined by Eq. (25) is obtained with the finite element method. The numerical code implemented is based on the approach described in (Dall'Asta and Zona [17]) where the geometric linear formulas are substituted by the relevant formulas of the moderate rotations theory.

A 10 degrees-of-freedom (DOF) beam element is adopted, i.e., two end nodes each with three DOF (axial displacement, transverse displacement, rotation) and four intermediate nodes with one axial DOF. Shape functions are third-order Hermite polynomials for transverse displacement $v(\mathrm{~S})$ and fifth-order polynomials for axial displacement $w(S)$. Using these shape functions any inconsistency between axial and flexural displacement fields is avoided as can be demonstrated with considerations similar to those presented in (Dall'Asta and Zona [22]). The numerical integrations at the cross-section level are performed by subdividing the domain into a number of fibers parallel 
to the $X_{3}$ axis. The numerical integrations along the beam axis are performed by using the Gauss rule with 7 points. External prestressing cables are included in the finite element model by assuming that the positions of deviators and end anchorages coincide with some of the nodal points of the finite element subdivision. Thus the cable deformation is a function of the nodal displacement vector of the structure, as described in (Dall'Asta and Zona [17]) for the geometric linear case.

The strategies adopted for the solution of the resulting nonlinear problem are the tangent NewtonRaphson iterative procedure combined with load control and displacement incremental procedures. The load control procedure is used for the first steps of the nonlinear analysis (i.e., the initial stiffness is not reduced by degradation of materials), while displacement control is used for tracing the nonlinear path up to collapse (i.e., reduced stiffness giving small load variations along with large deflection increments or even softening branches).

\subsection{Material constitutive laws}

General nonlinear constitutive material models can be implemented in the finite element formulation based on the proposed approach. In the numerical applications illustrated in this work the following material constitutive laws are adopted.

The concrete in compression is modeled by using the CEB-FIP Model Code 90 [23]; a linear law up to tensile strength, followed by descending exponential law is used for the concrete in traction (Figure 2a). Since the concrete constitutive law has a softening branch after the strength peak, meshsensitive results may be obtained. This problem can be overcome if the minimum admissible element size is specified; its suitable value is equal to the beam depth (Bazant et al. [24]).

The steel material (either steel for reinforcements and beam steel) is modeled by using an elastic - perfect plastic hardening law (Bruneau et al. [25]). The elastic - perfect plastic branches are given by

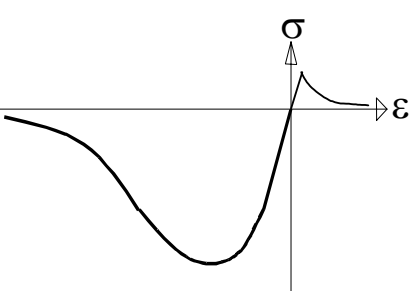

(a) concrete

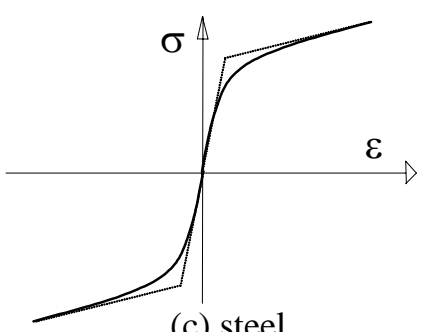

(c) steel (smooth curve)

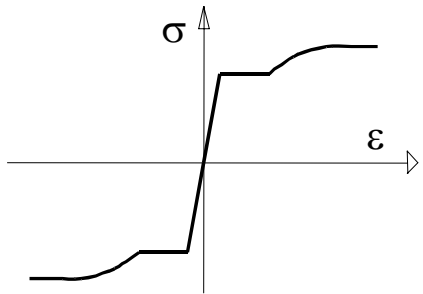

(b) steel

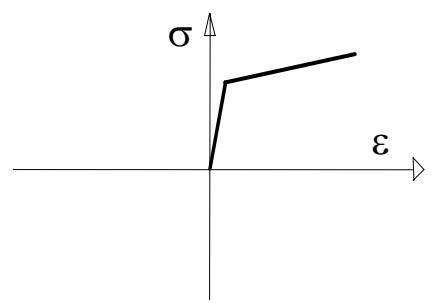

(d) tendon

Figure 2. Constitutive laws linear functions while the hardening tract is an exponential function (Figure 2b). This constitutive model is characterized by a sharp transition from the elastic to the plastic range. In common cases however, due to residual stresses in the steel beam section, the resulting behavior of the beam shows a gradual shift from the elastic to the plastic range. To model these cases a second steel constitutive law is included, i.e., the uniaxial Menegotto-Pinto [26] constitutive model, a smooth curved transition from an asymptotic straight line with slope $E_{0}$ to another asymptotic straight line with slope $E_{1}$ (Figure 2c). The MenegottoPinto equation, originally proposed for reinforcing bars, is a computationally efficient nonlinear smooth model for structural steel permitting very good agreement with experimental results (Bruneau et al. [25]).

The tendon steel behavior is described by a bilinear elastic - hardening law (Figure 2d).

The constitutive laws for steel beam, steel reinforcements and prestressing cable are characterized 
by assigned ultimate strains; zero stiffness and zero stress are assumed beyond these ultimate strains. The collapse of the structure in the finite element nonlinear analysis is attained when the ultimate strain in the steel (beam, reinforcements or tendon) is reached. In some cases, however, the collapse condition might be determined by the crushing of concrete. In fact exceeding the concrete peak strain might lead to a tangent stiffness matrix of the structure that becomes singular due to the negative stiffness contributions given by the softening branch.

\section{COMPARISONS WITH EXPERIMENTAL TESTS}

A limited number of experimental tests on steel-concrete composite beams prestressed by external tendons are available in literature. In some of these tests the geometric nonlinearity does not significantly influence the structural behavior due to the reduced beam slenderness. This is the case of the tests previously used for validating the geometric linear model (Dall'Asta and Zona [17]), capable in these conditions of giving results in very good agreement with the experimental tests. In a few situations however the beam geometry and the cable path are such as to highlight the effects of the geometric nonlinearity. This is for example the case of recent tests published by Chen and $\mathrm{Gu}$ [27] and used for validation purposes in this work. A comparison with the results of the simply supported beam tested is discussed hereafter. The beam, indicated as BS2 in (Chen and Gu [27]), is prestressed by a rectilinear eccentric cable without intermediate deviators and is subject to twopoint symmetric loading. For details on the geometric and material properties the reader may refer to (Chen and $\mathrm{Gu}[27])$.

The beam was unevenly subdivided in eight beam elements and the analysis was carried out in three phases: I) beam without prestressing under self-weight load (load control analysis); II) jacking of the prestressing tendons under self-weight load up to the initial experimental cable traction (load control analysis with null increase of the applied loads); III) application of the twopoint symmetric loading on the beam and increase of these two forces up to collapse (displacement control analysis with mid span deflection as controlled degree-of-freedom). The Menegotto-Pinto constitutive model was preferred over the elastic - plastic - hardening law for the steel beam for a more accurate description of the structural response in the transition phase between linear and plastic ranges.

In Figures 3 and 4 the numerical results (lines) and the experimental measures (series of points) are compared. The numerical results are obtained by the moderate rotation geometric nonlinear model illustrated in this work and by the correspondent material-nonlinear-only model. Good agreement

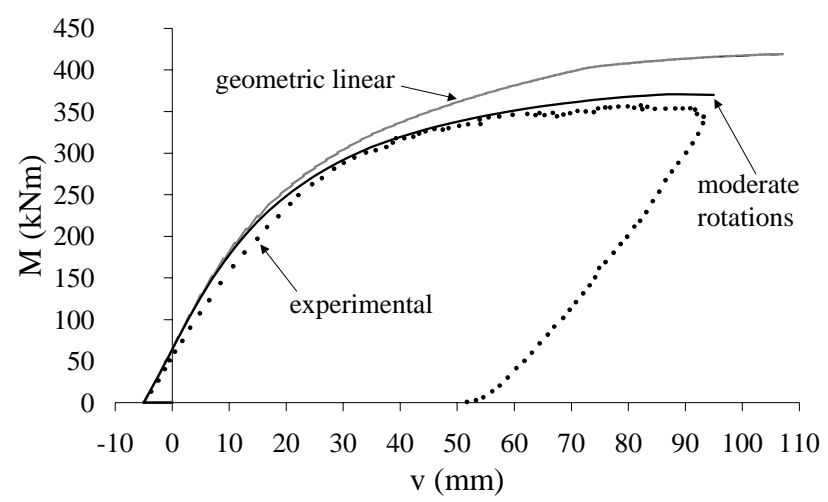

Figure 3. Comparison with experimental test: moment mid span deflection curves for beam BS2

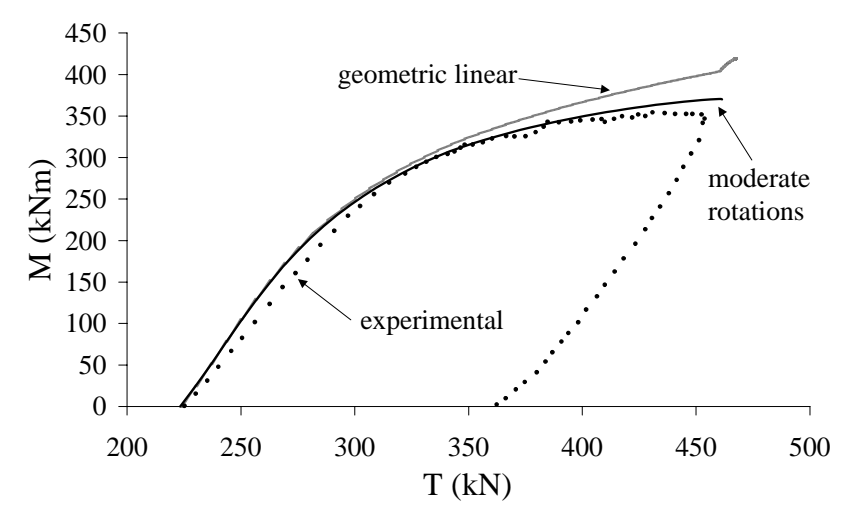

Figure 4. Comparison with experimental test: moment - cable traction curves for beam BS2 
between the moderate rotation model and the experimental results is attained, both in the bending moment versus mid span deflection curve and in the bending moment versus cable traction curve. The geometric linear model overestimates the ultimate capacity of the beam due to the importance of geometric nonlinearity affecting the beam structural behavior.

\section{NUMERICAL APPLICATIONS}

The geometric nonlinear effects and the difference between the moderate rotation model and the geometric linear model are thoroughly investigated and discussed in this section by means of numerical applications to slender steel-concrete composite beams with different structural configurations (simply supported and continuous beams) and different cable profiles. Each beam has equal steel concrete composite section (Figure 5), span length $(\mathrm{L}=46 \mathrm{~m})$ and thus span-to-depth ratio $(\mathrm{L} / \mathrm{h}=28.75)$, total area

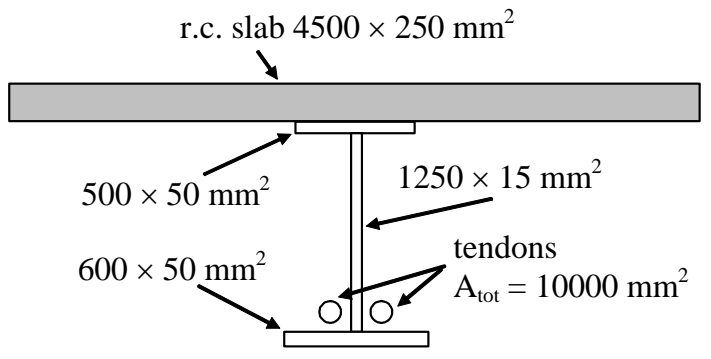

Figure 5. Cross section of the beams tested of the prestressing tendons $\left(\mathrm{A}_{\mathrm{tot}}=10000 \mathrm{~mm}^{2}\right)$, and material properties (Table 1 ). The beam cross section was designed to prevent local buckling phenomena of the web and overall instabilities under the applied loads and prestressing. The nonlinear analysis was divided into three phases: I) application of a uniform load $\mathrm{q}_{1}=30 \mathrm{kN} / \mathrm{m}$ representative of the structural self-weight on the non prestressed beam; II) jacking of the tendons to the total initial prestressing force $\mathrm{T}_{0}=11400 \mathrm{kN}$; III) application of a distributed uniform load $\mathrm{q}_{2}$ that is increased through to collapse. In the first two phases the nonlinear analysis was carried out

Table 1. Material parameters

\begin{tabular}{|c|c|c|c|c|c|}
\hline & $\begin{array}{c}\text { Concrete } \\
\text { (compression) }\end{array}$ & $\begin{array}{c}\text { Concrete } \\
\text { (tension) }\end{array}$ & $\begin{array}{c}\text { Reinforcement } \\
\text { steel }\end{array}$ & Beam steel & Tendon \\
\hline Yielding stress & - & - & $\mathrm{f}_{\mathrm{y}}=430 \mathrm{MPa}$ & $\mathrm{f}_{\mathrm{y}}=275 \mathrm{MPa}$ & $\mathrm{f}_{\mathrm{y}}=1600 \mathrm{MPa}$ \\
\hline Strength & $\mathrm{f}_{\mathrm{c}}=33 \mathrm{MPa}$ & $\mathrm{f}_{\mathrm{ct}}=2.50 \mathrm{MPa}$ & $\mathrm{f}_{\mathrm{t}}=473 \mathrm{MPa}$ & $\mathrm{f}_{\mathrm{t}}=360 \mathrm{MPa}$ & $\mathrm{f}_{\mathrm{t}}=1800 \mathrm{MPa}$ \\
\hline Elastic modulus & $\begin{array}{c}\mathrm{E}_{\mathrm{ci}}=32000 \\
\mathrm{MPa}\end{array}$ & $\begin{array}{c}\mathrm{E}_{\mathrm{ct}}=30500 \\
\mathrm{MPa}\end{array}$ & $\mathrm{E}_{\mathrm{s}}=200 \mathrm{GPa}$ & $\mathrm{E}_{\mathrm{s}}=200 \mathrm{GPa}$ & $\mathrm{E}_{\mathrm{s}}=200 \mathrm{GPa}$ \\
\hline Hardening strain & - & - & $\varepsilon_{\mathrm{h}}=0.02$ & $\varepsilon_{\mathrm{h}}=0.04$ & - \\
\hline Ultimate strain & - & - & $\varepsilon_{\mathrm{u}}=0.12$ & $\varepsilon_{\mathrm{u}}=0.18$ & $\varepsilon_{\mathrm{u}}=0.10$ \\
\hline
\end{tabular}

by using the load control procedure, the third phase by using the displacement control method with mid span deflection of the loaded span as controlled degree-of-freedom. The beams were unevenly subdivided in 24 elements per span. Each beam was analyzed by using the proposed geometric nonlinear model and the results are compared to those computed with a geometric linear model previously presented (Dall'Asta and Dezi [10]) and implemented in the finite element framework (Dall'Asta and Zona [17]) now extended to the moderate rotations model.

\subsection{Simply supported beams with rectilinear tendon path}

Three simply supported beams with rectilinear cable path are analyzed: beam R0 with no intermediate deviators, beam R1 with one deviator, and beam R2 with two deviators (Figure 6). The relevant load-deflection curves are reported in Figure 7. Values of the peak load $\mathrm{q}_{\max }=\mathrm{q}_{1}+\lambda_{\max } \mathrm{q}_{2}$ with the corresponding mid span deflection $\mathrm{v}_{\max }$ and values of the ultimate mid 
span deflection $\mathrm{v}_{\mathrm{ult}}$ and the corresponding load $\mathrm{q}_{\mathrm{ult}}=\mathrm{q}_{1}+\lambda_{\mathrm{ult}} \mathrm{q}_{2}$ are given in Table 2 for each beam and analysis type. Results for the non prestressed (NP) case is also included in Table 2. The geometric nonlinear analysis shows significant differences of behavior between the three cable paths. One intermediate deviator permits an increase of $23.2 \%$ of the peak load with respect to the solution without intermediate deviators. Two intermediate deviators are less efficient and the increase of the peak load is $14.5 \%$. Even larger is the increase of deflection associated to the load peak (increment of ductility). On the other hand the geometric linear analysis cannot describe the behavior differences due to deviators because only the displacement component parallel to the initial cable profile is measured (Dall'Asta and Dezi [10]). Thus one curve is representative for the three beams R0, $\mathrm{R} 1$, and R2 when a geometric linear analysis is performed. In this case the peak load level is overestimated with respect to the geometric nonlinear analysis of $25.2 \%, 1.7 \%$, and $9.5 \%$ for beams R0, R1 and R2 respectively.

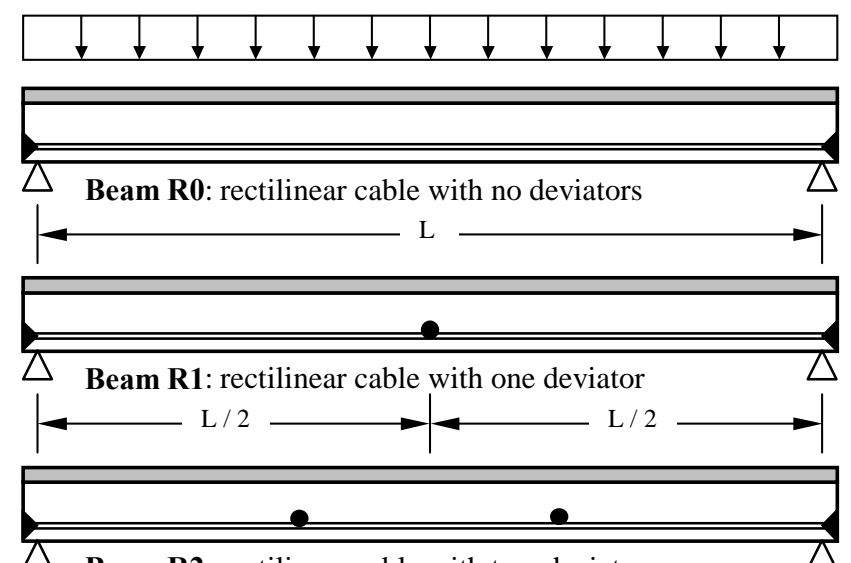

$\triangle$ Beam R2: rectilinear cable with two deviators (

Figure 6. Beams with rectilinear tendon tested

Table 2. Simply supported beams tested: loads and mid span deflections

\begin{tabular}{|c|c|c|c|c|c|c|c|c|}
\hline \multirow{2}{*}{ Beam } & \multicolumn{4}{|c|}{ Moderate rotations analysis } & \multicolumn{4}{c|}{ Geometric linear analysis } \\
\hline & $\mathrm{q}_{\max }$ & $\mathrm{v}\left(\mathrm{q}_{\max }\right)$ & $\mathrm{q}_{\text {ult }}$ & $\mathrm{v}_{\text {ult }}$ & $\mathrm{q}_{\max }$ & $\mathrm{v}\left(\mathrm{q}_{\max }\right)$ & $\mathrm{q}_{\text {ult }}$ & $\mathrm{v}_{\text {ult }}$ \\
\cline { 2 - 9 } & $(\mathrm{kN} / \mathrm{m})$ & $(\mathrm{mm})$ & $(\mathrm{kN} / \mathrm{m})$ & $(\mathrm{mm})$ & $(\mathrm{kN} / \mathrm{m})$ & $(\mathrm{mm})$ & $(\mathrm{kN} / \mathrm{m})$ & $(\mathrm{mm})$ \\
\hline NP & 73.20 & 1635 & 73.20 & 1635 & 73.20 & 1635 & 73.20 & 1635 \\
\hline R0 & 113.64 & 324 & 99.28 & 764 & & & & \\
\hline R1 & 139.95 & 1034 & 139.95 & 1034 & 142.33 & 871 & 142.33 & 871 \\
\hline R2 & 130.16 & 699 & 130.04 & 729 & & & & \\
\hline D1 & 125.99 & 892 & 125.73 & 962 & 144.76 & 1222 & 144.76 & 1222 \\
\hline D2 & 137.56 & 748 & 137.56 & 748 & 151.07 & 872 & 151.07 & 872 \\
\hline
\end{tabular}

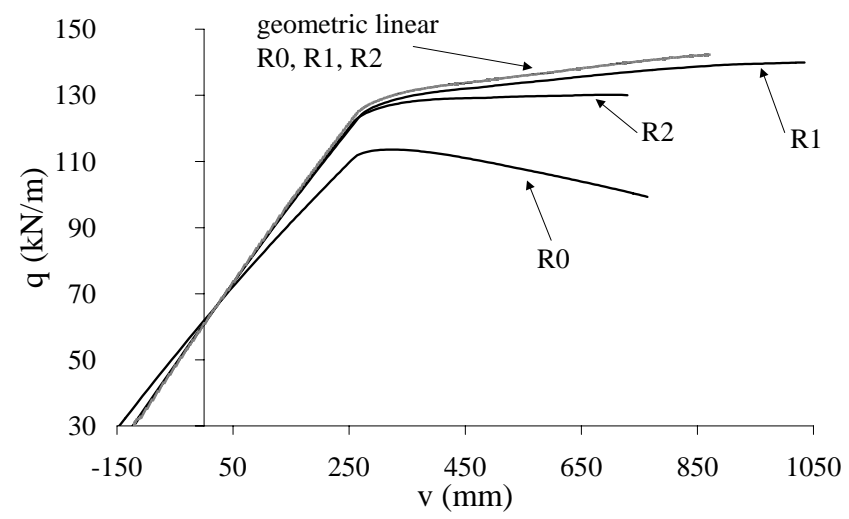

Figure 7. Beams R0, R1, and R2: load - mid span deflection

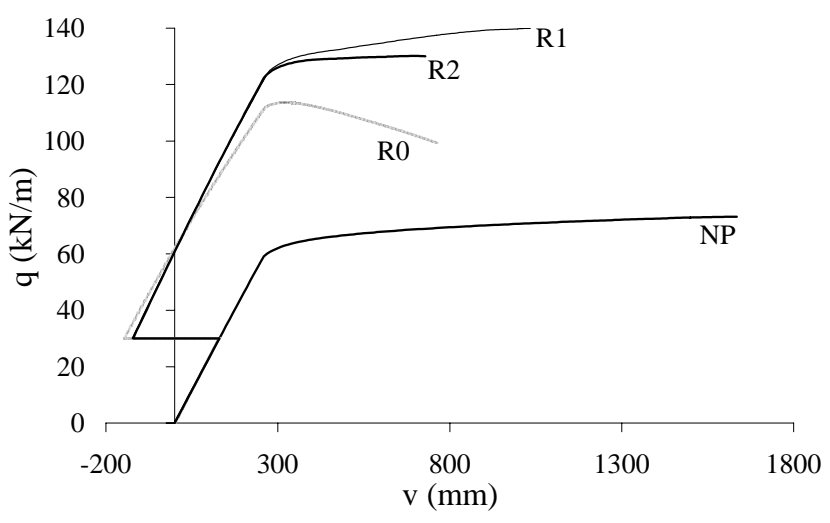

Figure 8. Beams R0, R1, R2 and NP: load - mid span deflection (moderate rotation analysis) 
Comparing the results for the prestressed beams with the results of the non prestressed beam (Table 2 and Figure 8), significant increases are observed in the carrying load capacity (55\% for R0, 91\% for R1, 78\% for R2 from the moderate rotations analysis) as well as a significant decrease of the ultimate deflection. It can also be noticed that the moderate rotations analysis and the material-nonlinear-only analysis give the same results for the non prestressed beam.

Figure 9 shows that in beam R0 under the same deflection level the tendon force is smaller when moderate rotation analysis is performed (the cable traction is represented in non-dimensional units by dividing its value $\mathrm{T}$ by the value of the initial traction $\mathrm{T}_{0}$ ). The geometric linear formulation in fact includes only the stress variations due to axial deformations and end rotations, conversely the moderate rotation theory also includes the stress variation deriving from the beam ends coming up to each other due to vertical deflection of the beam. In beams R1 and R2 the tendon traction is larger than in beam R0; in beam R1 it is even higher than the value obtained by geometric linear analysis. In fact when the cable is rectilinear, the geometric linear analysis is not able to consider the elongation caused by the vertical displacements of deviators. This contribution becomes remarkable after beam yielding.

A larger prestressing force under the same load level is obtained from the geometric nonlinear analysis in beams R0, R1, R2 (Figure 10) because of the major deflections of the beam as computed including the geometric nonlinearity.

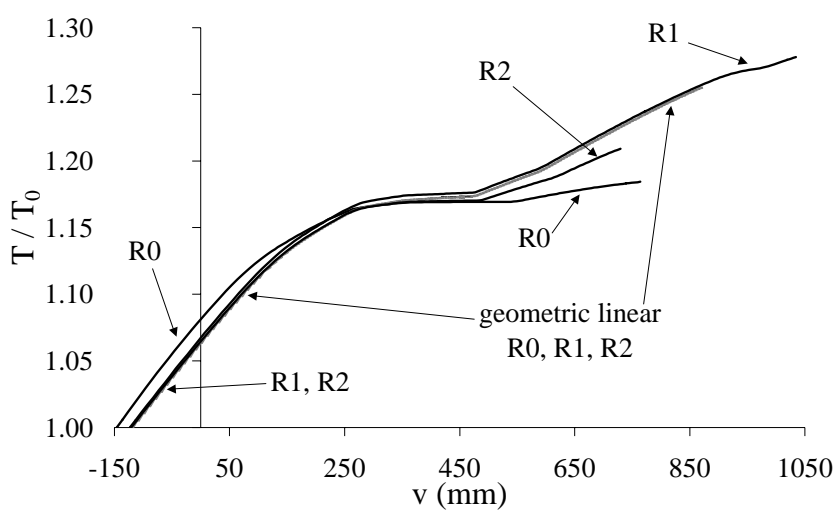

Figure 9. Beams R0, R1, and R2: cable traction mid span deflection

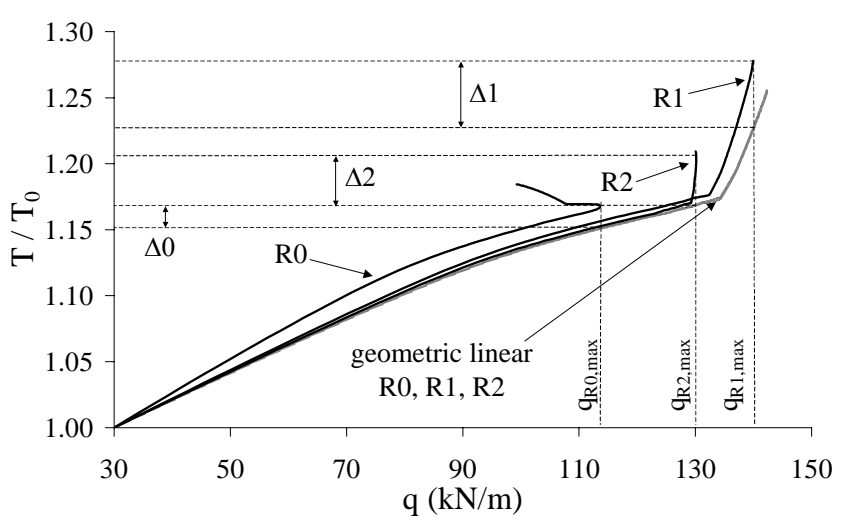

Figure 10. Beams R0, R1, and R2: cable traction - load.

In Figure 11 the total bending moment and the bending moment due to prestressing force only are plotted for each beam under the corresponding peak load level (i.e., $\mathrm{q}_{\mathrm{R} 0 \text {,max }}$ for R0, $\mathrm{q}_{\mathrm{R} 1, \max }$ for R1, and $\mathrm{q}_{\mathrm{R} 2 \text {,max }}$ for $\mathrm{R} 2$ ). The bending moment is represented in non-dimensional units by dividing its value by the positive plastic moment of the composite cross-section $\left(\mathrm{M}_{\mathrm{pl}}=19256.29 \mathrm{kNm}\right)$. The bending moments computed by the geometric linear analysis under the same load levels are also plotted. It is observed that at anchorages and deviators the negative bending moment due to prestressing only has a larger absolute value in the geometric nonlinear analysis than in the geometric linear analysis. This can be explained by considering the larger prestressing force under the same load level (Figure 10). The amount of these bending moment differences are proportional to the difference of the external prestressing force highlighted in Figure 10. Conversely in sections sufficiently far from anchorages and deviators the absolute value of the negative bending moment due to external prestressing is smaller in the geometric nonlinear analysis than in the geometric linear analysis. The reason is in the cable eccentricity variation (included in the nonlinear geometric analysis but not in the geometric linear analysis) that has a stronger effect than the higher tendon traction. As a result the total bending moment (summation of the negative bending moment due to prestressing and of the positive bending moment due to external loads) is larger in the geometric nonlinear analysis in sections sufficiently far from deviators and anchorages. 
In beam $\mathrm{R} 0$ the difference in bending moment due to prestressing between geometric linear and nonlinear analyses is remarkable. This significant variation of bending moment in the critical sections leads to the differences in ultimate load and ductility of the system. In beam R1 the presence of intermediate deviators makes it possible to increase the ultimate load and ductility and to reduce the differences between the geometric linear and nonlinear analysis. Furthermore, in this case the sections where the maximum bending moment is attained are different in the two analyses. The behavior of beam R2 is similar to that in beam R0 but the two intermediate deviators strongly reduce the differences between the two analysis. This means that the efficiency of deviators depends not only on their number but also on their position along the beams. In particular a deviator located at the critical section of the non prestressed beam strongly reduces the geometric nonlinear effects that decrease the ultimate capacity and ductility of the beam-cable system.

\subsection{Simply supported beams with draped tendon path}

Two simply supported beams with draped cable path are analyzed: beam D1 and beam D2 with one and two intermediate deviators respectively (Figure 12). The relevant loaddeflection curves are reported in Figure 13. Values of the peak load $\mathrm{q}_{\max }$ with the corresponding mid span deflection $\mathrm{V}_{\max }$ and values of the ultimate mid span deflection $v_{\text {ult }}$ and the corresponding load $\mathrm{q}_{\mathrm{ult}}$ are given in Table 2.

The geometric nonlinear analysis shows that prestressing with draped cables increases the load carrying capacity of the non prestressed beam (NP) of $72 \%$ and $88 \%$ when using one and two intermediate deviators respectively. The increase of the strength is associated to a significant reduction of deflections (Table 2 and Figure 14).

When draped tendons are used the geometric linear analysis can describe the behavior differences due to deviators. Both analyses
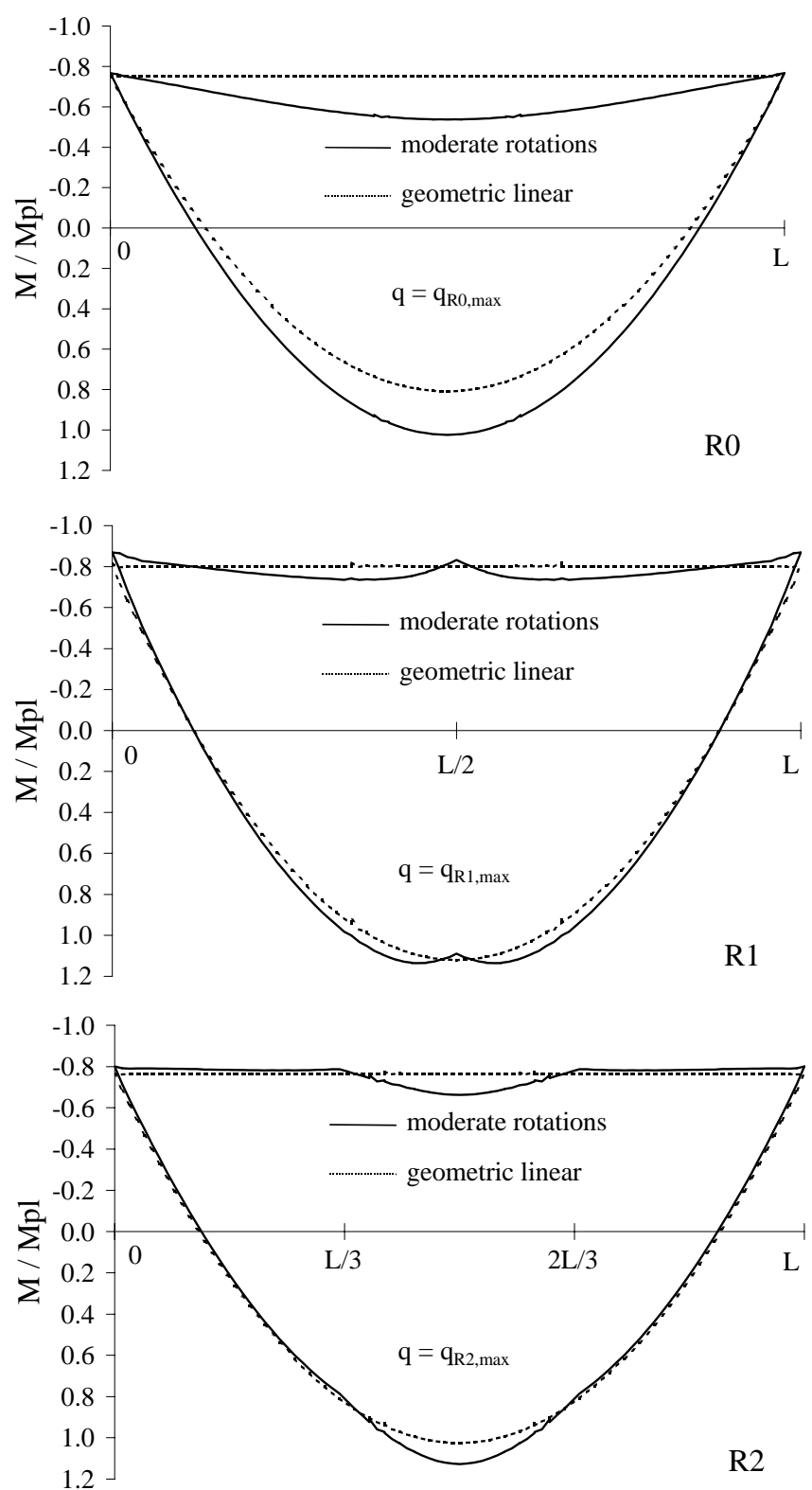

Figure 11. Total bending moment and moment due to prestressing force for beams R0, R1, and R2

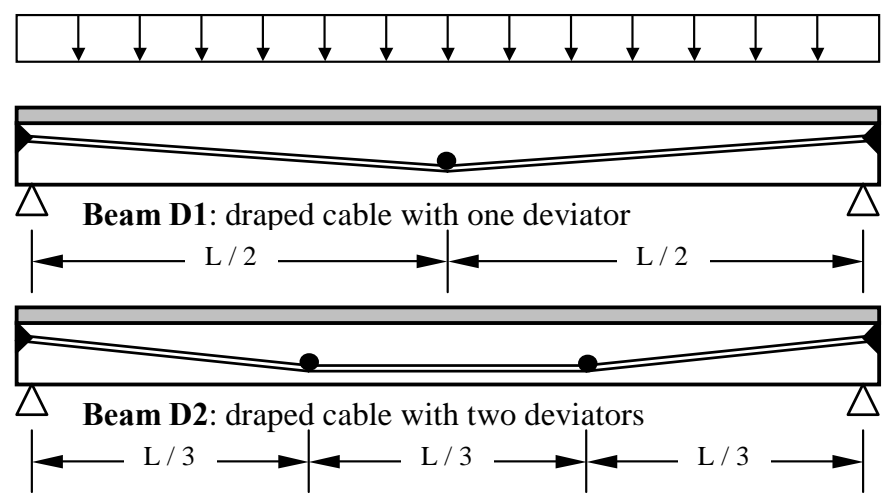

Figure 12. Simply supported beams with draped tendon tested 


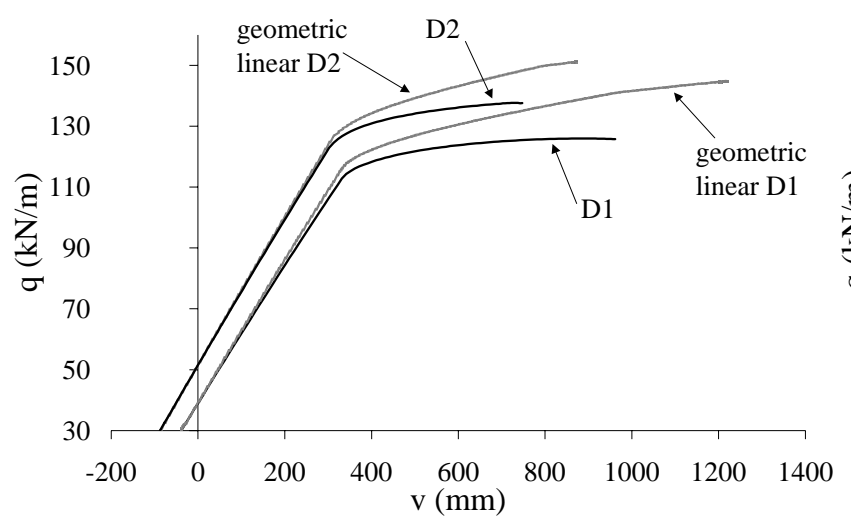

Figure 13. Beams D1 and D2: load - mid span deflection

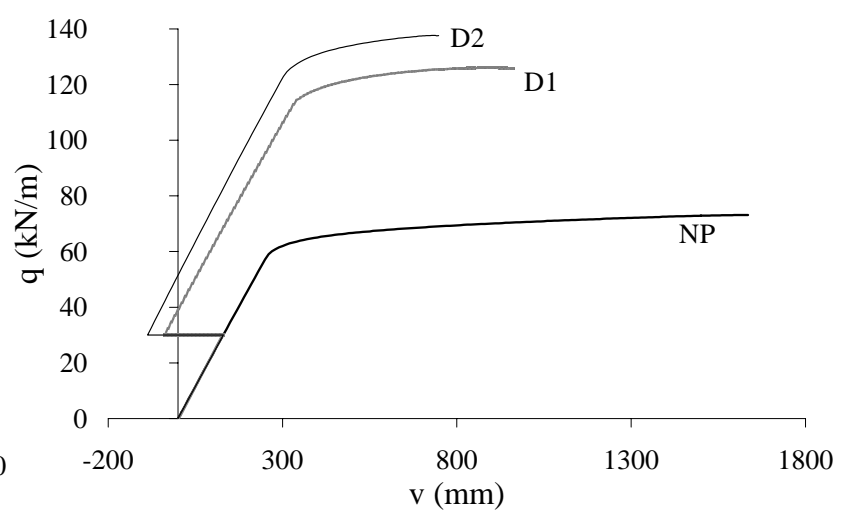

Figure 14. Beams D1, D2, and NP: load - mid span deflection (moderate rotations analysis)

can in fact consider the elongation due to vertical displacements of deviators although the geometric linear analysis does not consider the influence of the initial inclination of the cable profile tract. The peak load level is overestimated with respect to the geometric nonlinear analysis of $14.8 \%$, and $9.8 \%$ for beams D1 and D2 respectively while the overestimation of the ultimate deflection is larger (Table 2).

In Figure 15 it is observed that tendon forces at the same deflection level is smaller in the moderate rotation analysis. Both geometric linear and nonlinear analyses include the contribution of vertical displacement of deviators, even if evaluated in a different way. The reduction in tendon force due to the beam ends coming up to each other because of the vertical deflection of the beam also occurs, as already mentioned in the previous case of rectilinear tendon. On the other hand larger prestressing forces under the same load level obtained from the geometric nonlinear analysis (Figure 16) are due to the major deflections of the beam as computed including the geometric nonlinearity.

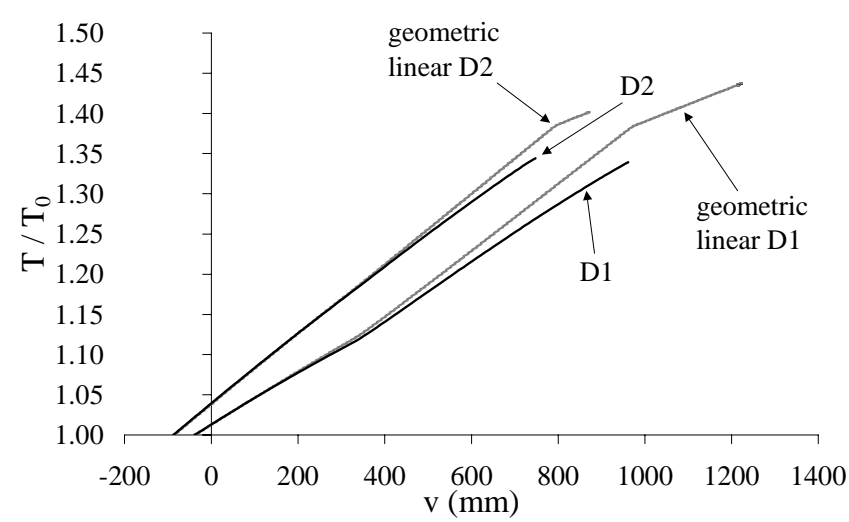

Figure 15. Beams D1 and D2: cable traction mid span deflection

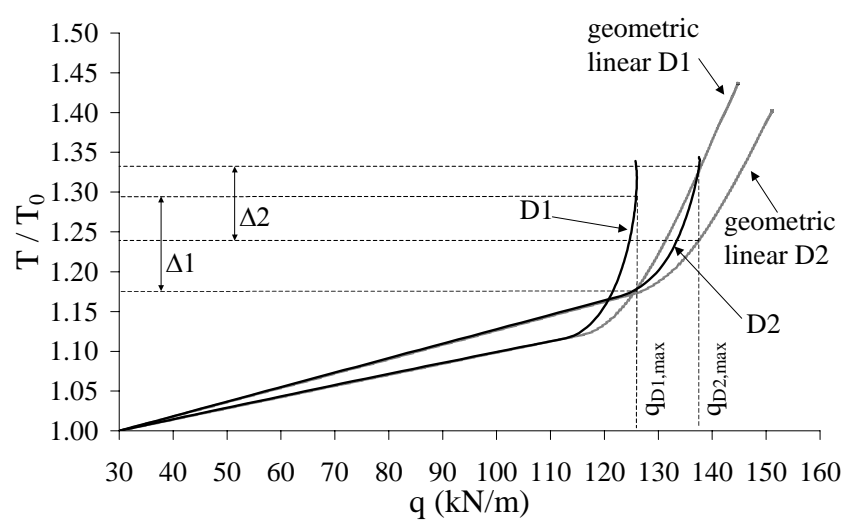

Figure 16. Beams D1 and D2: cable traction - load.

In Figure 17 the total bending moment and the bending moment due only to prestressing force are plotted for each beam under the corresponding peak load level (i.e., $\mathrm{q}_{\mathrm{D} 1 \text {,max }}$ for $\mathrm{D} 1$, and $\mathrm{q}_{\mathrm{D} 2 \text {,max }}$ for D2). The bending moments computed by the geometric linear analysis under the same load levels are also plotted. It is observed that at intermediate deviators the negative bending moment due to prestressing only has a larger absolute value in the geometric nonlinear analysis than in the geometric linear analysis. The reason is in the larger prestressing force under the same load level. The amount of these bending moment differences are proportional to the difference of external prestressing force highlighted in Figure 16. Conversely in sections sufficiently far from deviators the absolute value of the negative bending moment due to external prestressing is smaller in 

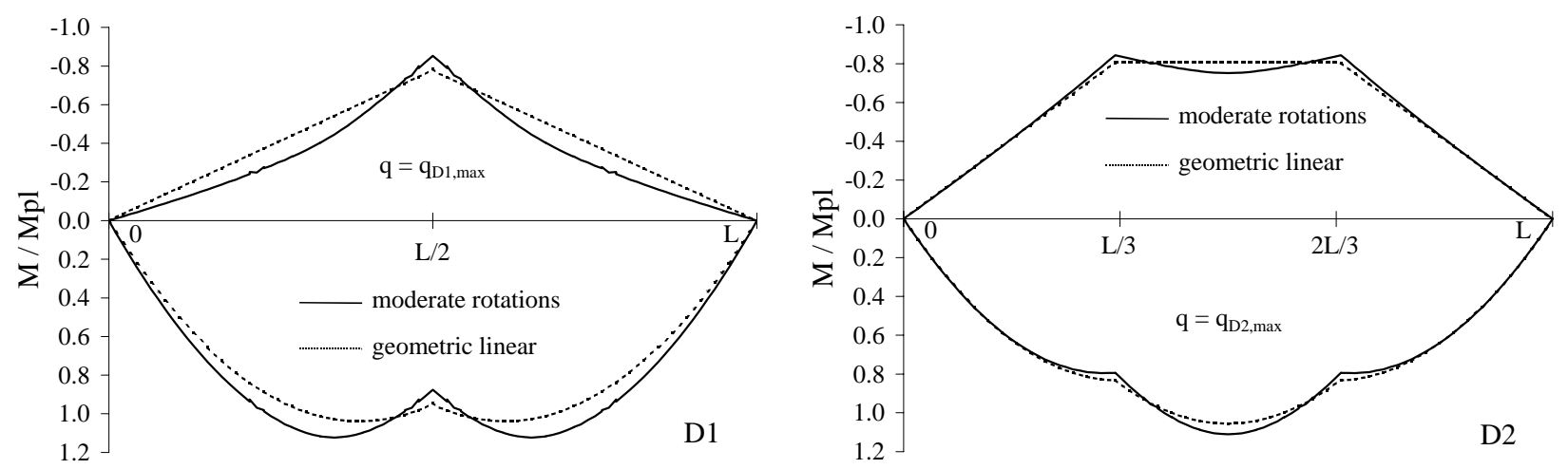

Figure 17. Total bending moment and moment due to prestressing force for beams D1 and D2

geometric nonlinear analysis than in geometric linear analysis. Cable eccentricity variation in fact has a stronger effect that the higher tendon traction, as in the previous case of rectilinear tendons. Accordingly the total bending moment is larger in the geometric nonlinear analysis in sections sufficiently far from deviators. In the critical sections the significant variation of bending moment leads to the differences in ultimate load and ductility of the system.

\subsection{Two-span continuous beam with draped tendon path}

A continuous beam with two equal spans of length $\mathrm{L}=46 \mathrm{~m}$ and with cable path defined by three intermediate deviators is analyzed (Figure 18). Symmetric (CD3S) and non symmetric (CD3N) load patterns are considered. In phase I (only self-weight) and phase II (jacking under self-weight load) the symmetric uniform load $\mathrm{q}_{1}$ representing self-weight is applied along the two spans and kept constant in both beams CD3S and CD3N. In phase III the uniform load $\mathrm{q}_{2}$ is applied and increased in both spans in the symmetric load case (CD3S) while $\mathrm{q}_{2}$ is applied and increased in the first span only in the non symmetric load case (CD3N). The relevant load-deflection curves are reported in Figure 19. A three-stage behavior of the beam is observed under symmetric loading (i.e., uncracked state, cracked state, plastic state) while the same beam under non symmetric loading is in cracked state right from the first steps of the analysis and the resulting behavior is subdivided in two stages (i.e., cracked state, plastic state). Values of the peak load $\mathrm{q}_{\max }=\mathrm{q}_{1}+\lambda_{\max } \mathrm{q}_{2}$ with the corresponding mid span deflection $\mathrm{v}_{\max }$ and values of the ultimate mid span deflection $v_{\text {ult }}$ and the corresponding load $q_{\text {ult }}=q_{1}+\lambda_{\text {ult }} q_{2}$ in the first span are given in Table 3 for each load case and analysis type. Results for the non prestressed case are also included (CNPS and CNPN for the symmetric and non symmetric case respectively). The geometric nonlinear analysis shows that prestressing in the continuous beam considered increases the load carrying capacity $54 \%$ and $46 \%$ under symmetric and non symmetric loading respectively. Once again the
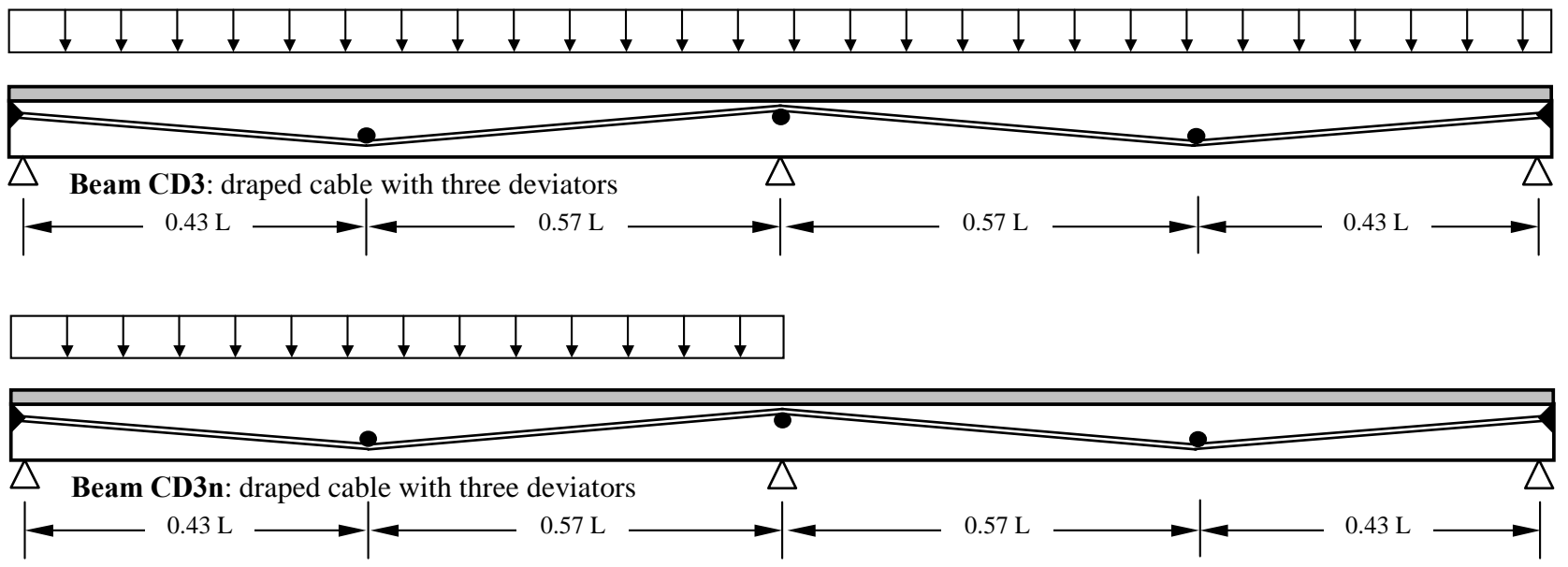

Figure 18. Two-span continuous beams with draped tendon tested 
increase in strength is associated to a significant reduction of deflections (Table 3 and Figure 20). The material-nonlinear-only analysis overestimates the peak load level with respect to the geometric nonlinear analysis of $12.9 \%$, and $9.8 \%$ for symmetric and non symmetric loading respectively.

As discussed in the previous case of simply supported beams with draped tendons, the tendon forces at the same deflection level are smaller when the moderate rotation analysis is performed (Figure 21) while larger prestressing forces under the same load level are obtained from the geometric nonlinear analysis (Figure 22).

Table 3. Continuous beams tested: loads and mid span deflections

\begin{tabular}{|c|c|c|c|c|c|c|c|c|}
\hline Beam & \multicolumn{4}{|c|}{ Moderate rotations analysis } & \multicolumn{4}{c|}{ Geometric linear analysis } \\
\hline & $\mathrm{q}_{\max }$ & $\mathrm{v}\left(\mathrm{q}_{\max }\right)$ & $\mathrm{q}_{\text {ult }}$ & $\mathrm{v}_{\text {ult }}$ & $\mathrm{q}_{\max }$ & $\mathrm{v}\left(\mathrm{q}_{\max }\right)$ & $\mathrm{q}_{\text {ult }}$ & $\mathrm{v}_{\text {ult }}$ \\
\cline { 2 - 10 } & $(\mathrm{kN} / \mathrm{m})$ & $(\mathrm{mm})$ & $(\mathrm{kN} / \mathrm{m})$ & $(\mathrm{mm})$ & $(\mathrm{kN} / \mathrm{m})$ & $(\mathrm{mm})$ & $(\mathrm{kN} / \mathrm{m})$ & $(\mathrm{mm})$ \\
\hline CNPS & 100.59 & 1350 & 100.59 & 1350 & 100.59 & 1350 & 100.59 & 1350 \\
\hline CNPN & 98.41 & 1382 & 98.41 & 1382 & 98.41 & 1382 & 98.41 & 1382 \\
\hline CD3S & 154.70 & 715 & 154.60 & 730 & 174.75 & 1015 & 174.75 & 1015 \\
\hline CD3N & 143.96 & 610 & 142.93 & 765 & 158.08 & 1065 & 158.08 & 1065 \\
\hline
\end{tabular}

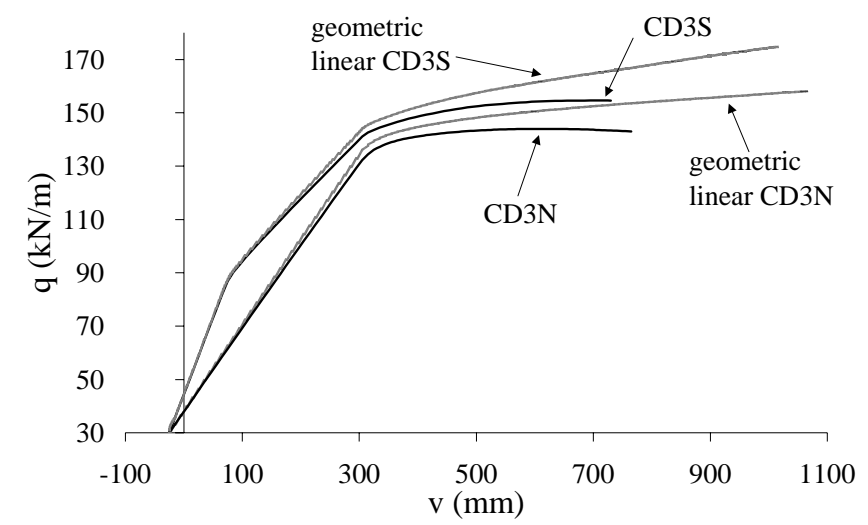

Figure 19. Beams CD3S and CD3N: load mid span deflection

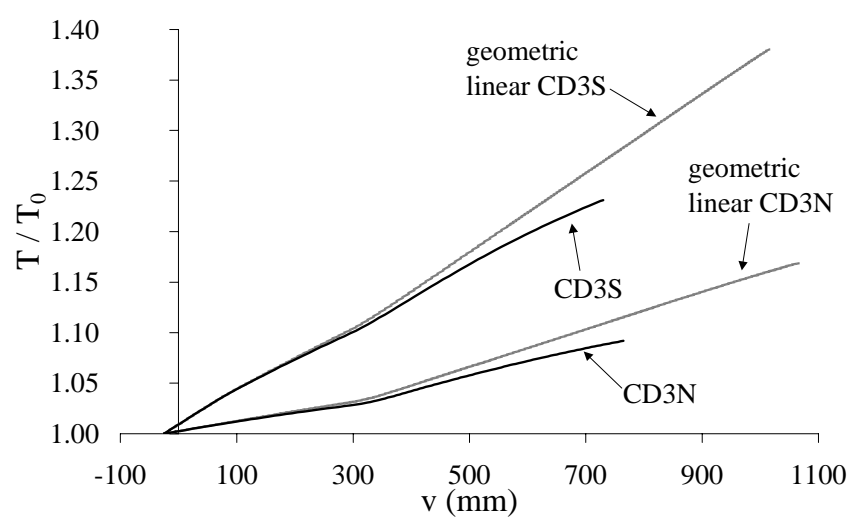

Figure 21. Beams CD3S and CD3N: cable traction mid span deflection

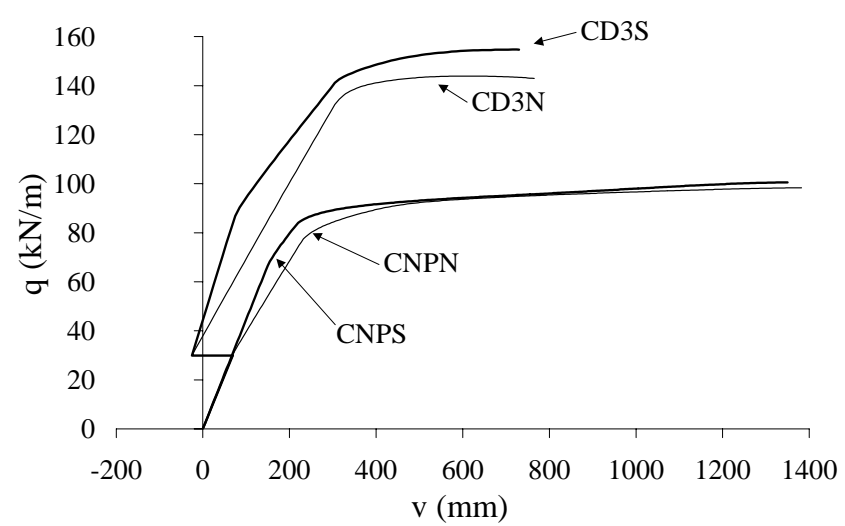

Figure 20. Beams CD3S, CD3N, CNPS, CNPN: loadmid span deflection (moderate rotations analysis)

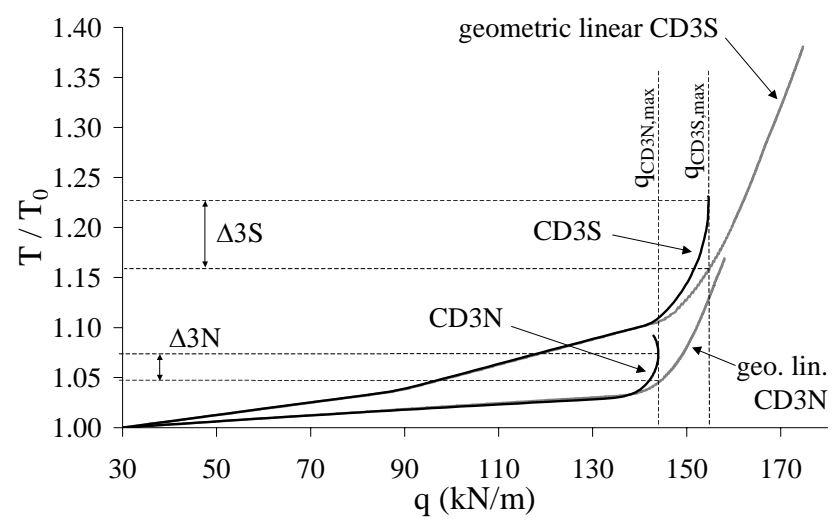

Figure 22. Beams CD3S and CD3N: cable traction - load. 
In Figure 23 and in Figure 24 the total bending moment is plotted for the symmetric and non symmetric loading conditions respectively under the corresponding peak load levels (i.e., qCD3s,max for symmetric loading, and $\mathrm{q}_{\mathrm{CD} 3 \mathrm{~N} \text {,max }}$ for the non symmetric loading). The bending moment due to prestressing only is also reported (i.e., primary moment computed from the actual tendon eccentricity and traction force without including the secondary moment due to the redundant system of supports). As in the previous cases bending moments computed by the geometric nonlinear analysis are compared to the bending moments from geometric nonlinear analysis under the same load levels.

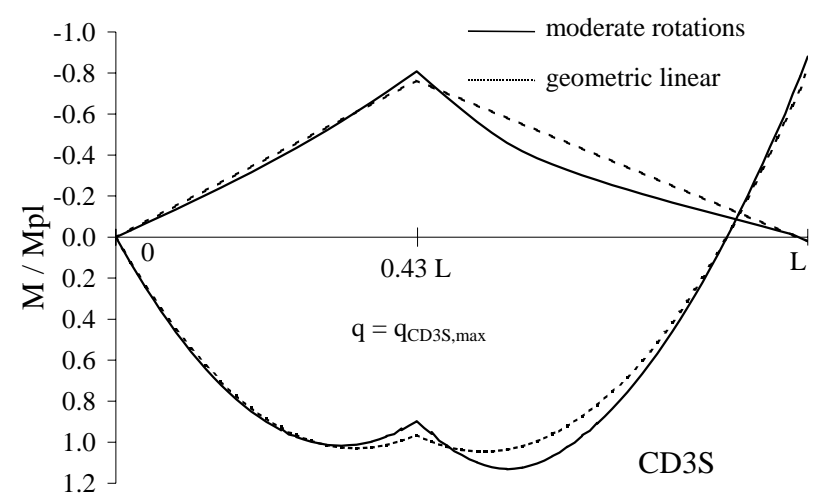

Figure 23. Total bending moment and moment due to prestressing force for beam CD3S

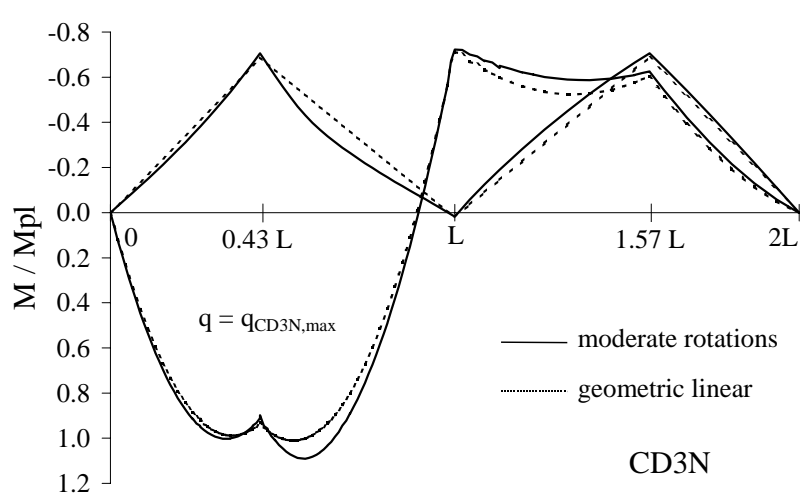

Figure 24. Total bending moment and moment due to prestressing force for beam CD3N

It is observed that at the deviators the total bending moment has a lower value with sign (i.e., smaller absolute value for positive moment and larger absolute value for negative moment) in the geometric nonlinear analysis rather than in the geometric linear analysis. Again the explanation is in the larger prestressing force under the same load. The amount of these bending moment differences are proportional to the difference of the external prestressing force highlighted in Figure 22. In sections sufficiently far from deviators there is an increase or decrease of the bending moment with sign depending on if the span has a downward deflection or un uplift. In fact the cable eccentricity decreases for a downward deflection of the beam while it increases for an uplift. This is clearly shown in two-span beam under non symmetric loading where the first span has a downward deflection and the second span has a upward deflection. The increase of bending moment in the critical section leads to the differences in ultimate load and ductility of the system.

\section{CONCLUSIONS}

In this work a model for geometric and material nonlinear analysis of beams prestressed with external tendons is illustrated. The formulation was obtained by deducing the beam-tendon model from the finite deformation theory. The hypotheses of small strain and moderate rotations were then assumed, according to the ultimate displacements observed in experimental tests. The weak form of the balance condition was obtained by considering the total Lagrangian formulation and the numerical solution was achieved with a displacement-based finite element formulation. Differently from existing methods starting from the linear theory and then including the eccentricity variation of the cable, the proposed moderate rotation model is based on a nonlinear kinematical theory so that all geometric nonlinearities are included. The actual tendon-beam relative position is consistently considered being the equilibrium imposed in the deformed configuration. In addition the balance conditions reveal that other terms, besides the eccentricity variation, play a rule in the evaluation of the cable force and, consequently, in the beam equilibrium. Specifically the proposed approach considers the coupling between the axial and flexural displacement fields of the beam. As 
a consequence a correct evaluation of the vertical displacements due to the large axial forces given by the applied prestressing is included. The axial shortenings of the beam given by the large vertical deflections are considered as well. With regards to the cable the moderate rotation theory leads to a quadratic relationship between tendon strain and beam deformations in which the nonlinear influence of displacements and cable inclination is explicitly shown.

The numerical model implemented was verified by comparison with experimental tests on externally prestressed steel-concrete composite beams. Some numerical applications involving slender simply supported and two-span composite beams post-tensioned with external cables were discussed to illustrate the nonlinear geometric effects and their influence on the ultimate capacity.

Generally the moderate rotation model furnishes higher tendon traction increments with respect to the geometric linear analysis. The reason is in the larger vertical displacements which prevails over the cable traction reduction due to the beam axial shortening. Despite the higher value of the tendon traction, the reduced cable eccentricity leads to a lower ultimate load of the externally prestressed beam. In the numerical applications considered the differences in the ultimate load in cases of practical interest (beams with draped cables) the difference can be up to 15\%. These variations increase for slenderer beams making geometric linear analysis unrealistic and unsafe. The numerical examples presented in this paper give a glance at the problem; more numerical studies are necessary for defining the applicability limits of the geometric linear analysis and the proposed model can be conveniently used for this task.

\section{REFERENCES}

[1] Szilard, R., "Design of prestressed composite steel structures”, Journal of Structural Division, ASCE, 1959, 85(9), pp.97-124.

[2] Hoadley, P.G., "Behavior of prestressed composite steel beams", Journal of Structural Division, ASCE, 1963, 89(3), pp.21-34.

[3] Berridge, P.S.A. and Donovan, L.H., "Prestressing restores weakened truss bridge”, Civil Engineering, 1959, 26(9), pp.48-49.

[4] Mancarti, G.D., "Strengthening California steel bridges by prestressing”, Transportation Research Record 950, Second Bridge Conference, Transportation Research Board, 1984, pp.183-187.

[5] Conti, E., Tardy, R. and Virlogeux, M., "Friction losses in some externally prestressed bridges in France”, Proceedings of the Workshop on Behaviour of External Prestressing in Structures, Conti E. and Tardy R. editors, Saint-Rémy-lès-Chevreuse, France, 1993.

[6] Virlogeux, M., "Non-linear analysis of externally prestressed structures”, Proc., XI Symp., Fédération Internationale de la Précontrainte (FIP), Hamburg, Germany, 1990, pp.163-195.

[7] Saadatmanesh, H., Albrecht, P. and Ayyub, B.M., "Analytical study of prestressed composite beams”, Journal of Structural Engineering, ASCE, 1989, 115(9), pp.2364-2381.

[8] Ayyub, B.M., Sohn, Y.G. and Saadatmanesh, H., "Prestressed composite girders under positive moment”, Journal of Structural Engineering, ASCE, 1990, 116(11), pp.2931-2951.

[9] Ayyub, B.M., Albrecht, P. and Saadatmanesh, H., "Prestressed composite girders. II: Analytical study for negative moment”, Journal of Structural Engineering, ASCE, 1992, 118(10), pp.2763-2783.

[10] Dall'Asta, A. and Dezi, L., "Nonlinear behavior of externally prestressed composite beams: analytical model”, Journal of Structural Engineering, ASCE, 1998, 124(5), pp.588-597.

[11] Alkhairi, F.M. and Naaman, A.E., "Analysis of beams prestressed with unbonded internal or external tendons”, Journal of Structural Engineering, ASCE, 1993, 119(9), pp.26802700. 
[12] Harajli, M., Khairallah, N. and Nassif, H., "Externally prestressed members: evaluation of second-order effects”, Journal of Structural Engineering, ASCE, 1999, 125(10), pp.11511161.

[13] Ramos, G. and Aparicio, A.C., "Ultimate analysis of monolithic and segmental externally prestressed concrete bridges”, Journal of Bridge Engineering, ASCE, 1996, 1(1), pp.10-17.

[14] Ariyawardena, N. and Ghali, A., "Prestressing with unbonded internal or external tendons: analysis and computer model”, Journal of Structural Engineering, ASCE, 2002, 128(12), pp.1493-1501.

[15] Naghdi, P.M. and Vongsarnpigoon, A., "Small strain accompanied by moderate rotations", Archive for Rational Mechanics and Analysis, 1982, 80(4), 245-283.

[16] Marzano, S. and De Tommasi, D., “Small strain and moderate rotations”, Journal of Elasticity, 1993, 32(1), pp.37-50.

[17] Dall'Asta, A. and Zona, A., "Finite element model for externally prestressed composite beams with deformable connection”, Journal of Structural Engineering, ASCE, 2005, 131(5), pp.706-714.

[18] Simo, J.C., "A finite strain beam formulation the three-dimensional dynamic problem. Part 1”, Computer Methods in Applied Mechanics and Engineering, 1985, 49(1), pp.55-70.

[19] Simo, J.C. and Vu-Quoc, L., "A three-dimensional finite-strain rod model. Part 2: computational aspects”, Computer Methods in Applied Mechanics and Engineering, 1986, 58(1), pp.79-116.

[20] Malvern, L.E., "Introduction to the Mechanics of a Continuous Medium”, Prentice-Hall, Inc., Englewood Cliffs, NJ., 1969.

[21] Dall'Asta, A., "On the coupling between three-dimensional bodies and slipping cables”, International Journal of Solids Structures, 1996, 33(24), pp.3587-3600.

[22] Dall'Asta, A. and Zona, A., "Slip locking in finite elements for composite beams with deformable shear connection”, Finite Elements in Analysis and Design, 2004, 40(13-14), pp.1907-1930.

[23] CEB-FIP, Comité Euro-International du Béton (1988). “Model Code 1990.” CEB Bulletin d'Information. n. 190, Paris, France.

[24] Bazant, Z.P., Pan, J. and Pijaudier-Cabot, G., "Softening in Reinforced Concrete Beams and Frames”, Journal of Structural Engineering, ASCE, 1987, 113(12), pp.2333-2347.

[25] Bruneau, M., Uang, C.M. and Whittaker, A., "Ductile Design of Steel Structures”, McGraw Hill., 1998.

[26] Menegotto, M. and Pinto, P.E., "Method of analysis for cyclically loaded reinforced concrete plane frames including changes in geometry and nonelastic behavior of elements under combined normal force and bending”, Proceedings, IABSE Symposium on Resistance and Ultimate Deformability of Structures Acted on by Well-Defined Repeated Loads, International Association for Bridge and Structural Engineering, Zurich, 1973, pp.112-123.

[27] Chen, S. and Gu, P., "Load carrying capacity of composite beams prestressed with external tendons under positive moment”, Journal of Constructional Steel Research, 2005, 61(4), pp.515-530. 


\title{
WIND TUNNEL TESTS AND WIND-INDUCED VIBRATION ANALYSIS OF SPHERICAL DOMES
}

\author{
Zhi-hong Zhang* and Yukio Tamura \\ Wind Engineering Research Center, Tokyo Polytechnic University, 1583 Iiyama Atsugi Kanagawa 243-0297 Japan \\ *(Corresponding author: E-mail: zhangzh@arch.t-kougei.ac.jp; Tel.: +81-46-242-9928; Fax: +81-46-242-9928)
}

\begin{abstract}
A series of wind pressure measurements on the surfaces of spherical domes are carried out in an atmospheric boundary-layer wind tunnel. The wind pressure distributions on the surfaces of spherical domes including mean and standard deviation are presented. Effects on wind pressure distribution due to wall-height-to-span ratio and rise-to-span ratio, terrain type and Reynolds number are discussed. This study focuses on wind-induced vibration analysis. The Proper Orthogonal Decomposition (POD) technique is adopted to reconstruct the wind pressure field for reticulated spherical domes with different mesh size and shape, and compared with those obtained from a wind-tunnel test model. A new treatment of non-uniformly distributed taps is proposed. Different treatments lead to different optimal problems with different physical meanings. For mode superposition analysis of wind-induced vibration analysis, a new matrix, designated by the authors as a mode-load-correlation matrix, is proposed to determine the special mode that contributes most to the wind effects. This mode contributes most to the background response and significantly to the resonant part. The physical meaning of this matrix is the spatial distribution of structural response. The advantage is that it only takes into account the known variables in the motion equation, without any quasi-static or dynamic assumption. Finally, the application of this matrix to background response is presented.
\end{abstract}

Keywords: Wind tunnel test; wind pressure; wind-induced vibration; spherical dome; reticulated shell; high modes effect

\section{LIST OF SYMBOLS}

$\begin{array}{ll}Z_{G} & \text { thickness of atomospheric boundary layer } \\ \alpha & \text { power law of terrain types } \\ f & \text { rise of spherical dome } \\ h & \text { height of surrounding wall of rigid models } \\ D & \text { span of spherical dome } \\ C_{\bar{p}} & \text { mean wind pressure coefficient } \\ \bar{p} & \text { mean wind pressure } \\ q_{H} & \text { reference wind pressure } \\ C_{\sigma_{p}} & \text { wind pressure standard deviation coefficient } \\ \sigma_{p} & \text { wind pressure standard deviation } \\ \phi(x, y) & \text { proper function } \\ \Delta S_{i} & \text { tributary area of each pressure tap } \\ {\left[R_{p}\right]} & \text { spatial correlation matrix of wind pressure } \\ \left\{\phi^{\prime}\right\} & \text { POD modes weighted by tributary area } \\ \lambda & \text { POD mode eigenvalues } \\ a_{j}(t) & \text { principal coordinates of POD analysis } \\ W\left(x_{i}\right) & \text { weighted function due to tributary area } \\ {[M]} & \text { mass matrix } \\ {[C]} & \text { damping matrix } \\ {[K]} & \text { stiffness matrix } \\ \{Y(t)\} & \text { displacement response of structure } \\ {\left[\phi^{\prime}\right]} & \text { POD modes matrix }\end{array}$




$\begin{array}{ll}\{a(t)\} & \text { matrix of principle coordinates } \\ \{P(t)\} & \text { external fluctuating load } \\ {[\varphi]} & \text { modal matrix that is independent of time } \\ \{q(t)\} & \text { modal coordinates } \\ \{q(t)\}_{B} & \text { background response } \\ \{q(t)\}_{R} & \text { resonant response } \\ {[M L C]} & \text { mode-load correlation matrix }\end{array}$

\section{INTRODUCTION}

A series of wind pressure measurements have been carried out in Wind Engineering Research Center of Tokyo Polytechnic University in order to detect the wind effects on large-span reticulated spherical shells. The author considers that, for a long time for large-span reticulated shells, there has been no consensus on high mode effects in mode superposition transient analysis. The motivation for this study was to determine this high-order "fundamental" mode.

Taniguchi et al. [1] measured the time-averaged pressure distribution over the surface of a hemisphere immersed in a fully developed turbulent boundary layer developing along a smooth, plane wall. The drag coefficient and lift coefficients were also studied. Toy et al. [2,3] investigated a hemispherical dome and a semi-cylindrical dome immersed in a boundary-layer wind tunnel. Newman et al. [4] measured the pressure distribution on three domes with different rise-to-span ratios ( $f / D=0.5,0.37,0.25)$. Cook [5] gave out some analytical formulas for wind pressure coefficient distribution of a semi-cylinder and a hemisphere in smooth uniform flow. Taylor [6] did a comprehensive study of the aerodynamic pressure distribution on hemispherical domes in boundary layer flows, including the determination of the mean, minimum, maximum and area-average pressure coefficients. The critical area and critical pressures for design were defined. Hongo [7] carried out a series of wind tunnel experiments on mean and fluctuating wind pressures with different rise-to-span ratios and different wall-height-to-span ratios.

For wind pressure field reconstruction on indirectly measured points on a model surface, Uematsu and Yamada [8] applied POD to investigate the structure of the pressure field on spherical domes and to generate wind loads at the interior nodes of the network by superimposing the first eight eigenfunctions of pressure obtained from POD analysis. They considered that mismatch between high-frequency pressure fluctuations of experiment and simulation may not significantly affect the dome's general response. This is because the spatial correlation of these pressure fluctuations is rather low and their frequencies are much higher than the dome's natural frequencies. Y. Uematsu et al. [9] carried out some basic investigations on wind-induced dynamic behavior and the resultant load estimation of a single-layer lattice dome with a large span. POD is used to generate the wind pressure time history at nodes measured indirectly. Carassale et al. [10] studied POD both in the time domain (Covariance Proper Transformation) and in the frequency domain (Spectral Proper Transformation).

For non-uniformly distributed taps of wind pressure measurement Jeong et al. [11] discussed POD applied to wind pressure specified at non-uniformly distributed pressure taps. The author considers that the first weighted method of the correlation/covariance matrix proposed by them leads to a non-symmetric covariance matrix, which is not good for the computational solution of eigenvalue problems. The second weighted method that needs both a weighted correlation/covariance matrix and a weighted POD mode leads to a different optimal mechanical 
problem. Thus, we re-derive the whole process of POD in Section 4.1. It is clear that there is a simple way to take account of the non-uniformly distributed taps' effect [12].

For wind-induced vibration analysis of single-layer reticulated spherical shells, Masuda et al. [13] and Nakayama et al. [14] proposed an efficient selection of dominant modes from the viewpoint of contribution to the expected fluctuating strain energy of the system. It was pointed out there existed a specific mode "X-mode", which was indispensable in estimating wind response, even though its natural frequency or modal order may be very high. A method for predicting the "quasi-X-mode" was also proposed. Ni et al. [15] studied the wind-induced response of a dome-like roof using the load-dependent Ritz vector method proposed by Wilson [16,17]. He and Dong [18] proposed a new frequency domain method for wind response analysis of spatial lattice structures with mode superposition. This is termed a mode compensation method. The authors of this paper [19] presented a new way for mode truncation by checking the relationship between the eigenpairs from Proper Orthogonal Decomposition analysis and Finite Element Method modes. This paper gives out the details of our idea.

Recently Li and Tamura [20,21] published their work on wind effects on a single-layer reticulated spherical dome. An equivalent static wind loading estimation method from the viewpoint of stability was also proposed.

Wind pressure distribution affected by wall-height-to-span ratio, rise-to-span ratio and Reynolds number is presented. A new treatment of POD analysis for reconstruction of the wind pressure field on the surface of reticulated spherical shells is discussed. The second objective of this paper is to investigate wind effects on large-span reticulated spherical shells. A new simple way to find out the special mode that contributes most to the wind effects is put forward. This mode contributes most to background response and significantly to the resonant part. A new matrix (mode-load-correlation matrix) is proposed. It is concluded that this matrix can reveal the spatial distribution of fluctuating structural response including the background response and the resonant response. Some suggestions are also made for further research.

\section{WIND PRESSURE MEASUREMENT EXPERIMENTS OF SPHERICAL DOMES}

\subsection{Wind Fields Simulation}

Four parameters are required to simulate the natural atmospheric boundary layer in the wind tunnel: mean wind speed profile, turbulence intensity profile, turbulence scale and power spectrum. Wind pressure measurements of spherical domes were carried out in the wind tunnel of the Wind Engineering Research Center of Tokyo Polytechnic University. This wind tunnel has a work section $15 \mathrm{~m}$ long, $2.2 \mathrm{~m}$ wide and $1.8 \mathrm{~m}$ high. A thickness $Z_{G}=100 \mathrm{~cm}$ of two boundary layers with terrain types with power laws $\alpha=0.195,0.346$ is generated using a set of spires and a number of roughness blocks on the wind-tunnel floor.

\subsection{Spherical Dome Models and Wind Pressure Measurements}

The geometry of the wind pressure measurement model is shown in Figure 1. 12 models of two terrain types (III, V) with rise-to-span ratios $f / D=1 / 3,1 / 5$ (Model 1,2) and wall-height-to-span ratios $h / D=1,2 / 3,1 / 2,1 / 3,1 / 6$ and 0 (Case 1 6) are measured. The wind pressure distribution of both the spherical dome and the wall surface are measured synchronously but separately. 
Shells with rise-to-span ratios smaller than $1 / 5$ are regarded as shallow shells. In this study, the length scale of the models is assumed to be 1/400. Thus, the dynamic responses of prototype shells with $120 \mathrm{~m}$ spans are analyzed later. The model surfaces were smooth. Each model had 91 pressure taps nearly uniformly distributed on the dome surface (K6-6, Figures 2 and 3). The maximum number of pressure taps on the wall was 108 . The frequency of the low pass filter was set to $300 \mathrm{~Hz}$. The sampling frequency of synchronous pressure measurement was $1000 \mathrm{~Hz}$. Tube correction is carried out by using a flat panel with 32 taps and a white noise generation machine. The test wind velocities were set to $10 \mathrm{~m} / \mathrm{s}, 8 \mathrm{~m} / \mathrm{s}$ and $6 \mathrm{~m} / \mathrm{s}$ at the top of model (Case 1) corresponding to a full-scale wind speed of $60 \mathrm{~m} / \mathrm{s}$. The sampling interval was $15 \mathrm{~s} / \mathrm{time}$, and each case was tested 10 times. The time interval was $0.04 \mathrm{~s}$ in full scale. The blockage effect in all of the measurements is considered small enough to be ignored.

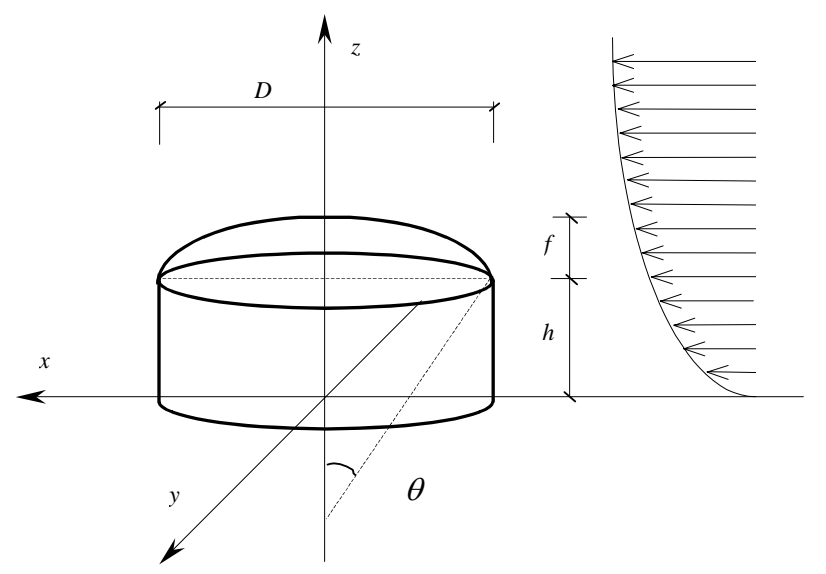

Figure 1. Dome model geometry

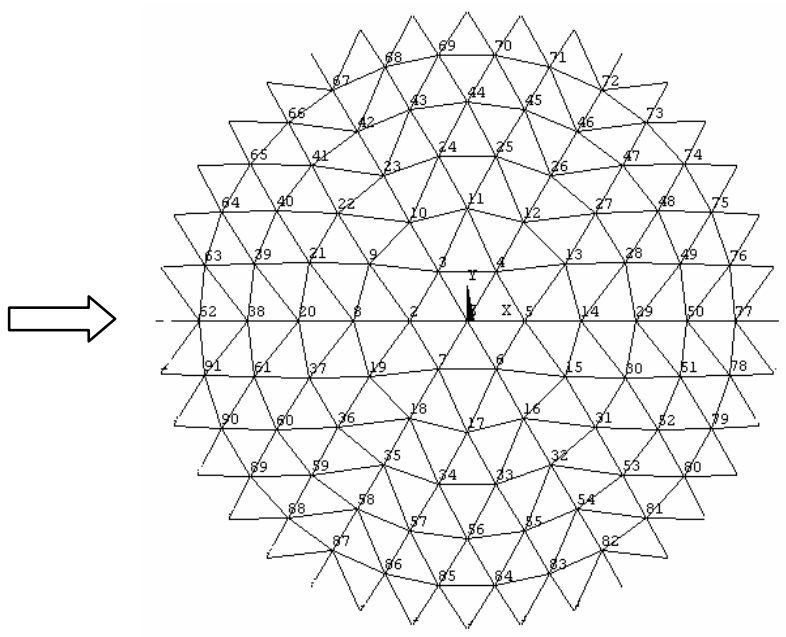

Figure 2. Numbering of pressure taps (K6-6)
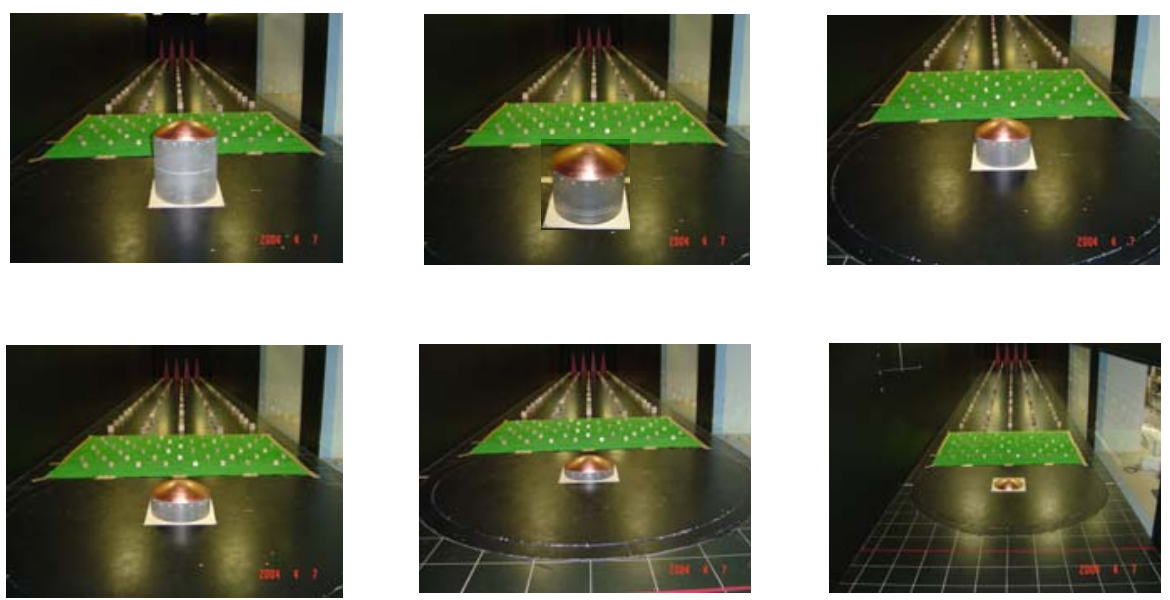

Figure 3. Test model (Case 1 6, Terrain type Ш, Taps distribution K6-6)

\section{EXPERIMENTAL RESULTS}

This section gives out experimental results from wind pressure measurements in details.

\subsection{Definition of Pressure Coefficients}

The wind pressure coefficients are defined in terms of the pressure at the top point of the roof model. 
Mean

Standard Deviation

$$
C_{\bar{p}}=\bar{p} / q_{H}
$$$$
C_{\sigma_{p}}=\sigma_{p} / q_{H}
$$

Where $\bar{p}$ is the mean pressure, $q_{H}$ is the reference wind velocity pressure at the reference height H (top of model).

\subsection{Effect of Different Wall-height-to-Span Ratios}

Figures 4 and 5 show the wind pressure coefficients $C_{\bar{p}}$ and $C_{\sigma_{p}}$, respectively, of model 1 in terrain type $\amalg$ with six different wall-height-to-span ratios. With decrease of wall height, the curves move integrally upward, since the turbulence intensity increases while the mean wind velocity decreases.

\subsection{Effect of Different Terrain Types}

Figure 6 shows the mean wind pressure coefficient distribution of model 1 in terrain types $\amalg$ and V with reference wind velocity $10 \mathrm{~m} / \mathrm{s}$. This shows that different terrain types give rise to different wind pressure distributions.

\subsection{Reynolds Number Effect}

Figures 7 and 8 show the mean and standard deviation coefficient distribution of model 1 in Terrain type $\amalg$ under three different reference velocities at the top of the roof. The Reynolds number is between $1.0 \times 105$ and $3.0 \times 105$ or so (subcritical). It is found that different reference wind velocities could affect the mean and the standard deviation wind pressure coefficient. This is consistent with that of Taylor [6] and Hongo [9]. It is proposed to carefully choose appropriate reference wind velocities for ABLWT tests on streamlined structures. In the practical situation (full scale dome) the Reynolds number is about 108 109 (Transcritical). It is nearly impossible to satisfy the Reynolds number simulation requirement in ABLWT tests. It is mentioned by Taylor [6] that for the turbulence intensity of natural wind $(>0.15 \%)$ the wind pressure is considered relatively insensitive when the Reynolds number is above $1.7 \times 105$. The main objective of this paper is not to detect the Reynolds number effect, but this is very important in practical design. A similar flow pattern corresponding to a high Reynolds number is usually generated by increasing the surface roughness or using tripping wires [22].

\section{WIND-INDUCED VIBRATION ANALYSIS}

There are three steps in analyzing the wind-induced vibration of reticulated spherical domes. First, convert the wind pressure time history of the reduced-scale model to that of the full-scale model. This will change the amplitude of the wind pressure and sampling frequency. Second, reconstruct the wind field, because there will usually be some nodes (practical lattice shell) that have not been measured. The efficiency and validation of POD in reconstructing the wind field are investigated using half the taps on the reduced-scale model to reconstruct the wind pressure time history of all of the taps [12]. Third is transient analysis of wind-induced response. It is not easy to determine the special predominant mode when the superposition method is adopted. A new way to find this mode is proposed in Sec. 4.2 . 


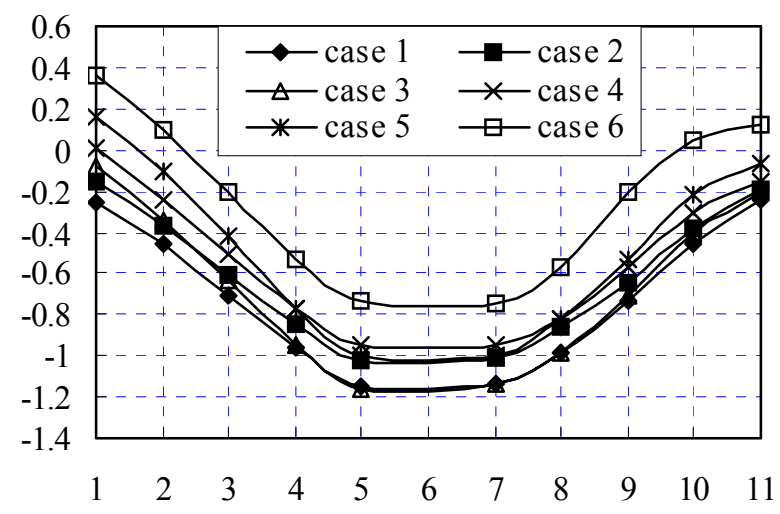

Figure 4. Mean value of Model 1,

Terrain type Ш

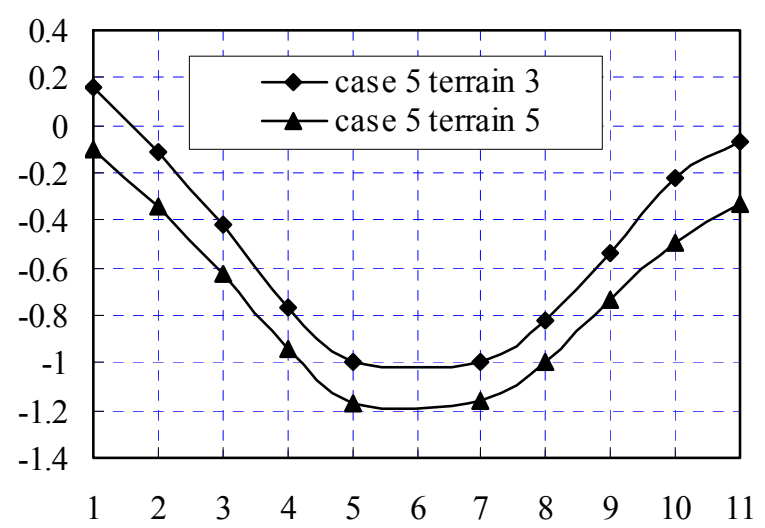

Figure 6. Terrain type effect

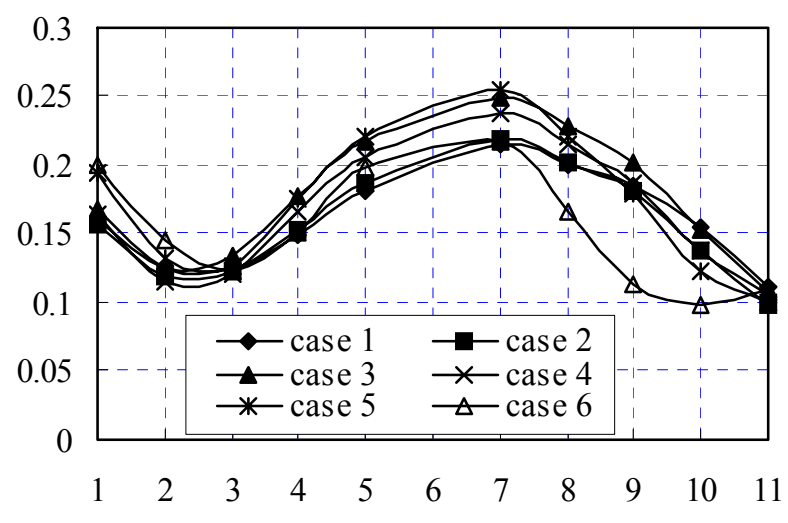

Figure 5. Standard derivation of Model 1, Terrain type Ш

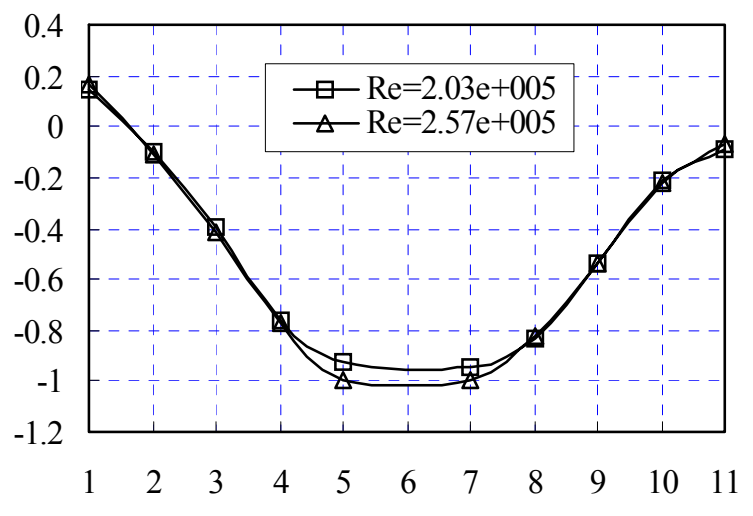

Figure 7. Reynolds number effects (Mean value, Model 1, Case 5, Terrain type Ш)

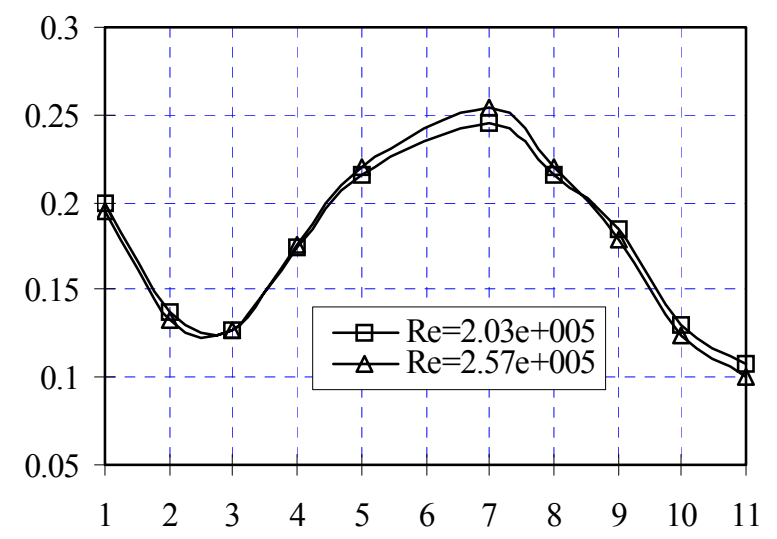

Figure 8. Reynolds number effects (Standard derivation, Model 1 Case 5 Terrain type Ш)

\subsection{Proper Orthogonal Decomposition method in application to reconstruction of wind pressure field for reticulated spherical domes}

There are two interpretations of POD at present. The first regards POD as Karhunen-loeve decomposition (KLD) and the second considers that it consists of three methods: KLD, Principal Component Analysis (PCA) and Singular Value Decomposition (SVD). 


\subsubsection{POD (Karhunen-Loeve decomposition) re-derivation in discrete form}

Assume there are $n$ taps (Figure 9) on the surface of the structure model for wind pressure measurement.

$$
\sum_{i=1}^{n} p\left(x_{i}, y_{i}, z_{i}, t\right) \phi\left(x_{i}, y_{i}, z_{i}\right) \Delta S_{i}=\max
$$

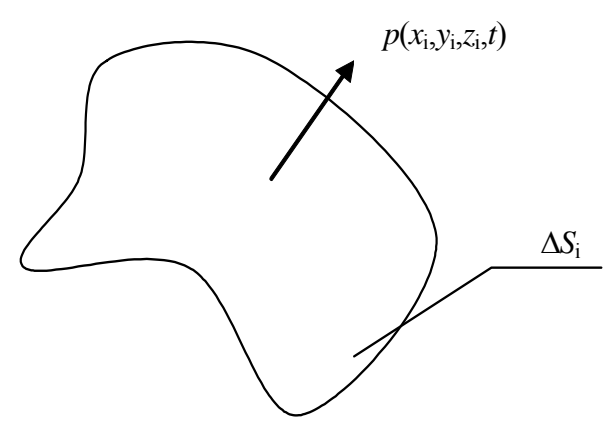

Figure 9. A tap for wind pressure measurement

This equation indicates that the fluctuating wind pressures should be measured synchronously (Condition 1).

$$
\begin{gathered}
\frac{\sum_{i=1}^{n} p\left(x_{i}, y_{i}, z_{i}, t\right) \phi\left(x_{i}, y_{i}, z_{i}\right) \Delta S_{i}}{\left(\sum_{i=1}^{n}\left(\phi\left(x_{i}, y_{i}, z_{i}\right) \Delta S_{i}\right)^{2}\right)^{1 / 2}}=\max \\
\frac{\left(\sum_{i=1}^{n} p\left(x_{i}, y_{i}, z_{i}, t\right) \phi\left(x_{i}, y_{i}, z_{i}\right) \Delta S_{i}\right)^{2}}{\sum_{i=1}^{n}\left(\phi\left(x_{i}, y_{i}, z_{i}\right) \Delta S_{i}\right)^{2}}=\lambda
\end{gathered}
$$

In order to look for the proper function of $\phi(x, y)$, both sides of the above equation are divided by $\delta \phi$.

$$
\frac{\delta}{\delta \phi}\left[\left(\sum_{i=1}^{n} p\left(x_{i}, y_{i}, z_{i}, t\right) \phi\left(x_{i}, y_{i}, z_{i}\right) \Delta S_{i}\right)^{2}-\lambda \sum_{i=1}^{n}\left(\phi\left(x_{i}, y_{i}, z_{i}\right) \Delta S_{i}\right)^{2}\right]=0
$$

- If $\Delta S_{i}=\Delta S_{j}(i, j=1,2, \cdots, n, i \neq j)$ is satisfied first, $\Delta S_{i}$ can be removed from the above equation. Thus, this condition requires the distribution of taps to be uniform (Condition 2).

If the fluctuating component of wind is considered as a steady random process with zero mean value (Condition 3), Eq. (4) is simplified as follows.

$$
\left\lfloor R_{p}\{\phi \phi\}=\lambda\{\phi\}\right.
$$

In Eq. (5) the spatial correlation matrix $\left[R_{p}\right]$ is symmetric.

Eq. (5) is a familiar form of eigenvalue problem. There are several developed algorithms to get the eigenpairs of matrix $\left[R_{p}\right]$ such as the subspace iteration method, the Lancosos method, the inverse iteration method, and so forth.

- If $\Delta S_{i}=\Delta S_{j}(i, j=1,2, \cdots, n, i \neq j)$ is not always satisfied, $\Delta S_{i}$ can not be removed from Eq. (4). 
If the fluctuating component of wind is considered as a steady random process with zero mean value (Condition 3), Eq. (4) is simplified as follows.

$$
\left\lfloor R_{p}\right\rfloor\left\{\phi^{\prime}\right\}=\lambda\left\{\phi^{\prime}\right\}
$$

where $\left\{\phi^{\prime}\right\}=\left\{\begin{array}{c}\phi\left(x_{1}, y_{1}, z_{1}\right) \Delta S_{1} \\ \phi\left(x_{2}, y_{2}, z_{2}\right) \Delta S_{2} \\ \vdots \\ \phi\left(x_{n}, y_{n}, z_{n}\right) \Delta S_{n}\end{array}\right\}$

\subsubsection{Physical meaning of $\left\{\phi^{\prime}\right\}$ in Eq. (6) and discussion when taps non-uniformly distributed}

In terms of POD, the complex time and spatially varying wind pressure field on a building can be divided into time-varying parts $a_{j}(t)$ independent of spatial position and spatially varying 'modes' $\left\{\phi_{j}^{\prime}\right\}$ that depend on spatial position, $j$, and the tributary area, i.e., the geometry of the model surface, but independent of time.

It is noted that in Eq. (7) the eigenvector is weighted by the tributary area of the taps. This is very different from the two methods proposed by Jeong et al. [11]. Modification of the covariance matrix in reference [11] will give rise to a different physical meaning of the principal coordinate/eigenvector and a different optimal problem. In section 2 of reference [11], the weighted-POD of taps non-uniformly distributed of the wind pressure field is denoted by Eq. (8).

$$
\sum_{i=1}^{n} R_{p}^{t}\left(x_{j}, x_{i}\right) \phi^{t}\left(x_{i}\right)=\lambda \phi^{t}\left(x_{j}\right)
$$

where $R_{p}^{t}\left(x_{j}, x_{i}\right)=W\left(x_{j}\right)^{1 / 2} R_{p}\left(x_{j}, x_{i}\right) W\left(x_{i}\right)^{1 / 2}, \phi^{t}\left(x_{i}\right)=W\left(x_{i}\right) \phi\left(x_{i}\right)$ are the modified correlation matrix and eigenvector. Eq. (8) can be rewritten as Eq. (9).

$$
\left[R_{p}\right]\left\{\phi^{\prime}\right\}=\lambda\{\phi\}
$$

while Eq. (9) can be derived from Eq. (10).

$$
\frac{\sum_{i=1}^{n} p\left(x_{i}, y_{i}, z_{i}, t\right) \phi\left(x_{i}, y_{i}, z_{i}\right) \Delta S_{i}}{\left(\sum_{i=1}^{n}\left(\phi\left(x_{i}, y_{i}, z_{i}\right)\right)^{2}\right)^{1 / 2}}=\max
$$

When comparing Eq. (10) with Eq. (1), it is found that they are obviously two mechanical problems. Eq. (10) describes the wind force field on the building surface other than the wind pressure field as depicted in Eq. (1). In terms of the physical meaning of mode $\left\{\phi^{\prime}\right\}$, as mentioned above, in our opinion, it is not rational to regard Eq. (10) as a wind pressure field by proper orthogonal decomposition.

A comprehensive introduction of reconstruction of wind pressure field with consideration of the non-uniform tributary area is presented as follows. 


\subsubsection{Reconstruction of wind pressure field with respect to non-uniformly distributed taps}

Assume that there are $n$ taps non-uniformly distributed on the surface of the test model and $k$ is the sampling time. We can reconstruct the wind pressure field of the test model in terms of POD, Eq. (11), where $p\left(x_{i}, y_{i}, z_{i}, t\right)$ is the wind pressure time history of the test model, $\phi_{i}^{\prime}$ is the eigenvector of covariance matrix, i.e., mode, and $a_{i}(t)$ is the principal coordinate.

$$
\left\{\begin{array}{c}
p\left(x_{1}, y_{1}, z_{1}, t\right) \\
p\left(x_{2}, y_{2}, z_{2}, t\right) \\
\vdots \\
p\left(x_{n}, y_{n}, z_{n}, t\right)
\end{array}\right\}_{n \times k}=\left\{\begin{array}{llll}
\phi_{1}^{\prime} & \phi_{2}^{\prime} & \cdots & \phi_{n}^{\prime}
\end{array}\right\}_{n \times n}\left\{\begin{array}{c}
a_{1}(t) \\
a_{2}(t) \\
\vdots \\
a_{n}(t)
\end{array}\right\}_{n \times k}
$$

If the values of $\phi_{i}^{\prime}$ at the nodes of the dome's network are interpolated or extrapolated from those at the tap locations, we get Eq. (12) as follows.

$$
\left\{\begin{array}{c}
p i\left(x_{1}, y_{1}, z_{1}, t\right) \\
\operatorname{pi}\left(x_{2}, y_{2}, z_{2}, t\right) \\
\vdots \\
\operatorname{pi}\left(x_{l}, y_{l}, z_{l}, t\right)
\end{array}\right\}_{l \times k}=\left\{\begin{array}{llll}
\phi_{1}^{\prime i} & \phi_{2}^{\prime i} & \cdots & \phi_{n}^{\prime i}
\end{array}\right\}_{l \times n}\left\{\begin{array}{c}
a_{1}(t) \\
a_{2}(t) \\
\vdots \\
a_{n}(t)
\end{array}\right\}_{n \times k}
$$

where $\operatorname{pi}\left(x_{i}, y_{i}, z_{i}, t\right)$ is the simulated wind pressure time history for the practical structure, $\phi_{j}^{\prime i}$ is the interpolated eigenvector of the covariance matrix, and $l$ is the node number of a practical dome structure in reduced scale. $l$ can be larger or smaller than $n$. It is noted here that the taps are non-uniformly distributed. $\phi_{i}^{\prime}$ should not be divided by the tributary area before interpolation. This may be questioned. It seems that there would be no difference between uniformly and non-uniformly distributed taps. In the authors' opinion, the geometry information (tributary area) is inherent in the eigenvector matrix $\left\{\phi_{i}^{\prime}\right\}$, and the interpolation is within the column subspace of $\left\{\phi_{i}^{\prime}\right\}$. It would be wrong to remove the tributary area from $\phi_{i}^{\prime}$ before interpolation of POD modes. The steps are as follows. Actually, in this paper the wind pressure time history has been transformed to wind pressure coefficient time history including the mean one since the pressure coefficients are non-dimensional.

Step 1. Input the nodal coordinates and tributary area on the surface of a practical structure in reduced scale (reticulated shell, cable dome, and suspen-dome) and test model;

Step 2. Input the original wind pressure time history on the taps of the spherical dome model measured in ABLWT (different exposure type, height of surrounding wall, reference wind speed). Calculate the covariance of wind pressure time history (exclude mean value, with tributary area). POD does not include the mean value component of the wind pressure time history. It is indispensable to interpolate the mean value for the reduced scale practical structure mesh shape and distribution;

Step 3. POD analysis of wind pressure data on the test model Eq. (6);

Step 4. Scattered data interpolation of eigenvector to $l$ dimension in terms of the nodal coordinates of a practical structure (spatial location of nodes). The cubic interpolation method is adopted in this paper and the linear interpolation method is verified to be worse than the cubic one;

Step 5. Reconstruction/simulation of wind pressure field on the surface of a practical structure in reduced scale;

Step 6. Output the data file of wind pressure history on the surface of the practical structure in reduced scale. 


\subsubsection{Validation}

The spherical dome ABLWT wind pressure test data of half of the taps (K3-6, Figure 10) were utilized to reconstruct the wind pressure field, and they are compared with those for all the taps (K6-6, Figure 3) for validation of Eq.(1) Eq.(7). K3-6 includes half of the taps of K6-6. The first mode is predominant. Figure 11 gives the time history of reconstruction by using and the corresponding measured one at node 3 (K6-6).

Before interpolation, $\phi_{i}^{\prime}$ should not be divided by the tributary area. The geometry information (tributary area) is inherent in the eigenvector. Moreover, the interpolation is within the column space of the

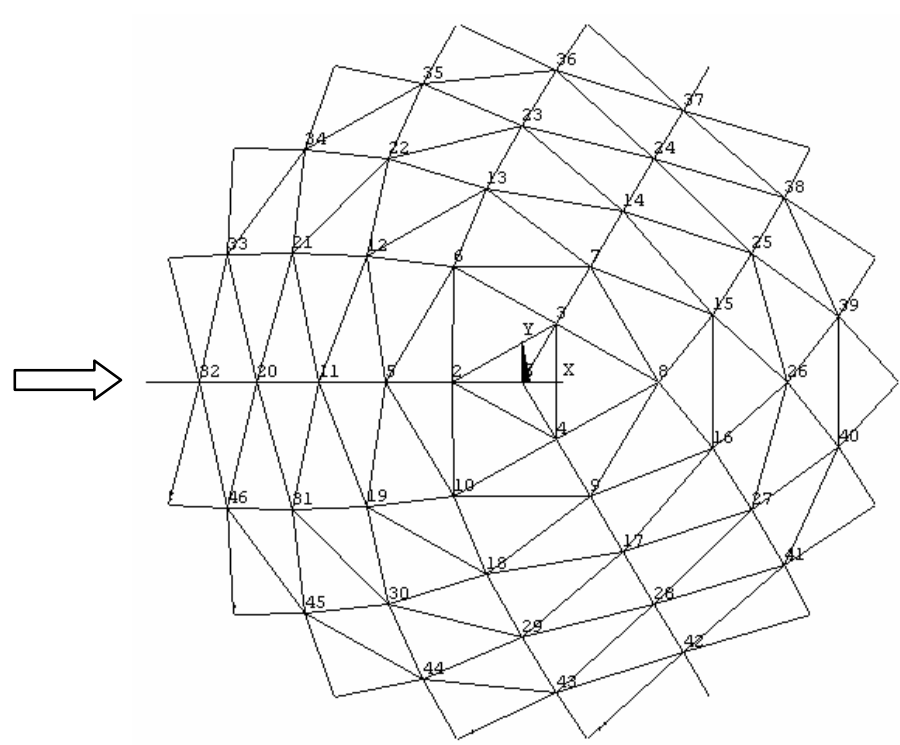

Figure 10. Node numbering (K3-6) eigenvector matrix. The error in the reconstructed time history of the wind pressure coefficients is due to the error of scattered data interpolation of the POD modes. Linear interpolation causes much bigger errors than cubic interpolation. The error of POD mode interpolation increases as the corresponding eigenvalue decreases. The real POD modes are smoother than the interpolated ones. It is considered in reference [12] that the precision of the reconstruction of wind pressure time history on the surface of practical structures depends on not only scattered data interpolation methods but also on the density of taps on a test model.

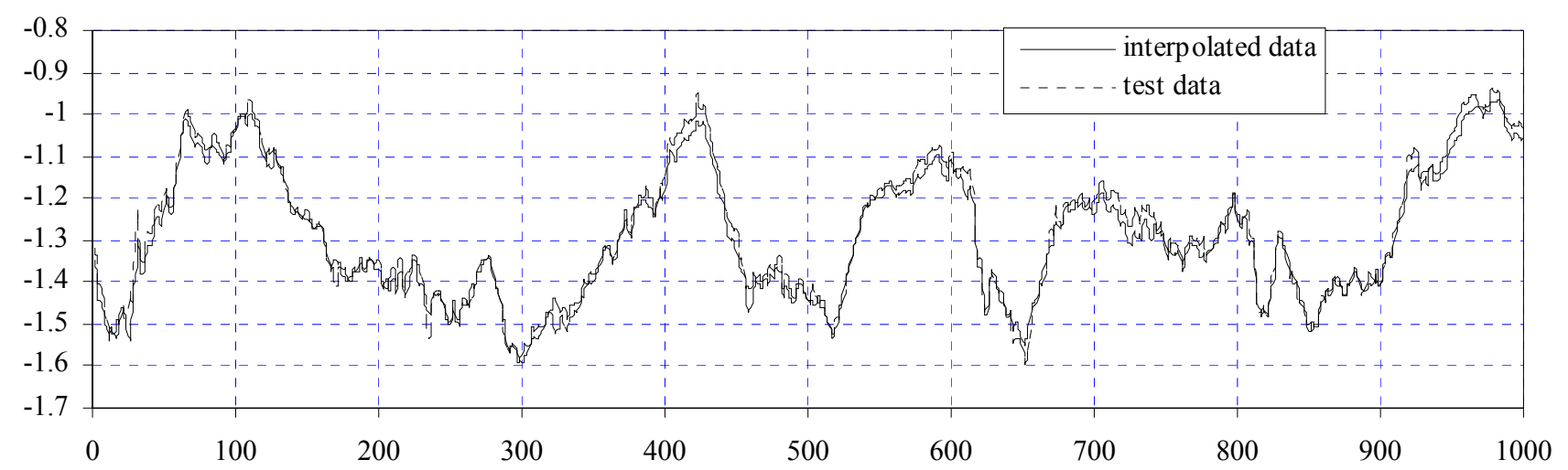

Figure 11. Time history of wind pressure coefficient at node 3 (1s, interpolated from K3-6 to K6-6 based on POD)

\subsection{Wind-induced vibration analysis of single-layer reticulated shells using mode superposition}

The second objective of the wind tunnel test was to study wind effects on practical structures.

\subsubsection{Motion equation and mode superposition method}

The dynamic motion equation can be written as follows. 


$$
[M]\{\ddot{Y}(t)\}+[C]\{\dot{Y}(t)\}+[K]\{Y(t)\}=\left[\phi^{\prime}\right]\{a(t)\}=\{P(t)\}
$$

where $[M]$ is the mass matrix, $[C]$ is the damping matrix, $[K]$ is the stiffness matrix, and $\{Y(t)\}$ is the displacement response of the structure. [ $\left.\phi^{\prime}\right]$ is the POD mode matrix, $\{a(t)\}$ is a matrix of principle coordinates. All possible types of time-dependent load, for example seismic, sea wave and wind, can be represented by the sum of orthogonal load modes that are independent of time. $\{P(t)\}$ is the external fluctuating load.

Assume a displacement solution in the form of Eq. (14)

$$
\{Y(t)\}=[\varphi]\{q(t)\}
$$

where $[\varphi]$ is designated as a modal matrix, which is also independent of time, and $\{q(t)\}$ denotes the modal coordinates. Substitute Eq. (14) into Eq. (13) and pre-multiply by $[\varphi]^{T}$, thus

$$
[\varphi]^{T}[M][\varphi]\{\ddot{q}(t)\}+[\varphi]^{T}[C][\varphi]\{\dot{q}(t)\}+[\varphi]^{T}[K][\varphi]\{q(t)\}=[\varphi]^{T}\left[\phi^{\prime}\right]\{a(t)\}
$$

where $[m p f]=[\varphi]^{T}\left[\phi^{\prime}\right]$ is termed modal participation factor matrix.

\subsubsection{New mode-load-correlation matrix on the basis of POD modes and eigenvalues}

For wind loading, it is indispensable to determine how many vibration modes are adequate to be included in mode superposition transient analysis. This gives rise to many kinds of modal truncation methods. This section gives out a new matrix to detect the spatial distribution of the structural response. The static/dynamic load participation factors proposed by Wilson [23] are very interesting. However, they need to make quasi-static/dynamic assumption of unknown variables.

\section{(1) Square of external work associated with fluctuating wind loading}

In order to determine the predominant mode, in reference [19] the authors checked the correlation coefficient between the dominant modes and the dominant frequency of the principal coordinates obtained by Proper Orthogonal Decomposition (POD) of the fluctuating pressure fields acting on the dome model and the mode shapes and the natural frequencies of the dome structures obtained by Finite Element Method (FEM) analysis. It is verified that it is necessary to take into account the effect of the principal coordinates $\{a(t)\}$ in Eq. (11). A clear and interesting derivation is presented as follows.

The total external work associated with wind load at time $t$ is expressed in Eq. (16). The square of the total external work can be rewritten in the form shown in Eq. (17).

$$
\begin{aligned}
& E_{L}(t)=\frac{1}{2}\{Y(t)\}^{T}\{P(t)\}=\frac{1}{2}\{P(t)\}^{T}\{Y(t)\} \\
& E_{L}^{2}(t)=\frac{1}{2}\{Y(t)\}^{T}\{P(t)\} \times \frac{1}{2}\{P(t)\}^{T}\{Y(t)\}=\frac{1}{4}\{Y(t)\}^{T}\left(\{P(t)\}\{P(t)\}^{T}\right)\{Y(t)\}
\end{aligned}
$$

Substitute Eq. (12) and Eq. (1) to Eq. (15), then

$$
E_{L}^{2}(t)=\frac{1}{4}\{q(t)\}^{T}[\varphi]^{T}\left(\left[\phi^{\prime}\right]\{a(t)\}\{a(t)\}^{T}\left[\phi^{\prime}\right]^{T}\right)[\varphi]\{q(t)\}
$$

On the basis of POD analysis [24]

$$
E\left(\{a(t)\}\{a(t)\}^{T}\right)=[\operatorname{Diag}(\lambda)]
$$

where $E($ ) denotes the mathematic expect in statistics. Substitute [mpf] into Eq. (18)

$$
E_{L}^{2}(t)=\frac{1}{4}\{q(t)\}_{1 \times k}^{T}[m p f]_{k \times m}\left(\{a(t)\}\{a(t)\}^{T}\right)_{m \times m}[m p f]_{m \times k}^{T}\{q(t)\}_{k \times 1}, \quad(0<k \leq n)
$$

where $k$ is the number of modes truncated for approximation of structural response, and $n$ is the 
number of degrees of freedom of the whole structural system. On the right side of Eq. (20), only the modal coordinate $\{q(t)\}$ is unknown. Thus, if we eliminate the modal coordinate items and average the time history, a new matrix is given out, as Eq. (21).

$$
[m p f]_{k \times m} E\left(\{a(t)\}\{a(t)\}^{T}\right)_{m \times m}[m p f]_{m \times k}^{T}, \quad(0<k \leq n)
$$

Substitute Eq. (19) into Eq. (21), and Eq. (21) can be simplified as follows Eq. (22).

$$
[m p f]_{k \times m}[\operatorname{Diag}(\lambda)]_{m \times m}[m p f]_{m \times k}^{T}, \quad(0<k \leq n)
$$

Thus, a new indicator for the predominant vibration mode effect can be defined as

$$
[M L C]=[\varphi]_{k \times n}^{T}\left[\phi^{\prime}\right]_{n \times m}[\operatorname{Diag}(\sqrt{\lambda})]_{m \times m}, \quad(0<k \leq n)
$$

where $[M L C]$ is designated by the authors as mode-load-correlation matrix. Then

$$
[m p f]_{k \times m} E\left(\{a(t)\}\{a(t)\}^{T}\right)_{m \times m}[m p f]_{m \times k}^{T}=[M L C][M L C]^{T}, \quad(0<k \leq n)
$$

\section{(2) Physical meaning of mode-load-correlation matrix}

It is noted here that POD is utilized in Eq. (18). By virtue of the physical meaning of POD analysis, the mean value should be excluded in $\{F(t)\}$. Thus, in Eq. (20) the modal coordinate vector $\{q(t)\}$ includes only two parts of structural response with respect to wind-induced vibration, for example, the background response $\{q(t)\}_{B}$ and the resonant response $\{q(t)\}_{R}$. The mean wind load effect $\{q(t)\}_{\text {mean }}$ is not included. It is not difficult to follow that $\{q(t)\}$ is weighted by $[M L C]$. Thus, we conclude that [MLC] is the spatial distribution of the fluctuating structural response that is independent of time. The advantage of this matrix is that it only takes into account of the known variables in the motion equation, without any quasi-static or dynamic assumption.

\section{(3) Numerical example}

In order to verify this point, a numerical example of a single layer reticulated shell (Kiewitt-type, K6-6) with span $120 \mathrm{~m}$, rise $24 \mathrm{~m}$ and lattice type as shown in Figure 2. The section of all elements of the shell (steel tube) is $\Phi 200 \times 8 \mathrm{~mm}$. The density of the material is $7860 \mathrm{Kg} / \mathrm{m}^{3}$. The elastic modulus is $2.1 \times 10^{5} \mathrm{MPa}$.

Time history analysis using the Newmark- $\beta$ method is carried out first. Second, referenced with the results from time history analysis, modal superposition transient analysis is conducted again. The strain energy of each mode accumulated along the time history and kinetic energy are obtained. Figure 12 shows the 91st and 93rd modes of a K6-6 reticulated spherical shell (rise-to-span ratio $1 / 5$, span $30 \mathrm{~m}$ ). The $91 \mathrm{st}$ mode is integrally rising up (see [14]). It should be pointed out that this mode is usually speculated as the 'fundamental mode' of the whole structure. However, the order of this mode depends upon the structure type, rise-to-span ratio, boundary conditions and so forth. The 92nd mode is integrally a torsional mode and the 93rd mode is an anti-symmetric mode of the whole structure. Figure 13 shows the natural frequency. Figures 14 and 15 show the strain energy and kinetic energy distribution of each vibration mode. The peak value is at the 91 st order, which is very interesting. It seems that this special mode contributes most to the background response and significantly to the resonant part. 

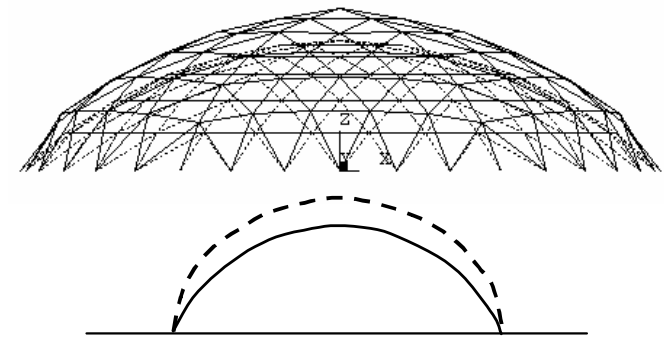

$91^{\text {st }}$ mode
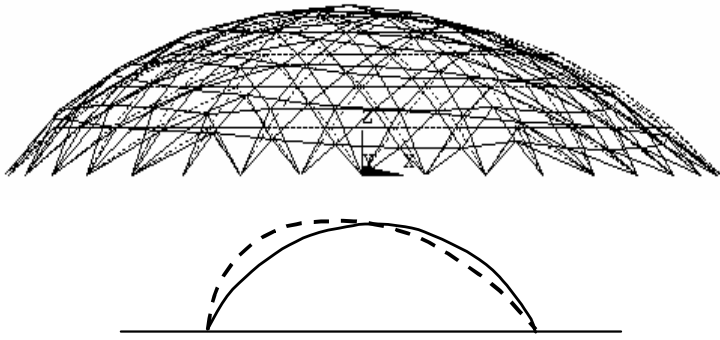

$93^{\text {rd }}$ mode

Figure 12. $91^{\text {st }}$ and $93^{\text {rd }}$ vibration mode of K6-6

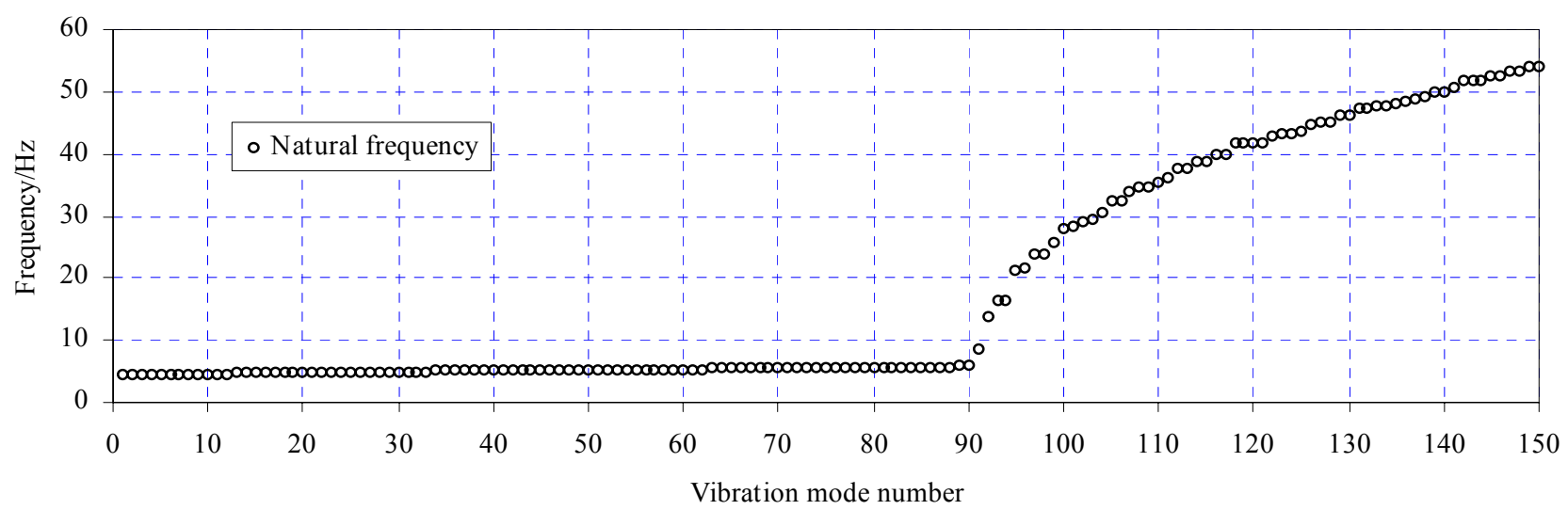

Figure 13. Natural frequency of K6-6

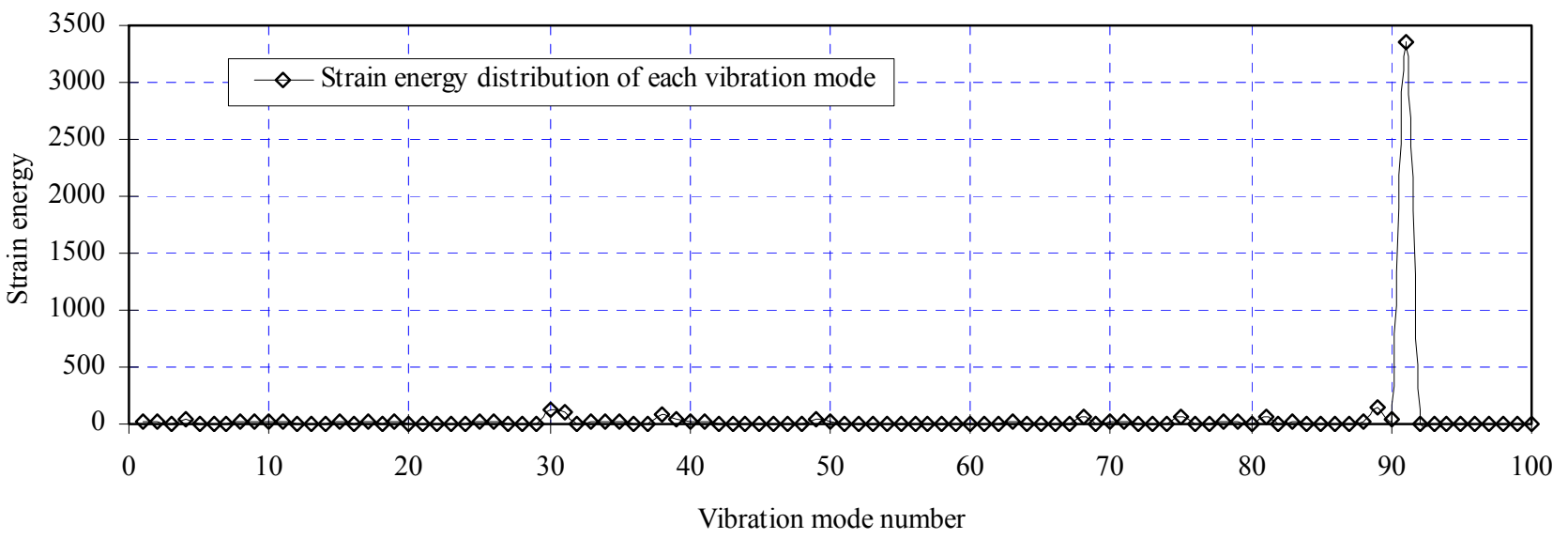

Figure 14. Strain energy distribution of each mode

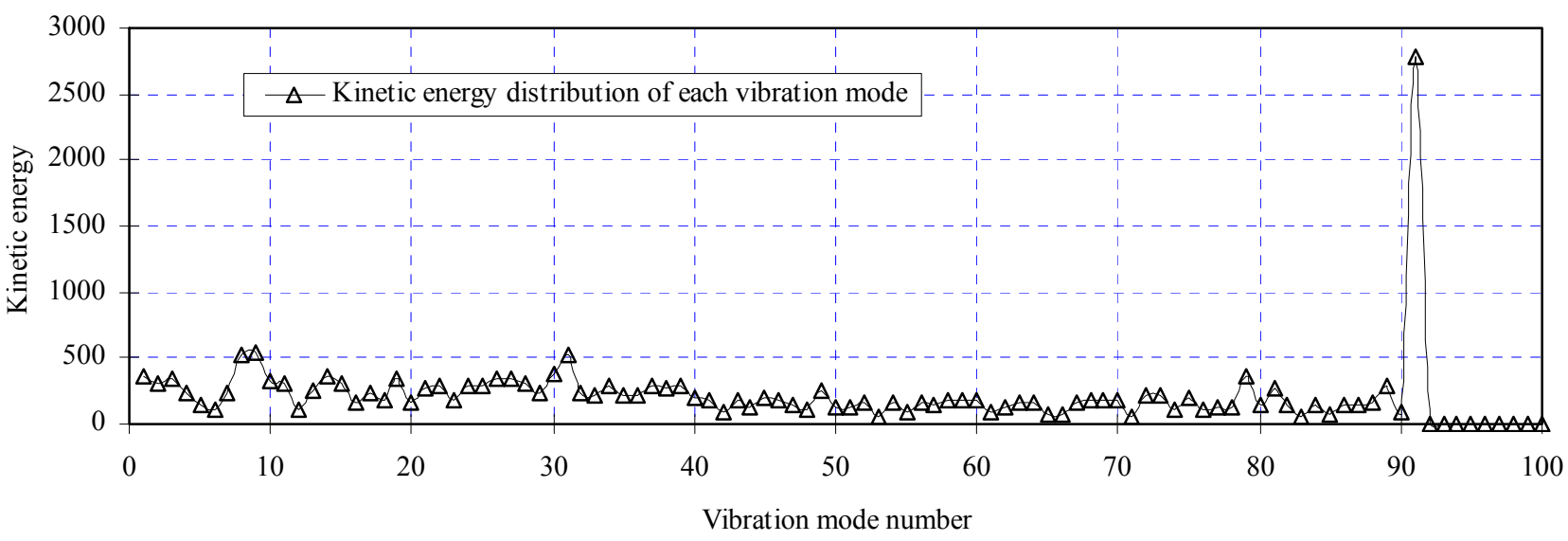

Figure 15. Kinetic energy distribution of each mode 
Figure 16 shows the results of the correlation coefficient of vibration mode (1 100) and POD mode vector (1 91) weighted by eigenvalues from POD analysis. In Figure 16, the 91st POD mode corresponds to the largest eigenvalue. The peak value is at the 91st vibration mode. This is consistent with Figures 14 and 15. This is a new way to find the predominant mode before modal superposition transient analysis. It also suggests that the POD mode with the largest eigenvalue can be utilized to find out a Ritz vector base other than the mean wind load in reference [15].

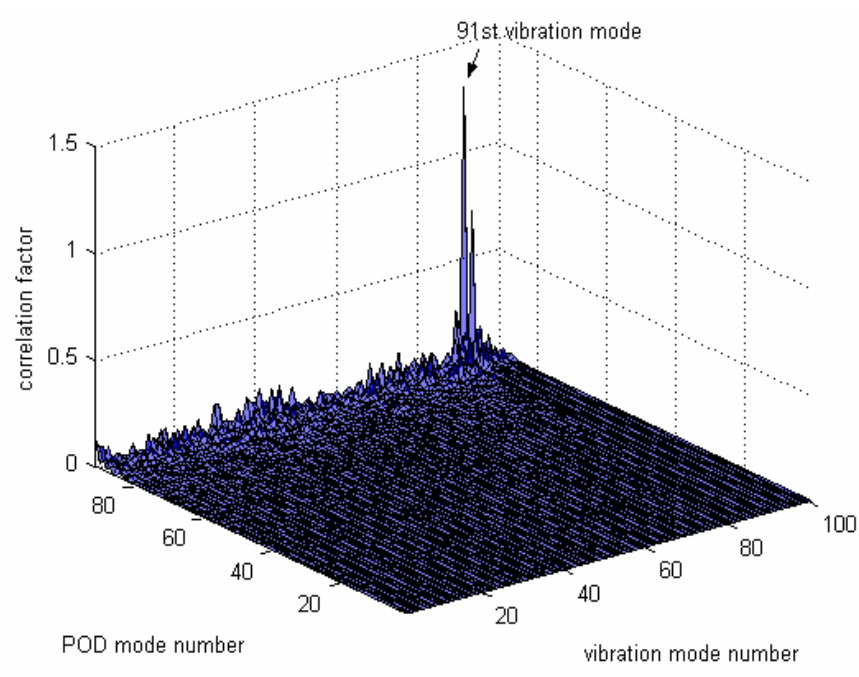

Figure 16. Mode-Load-Correlation

The authors are also very interested in the reason for high mode effects on wind-induced vibration analysis of single-layer reticulated shells. A pseudo-continuum thin shell model is checked for the vibration mode shape and natural frequency distribution of single-layer reticulated spherical shells. It gives out the reason why a mode contributing most to the quasi-static response and significantly to the resonant part ranks as a very high order. Actually, it is because of the membrane-like characteristics of the single-layer reticulated shells. The order of this mode is usually around the total number of unconstrained nodes for low rise-to-span ratio cases. The mode shape is wholly rising up. Further details will be presented in another paper in the near future.

\subsection{3. $[\mathrm{MLC}]$ in application to background response}

For structures in which resonant response is neither significant nor dominant (and can thus be neglected) Holmes [25] applied POD into computation of the covariance of background response. Section 4.2.2 is devoted to finding an effective indicator [MLC] for mode truncation. In this section [MLC] in application to background response is discussed. Regarding background response, the mechanical admittance is consider to be unity. The motion equation can be re-written as in Eq. (25).

$$
\begin{gathered}
\left\{\begin{array}{r}
{\left[\operatorname{Diag}\left(\omega^{2}\right)\right]\{q(t)\}=\{F(t)\}=[\varphi]^{T}\{P(t)} \\
\{\ddot{q}(t)\}+[\operatorname{Diag}(2 \xi \omega)]\{\dot{q}(t)\}=0
\end{array}\right. \\
\{q(t)\}=\left[\operatorname{Diag}\left(\omega^{2}\right)\right]^{-1}[\varphi]^{T}\{P(t)\} \\
E\left(\{q(t)\}\{q(t)\}^{T}\right)=E\left(\left[\operatorname{Diag}\left(\omega^{2}\right)\right]^{-1}[\varphi]^{T}\{P(t)\}\{P(t)\}^{T}[\varphi]\left[\operatorname{Diag}\left(\omega^{2}\right)\right]^{-1}\right)
\end{gathered}
$$

Substitute Eq. (24) into Eq. (28), then

$$
E\left(\{q(t)\}\{q(t)\}^{T}\right)=\left[\operatorname{Diag}\left(\omega^{2}\right)\right]^{-1}[M L C][M L C]^{T}\left[\operatorname{Diag}\left(\omega^{2}\right)\right]^{-1}=\left[R_{q_{i} q_{j}}(0)\right]
$$

Thus

$$
E\left(\{Y(t)\}\{Y(t)\}^{T}\right)=[\varphi] E\left(\{q(t)\}\{q(t)\}^{T}\right)[\varphi]^{T}=[\varphi]\left[R_{q_{i} q_{j}}(0)\right][\varphi]^{T}
$$

A simple and concise formula for computation of background response is shown in Eq. (30) in the time domain. For large-span space structures in which resonant response is either significant or dominant and the corresponding background response is not negligible, basically, no simplified method is convincing at present except transient time history analysis. Further work is needed in future. 


\section{CONCLUSIONS}

Wind pressure distributions on spherical roofs including mean and standard deviation have been presented. Effects on wind pressure distribution of rise- or wall-height-to-span ratio, terrain type and Reynolds number have been investigated. With decrease in wall height, the curves integrally move upward since the turbulence intensity increases while the mean wind velocity decreases. The effect on the pressure distribution of different terrain types is significant. Regarding Reynolds number effect, it is proposed to carefully select proper reference wind velocities for ABLWT tests on streamlined structures.

The second objective of this paper was to investigate wind effects on large-span reticulated spherical shells by a mode superposition method. A new way to determine the special mode that contributes most to wind effects has been put forward. This mode seems to contribute most to background response and significantly to the resonant part. A new matrix (mode-load-correlation matrix) has been proposed. It is concluded that this matrix reveals the spatial distribution of fluctuating structural response including the background response and the resonant response. A simple derivation with respect to mode-load-correlation matrix and background response has been presented.

\section{ACKNOWLEDGEMENTS}

This study was funded by the Ministry of Education, Culture, Sports, Science and Technology, Japan, through the "Academic Frontier" Project, 2000-2004.

\section{REFERENCES}

[1] Seiichi Taniguchi, Hiroshi Sakamoto et al., "Time-averaged aerodynamic acting on a hemisphere immersed in a turbulent flow", International journal of wind engineering and industrial aerodynamics, 1982, 9, pp.257-273.

[2] Toy, N., Moss, W.D. and Savory, E., "Wind tunnel studies on a dome in turbulent boundary layers", International journal of wind engineering and industrial aerodynamics, 1983, 11, pp.201-212.

[3] Toy, N. and Tahouri, B., "Pressure distributions on semi-cylindrical structures of different geometrical cross-sections", International journal of wind engineering and industrial aerodynamics, 1988, 29, pp.263-272.

[4] Newman, B.G. and Ganguli, U. "Flow over spherical inflated buildings", International journal of wind engineering and industrial aerodynamics, 1984, 17, pp.305-327.

[5] Cook, N.J., "The designer's guide to wind loading of building structures. Part 1: Background, damage survey, wind data and structural classification”, Building research establishment report, 1985.

[6] Taylor, T.J., "Wind pressures on a hemispherical dome", International journal of wind engineering and industrial aerodynamics, 1991, 40, pp.199-213.

[7] Hongo, T., "Experimental study of wind forces on spherical roofs", Ph.D. thesis, Tohoku University, 1995. (In Japanese)

[8] Yasushi Uematsu, Motohiko Yamada, Akira Inoue, Takeshi Hongo, "Wind loads and wind-induced dynamic behavior of a single-layer latticed dome", International journal of wind engineering and industrial aerodynamics, 1997, 66, pp.227-248. 
[9] Yasushi Uematsu, Osamu Kuribara, Motohiko Yamada, Akihiro Sasaki, Takeshi Hongo, "Wind induced dynamic behavior and its load estimation of a single-layer latticed dome with a long span", International journal of wind engineering and industrial aerodynamics, 2001, 89, pp.1671-1687.

[10] Carassale, L., Hibi, K., Pagnini, L.C., Solari, G., Tamura, Y., "POD analysis of the dynamic wind pressure on a tall building", BBAA V., 2004.

[11] Seung-Hwan Jeong, B. Bienkiewicz and Hee-Jung Ham, "Proper orthogonal decompostion of building wind pressure specified at non uniformly distributed pressure taps", Journal of wind engineering and industrial aerodynamics, 2000, 87, pp.1-14.

[12] Zhang Zhi-hong and Yukio Tamura, "Some problems of proper orthogonal decomposition method in application to reconstruction of wind pressure field for reticulated spherical domes", Proceedings of 10th ACWE, the tenth Americas conference on wind engineering, 31 May 4 June, 2005. Baton rouge, Louisiana, U. S. A. submitted.

[13] Masuda, K., Nakayama, M., et al., "An efficient evaluation of wind response of dome roof through modal analysis method", Proceeding of $13^{\text {th }}$ national symp. on wind engineering, Tokyo, 1994, pp.209-214. (In Japanese)

[14] Masanao Nakayama, Yasuhito Sasaki, Keiji Masuda, Toshiyuki Ogawa, "An efficient method for selection of vibration modes contributory to wind response on dome-like roofs", International journal of wind engineering and industrial aerodynamics, 1998, 73, pp.31-43.

[15] Ni, Z.H., Huang, M.K. and Xie, Z.N., "Wind-induced response of dome-like roof", Proceedings of the third international conference on Advances in Structural Engineering and Mechanics, Seoul, Korea, Sept. 2-4, 2004, pp.763-771.

[16] Wilson, E.L., "A new method of dynamic analysis for linear and nonlinear systems", Finite elements in analysis and design, 1985, 1, pp.21-23.

[17] Wilson, E.L., Yuan, M.W. and Dickens, J.M., "Dynamic analysis by direct superposition of Ritz vectors", Earthquake engineering and structural dynamics, 1982, 10, pp.813-821.

[18] He, Y.L. and Dong, S.L., "A new frequency domain method for wind response analysis of spatial lattice structures with mode superposition", International Journal of Space structures, 2002, 17(1), pp.67-76.

[19] Zhang Zhihong, Yukio Tamura, Masahiro Matsui, Yoshida Tomoya, "Wind tunnel tests and wind induced vibration analysis on spherical domes", Proceedings of the fourth international conference on advances in steel structures, ICASS'05, 13-15 June 2005, Shanghai, China.

[20] Li, Y.Q. and Tamura, Y., "Wind-resistant analysis for large-span single-layer reticulated shells", International Journal of Space Structures, 2004, 19(1), pp.47-59.

[21] Li, Y.Q. and Tamura, Y., "Nonlinear dynamic analysis for large-span single-layer reticulated shells subjected to wind loading", International Journal of Wind Structures, 2005, 8(1), pp.35-48.

[22] Buresti, G., "The effects of surface roughness on the flow regime around circular cylinder", Journal of wind engineering and industrial aerodynamics, 1981, 8, pp.105-114.

[23] Wilson, E.L., "Three dimensional static and dynamic analysis of structures - a physical approach with emphasis on earthquake engineering”, Third edition, Computers and structures, Inc. Berkeley, California, U.S.A., 2000.

[24] Tamura Y., Suganuma, S., Kikuchi, H. and Hibi, K., "Proper orthogonal decompostion of random wind pressure field", Journal of fluids and structures, 1999, 13, pp.1069-1095.

[25] Holmes, J.D., "Effective static load distribution in wind engineering", Journal of wind engineering and industrial aerodynamics, 2002, 90, pp.91-99. 


\title{
AN INVESTIGATION ON STRUCTURAL PERFORMANCE OF PROFILED STEEL SHEET TO DEVELOP SELF-SUPPORTING ROOFING SYSTEM
}

\author{
S. M. Zahurul Islam*, A. A. Abang-Abdullah, M. S. Jafar \\ Housing Research Centre, Department of Civil Engineering, Universiti Putra Malaysia \\ *(Corresponding author: E-mail: smzislam190@yahoo.com)
}

\begin{abstract}
Profile steel shell structures are used popularly due to aesthetic and economical use of materials. The aim of this research work is to develop a self-supporting roofing element using profiled steel sheet such as zincalume, with potential for application in affordable quality housing. An analytical investigation using nonlinear finite element method is carried out on the structural strength and behaviour of different types of self-supporting roofing elements. An experimental study is conducted to validate the analytical investigation. Conventionally, profile steel sheet such as zincalume is using in roof as a covering materials using different types of internal support without any attention paid to their structural capability. Self-supporting of roofing system has significant advantages of removing the internal trussing and support. An attempt has been made to find out efficient, economic and aesthetically pleasing shape of shell elements to provide self- supporting roofing system on the basis of present results. The loaddeflection, stress- strain and deflected shape profiles for investigated roofing element is showed that parabolic roofing element having crown height $1 / 6$ of chord length is more efficient than others. It is observed that the proposed roofing system has a great potential to be exploited for housing construction.
\end{abstract}

Keywords: Structural performance, profiled steel sheet (zincalume), self-supporting, roofing element, semi-loof elements.

\section{INTRODUCTION}

The housing need is ever increasing due to rapid industrialization, urbanization and population explosion. The roof protects the building and its occupants from the effects of weather, but it are also is an architectural feature that gives the building a desired appearance.

Roof accounts to a substantial part (about 25\%) of the total cost of a building whether it is residential or industrial [1]. Therefore, it demands high technical and design specifications for both of the individual products elements and for the roof as a whole in order to achieve a satisfactory design life. Recent trends, research and developments are directed towards developing a lightweight, economical and structurally strong material that can be precast or prefabricated and easily erected. Conventionally, profile steel sheet such as zincalume and galvanized iron sheet is using in roof as a covering materials using different types of internal support without any attention paid to their structural capability. It is an innovative system that is self-supporting roofing system where sheeting roofs run continuous lengths of roof sheeting from one end to other end support through eliminating internal support. The use of the corrugated metal sheet goes back to the beginning of this century. For a long time, corrugated metal sheets were used as covering materials, without any attention paid to their structural capability. The reason for not considering them as structural elements was the lack of sound basis for using these sheets together to form a continuous self-supporting medium. This approach provides particularly neat and attractive roofing whilst eliminating the ridge capping, thereby avoiding any possibility of leakage along this fitting. The use of the corrugated metal thin shells in roofs, leads to considerable saving in materials, labour and cost. Analytically critical loads of self-supporting cylindrical roofs can be found out by energy theorem [2]. The possibility of using these sheets in folded plate roofs was investigated [3]. A study has been performed on structural strength and practical applications of cylindrical shell roofs made of corrugated metal sheets [4]. The exact differential equations used to explain the behavior of orthotropic shells. More recently, a study was carried out to develop a procedure for the design of 
steel roof subjected to non-uniform loads such as drifted snow using purlins frame [5]. Selfsupporting concept was not considered in their study. Rib steel deck ware used as a covering materials, without any attention paid to their structural capability. Geometric and materials nonlinearity also was ignored. Extensive study on support settlement of cylindrical shell roofs was carried out [6-8]. Experimentally an investigation on structural strength and behaviour of ferrocement semicircular roofing elements were conducted [9], Theoretical studies relating to ferrocement have been reported in the literature observed and found out an optimum shape within selected five shapes [10-11]. Thin cylindrical shell roof was solved [12] and was extensively used for checking the performance of various types of shell elements. They used support along the circumferential edge not straight edge as a self- supporting concept. Nonlinear analysis was not carried out. Steel instead of ferrocement is very much use now a day in the design of lighter structures. In ferrocement construction needs skilled, creative carpenters to produce good quality items with fine finishes. Zincalume is lighter than ferrocement, which is easier for construction, handling and efficiently erection. The self-supporting roofing element using profile steel sheeting (zincalume); a thin shell, lightweight structure, is a structural load bearing system describe in an earlier publication [13-14].

The main objective of this study is to develop a self-supporting roofing system, with potential and efficiency for application in affordable quality housing. Structural behavior of Inverted V shape, Cylindrical, Parabolic, Doubly curve, Single pitch and Flat plane shell roofing system are investigated analytically to provide as a self-supporting roofing system. This research was an attempt to investigate the contribution of corrugated sheet in reducing the buckling and displacement and enhances its load carrying capacity. An experimental program was undertaken in the course of present study. The experimental results showed good agreement with those obtained theoretically. The deflection and stress behavior of different types of roofing elements are compared each other. The efficient and economic shape of self-supporting roofing elements has been found out after a through investigation on the basis of present results.

\section{ROOFING MATERIAL ZINCALUME}

Shell structures are used popularly due to aesthetic and economical use of materials. Great variety of shell roofs have been designed and constructed in many part of the world [15]. The use of the shells in roofs, leads to considerable savings in materials. Normally corrugated metal sheet such as zincalume is used in roofs as a covering only, while depending on different types of intermediate support. A self-supporting roofing system is when a roof runs its continuous length from on end to other end support by eliminating internal supports such as purlins, rafter, fastener and truss. This method provides a particularly neat and attractive solution to roofing whilst eliminating the ridge capping, thereby avoiding any possibility of leakage along this fitting. This roof can save material, construction and erection cost.

The shape and size of precast/prefabricated roofing element is chosen to satisfy the general requirements of strength and stiffness, lightness and economy, ease of handle and erection, proper seating and leak proof joint. There are different types of materials for construction of roof frame and roof covering. Common types of materials are metal sheet, ferrocement, plastic, and concrete and clay tile for roof covering. Timber and metal are normally used for the trusses. For this investigation the corrugation metal sheet zincalume was chosen in an effort to develop the selfsupporting roofing system. The main features of using of zincalume sheet as roofing material as according to Bluescope-Lysaght are as follows: 
(a) Speedy installation; no shuttering required, less installation errors

(b) $\quad 30-40 \%$ cost saving over RCC roofing

(c) Lower dead load on the walls, light weight and easy handling

(d) High strength to weight ratio

(e) Easy to for into complex shapes, new shape more efficiently allowing to be used.

(f) Elegant profile and uniform sizes, large span possible with intermediate supports

(g) Abundantly available, and inexpensive and corrosion-resistant

(h) Fire registrant and material consistency high

(i) Unaffected by termites and longevity and does not required paint

(j) No materials wastage and recyclining system is applicable

(k) Economical considering mean service life

Zincalume sheet can be considered as the best and most durable roofing elements for affordable quality housing in the world. Zincalume consists of high strength steel substrate protected with corrosion inhibitive treatments and coatings designed to provide the broad spectrum of performance that is essential for long life and minimum maintenance. All steel sheets used in the manufacture of the roofing sheets shall have a protective metallic alloy coating of zinc $(43.5 \%)$, aluminium (55\%) and silicon (1.5\%), applied by the hot dip process and having a coating thickness of $0.05 \mathrm{~mm}$ as stipulated in AS1397-1993 for coating class AZ 150. Chromic acid sealed, zinc phosphate pretreatment is applied after alkaline cleaning for coating. Galvanized steel is treated on both sides with phosphate conversion coating followed by application of an impervious epoxy primer incorporating a corrosion inhibiting compound. Modified polyester coating of 20 micrometers is used for finish coat to ensure maximum durability. Composition layer of zincalume is shown in Figure 1.

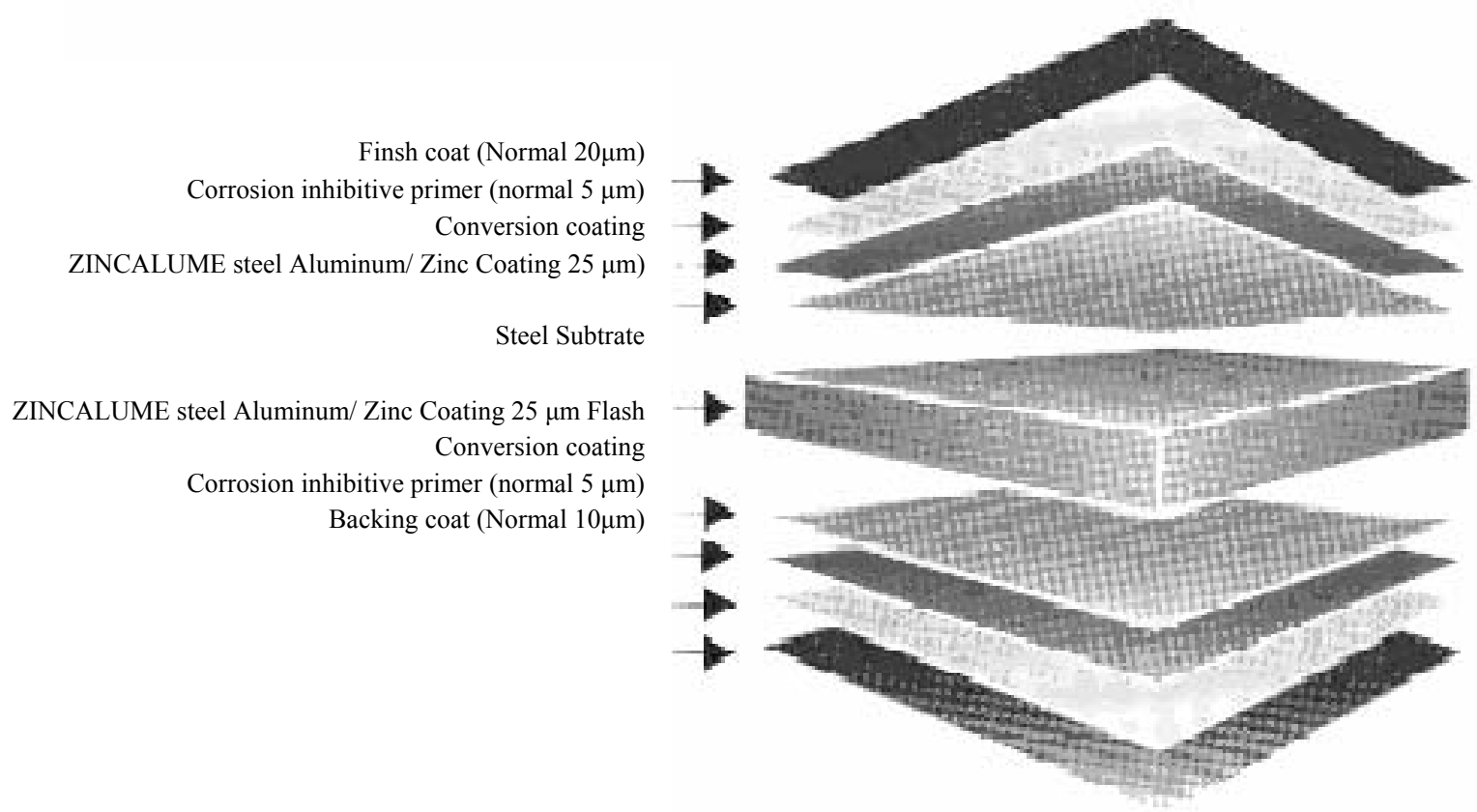

Figure 1. Different composition layer of zincalume sheet

Zincalume, which is used in the investigation, are locally available in Malaysia, Singapore and Australian market. It is obtained strength as steel grade ASTM A446 E, minimum yield strength $550 \mathrm{MPa}$, Modulus of elasticity $\mathrm{E}=210 \mathrm{GPa}$, poisons ratio $v=0.30:$ mass $=4.7 \mathrm{~kg} / \mathrm{m}^{2}$ (for thickness of $0.47 \mathrm{~mm}$ sheet). Zincalume obtained two basic strength grades G 550 and G 300, which are shown in Figure 2. High tensile steel G550 was used in this study to develop selfsupporting roofing elements. 


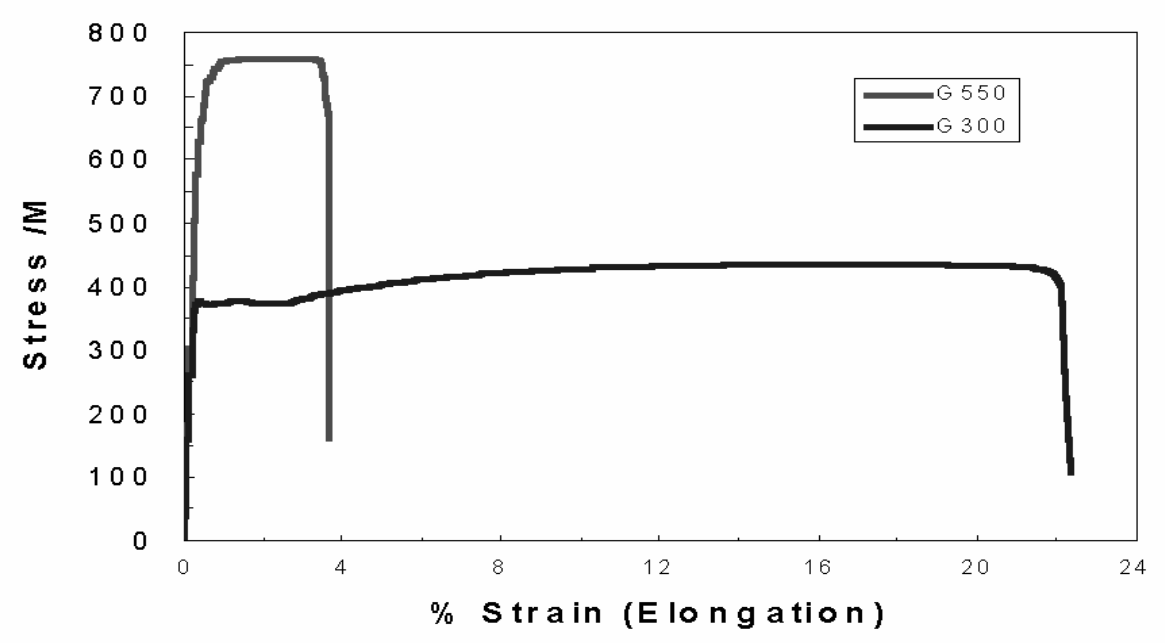

Figure 2. Stress-strain diagram for zincalume steel (Bluescope-Lysaght, 2003)

\section{FINITE ELEMENT MODELS}

The self-supporting roofing elements were models and analysed employing the finite element software (LUSAS) [16]. The shell-roofing element was analysed as a 3-D problem. It was discretised by means of 8-noded semi-loof elements having three translational displacements in the global axes at the corner and mid side nodes and one rotation with respect to axes in the plane of middle surface. The semi-loof element is probably one of the most efficient elements for the solution of thin shell of arbitrary geometry [17-18]. At first an arc was drown by three Cartesian points and then translate required width and corrugation for profile sheet. Width of different types of roofing elements was considered as $0.76 \mathrm{~m}$ and $8.0 \mathrm{~m}$ for analysis. Thickness of flat sheet and profile sheet were assigned as $1.2 \mathrm{~mm}$ and $0.47 \mathrm{~mm}$ respectively. A nonlinear FEM analysis was carried out assuming zincalume to be elastic-plastic material. The model was subjected to global distributed load along the vertical direction. Different types of roofing element such as Inverted V shape, Cylindrical, Parabolic, Doubly curve, Single pitch and Flat plane have been subjected to incremental global distributed load. The boundary conditions for the roofing element were assumed as fixed, pin and simple supported to make a comparative study of effect of boundary condition. Different mesh sizes and different numbers of element were tried so that accurate results could be obtained. Material and geometric nonlinearity were considered in FEM analysis. Three different types of profile sheet such as Trim, Spendek, and Klip-lok are model that is shown in Figures 3, 4, and 5.

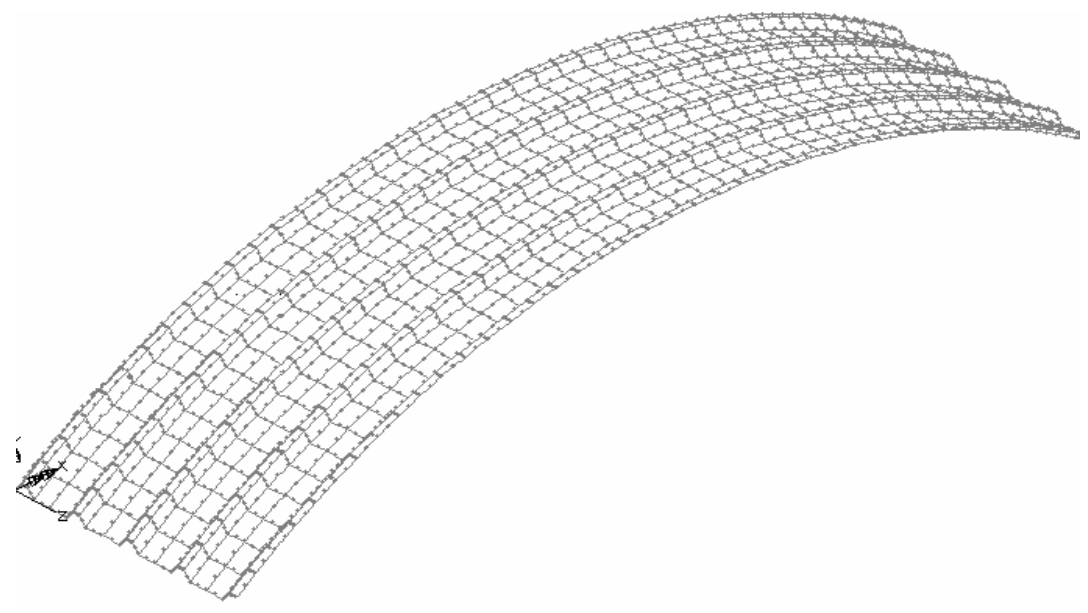

Figure 3. Finite element model of TRIM profile of parabolic shell roof 


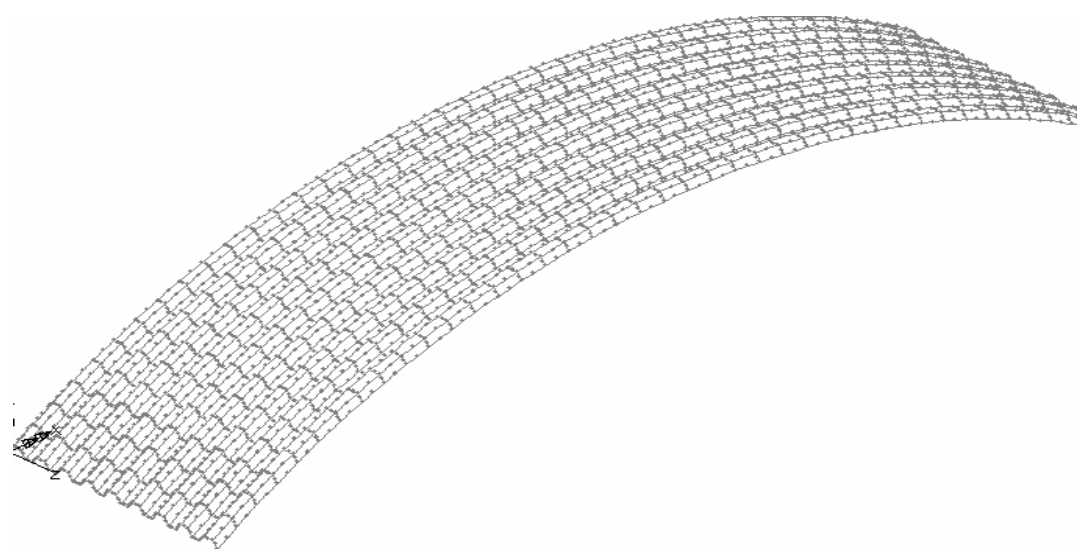

Figure 4. Finite element model of Spendek profile of parabolic shell roof

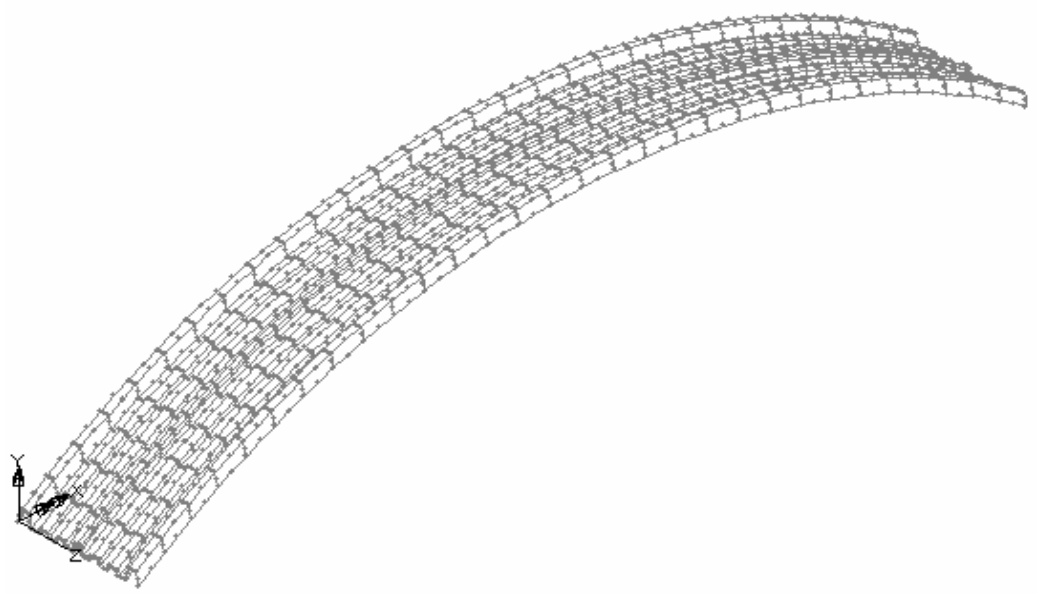

Figure 5. Finite element model of Klip-lok profile parabolic shell roof

\section{THEORETICAL FORMULATION OF DEGENERATED SHELL ELEMENT}

A good number of finite elements have been developed for the analysis of thin, circular cylindrical shells. These include flat elements and curved elements. Flat elements are lower- order elements and hence may require refined mesh, where as curved elements are higher -order elements and may more efficient than flat element [19]. The semi-loof element is probably one of the most efficient for the solution of thin shell of arbitrary geometry. It was originally published by Irons and since then it has been the object of much research with respect to its philosophy and performance in various structural situation. Finite element modeling of general shells has been using semi-loof elements, elements formulated on the basis of curved shell theory; and by means of degenerated isoparametric elements. The semi-loof shell element is a thin, doubly curved, isoparametric element formed by applying Kirchhoff constraints to a three-dimensional degenerated thick shell element (LUSAS). It is able to predict properly the bending performance of thin shell structures. The final nodal configurations are obtained corner and mid-side nodes at which displacement $\mathrm{U}, \mathrm{V}, \mathrm{W}$ along respectively the axis $\mathrm{X} . \mathrm{Y}, \mathrm{Z}$ is used as parameter: loof nodes at which the parameters are $\theta \mathrm{i}$ (rotation) which is shown in Figure 6.

The strain matrix B, relating the strain components in the local system to the element nodal variable can be constructed as $\quad \varepsilon=\sum_{k=1}^{n} B_{i} d_{i}$ 
Eq.(1) often written in the partitioned form

$$
\left[\begin{array}{l}
\varepsilon_{f} \\
\varepsilon_{s}
\end{array}\right]=\left[\begin{array}{l}
\sum_{k=1}^{n} B_{f i} d_{i} \\
\sum_{k=1}^{n} B_{s i} d_{i}
\end{array}\right]
$$

In which $\varepsilon_{\mathrm{f}}$ and $\varepsilon_{\mathrm{s}}$ is the in plain strains and the transverse shear strains. The total potential energy can be written as

$$
\Pi=\frac{1}{2} d^{T}\left[\int_{v_{e}} B^{T} D B d v\right] d=\frac{1}{2} d^{T}\left[\int_{v_{e}} B^{t}{ }_{f} D_{f} B_{f d v}\right] d+\frac{1}{2} d^{T}\left[\int_{v_{e}} B^{t}{ }_{s} D_{s} B_{s} d v\right] d
$$

Where the elasticity matrix $\mathrm{D}$ is divided into an in plane part $\mathrm{D}_{\mathrm{f}}$ and a transverse part $\mathrm{D}_{\mathrm{s}}$. Upon finite element discretisation and subsequent minimization of total potential energy [20-22] with respect to nodal variabled the following equations are obtained

$$
K_{i j} d_{j}=f_{i}
$$

In which the stiffness matrix $K_{i j}$ linking nodes $i$ and $j$ has the following typical contributions emanating from the in plane and transverse shear strain energy terms respectively.

$$
\begin{aligned}
K_{f i j}^{e} & =\int_{v_{e}} B^{T}{ }_{f i} D_{f} B_{f i} d v \\
K_{s i j}^{e} & =\int_{v_{e}} B_{s i}^{T} D_{s} B_{s j} d v
\end{aligned}
$$

A 2-point integration rule through the shell thickness and a full integration rule in the $\zeta-\eta$ surface can be used and

$$
d v=d x d y d z=|J| d \xi d \eta d \zeta
$$

Where $|\mathrm{J}|$ is determinant of the Jacobian matrix

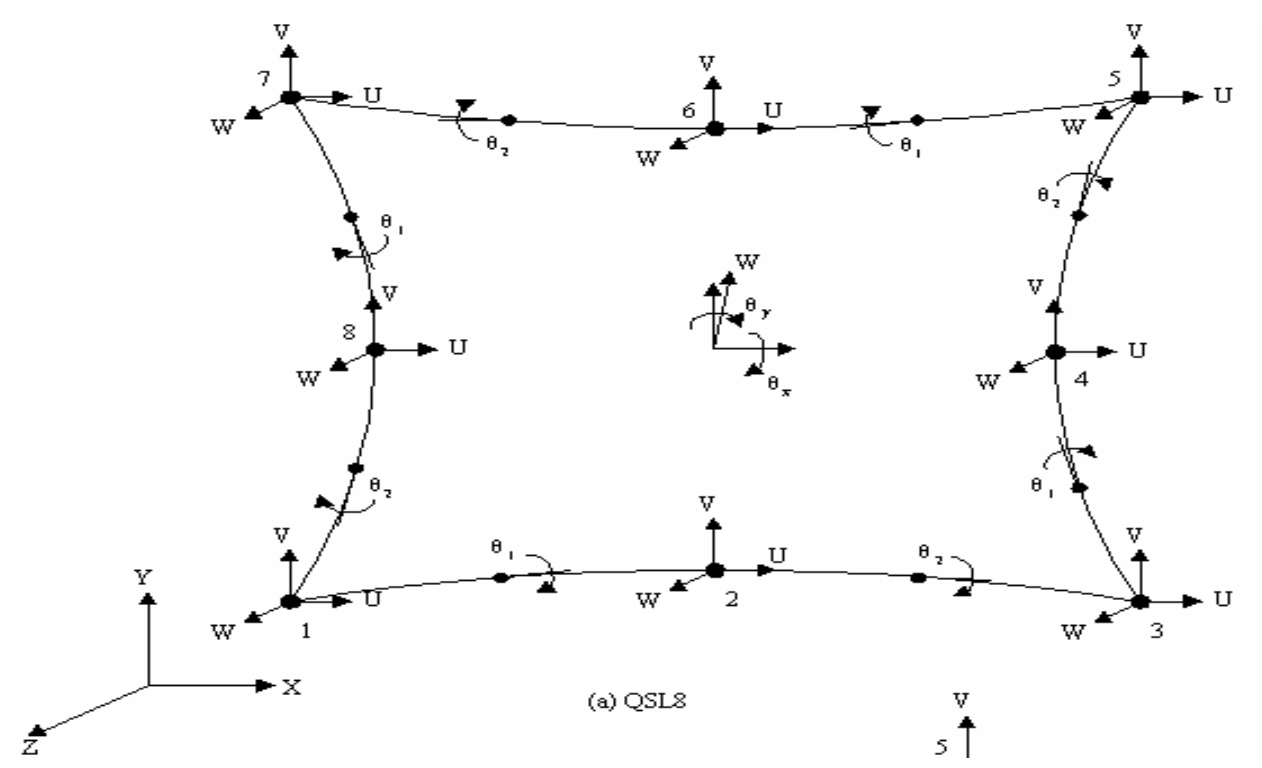

Figure 6. Final nodal configuration for Semi-loof elements

If the axes of the local coordinate system are parallel to those of the global coordinate system at all points in the shell mid surface, then the formulas for the shell element are the same as those of the Mindilin plate element. Shell structural behavior and strength is predicted in LUSAS by the following matrix: 


$$
\left[\begin{array}{l}
N_{x} \\
N_{y} \\
N_{x y} \\
M_{x} \\
M_{Y} \\
M_{x y}
\end{array}\right]=\left[\begin{array}{cccccc}
D_{1} & D_{2} & D_{4} & D_{7} & D_{11} & D_{16} \\
D_{2} & D_{3} & D_{5} & D_{8} & D_{12} & D_{17} \\
D_{4} & D_{5} & D_{6} & D_{9} & D_{10} & D_{18} \\
D_{7} & D_{8} & D_{9} & D_{10} & D_{14} & D_{19} \\
D_{11} & D_{12} & D_{13} & D_{14} & D_{15} & D_{20} \\
D_{16} & D_{17} & D_{18} & D_{19} & D_{20} & D_{21}
\end{array}\right]\left[\begin{array}{l}
\varepsilon_{x} \\
\varepsilon_{y} \\
\Gamma_{x y} \\
\Psi_{x} \\
\Psi_{y} \\
\Psi_{x y}
\end{array}\right]-\left[\begin{array}{l}
\varepsilon_{x o} \\
\varepsilon_{y o} \\
\Gamma_{x y o} \\
\psi_{x o} \\
\Psi_{y o} \\
\Psi_{x y o}
\end{array}\right]+\left[\begin{array}{l}
N_{x o} \\
N_{Y o} \\
N_{x y o} \\
M_{x o} \\
M_{y o} \\
M_{x y o}
\end{array}\right]
$$

where $\quad \mathrm{N} \quad$ are the membrane stress resultants (Force per unit width)

M are the flexural stress resultants (Moments per unit width)

$\mathrm{D} \quad$ are the Flexural and shear rigidies

E membrane strains

$\psi_{\mathrm{x}}, \psi_{\mathrm{y}}^{\prime}$ and $\psi_{\mathrm{xy}} \quad$ are the flexural strains in the local Cartesian system.

\section{NUMERICAL EXAMPLES AND RESULTS}

The primary effect of wind is visualized in the form of pressures normal to the structure's exterior surfaces. In this paper, the assessment of imposed load and wind loading was carried out according to Uniform Building by Law (Malaysian code of practice) [23] and the British code of practice [2426]. With the help of well-known FEM based software package LUSAS, different benchmark problem are solved. The LUSAS is used for the evaluation of deflection and stress-stran behavior of different types of roofing elements. The numerical results are studied for Parabolic, Cylindrical, Doubly Curve, Flat Plane and Single pitch roofing elements. The roofing elements are analyzed with span length $3 \mathrm{~m}$, width $0.76 \mathrm{~m}$ and thickness $0.47 \mathrm{~mm}$ and $1.2 \mathrm{~m}$ for profile sheet and flat sheet respectively [27] Different types of roofing elements are shown in Figure 7.

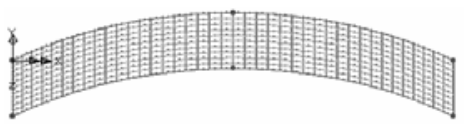

Parabolic shape

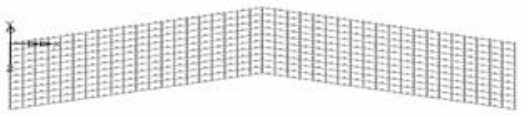

Inverted V shape

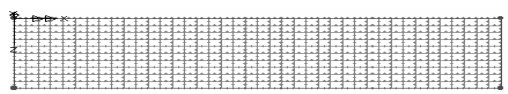

Flat plane shape

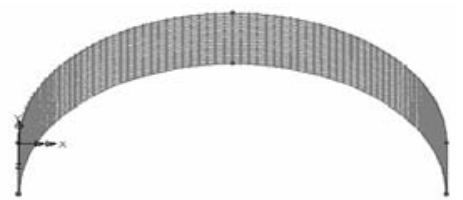

Cylindrical shape

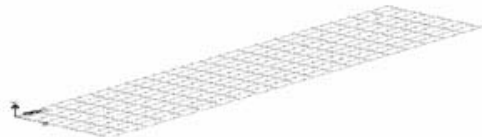

Single pitch shape

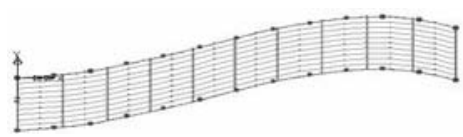

Doubly curve shape

Figure 7. Different types of roofing elements

The numerical results are studied for Parabolic, Cylindrical, Doubly Curve, Inverted V, Flat plane and Single pitch roofing system. The roofing shell elements are analyzed with span length $3 \mathrm{~m}$, width $0.76 \mathrm{~m}$ and thickness $0.47 \mathrm{~mm}$ and $1.2 \mathrm{~m}$ for profile sheet and flat sheet respectively. 


\section{EXPERIMENTAL INVESTIGATIONS}

In order to verify the validity of the finite element analysis of different types of roofing elements, critical and limited model test was conducted. The dimension of the model was span $3 \mathrm{~m}$, width $0.76 \mathrm{~m}$ and crown height $0.125 \mathrm{~m}, 0.25 \mathrm{~m}, 0.5 \mathrm{~m}, 1.0 \mathrm{~m}$ and $1.5 \mathrm{~m}$ respectively. All specimens were tested to ensure curve edge free and straight edge hinged. $U$ type metal channel were used to provide hinge support at straight of cylindrical and parabolic shell roofing element to maintain selfsupporting condition. All the specimens were tested in the vertical position. Sand bag loading was used to provide uniformly distributed load. Each bag was contained $5 \mathrm{~kg}$ load. The load was applied manually by gradually increased until yield failure of the model. Four deformation gauge, two LVDT and ten electronic strain gauges are used to measure deflection and stain. Deformation gauge and LVDT were set at the centre of bottom surface for the specimen with required stand. Strain gauges also were used the mid position of top surface of the specimen. Test setup was shown in Figures 8, 9, 10 and 11.

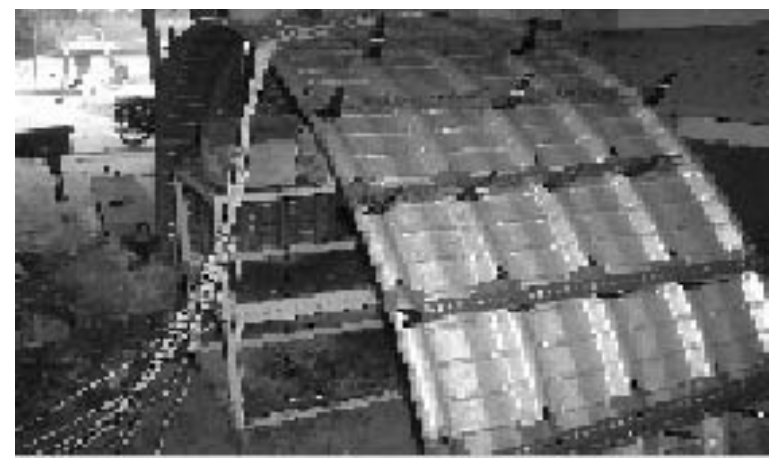

Figure 8. Test setup for cylindrical roofing element

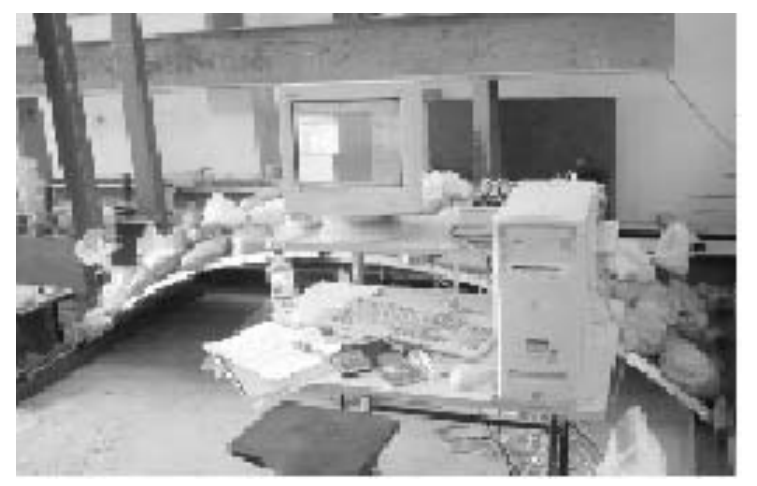

Figure 10. Test setup for parabolic shell roofing element

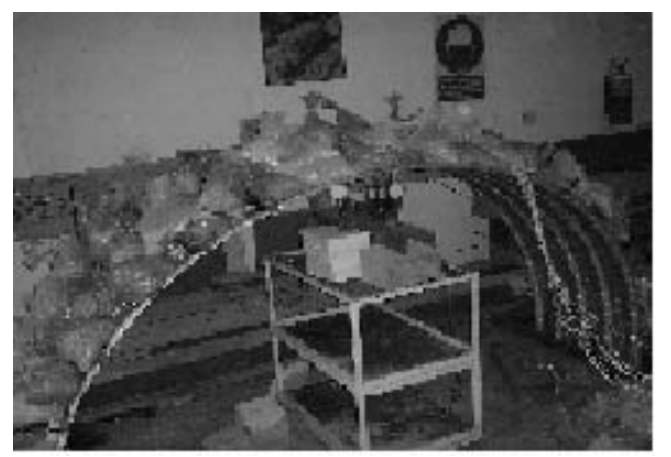

Figure 9. Sand bag loading on cylindrical roof

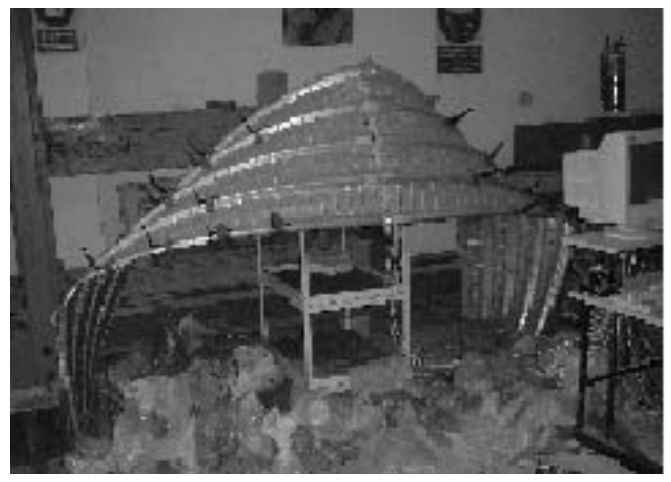

Figure 11. Experimental deflected shape of cylindrical roofing element

\section{RESULTS AND DISCUSSIONS}

The results were collected into two parts namely the finite element analysis (FEM) results and experimental results, which are then followed by the comparison section. The graphical representation of load deflection and stress-strain behavior of different types of roofing element is shown in Figures 12 and 13.

According to the non-linear finite analysis, parabolic shell roofing element is more efficient than other types of roofing element due to its less deflections and stresses. Parabolic and cylindrical roofing elements obtain arch action so load carrying capacity is higher those others as selfsupporting conditions. Nonlinear and non-planer parabolic system resist applied loads by direct 
stress, as opposed to membrane stress and bending stress. Experimental load-deflection profile of different crown heights parabolic roof using $0.47 \mathrm{~mm}$ thick corrugated zincalume sheet, $3 \mathrm{~m}$ span, $0.76 \mathrm{~m}$ width and pin support along the straight edge are shown in Figure 14.

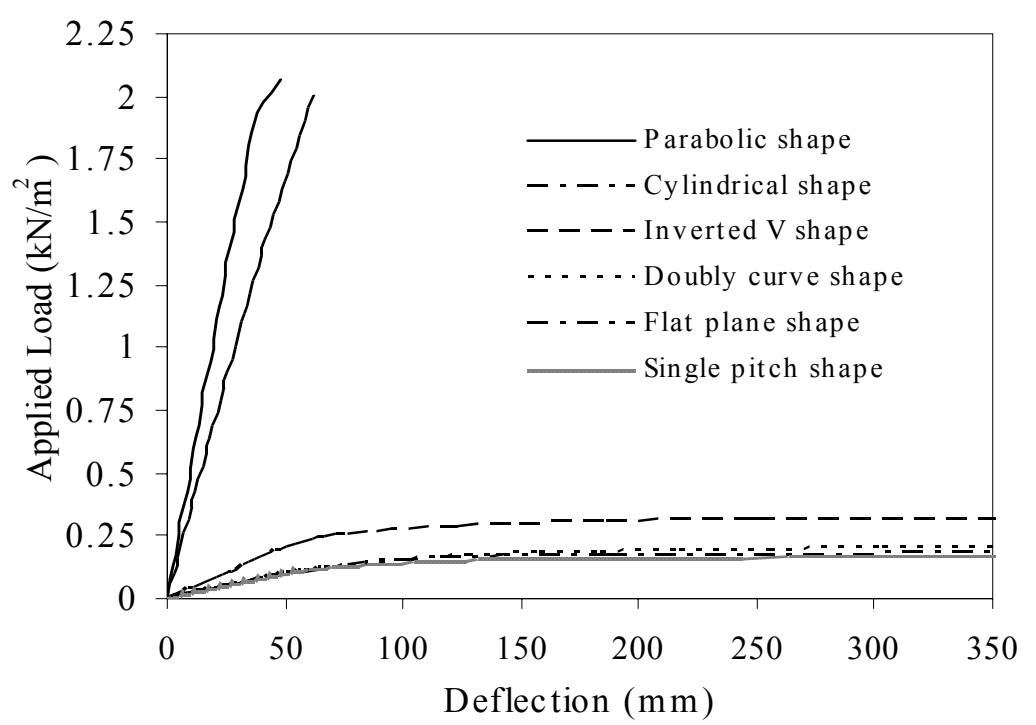

Figure 12. Load-deflection profile of different roofing element

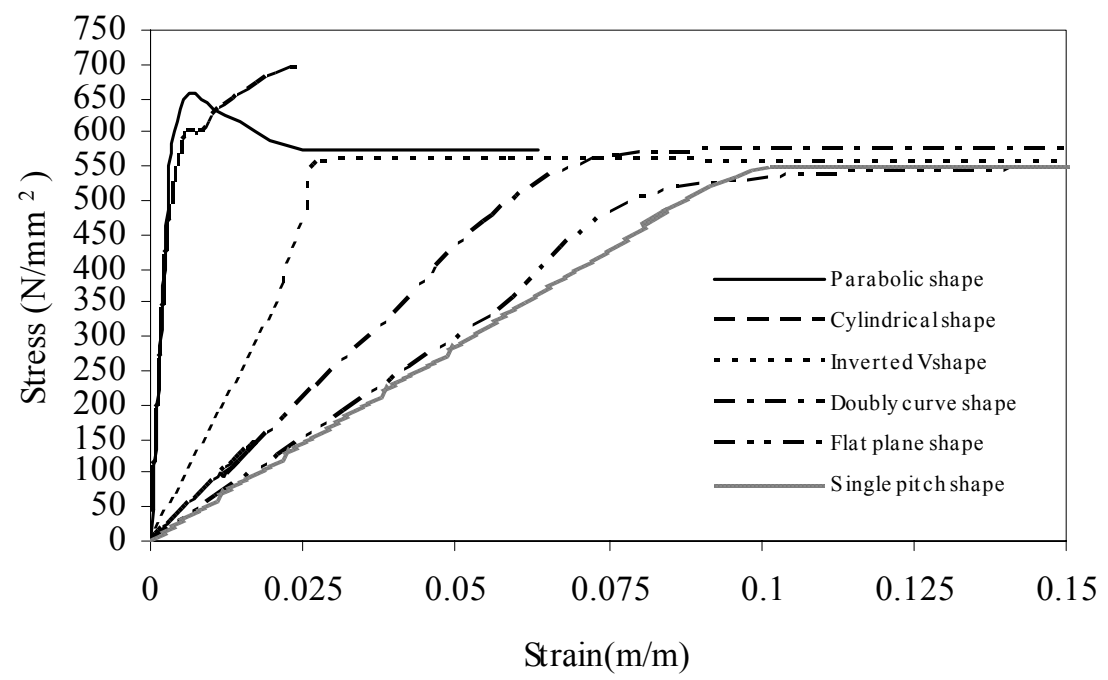

Figure 13. Stress strain profile of different types of roofing element

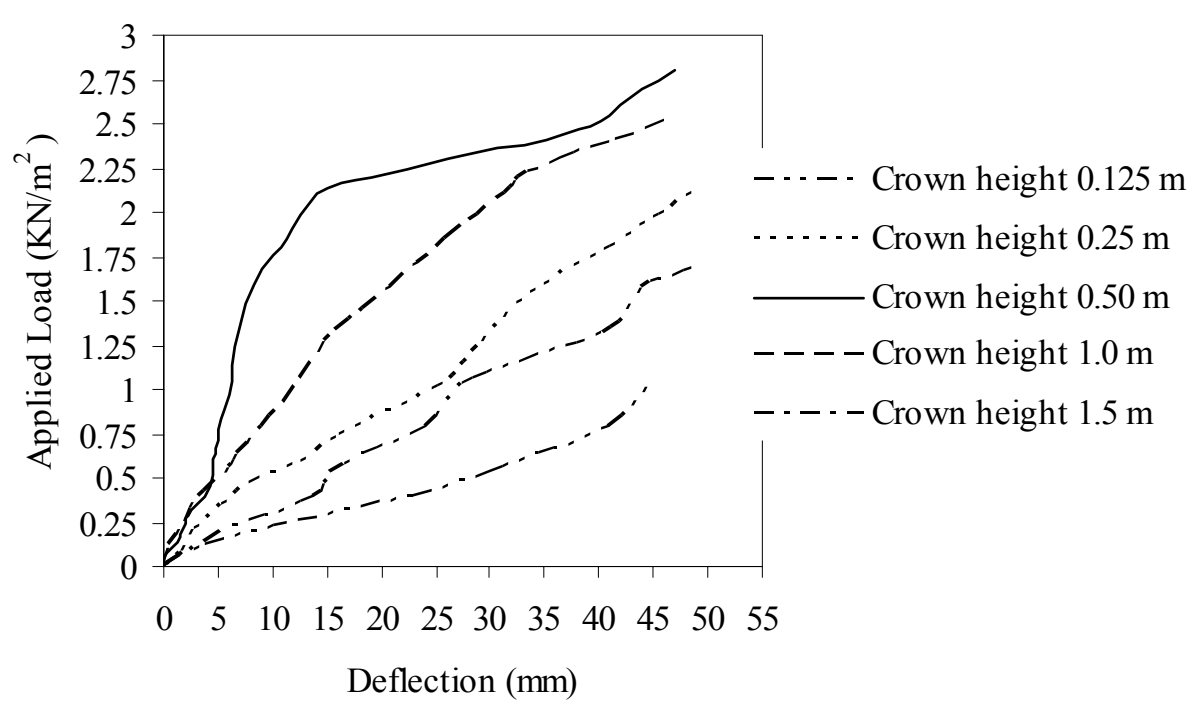

Figure 14. Experimental load deflection profile of different crown height parabolic shell roofing element 
Crown displacement is occurred due to two causes, (1) bending and (2) shortening of shell. Bending of shell is created by bending field such as $M_{x}, M_{y}, M_{x y}, M_{y x}, Q_{x}$, and $Q_{y}$ and on the other shortening is created by membrane field $N_{x}, N_{Y}, N_{x y}$, and $N_{y x}$. At crown height $1 / 6$ of chord width membrane field is predominant than bending field. As a result deflection is least. When crown height is lower membrane force also lower than bending force. When crown height increase membrane force also increases. After a certain limit of crown height membrane force also decrease. Load carrying capacity higher and least deflection was obtained at crown height $1 / 6$ of chord width or span length. In order to validate the analytical work, a comparison between the finite element analysis and experimental results are shown in Figures 15, 16, 17, 18 and 19. It is interesting to note that both the central deflection and stresses are lower in parabolic shape of roofing element with crown height of $0.5 \mathrm{~m}$. When crown height decrease then deflection and stresses increase i.e., valid for less crown height of $0.5 \mathrm{~m}$.

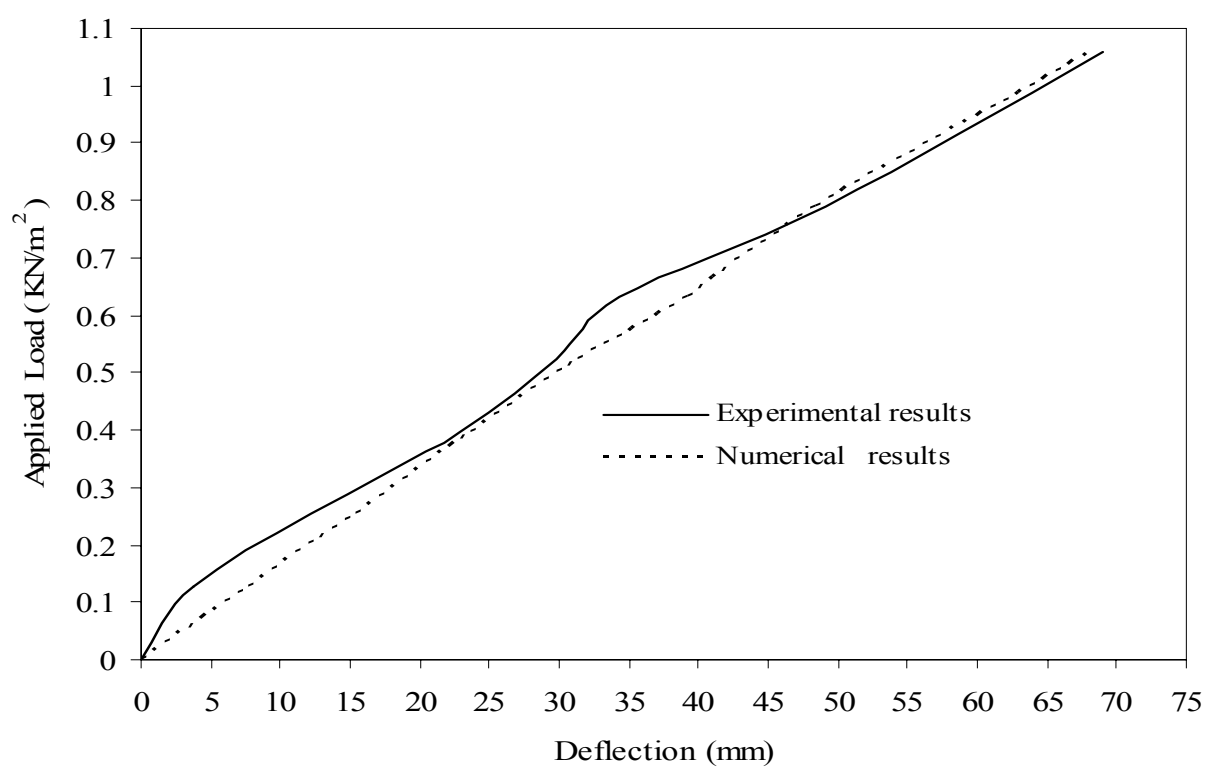

Figure 15. Load deflection profile at crown of parabolic roofing element for $0.125 \mathrm{~m}$ crown height

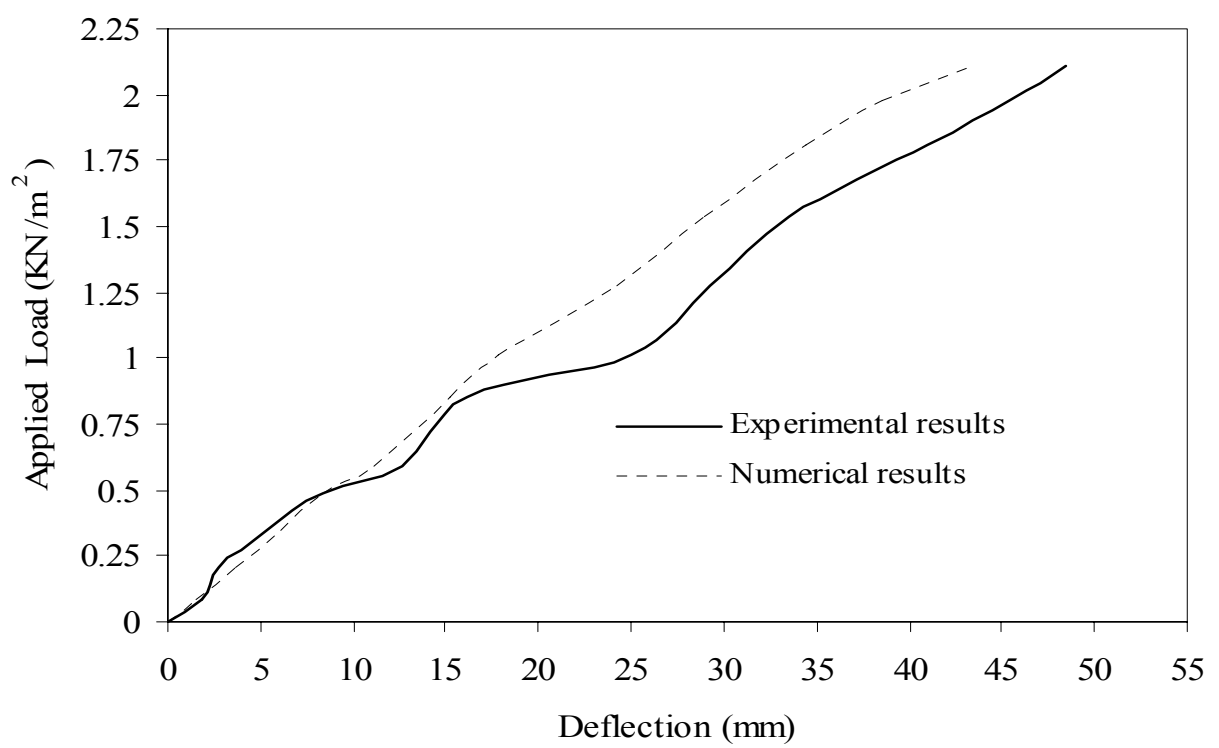

Figure 16. Load deflection profile at crown of parabolic roofing element for $0.25 \mathrm{~m}$ crown height 


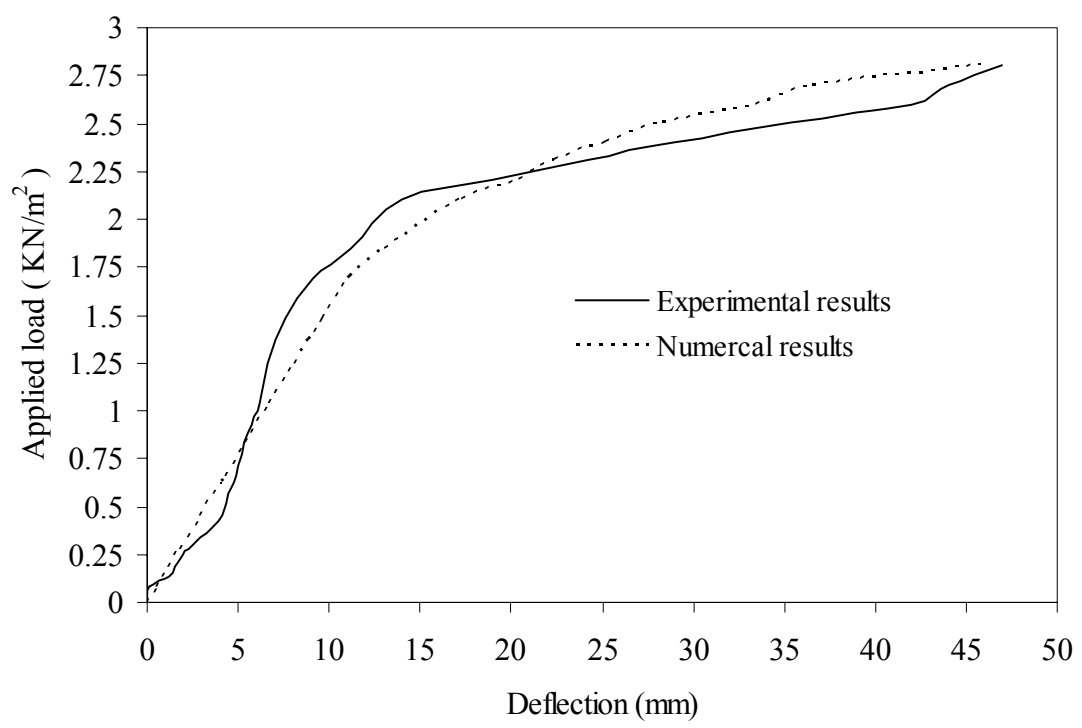

Figure 17. Load deflection profile at crown of parabolic roofing element for $0.5 \mathrm{~m}$ crown height

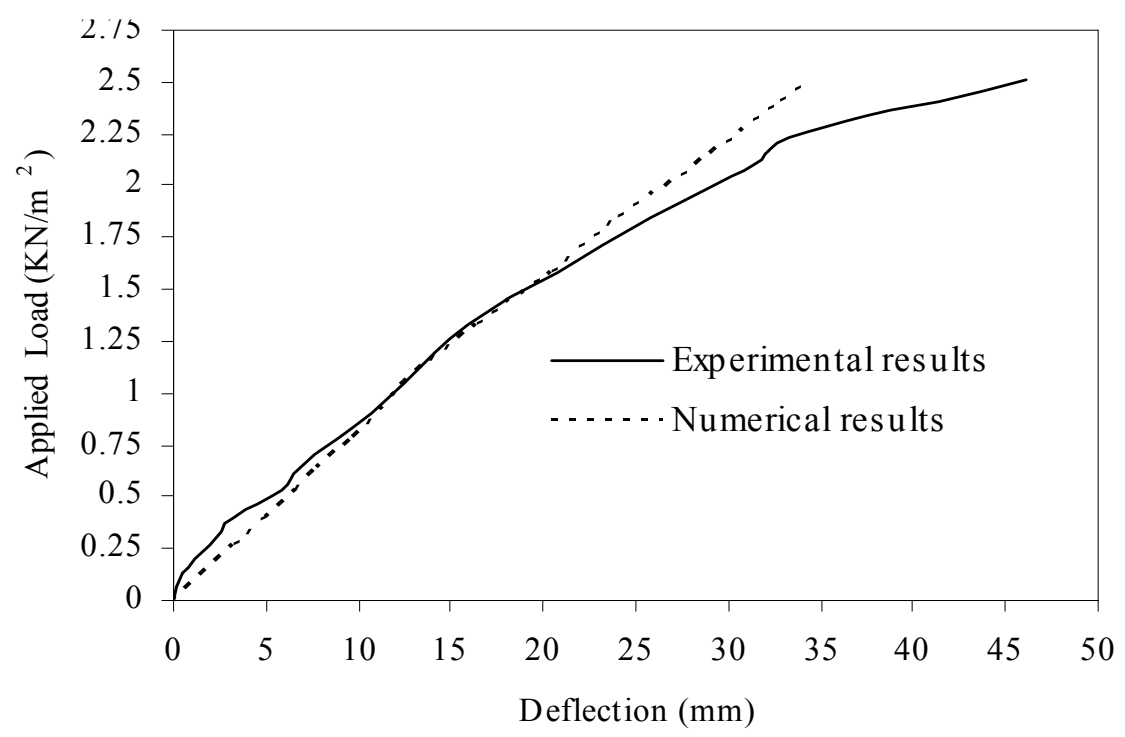

Figure 18. Load deflection profile at crown of parabolic roofing element for $1.0 \mathrm{~m}$ crown height

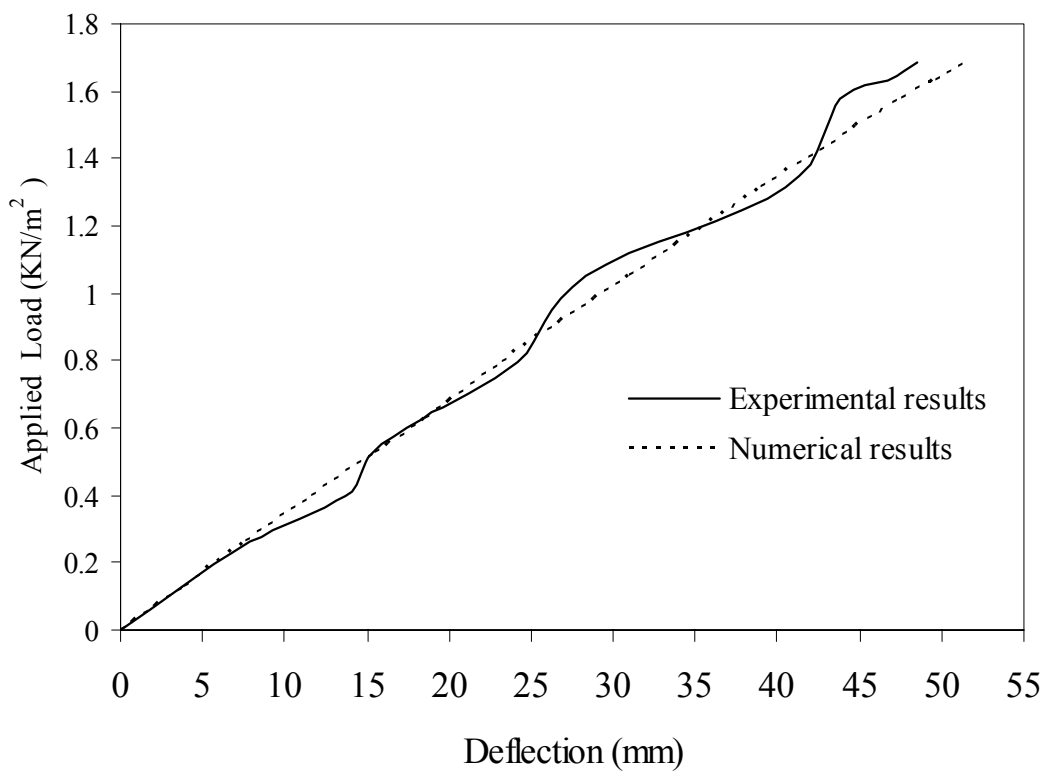

Figure 19. Load deflection profile at crown of parabolic roofing element for $1.5 \mathrm{~m}$ crown height 
The results showed load carrying capacity, deflection and stresses in parabolic roofing shell elements with different crown height. Load carrying capacity was 1.059, 2.108, 2.80, 2.508 and $1.684 \mathrm{kN} / \mathrm{m}^{2}$ without geometrical failure for $0.125,0.25,0.5,1.0$ and $1.5 \mathrm{~m}$ crown height parabolic and cylindrical roofing element respectively. Geometrical as well as yield failure load was found due to $1.283,2.23,3.164,2.71,1.739 \mathrm{kN} / \mathrm{m}^{2}$ for $0.125,0.25,0.5,1.0$ and $1.5 \mathrm{~m}$ crown height parabolic and cylindrical roofing element respectively.

Since the surface area also increases with the crown height, it is found that optimum crown height will be more economical due to materials. Both end fixed and pin support showed almost same results with minor changes. Horizontal displacement of simple supported condition was more than that of pin and fixed supporting condition. The behaviour of this structure depends on the loadtransferring action of its member and connection. The graphical representation of stress-strain behaviour of selected roofing element is shown in Figures 20, 21 and 22.

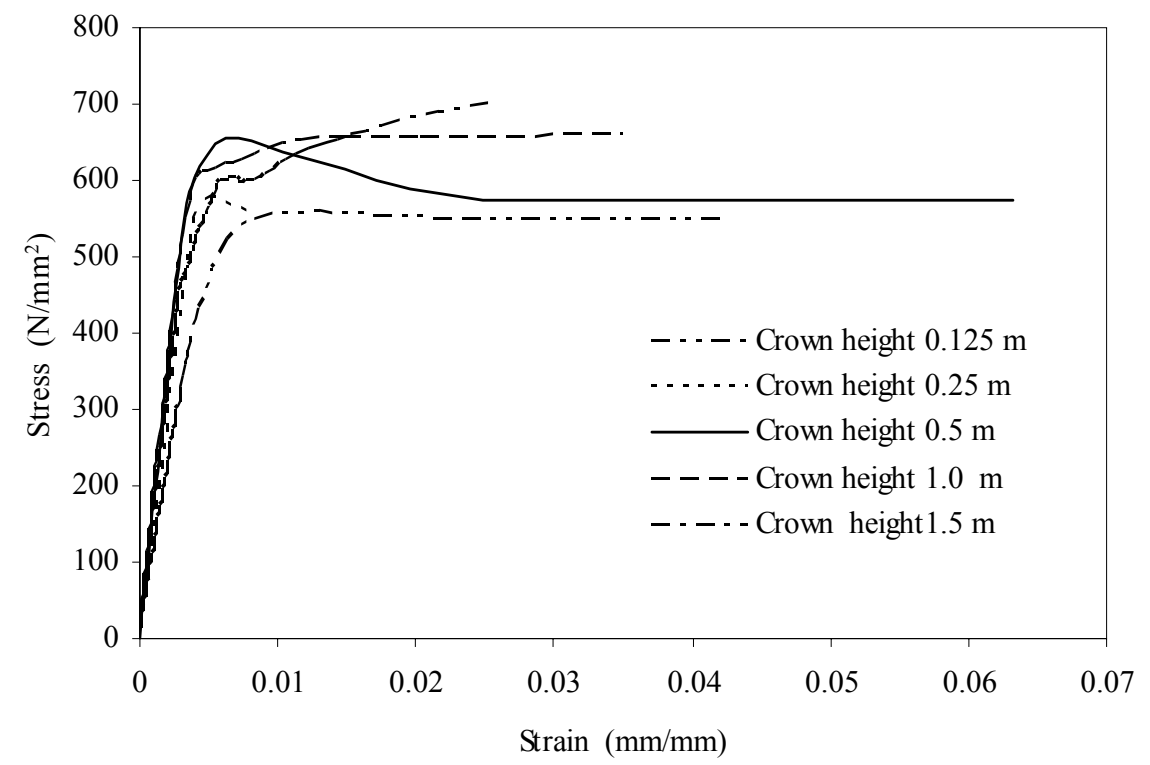

Figure 20. Stress strain profile of different crown height parabolic roofing element

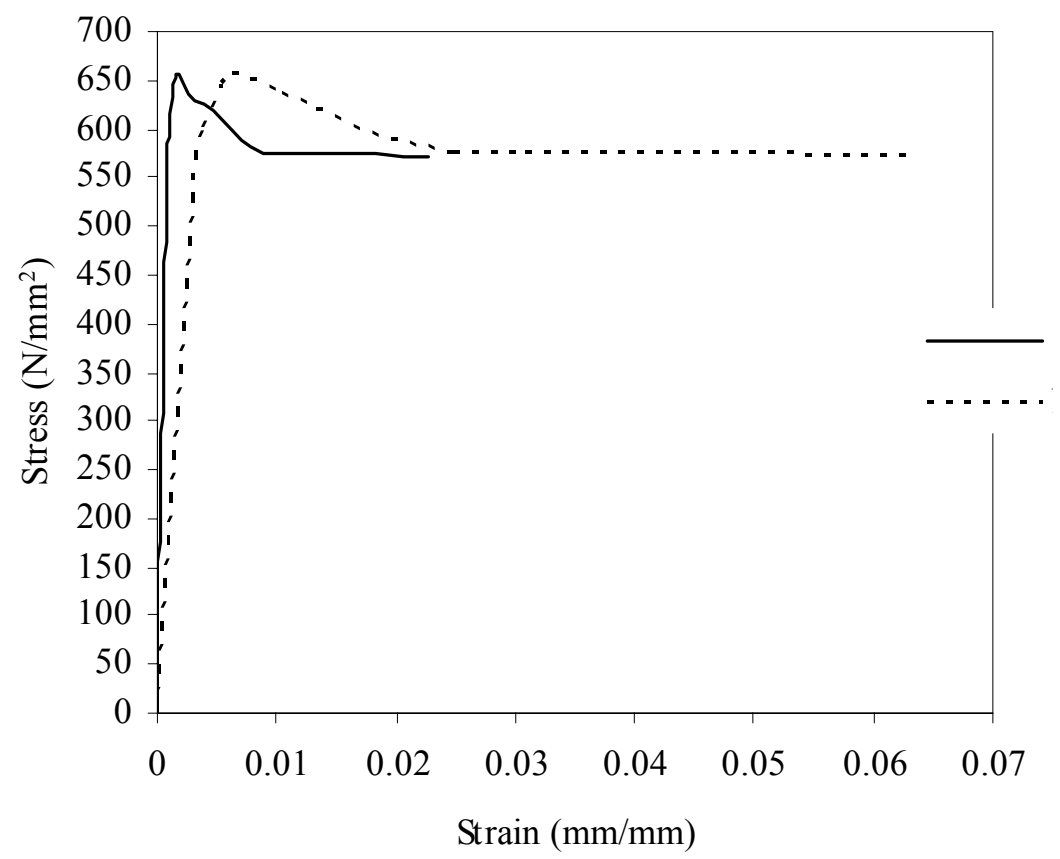

Figure 21. Stress strain profile of crown height $0.5 \mathrm{~m}$ parabolic roofing element 


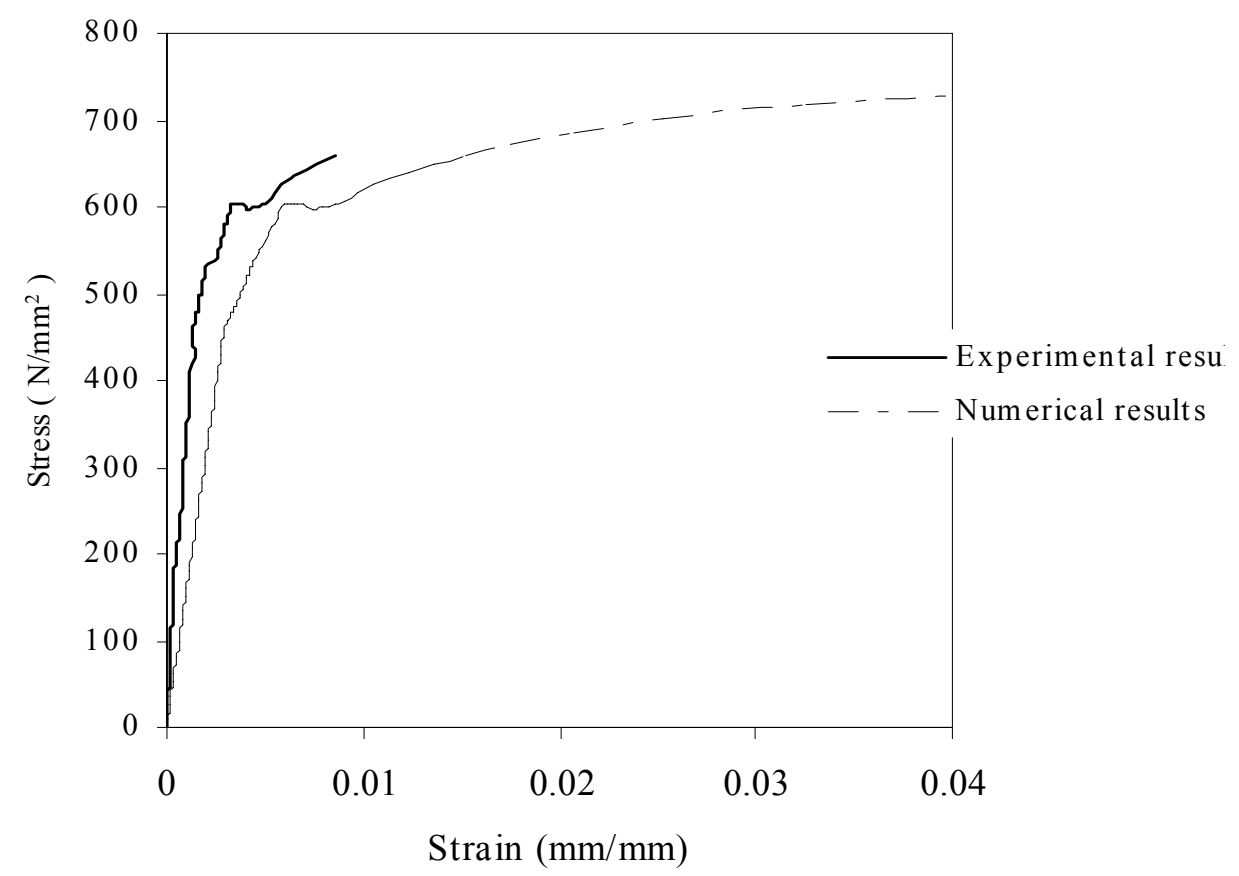

Figure 22. Stress strain profile of crown height $1.0 \mathrm{~m}$ parabolic roofing element

Nine types of roofing elements are studies in the present work. The presence of corrugation in the metal roofing element resulted in a significant improvement on the roof's structural performance compared to flat sheet element.

Good agreement was found between the results from non-linear analysis and those obtained experimentally. The load -deflection, stress strain and deflected shape profiles for investigated roofing element showed that parabolic roofing element having crown height $1 / 6$ of chord width is more efficient than others as self supported condition. It was observed that a parabolic shape roofing element with optimum crown height was structurally and economically able to use as a selfsupport roofing system for $8 \mathrm{~m}$ span lengths using $1.2 \mathrm{~mm}$ thick corrugated zincalume. Deflection along the arc length of different crown height of parabolic shell roof is shown in Figure 23 due to service load $0.528 \mathrm{kN} / \mathrm{m}^{2}$. Form the analysis, it was seen that maximum deflection obtained at the center point of curve roofing element.

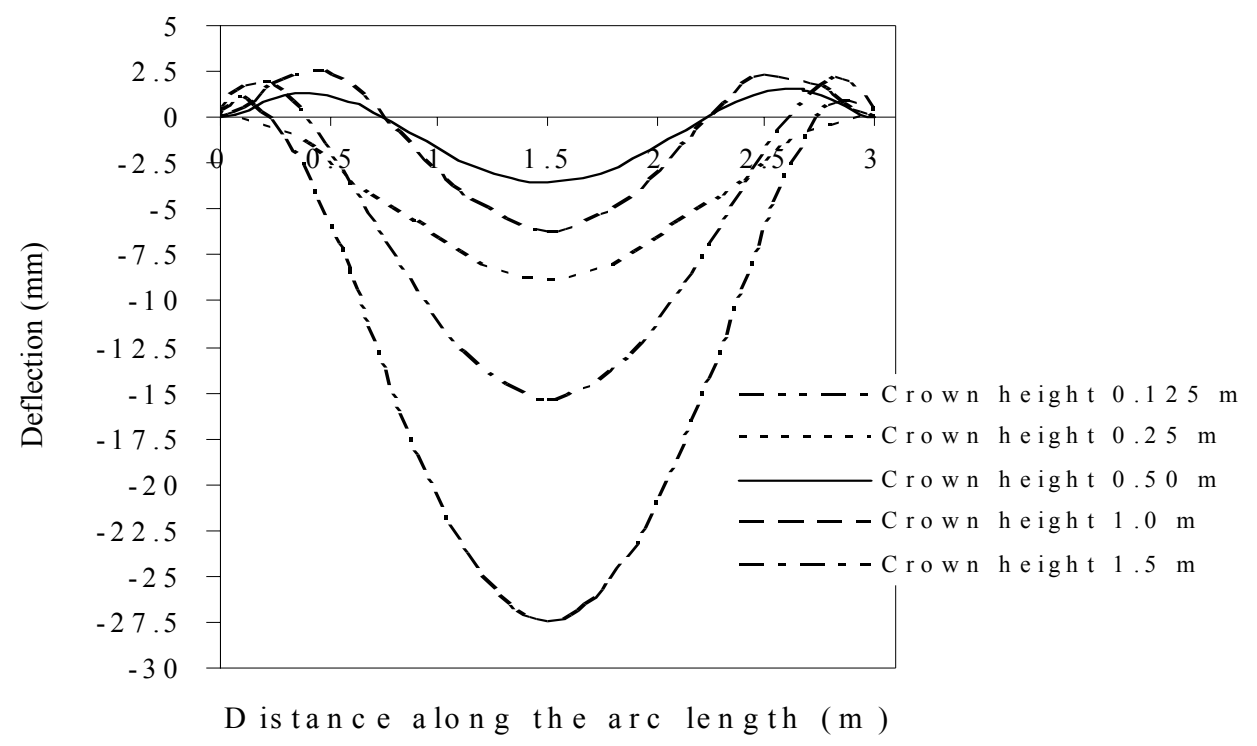

Figure 23. Deflection profile of different crown height parabolic roofing element along the arc length 
It was observed that both the central deflection and stresses are lower parabolic shape of roofing element with crown height of $0.5 \mathrm{~m}$. When crown height decreased then deflection and stresses increased i.e., valid for lower crown height of $0.5 \mathrm{~m}$. The results showed optimum crown height, deflection and stresses in parabolic roofing shell elements. Since the surface area also increases with the crown height, it was found that optimum crown height would be more economical due to materials.

Nine types of roofing elements are studies in the present work. It was found that support condition has a great impact on behavior of shell structure. Both end fixed and pin support showed almost same results with minor changes. Horizontal displacement of simple supported condition was more than that of pin and fixed supporting condition. Figure 4 shows different shapes of roofing elements; Doubly curve shape of roofing element is architecturally beautiful. The parabolic roofing element is suitable to use as a self- supporting roofing system up to $8 \mathrm{~m}$. On the basis of the present analysis, it is found that the corrugated parabolic roofing element is the most economical, efficient, architecturally pleasing shape in self- supporting condition. Three types of profile sheet were analyzed which deflection behaviour is shown in Table1.

Table 1. Deflection of different types of profile sheet

\begin{tabular}{|c|c|c|c|c|}
\hline \multirow{2}{*}{$\begin{array}{c}\text { Thickness of } \\
\text { Materials (mm) }\end{array}$} & $\begin{array}{c}\text { Applied load for } \\
\text { Analysis kN/ m }\end{array}$ & TRIM profile & Spandek profile & Klip-lok \\
\cline { 3 - 5 } & 0.528 & 4.99 & 4.52 & 5.13 \\
0.47 & 0.633 & 5.98 & 5.42 & 6.16 \\
(Profile Sheet) & 0.950 & 8.98 & 8.13 & 9.23 \\
\hline
\end{tabular}

In shell elements, it was observed that corrugated sheet is structurally 10 times stiffer than flat sheet, which is shown in Table 2. Profile sheet is stronger because of its rib and section modulus. Generally, based on the results obtained, the objectives of this work have been achieved where the parabolic corrugated steel roofing element was able to show good structural performance under self-supporting condition.

Table 2. Displacement of parabolic roofing elements with different span length

\begin{tabular}{|c|c|c|c|c|c|c|c|}
\hline \multirow{3}{*}{ Roofing System } & \multirow{3}{*}{ Thickness (mm) } & \multirow{3}{*}{$\begin{array}{c}\text { Load } \\
\mathrm{kN} / \mathrm{m}^{2}\end{array}$} & \multicolumn{5}{|c|}{ Span length (m) } \\
\hline & & & 3 & 4 & 5 & 6 & 7 \\
\hline & & & \multicolumn{5}{|c|}{ Deflection (mm) } \\
\hline \multirow{2}{*}{$\begin{array}{l}\text { Parabolic shell } \\
\text { roof }\end{array}$} & 0.65 (Flat sheet) & 0.528 & 44 & 171 & 384 & 688 & 1210 \\
\hline & 0.47 (Profile-sheet) & 0.528 & 4.9 & 9.5 & 21 & 42 & 228 \\
\hline
\end{tabular}

Experimentally load vs strains were measured by electronic strain gauge. Then load was converted to equivalent stresses using LUSAS. These parabolic and cylindrical roofing elements were a complex geometry due to presences of corrugation. It was quiet difficult to find out equivalent stress under UDL using classical formulla. The scalar stress state obtained by combining the individual component stresses at a point according to the classical von Mises failure criterion which is known as generalised stress, equivalent stress, von Mises stress or effective stress. The equivalent stress is most universally accepted yield criterion for metals (LUSAS Theory Manual, 2003) [28]. Stress - strain graphical presentation are shown in Figures 24, 25, 26, 27 and 28. 


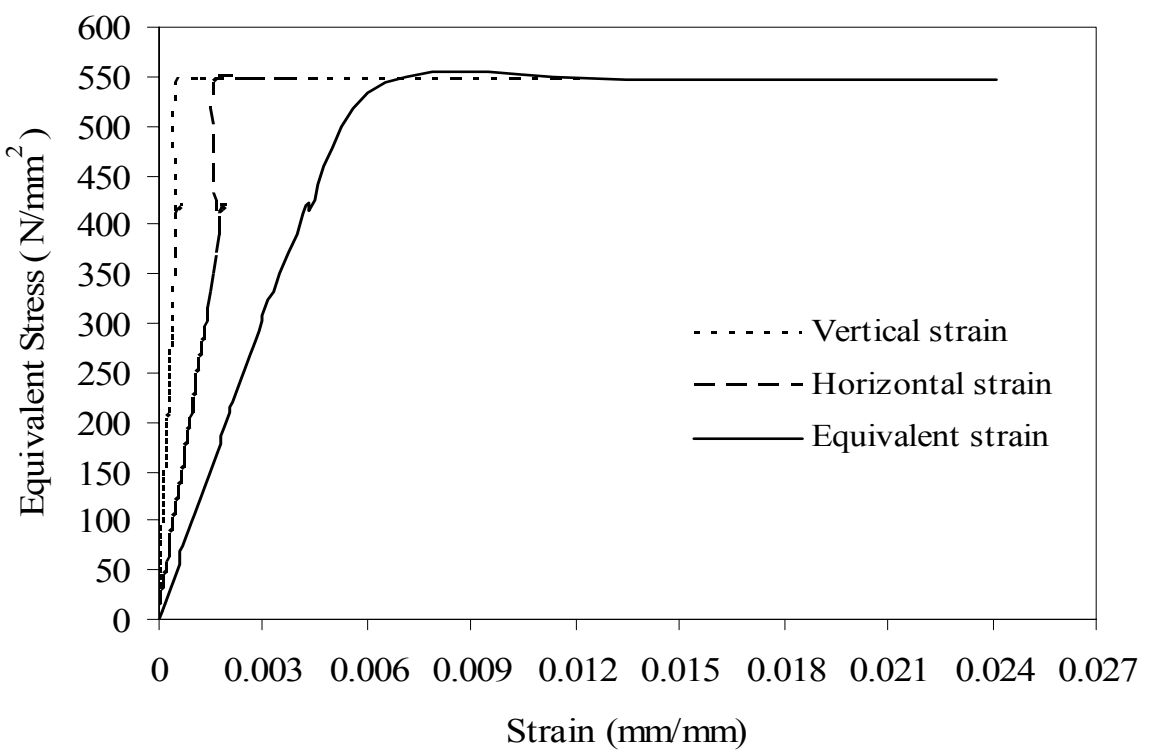

Figure 24. Stress-strain profile at crown of parabolic roofing element for $0.125 \mathrm{~m}$ crown height

The failure occurs when the energy of distortion reaches the same as energy for yield/failure in uniaxial tension. Mathematically, this is expressed as:

$$
F(\sigma, \kappa)=\sigma-\kappa\left(e^{-p}\right)=0
$$

Where $\quad \bar{\sigma}=\sqrt{3}\left(J_{2}\right)^{1 / 2}$

Equivalent, generalized or effective stress $\bar{\sigma}$ is calculated by the following formula.

$$
\frac{1}{2}\left[\left(\sigma_{1}-\sigma_{2}\right)^{2}+\left(\sigma_{2}-\sigma_{3}\right)^{2}+\left(\sigma_{3}-\sigma_{1}\right)^{2}\right] \leq \sigma_{y}^{2}
$$

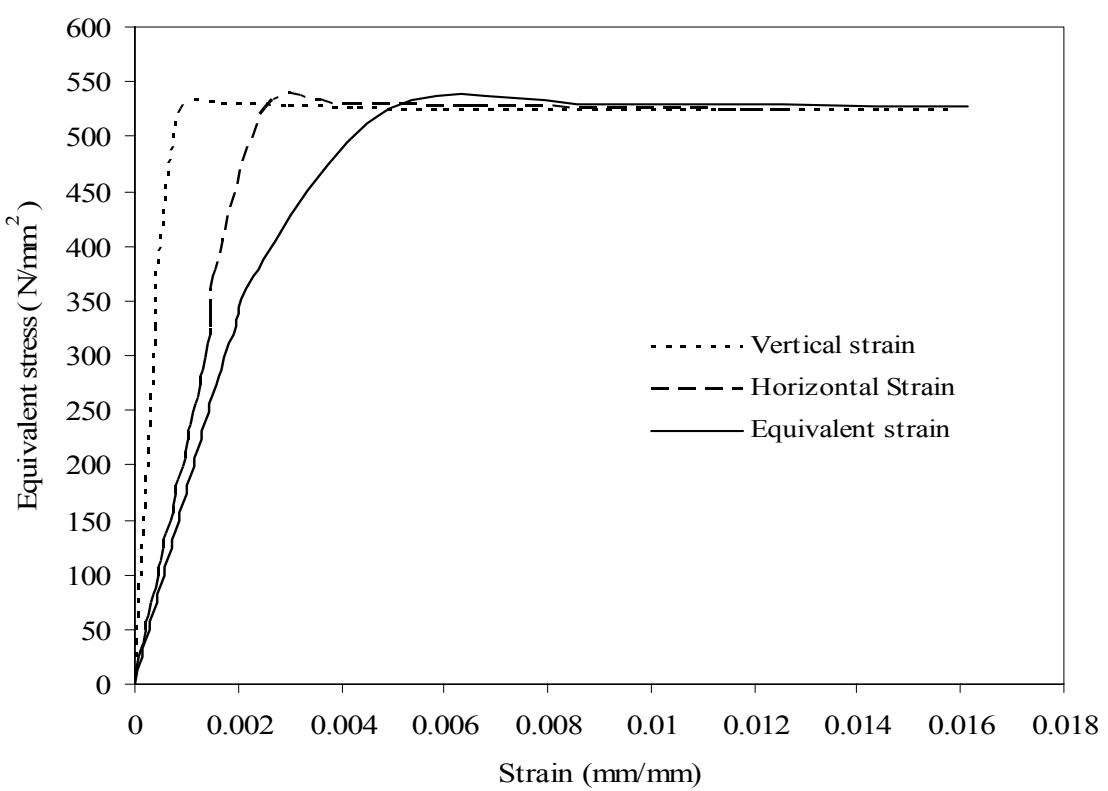

Figure 25. Stress-strain profile at crown of parabolic roofing element for $0.25 \mathrm{~m}$ crown height 


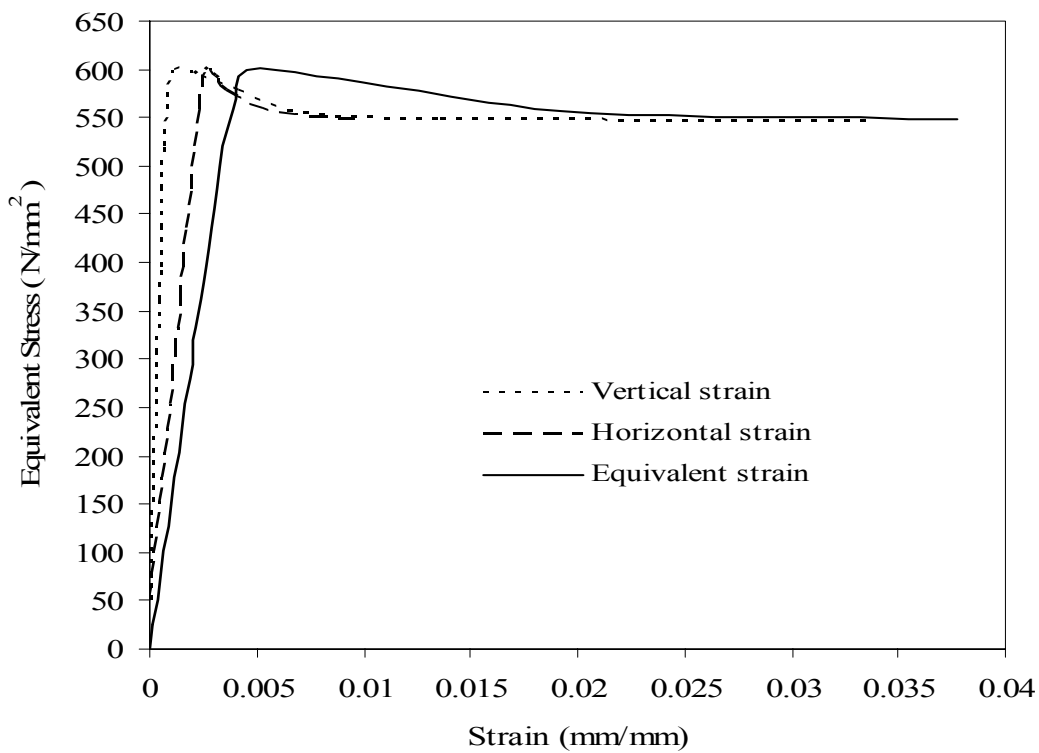

Figure 26. Stress-strain profile at crown of parabolic roofing element for $0.5 \mathrm{~m}$ crown height

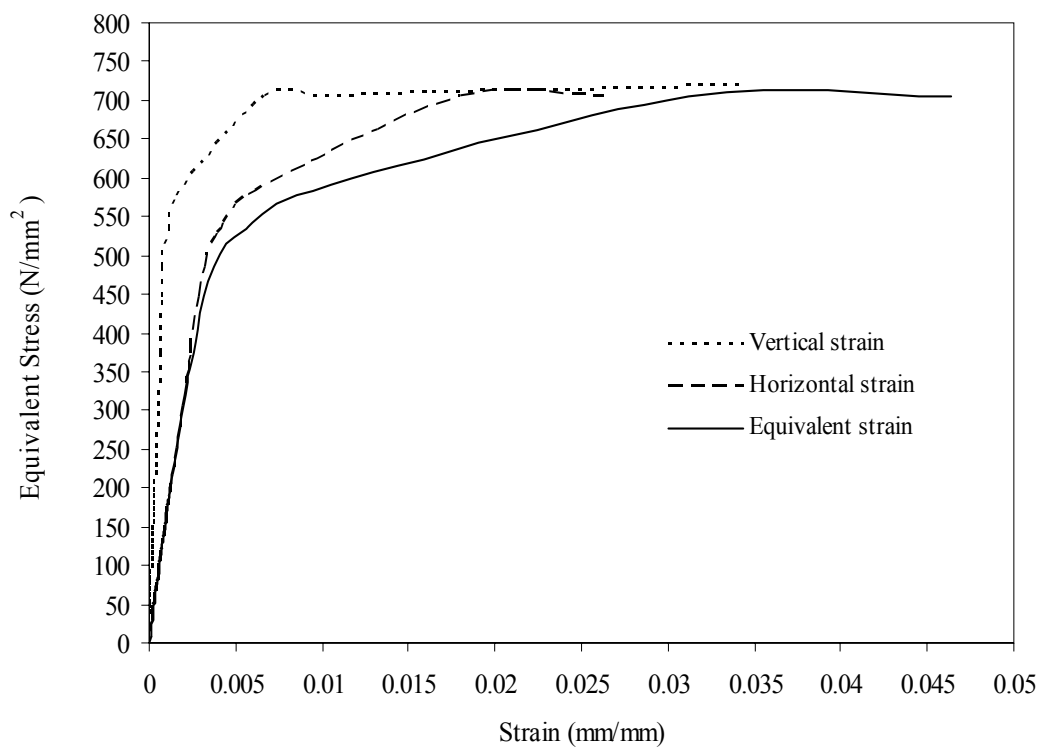

Figure 27. Stress-strain profile at crown of parabolic roofing element for $1.0 \mathrm{~m}$ crown height

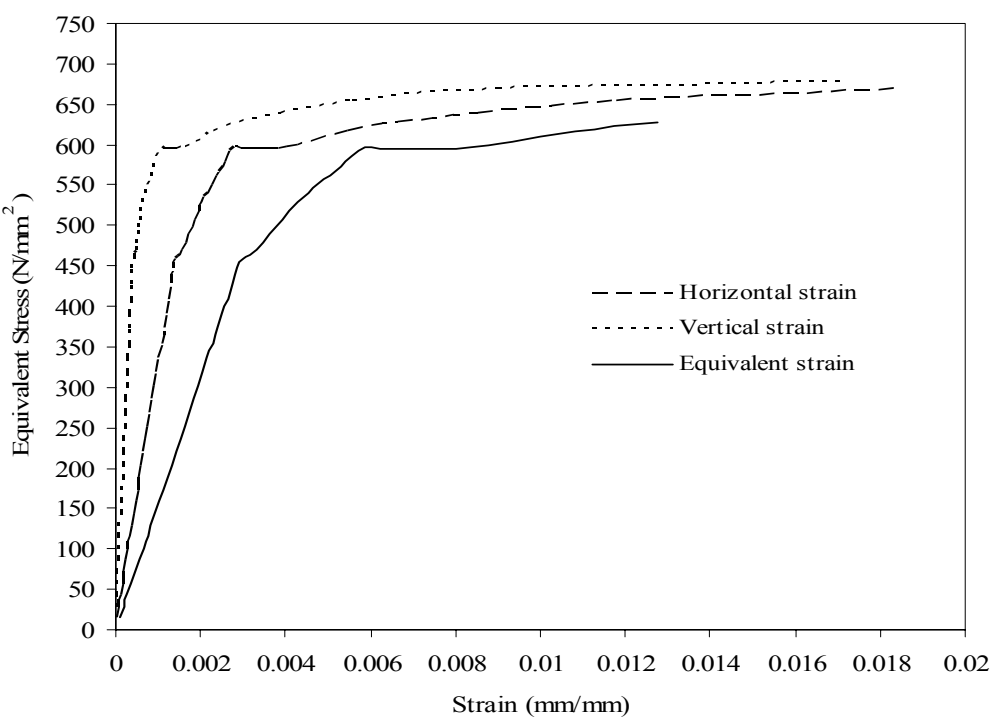

Figure 28. Stress-strain profile at crown of parabolic roofing element for $1.5 \mathrm{~m}$ crown height 


\section{DEFLECTED SHAPE}

In order to validate the proposed models a comparison between analytical and experimental deflected shape were carried out as shown in Figures 29 to 38. It was found that when the crown height of parabolic shape was increased, the central deflection decreased until optimum crown height.

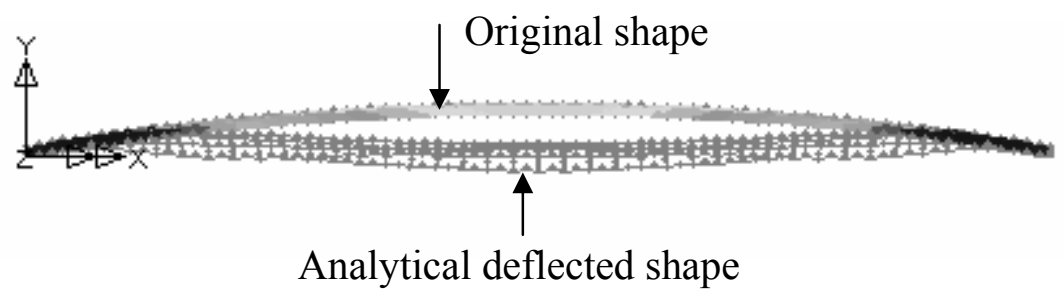

Figure 29. Analytical deflected shape of $0.125 \mathrm{~m}$ crown height parabolic roofing element

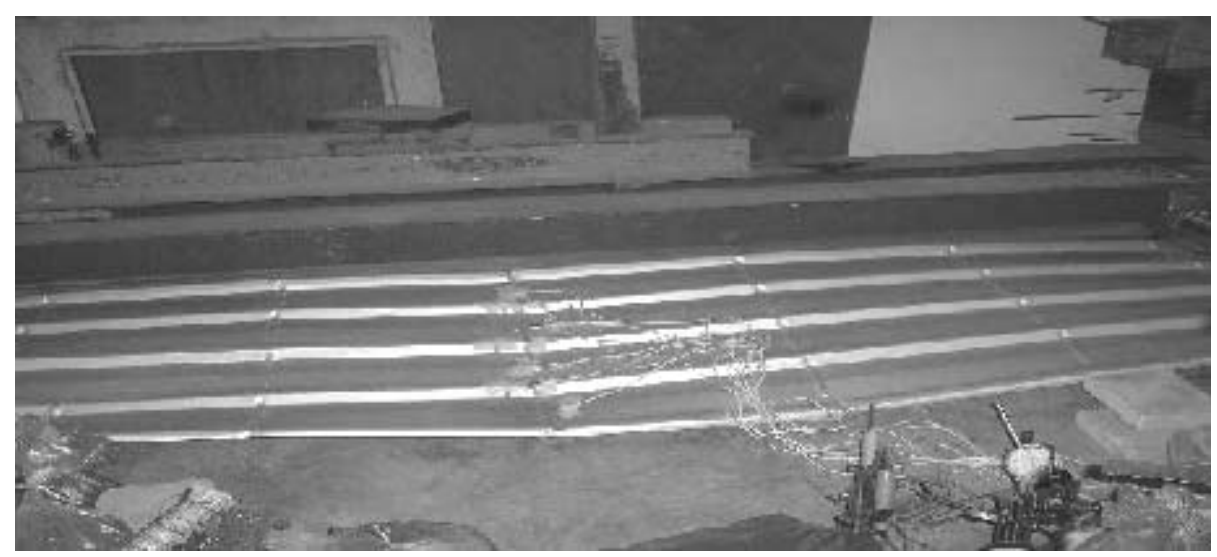

Figure 30. Experimental deflected shape of $0.125 \mathrm{~m}$ crown height parabolic roofing element

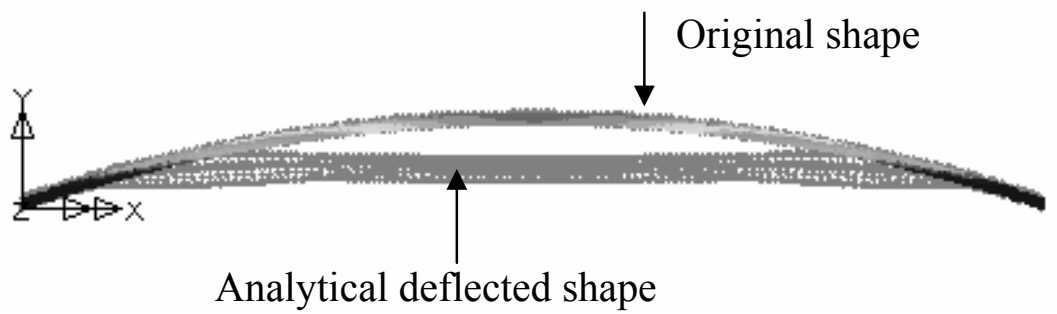

Figure 31. Analytical deflected shape of $0.25 \mathrm{~m}$ crown height parabolic roofing element

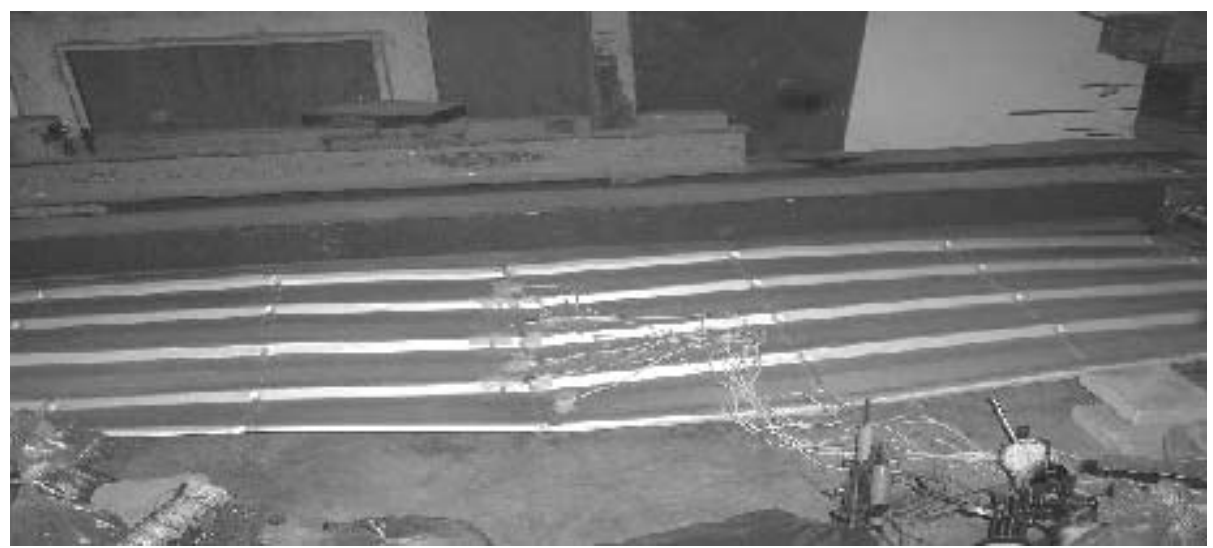

Figure 32. Experimental deflected shape of $0.25 \mathrm{~m}$ crown height parabolic roofing element 


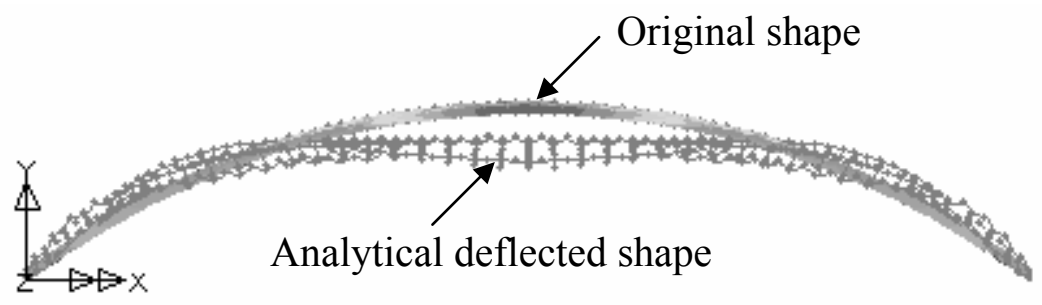

Figure 33. Analytical deflected shape of $0.5 \mathrm{~m}$ crown height parabolic roofing element

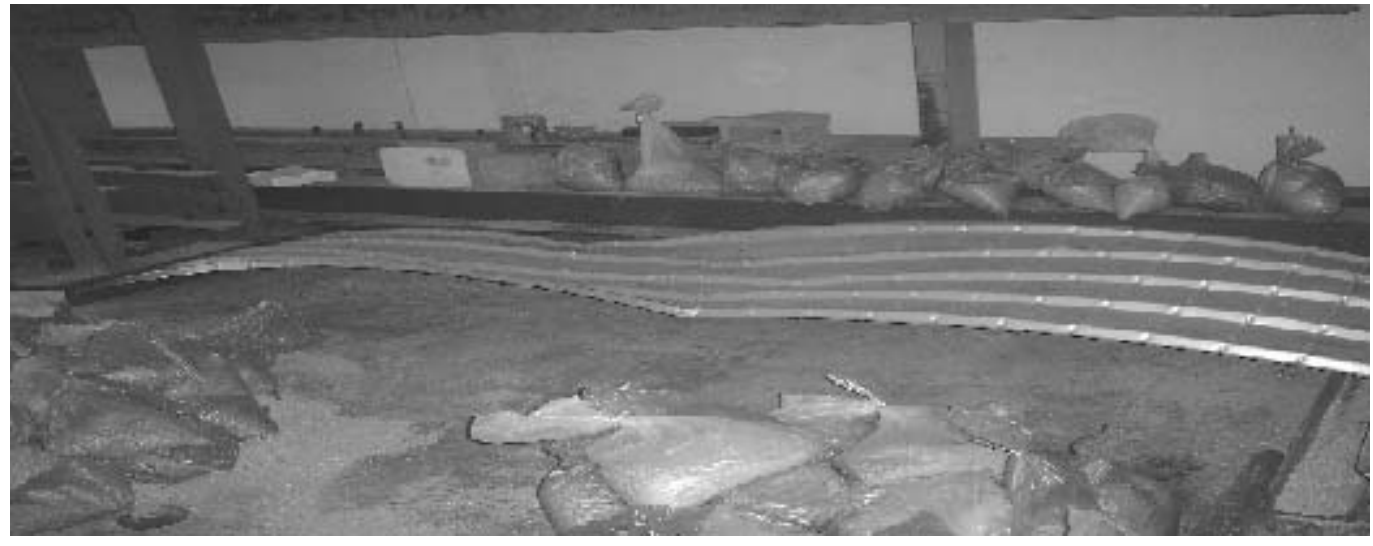

Figure 34. Experimental deflected shape of $0.5 \mathrm{~m}$ crown height parabolic roofing element

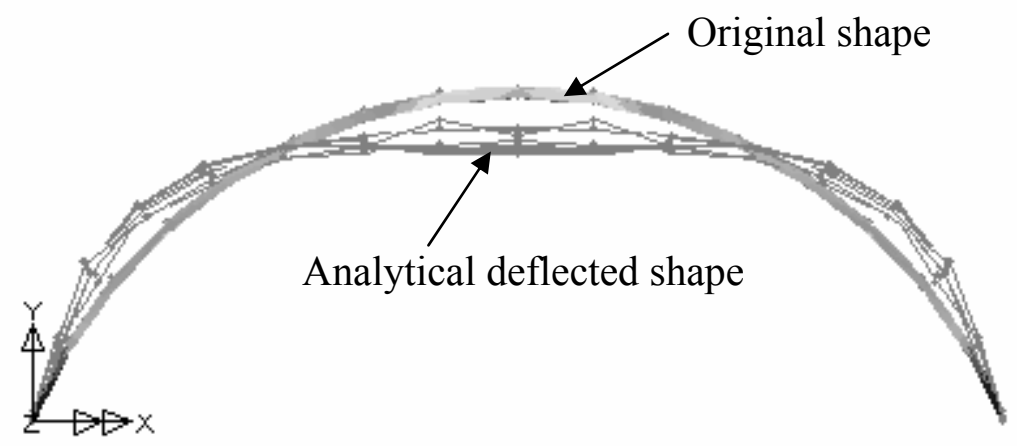

Figure 35. Analytical deflected shape of $1.0 \mathrm{~m}$ crown height parabolic roofing element

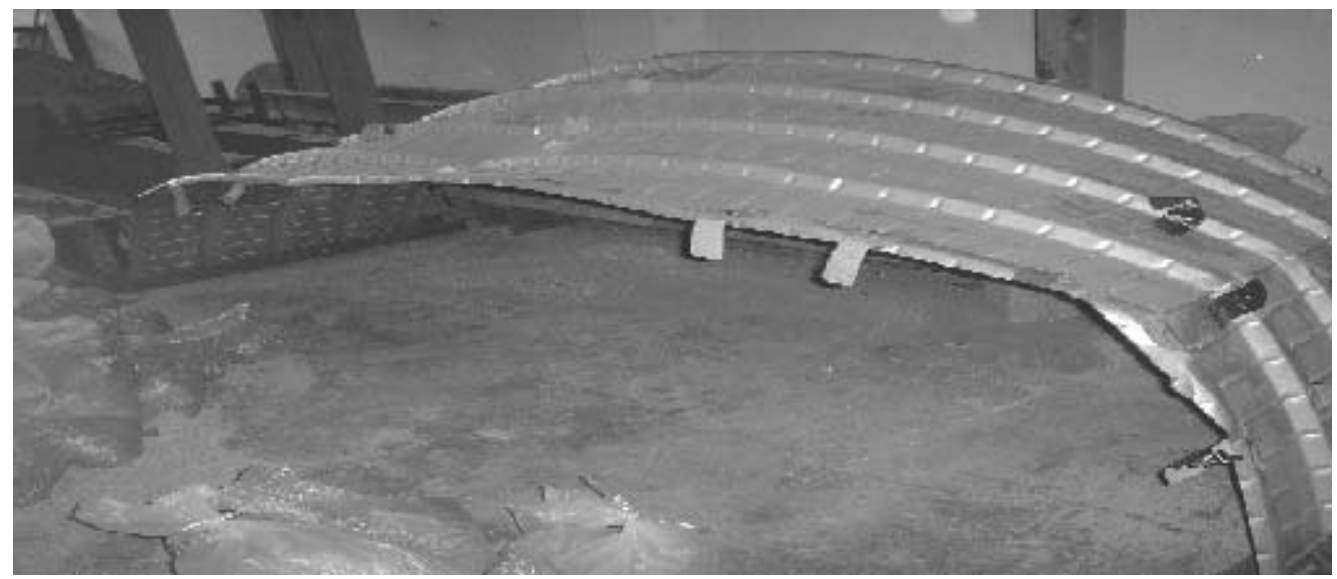

Figure 36. Experimental deflected shape of $1.0 \mathrm{~m}$ crown height parabolic roofing element 


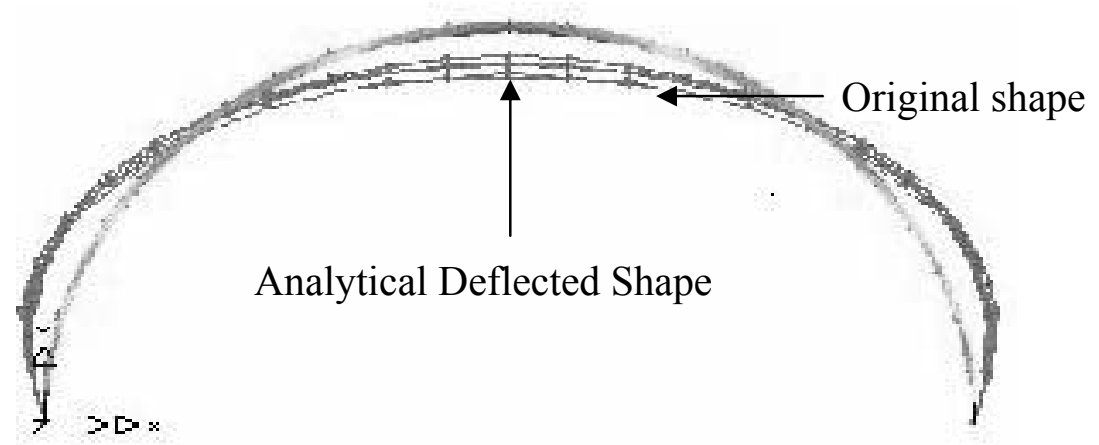

Figure 37. Analytical deflected shape of $1.5 \mathrm{~m}$ crown height cylindrical roofing element

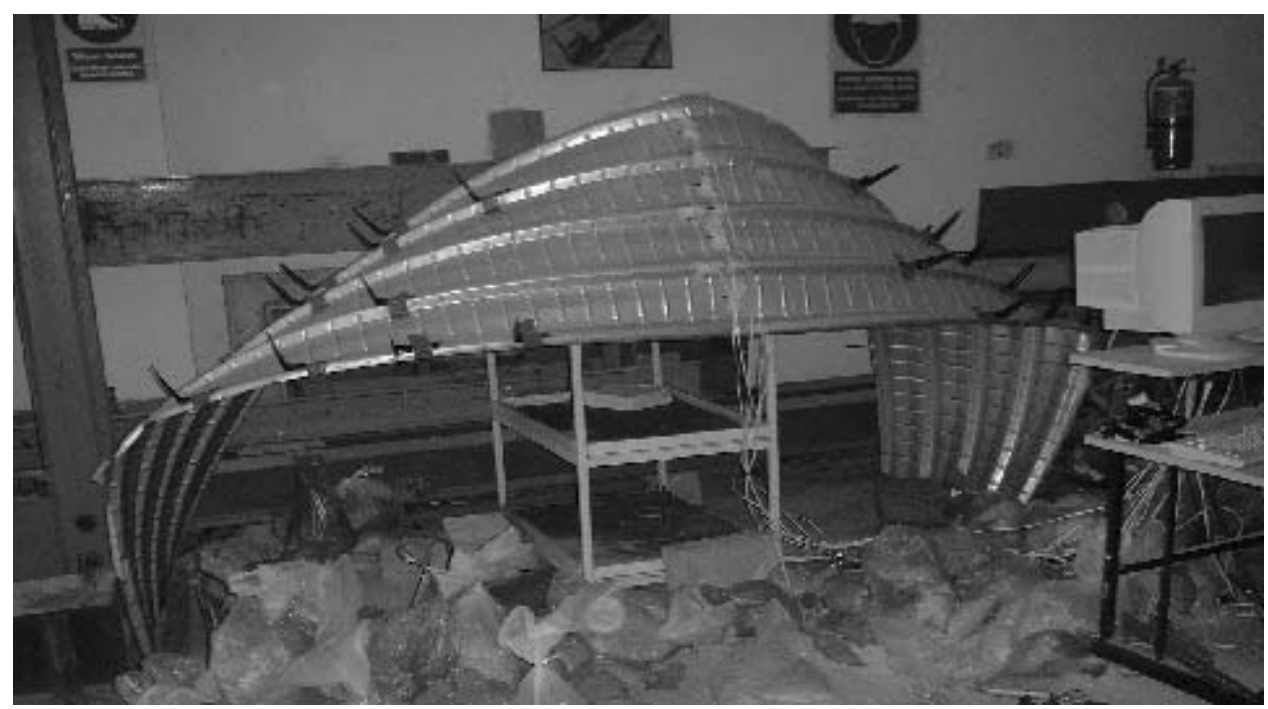

Figure 38. Experimental deflected shape of $1.5 \mathrm{~m}$ crown height cylindrical roofing element

\section{DETAILED STUDY ON 8M PARABOLIC ROOFING ELEMENTS}

The FEM investigation was extended to explore the feasibility of usage of zincalume as a selfsupporting roofing system. Based on FEM investigation and experimental validation, this study was extended up to $8 \mathrm{~m}$ span using $1.33 \mathrm{~m}$ crown parabolic roofing element for using as self-supporting condition for affordable quality housing. According to the FEM results analysis, it was seen that the parabolic roofing element can be used efficiently as a self supporting roofing system using $8 \mathrm{~m}$ span and $1.25 \mathrm{~mm}$ thick profile zincalume sheet for affordable quality housing. Load- deflection and stress-strain graphical presentation are shown in Figures 39 and 40 respectively.

The stress distributions along the arc of $8 \mathrm{~m}$ span parabolic roofing elements were observed with stress contour plot. It was seen that the stresses were not uniformly distributed all over the element. Maximum equivalent stress $406.1 \mathrm{~N} / \mathrm{mm}^{2}$ was found at the lower part of the element, which is connected with the support. The displacement distribution of $8 \mathrm{~m}$ parabolic roofing elements was observed by Displacement contour plot. The maximum displacements obtained at crown height were $39.69 \mathrm{~mm}$, under service load $0.612 \mathrm{kN} / \mathrm{m}^{2}$. Deflection and equivalent stress obtained within permissible limit $40 \mathrm{~mm}$ and $550 \mathrm{~N} / \mathrm{mm}^{2}$ respectively. 


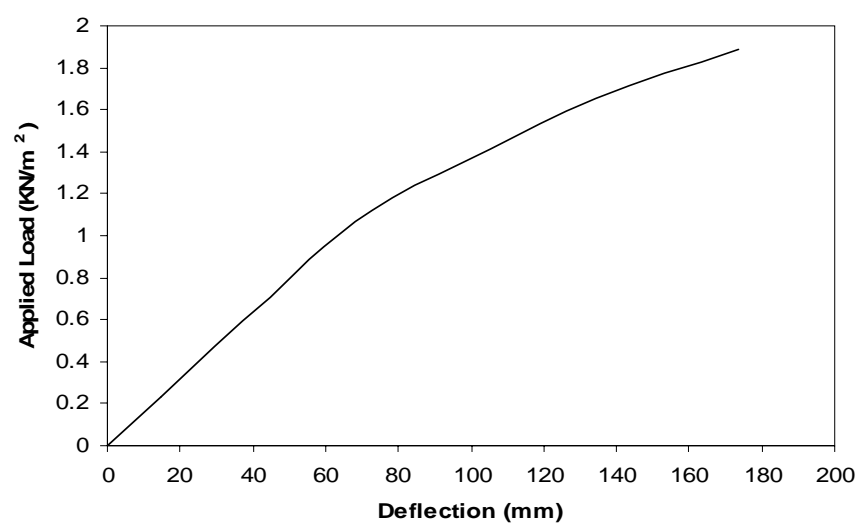

Figure 39. Load -deflection profile of $8 \mathrm{~m}$ span parabolic roofing elements

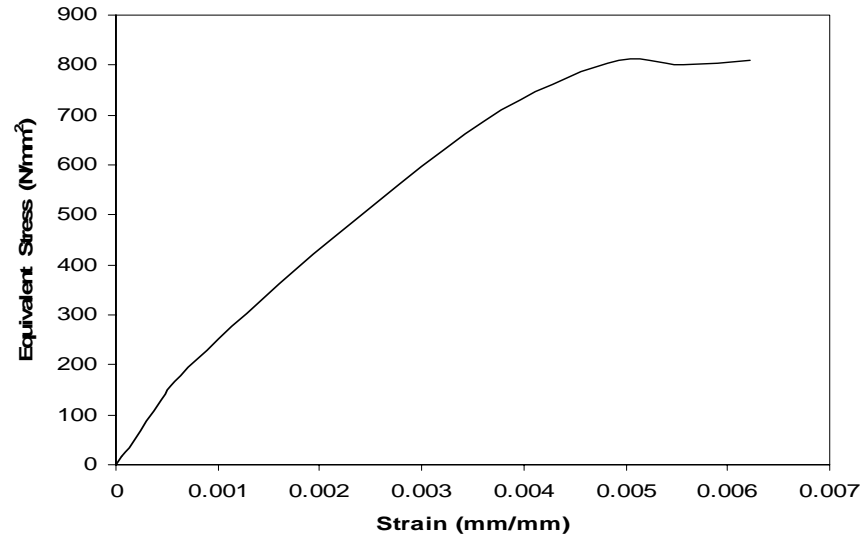

Figure 40. Stress-strain profile at crown of $8 \mathrm{~m}$ span parabolic roofing elements

\section{COST ANALYSIS}

The cost of the various zincalume roofing elements $\left(\right.$ per $\mathrm{m}^{2}$ ) are computed based on the material market cost in Kula Lumpur, Selangor Darul Ehsan, Malaysia. Zinaclume is manufactured mechanically in Bluescope Lysaghat Sdn Bhd. So, labour costs are included in its market prize. As a self-supporting condition, that easily can be handled and erected. So, labour cost will be very lower. Hence, labour cost of erection was not considered in this cost analysis. The cost analysis of zincalume roofing element as self-supporting condition is shown in Table 3

Table 3. Cost analysis for different types of roofing elements with $3 \mathrm{~m}$ span

\begin{tabular}{|l|l|c|c|c|}
\hline Material-s & Roofing elements types & $\begin{array}{c}\text { Quantity } \\
\left(\mathrm{m}^{2}\right)\end{array}$ & $\begin{array}{c}\text { Rate } \\
\left(\mathrm{RM} / \mathrm{m}^{2}\right)\end{array}$ & Cost (RM) \\
\hline Lysaghat Crim & Cylindrical( C.H.-1.5 m) & 3.58 & 33.5 & 120.0 \\
Curve Trimdek Hi- & Parabolic (C.H.-1.0 m) & 2.90 & & 97.25 \\
Tensile Zinaclume & Parabolic (C.H. 0.5 m) & 2.44 & & 81.84 \\
$(0.47 \mathrm{~mm}$ thickness) & Parabolic (C.H. 0.25 m) & 2.33 & & 77.92 \\
& Parabolic (C.H.125 m) & 2.29 & & $76.74^{*}$ \\
& Inverted V (C.H.0.5 m) & 2.40 & & $80.40^{*}$ \\
& Doubly curve (C.H. 0.5 m) & 2.46 & & $82.41^{*}$ \\
& Single pitch (C.H.0.5 m) & 2.31 & & $77.43^{*}$ \\
& Flat plane shape & 2.28 & & $76.38^{*}$ \\
\hline
\end{tabular}

Note: * Structurally not efficient

C.H. - Crown Height

\section{CONCLUSIONS}

Conventionally, metal sheet such as zincalume is using in roof covering through truss as a costume. It has been implemented a novel and new approach to provide self- supporting roofing system. The behaviour of nine different types of roofing element is studied to find out an economical, efficient, architecturally pleasing shape in self -supporting condition. Nonlinear effect has been adopted in the finite element analysis. From the parametric study, it is found that the central deflection and stresses are lower in parabolic shape of roofing element with crown height about 1/6 of chord length. Optimum crown height is obtained at about crown height $1 / 6$ of chord width due to higher load carrying capacity and lower deflection and stress. Internal horizontal reaction in parabolic shape roofing element always reduced shear force and bending moment. 
On the basis of the present analysis, it is found that the corrugated zincalume shell element is the most economical, efficient, architecturally pleasing shape in self- supporting condition. Based on the results obtained, the objectives of this work have been achieved where the parabolic corrugated roofing element showed significant improvements to the roof's structural performance. It was observed that corrugated parabolic shell element which, have $8 \mathrm{~m}$ span and $1.25 \mathrm{~mm}$ thickness could be used efficiently as self -supporting roofing system in housing construction.

\section{ACKNOWLEDGEMENTS}

The authors would like to thank the Construction Industry Development Board (CIDB) Malaysia for financial support and Blue scope Lysaght (Malaysia) Sdn Bhd for the free supply of experimental test specimens. The present study is part of graduate research of civil engineering department, Universiti Putra Malaysia (UPM) and National Research Programme on Affordable Quality Housing.

\section{REFERENCES}

[1] Jagannath, V. and Sekar, U.C., "Precast L-pan roof elements for low cost housing", Journal of Engineering Mechanics, 1992, 120(1), pp.120-113.

[2] Capurso, M., "Critical loads of self-supporting cylindrical shell roofs", International Journal of Solids Structure, 1967, 3, pp.117-141.

[3] Nilson, A.H., "Folded plate structures of light gauge steel”, ASCE transactions paper, 1963, 128(II), pp.848-880.

[4] EL-Atrouzy, M.N., "Cylindrical shell roofs made of corrugated metal sheets", Proceedings of the Fourth International Symposium on Roofing Technology, pp.138-141.

[5] Sakla, S.S., and Elbeltagi, E., "Design of Steel roofs subjected to drifted snow using genetic optimization", Computer and Structure, 2003, 81, pp.339-348.

[6] Rao, P.S. and Rao, A.P., "Behavior of cylindrical shells subjected to support settlement", Journal of Structural Engineering, 1988, 114(4), pp.931-941.

[7] Kostem, C.N., and Garrabrant, M.E., "The Effect of vertical support settlements on cylindrical shells", IASS Conference on Light-Weight Shell and Space Structures for Normal and Seismic Zones, Alma-Ata, 1977, USSR, pp.187-191.

[8] Simmonds, S.H., "Effect of support movement on hyperbolic paraboloid shells", Journal of Structural Engineering, 1989, 115(1), pp.19-31.

[9] Stekelenburg, P.J.Van., Walraven, J.C. and Mathews, M.S., "Development of semi cylindrical ferrocement roofing system", Journal of Ferrocement, 1980, 10(2), pp.111-118.

[10] Imam, N., Maity, D. and Kalita, U.C., "An investigation on the shape of ferrocement roofing elements", Journal of Ferrocement, 2002, 32(4), pp.271-286.

[11] Maity, D., Imam, N. and Kalita, U.C., "Finite element analysis of ferrocement roofing shell elements", International Conference on Construction Management and Materials (CONMAT), 2003, pp.285-294.

[12] Scordelis, A.C. and Lo, K.S., "Computer Analysis of Cylindrical Shells", ACI Journal, 1964, 61, pp.539-561.

[13] Zahurul-Islam, S.M., Abang-Ali, A.A and Jaafar, M.S., "An Investigation on the Shape of Thin Shell Metal Elements to Develop Self-supporting Roofing System”, International Conference on World Innovation of Structural Engineering WISE, Hyderabad, Andhra Pradesh, India, December 1-3, 2004, pp.42-50.

[14] Abang-Ali, A. A., Zahurul, S. M. and Jaafar, M.S., "Self -supporting Roofing System for Affordable Quality Housing, National Conference on Affordable Quality Housing”, Miri, Sarwak, Malaysia, November, 2004, pp.15-21. 
[15] Farshad, M., "Design and Analysis of Shell Structures", Kluwer Academic Publishers, The Netherlands, 1992, pp.2-39.

[16] LUSAS version 13.5-7, "Finite Element System", Powerful FE technology for specialist applications, UK, FEA Ltd, 2003.

[17] Martins, R.A.F and Oliveira, C.A.M., "Semi-loof Shell, Plate and Beam Elements-New Computer Versions: Part 1. Elements Formulation", Engineering Computer, 1988, 1(5), pp.15-25.

[18] Sze, K.Y., "Simple Semi-Loof Element for Analyzing Folded -Plate Structures”, Structural Engineering, 1989, 115(1), pp.19-31.

[19] Rao, P.S. and Rao, A.P., "Support settlement in continuous cylindrical shell roofs", Journal of Structural Engineering, 1986, 112(8), pp.1781-1795.

[20] Zienkiewcz, O.C., "The Finite Element Method", Third edition, McGraw-Hill, UK, 1979, pp.398-422.

[21] Huang, H., "Static and Dynamic Analysis of Plates and Shell", Springer-verlag, Berling Heidelberg, 1989, pp.67-83.

[22] Krishnamoorthy, C.S., "Finite Element Analysis theory and programming" (Second edition). New Delhi: Tata McGraw-Hill Publishing Company Limited, 2001, pp.465-510.

[23] Uniform Building by Law, Malaysian Standard Code of Practice, 1998, pp.34-37.

[24] BS 5427: Part 1: Code of Practice, "The use of profiled sheet for roof and wall cladding on building", British Standards Institution, 1996, pp.14-15.

[25] BS 6399: Part 1: Design Loading for Building, "Code of Practice for Dead and Imposed Loads", British Standards Institution, 1996, pp.2-3.

[26] CP 3: Chapter V: Part 2: Wind Loads. "Code of Basic Data for the Design of Building", British Standards Institution, 1972, pp.4-29.

[27] Zahurul-Islam, S.M., "Structural Strength and Behaviour of Cylindrical Steel Sheet Roofing", Master Thesis, Civil Engineering Department, Universiti Putra Malaysia, March 2006, pp.33-98.

[28] LUSAS Finite Element System, “LUSAS theory manual”, FEA Ltd, UK., 2004. 